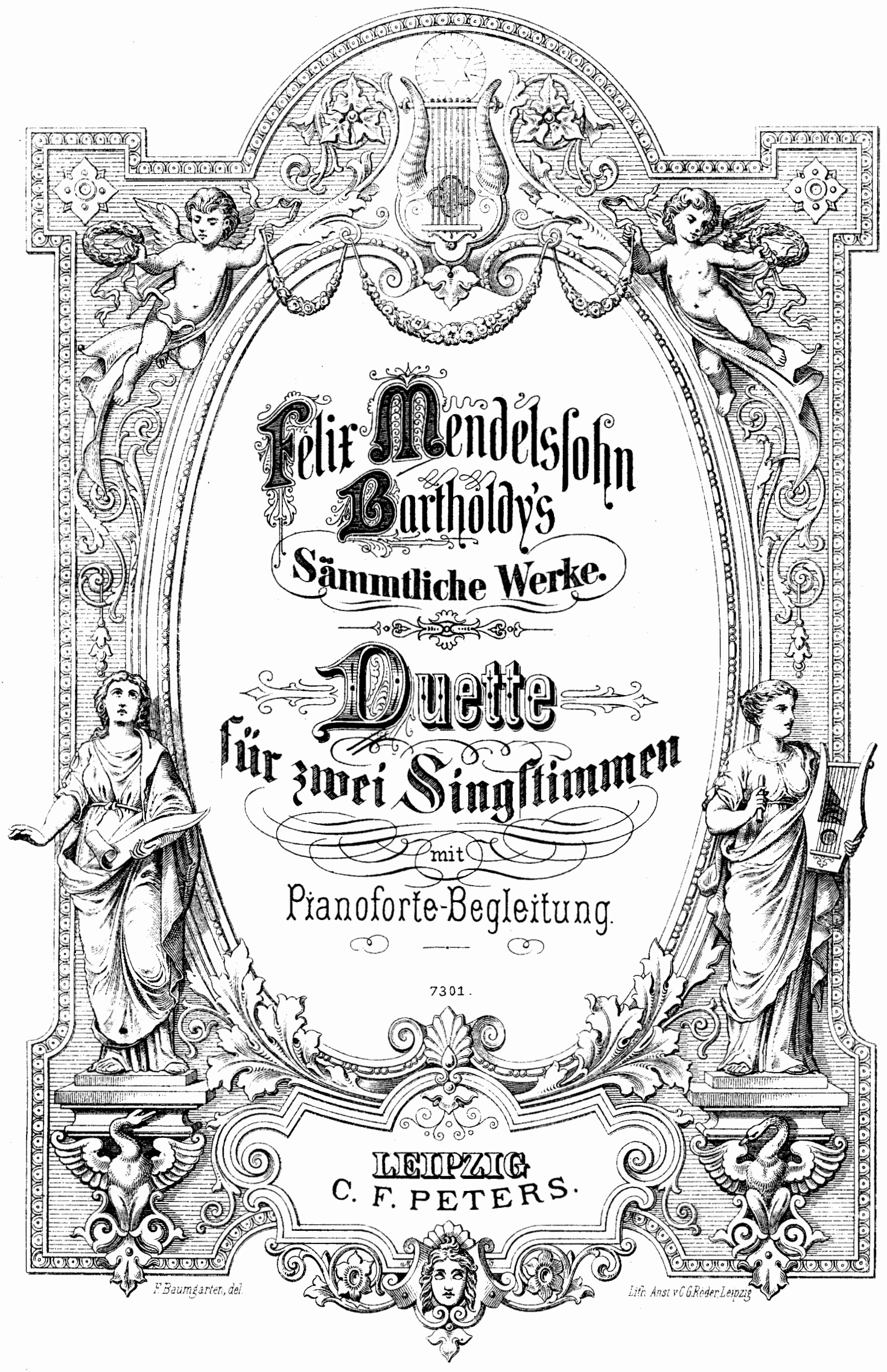




\section{Inhalt.}

Pag.

1. Ich wollt' meine Lieb' ergösse sich . . . . . . . . . . . . . . . . 3.

2. Abschiedslied der Zugvögel: Wie war so schön doch . . . . . . . . . . . 7.

3. Gruss: Wohin ich geh' und schaue . . . . . . . . . . . . . . . . . . . . 10.

4. Herbstlied: Ach, wie so bald verhallet . . . . . . . . . . . . . . . . . . . 13.

5. Volkslied: o säh' ich auf der Haide dort . . . . . . . . . . . . . . . . 17.

6. Maiglöckchen und die Blümelein: Maiglöckchen lïutet in dem Thal . . 19.

7. Sonntagsmorgen: Das ist der Tag des Herrn . . . . . . . . . . . . 24.

8. Das Aehrenfeld: Ein Leben war's im Aehrenfeld . . . . . . . . . . 26.

9. Lied aus Ruy Blas: Wozu der Vöglein Chöre . . . . . . . . . . . . . 30.

10. Wie kann ich froh und lustig sein? . . . . . . . . . . . . . . . . . . . . . 33.

11. Abendlied: Wenn ich auf dem Lager liege . . . . . . . . . . . . . . . . . 36.

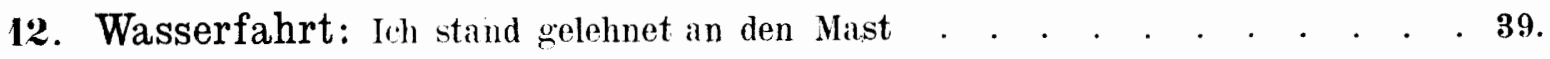

13. Suleika und Hatem: An des lust'gen Brunnens Rand . . . . . . . . . 42.

14. Aus Psalm 95: Denn in seiner Hand ist, was die Erde bringt . . . . . . 45.

15. Aus dem ,Lobgesang": Ich harrete des Herrn . . . . . . . . . . . . . 51.

16. Aus „Elias“: Zion streckt ihre Hïnde aus . . . . . . . . . . . . . . . 57 .

17. Aus der Motette Opus 39 No 3: Wohin habt ihr ihn getragen? . . . . . 61.

18. Aus "Athalia“" 0 wie selig ist das Kind . . . . . . . . . . . . . . . . 64 . 


\title{
Zweistimmige Lieder.
}

\section{„Ich wollt' meine Lieb’ ergösse sich“"}

\author{
(H. Heine.)
}

Allegro con moto.

Mendelssohn, Op.63 Nr.1.

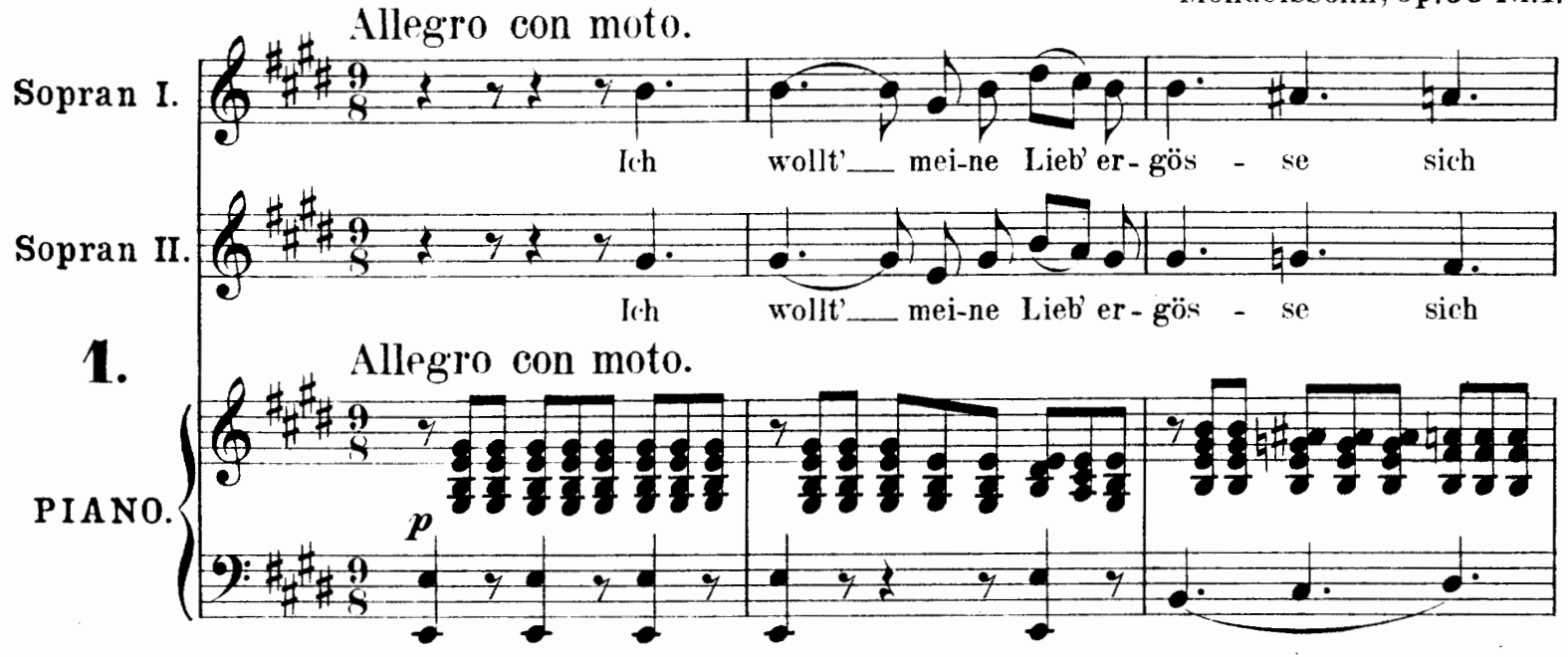

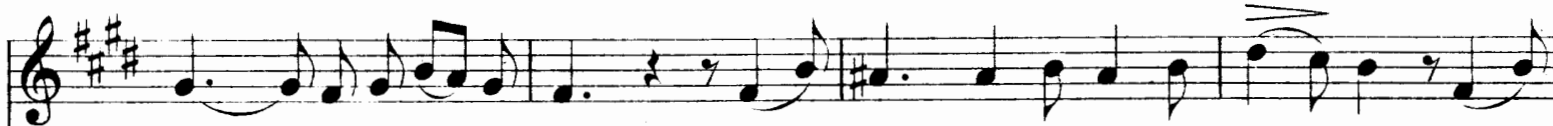

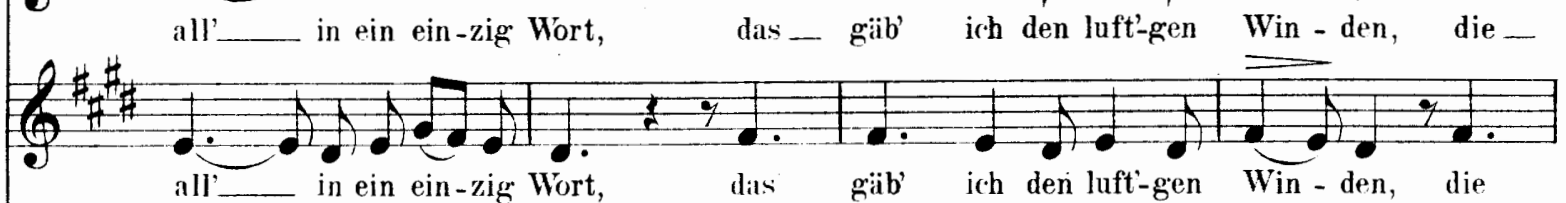

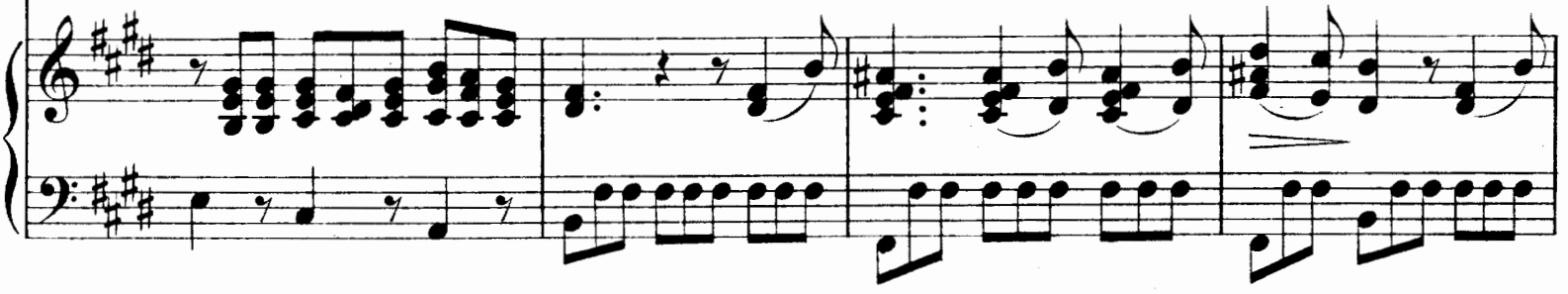

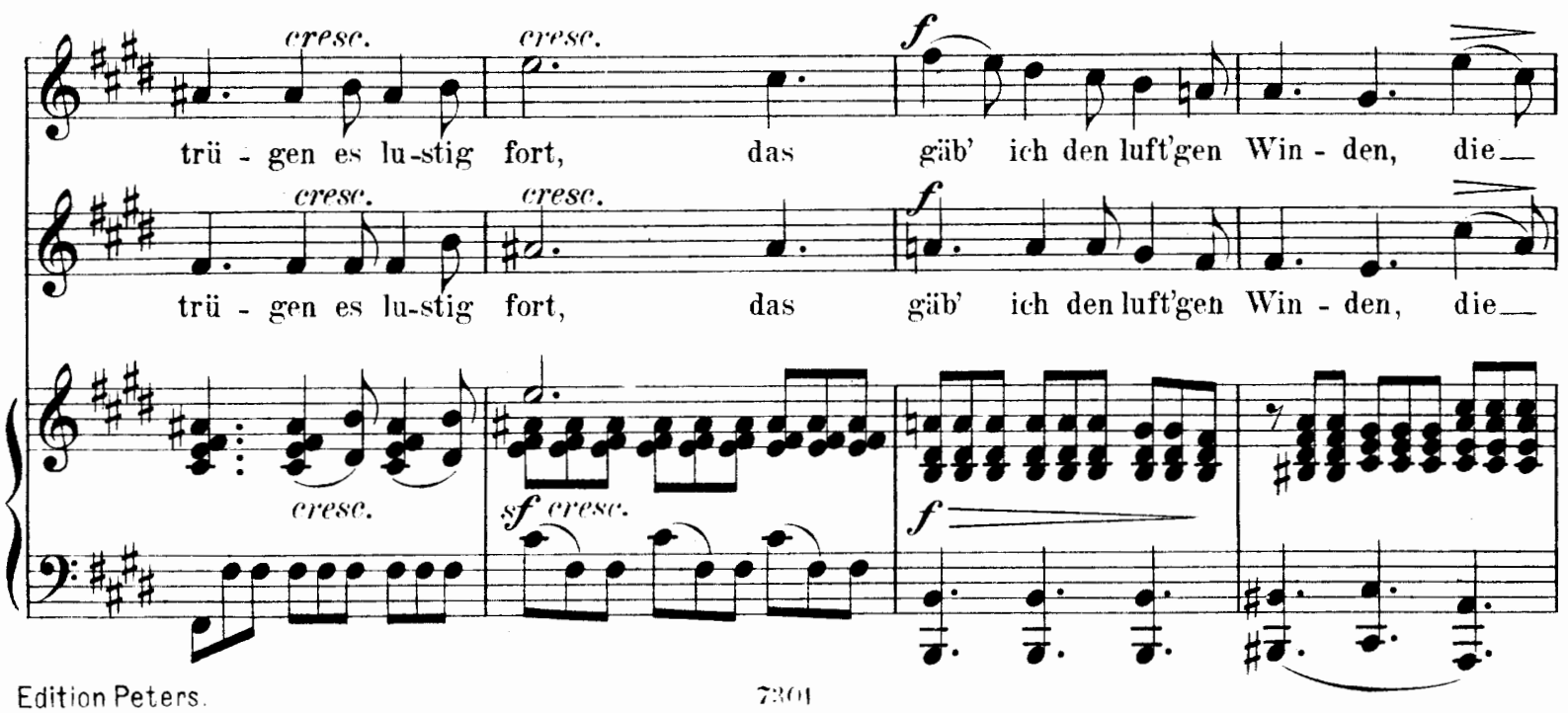




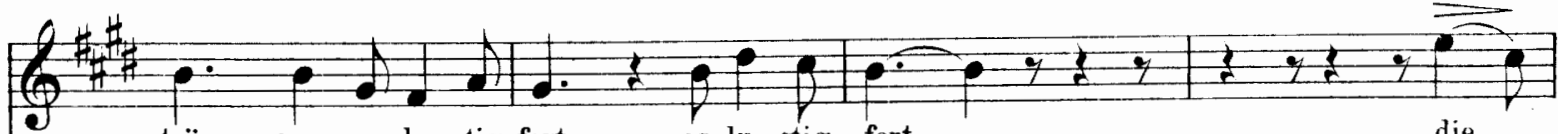

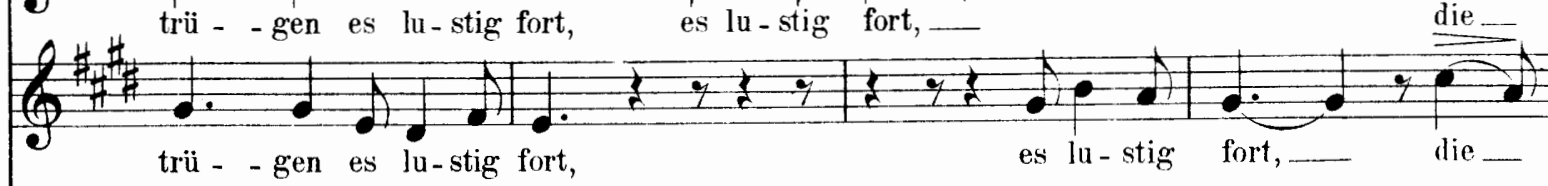

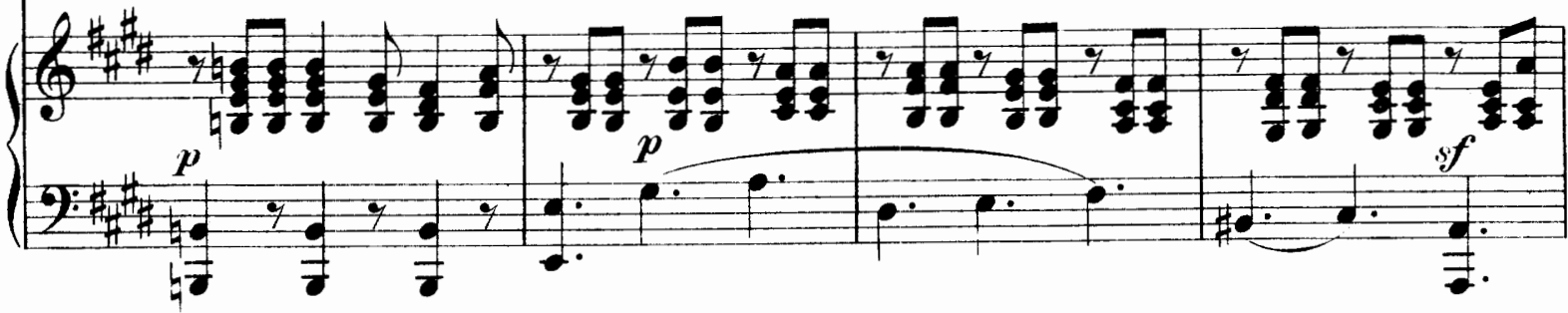

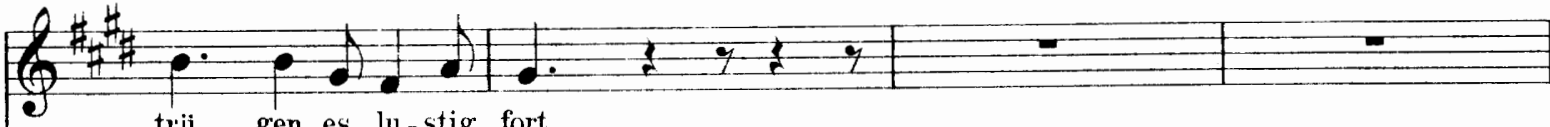
trï - gen es lu-stig fort.

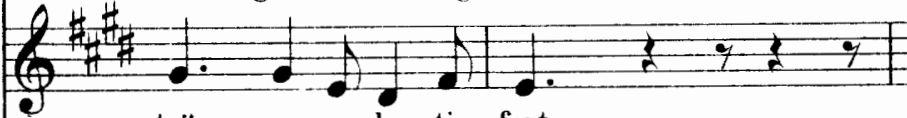
trü - gen es lu-stig fort.

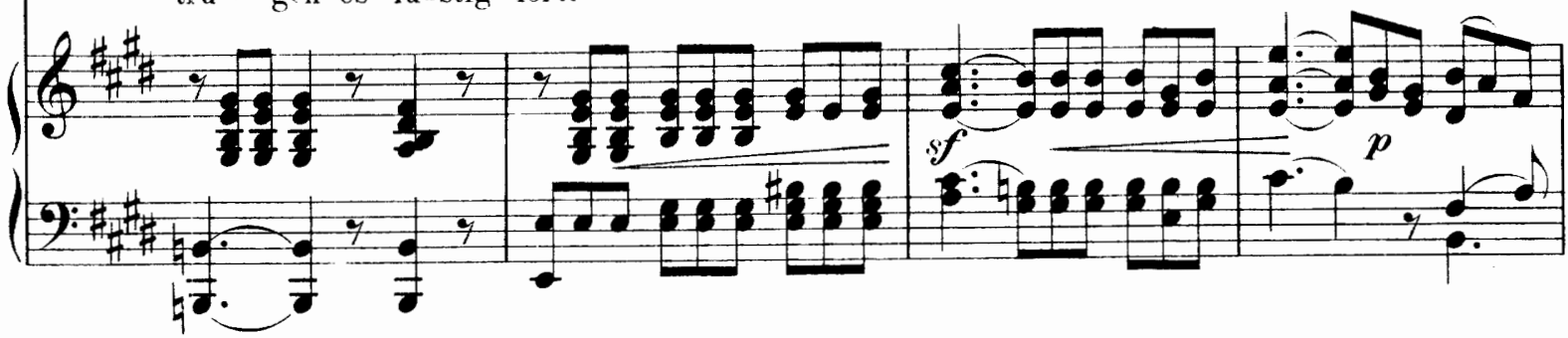
(6)

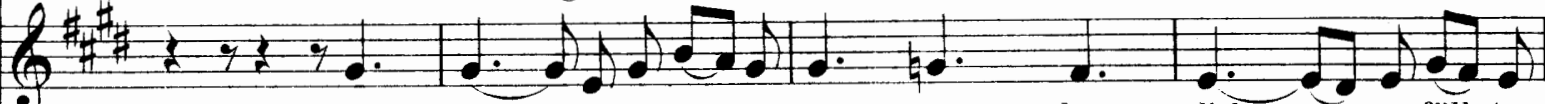
Sie tra - gen zu dir, Ge-lieb - - te, das lieb - - er-füll-te

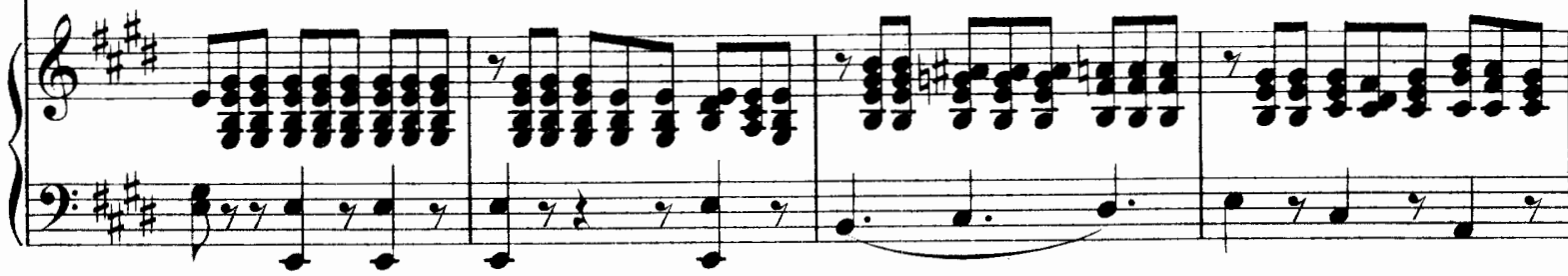

(9) Wort; du_ hörst es zu je-der Stun - de, du__ hörst es an je-dem

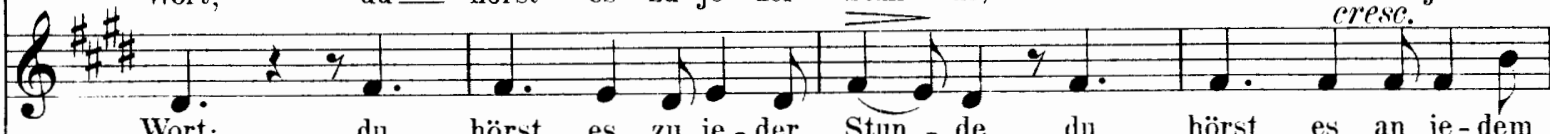

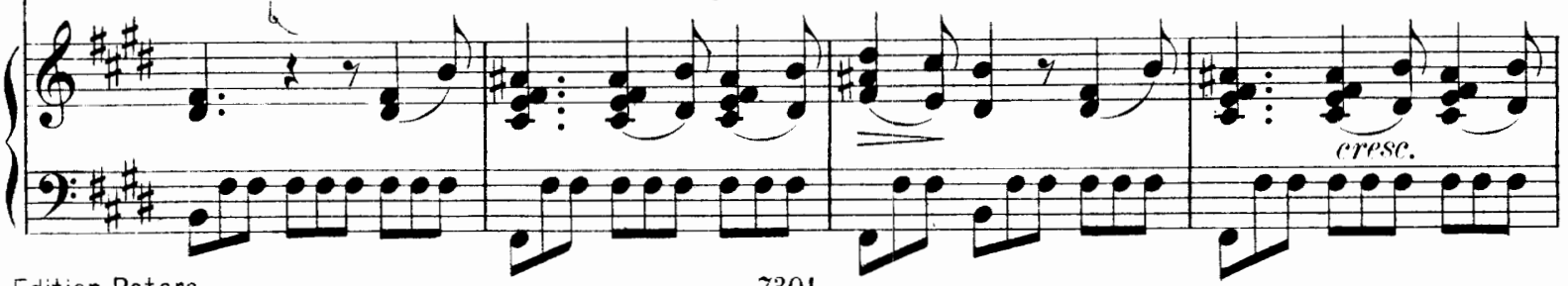



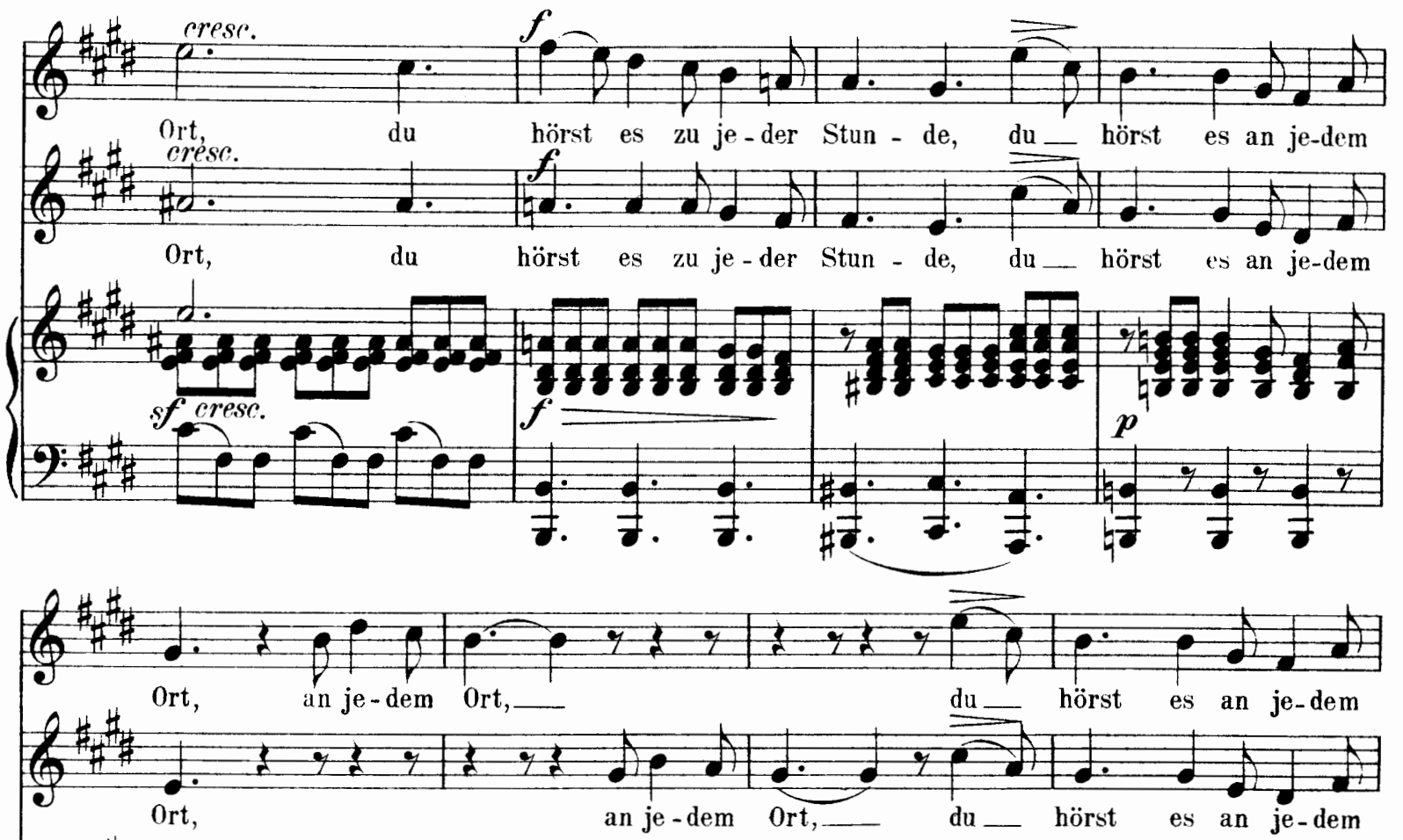

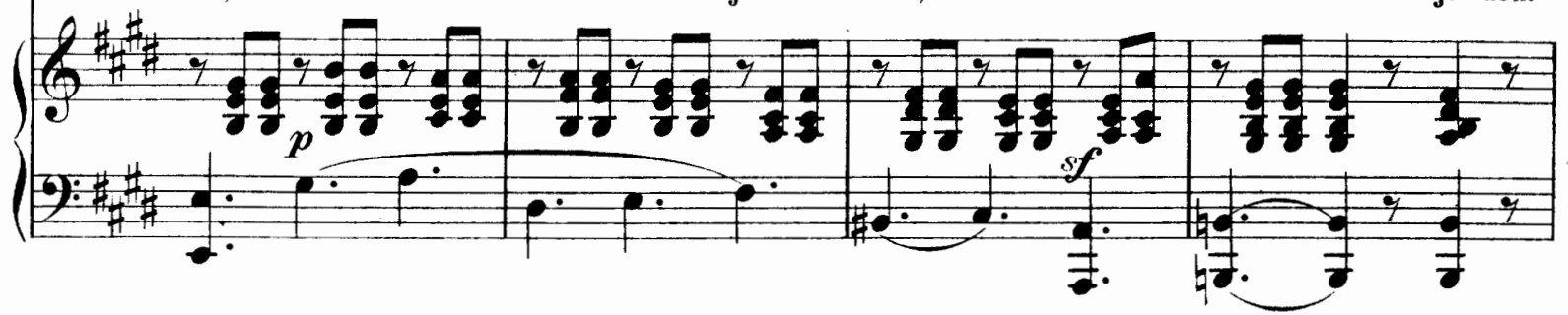
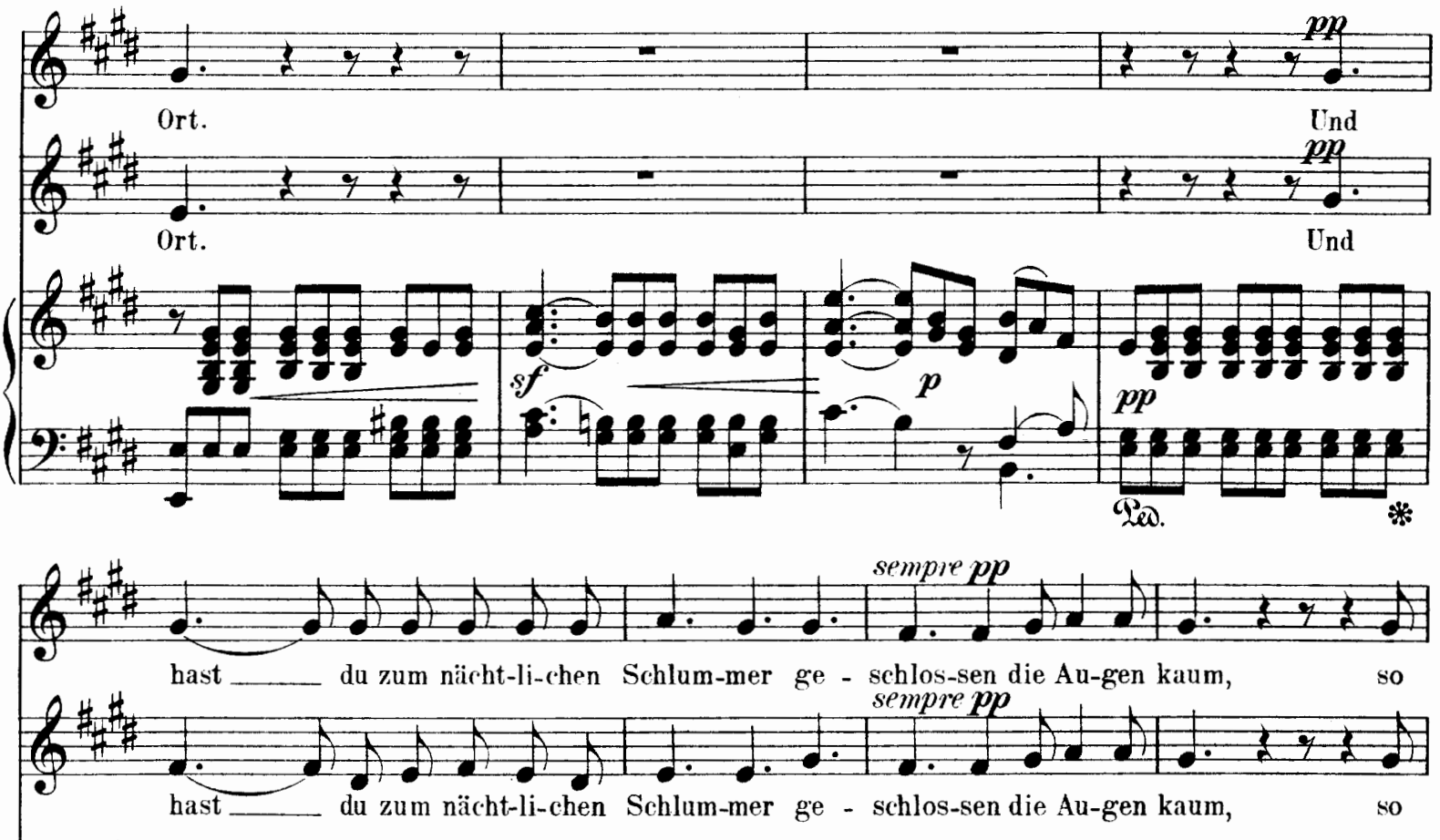

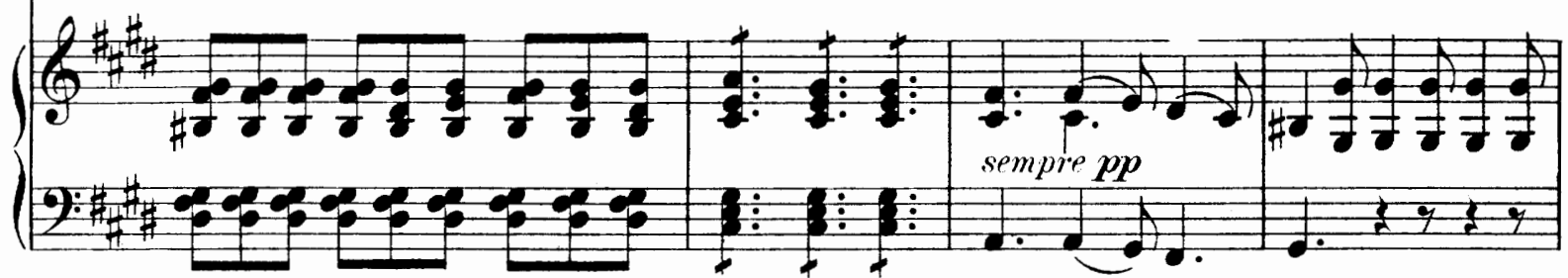




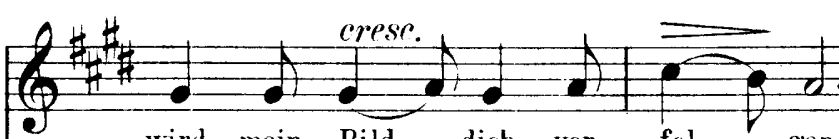

crese.

wird mein Bild _ dich ver - fol - gen bis den tief - sten

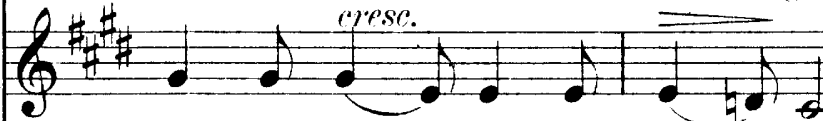

wird mein Bild__ dich rer - fol-t gen srese.

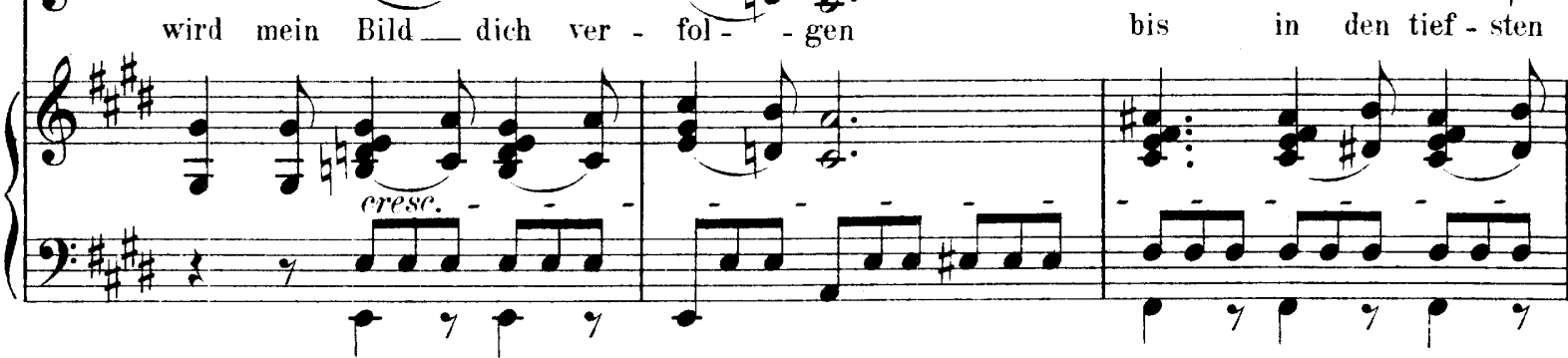

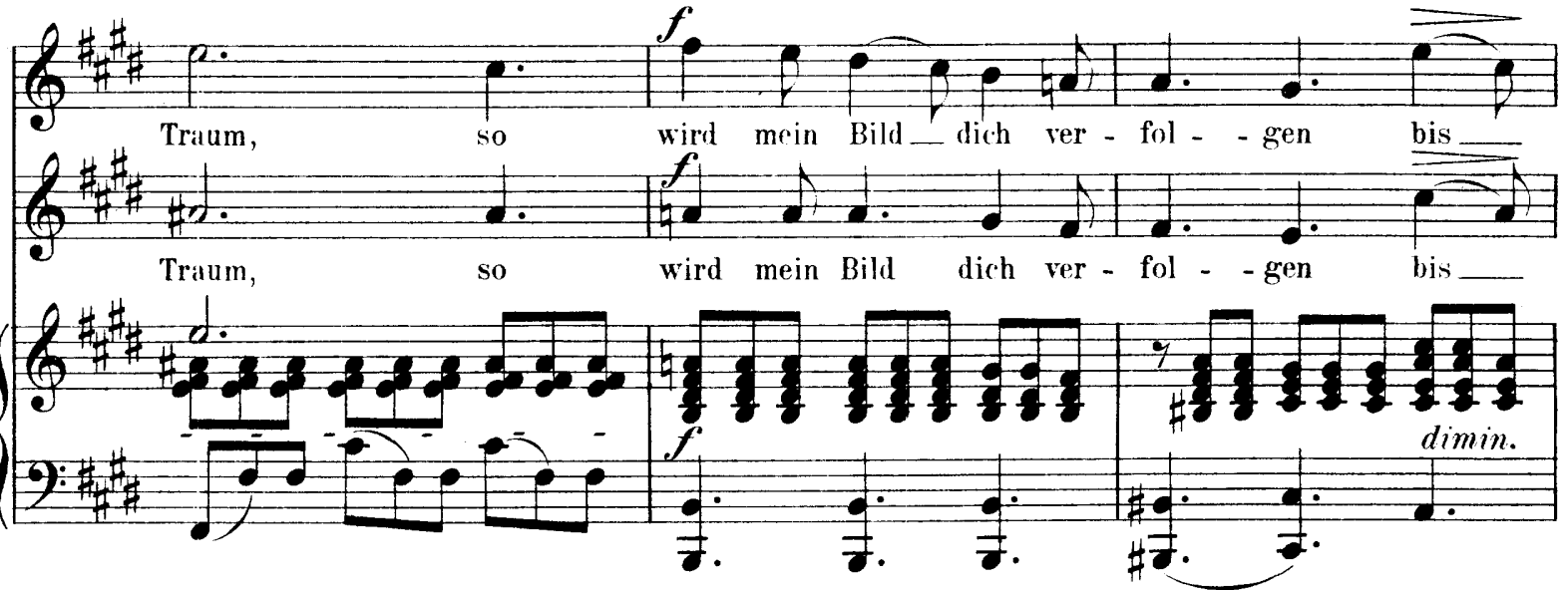

$(9)$ den tief-sten Traum, den tief-sten Traum, bis in den tief- sten,

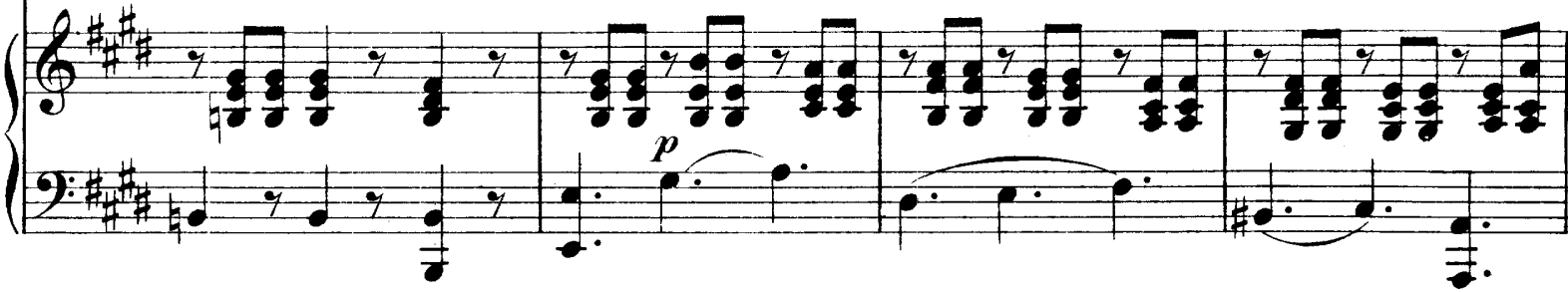

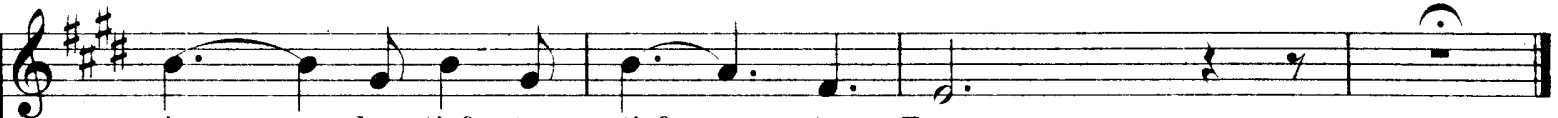
dentief. sten, tief - . sten Trum.

in den tief - sten, tief - - - sten Traum.

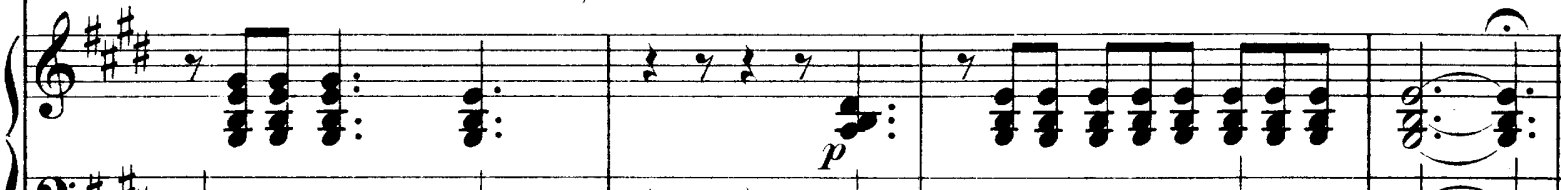
2:

So

**

Sed.

溇

Edition Peters. 
(Hoffmann von Fallersleben.)

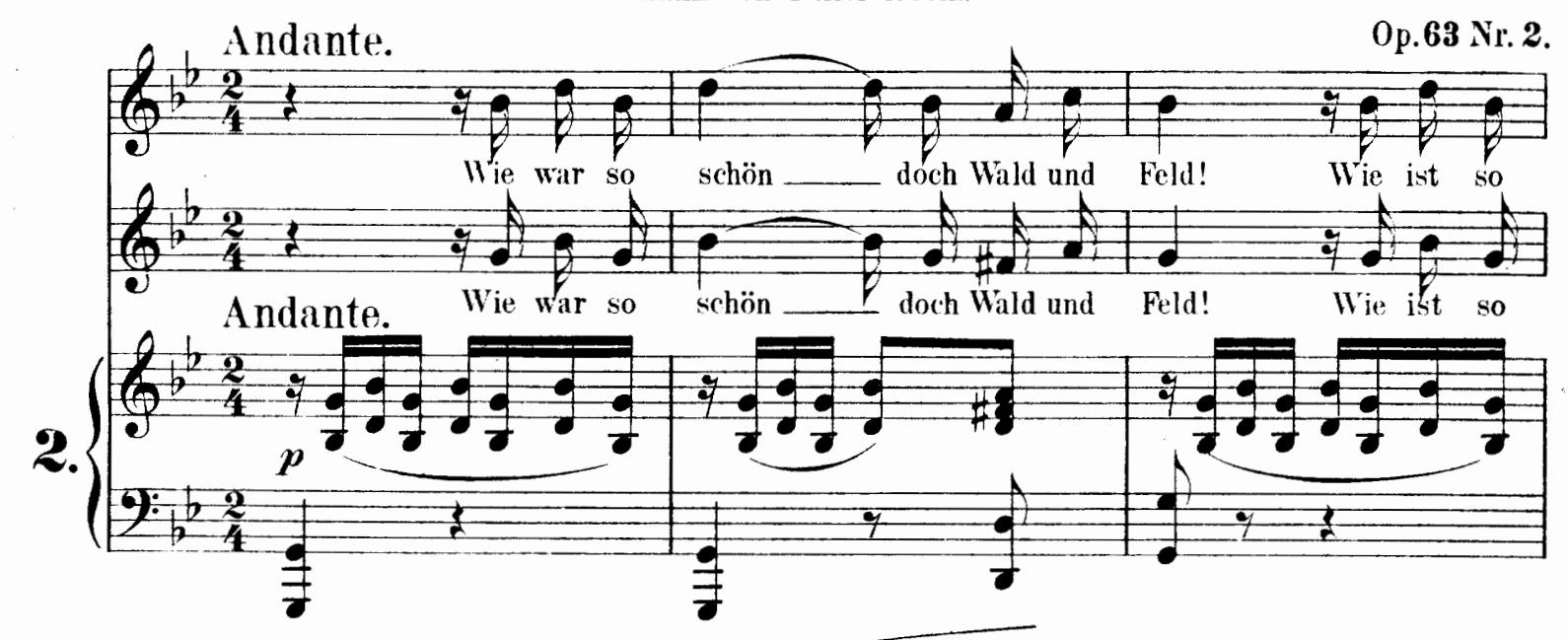

$\left(\frac{a}{b^{b}}\right.$

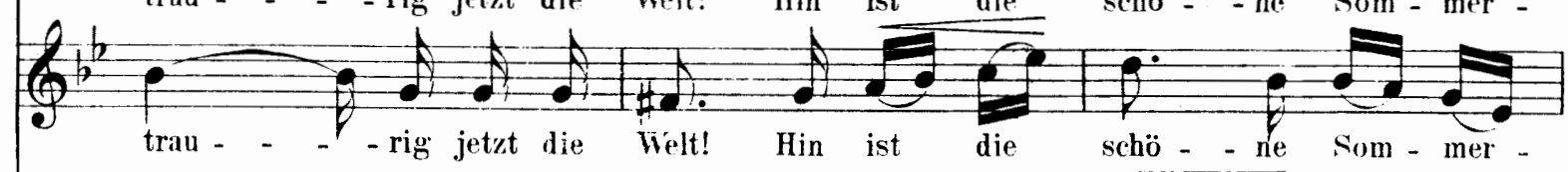

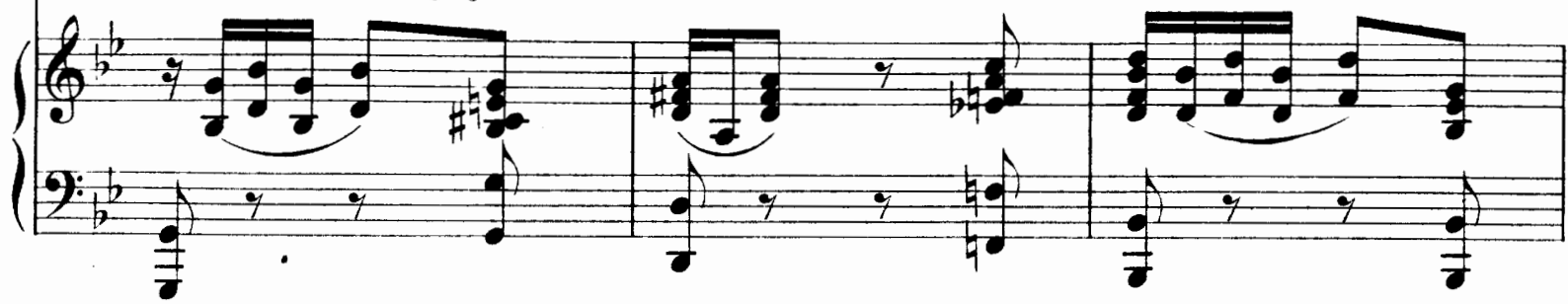

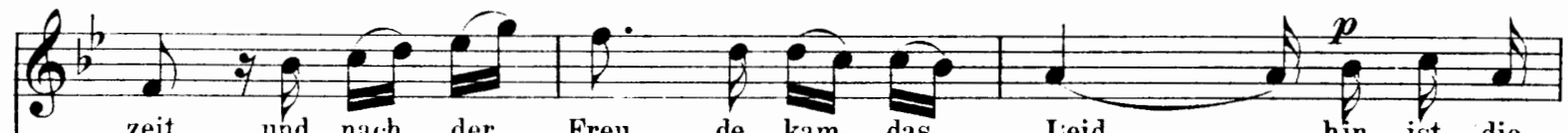
zeit und nach der Freu - - de kam das Leid,__ hin ist die

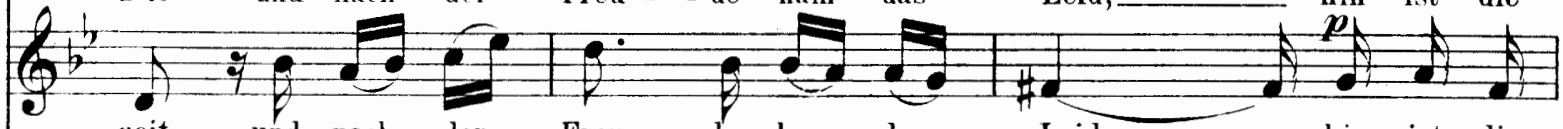
zeit und nach der Freu _. de kam das Leid,_ hin ist die
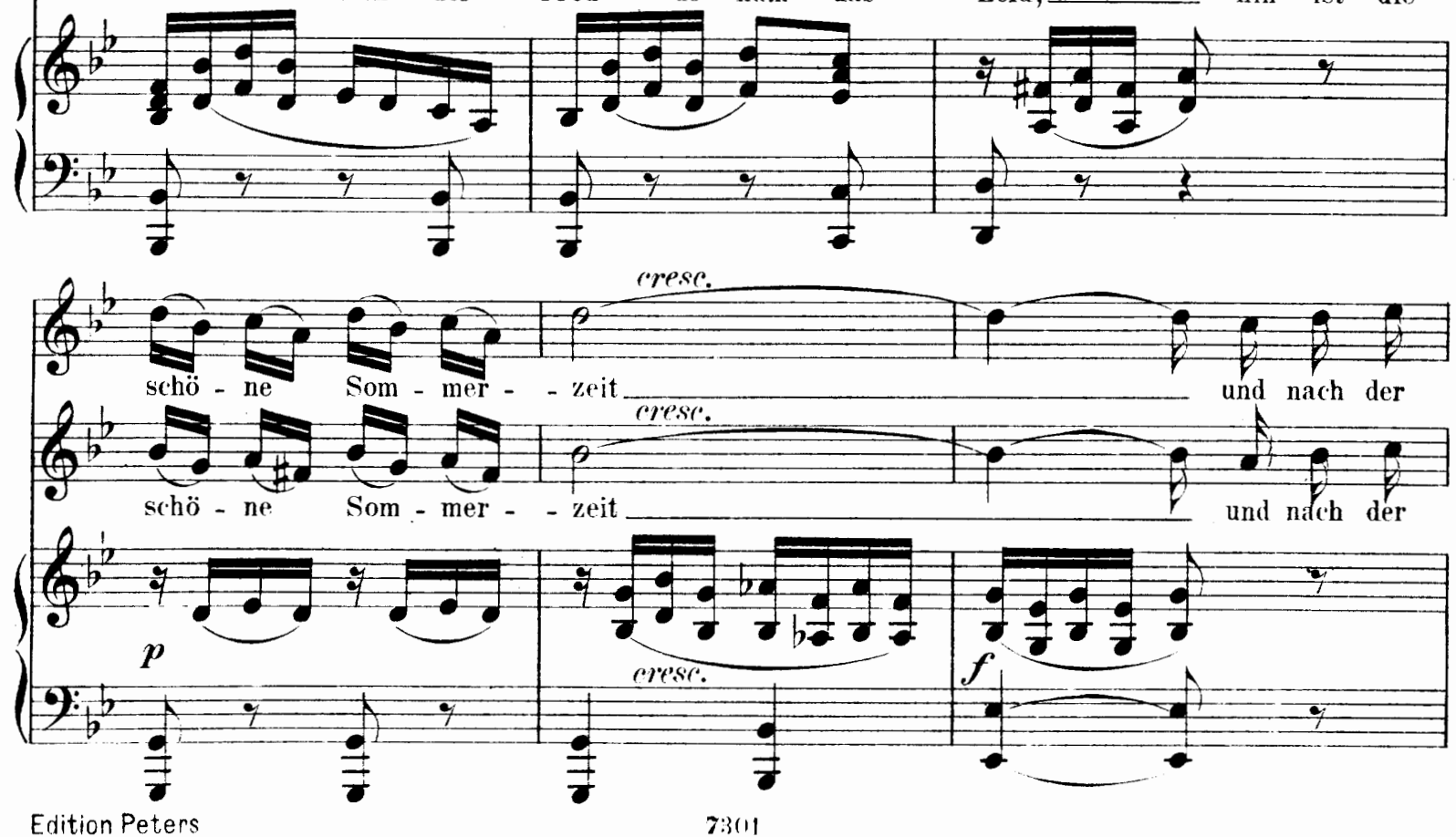


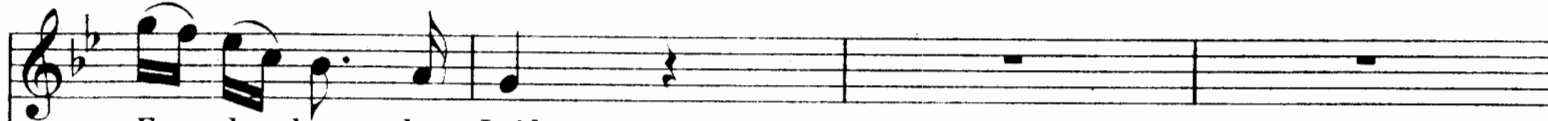
Frea-de kam das Leid.

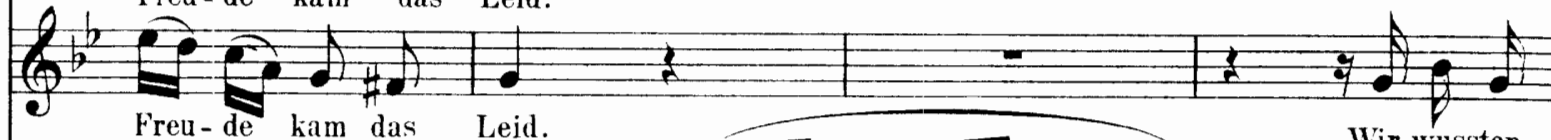

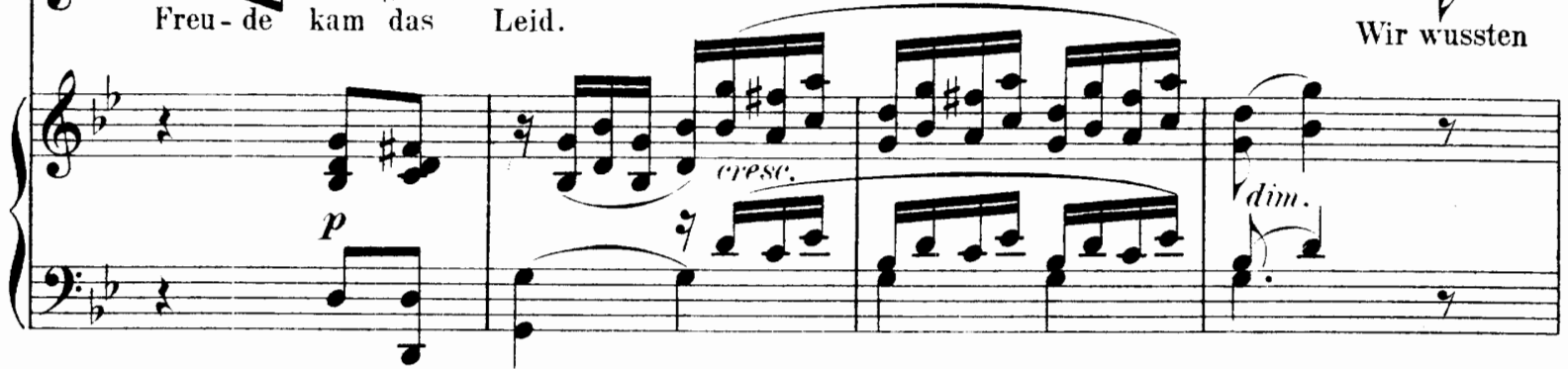

$\left(\frac{6^{b^{b}}}{2}=\right.$

0 r vergnïgt und

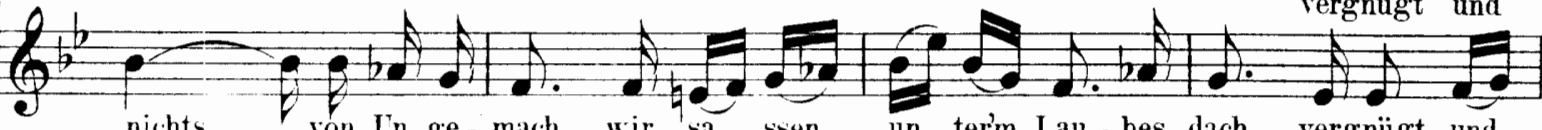

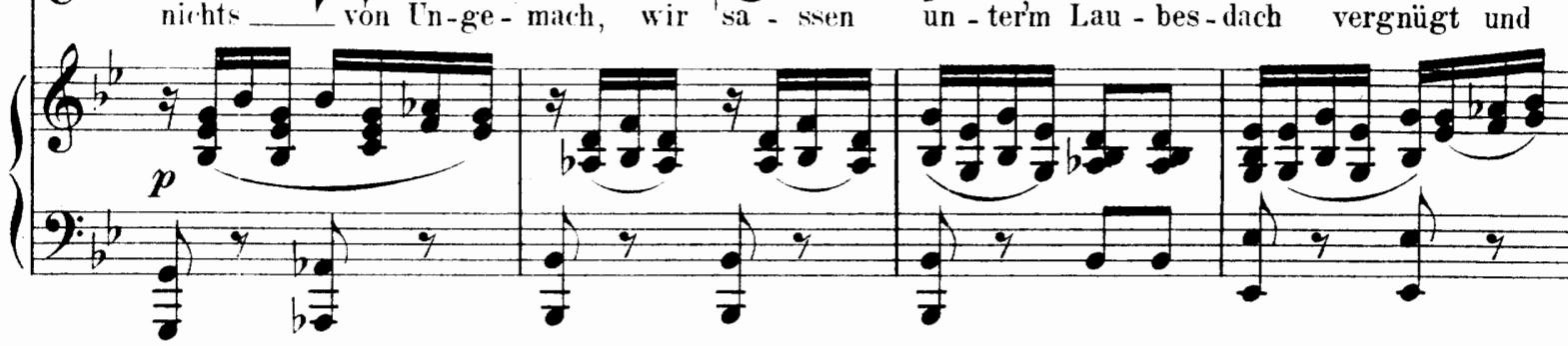

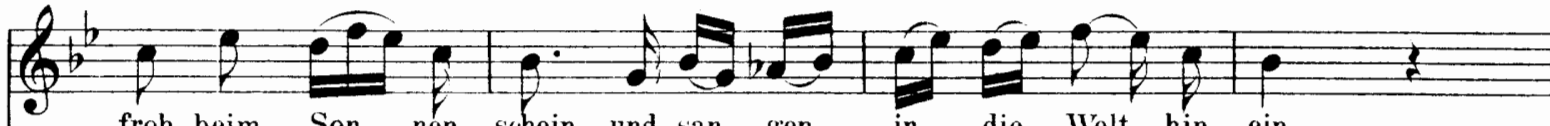
froh beim Son - nén - schein und san - gen in die Welt hin - ein,

froh beim son - nen - schein und san - gen

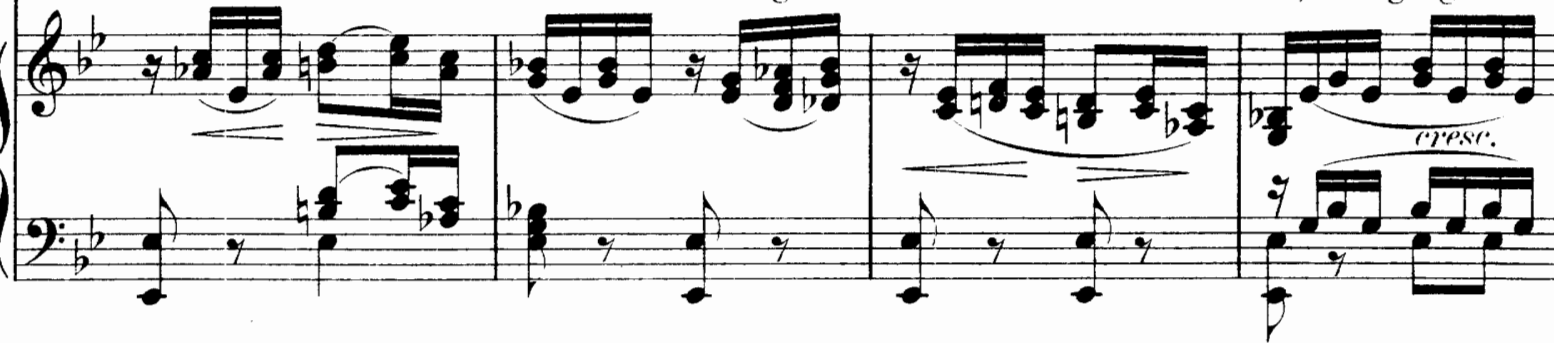

$e^{\frac{b}{b^{2}}}=$ $\left(a^{b}+9:\right.$ und san - gen in die Welt hin - ein.

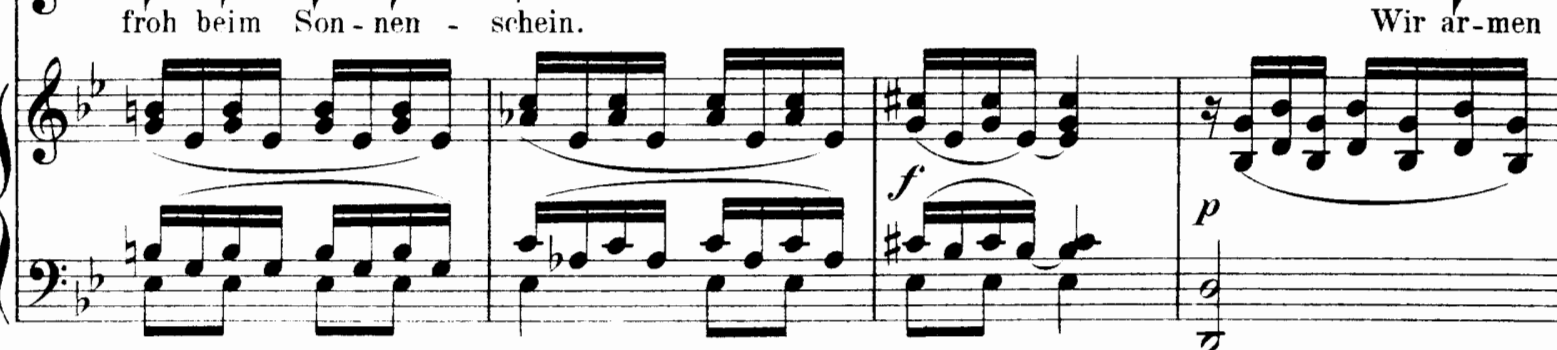




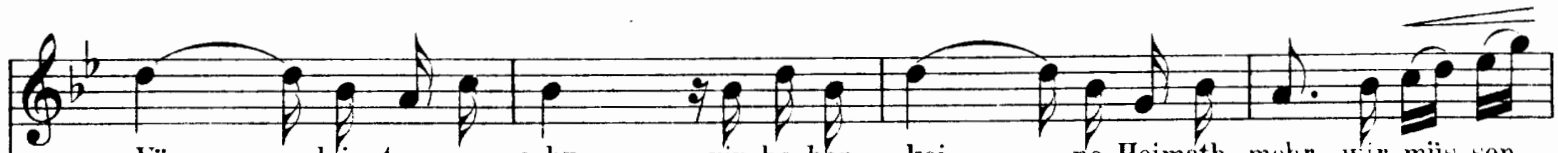
Vög - - - lein trauern sehr: wir ha-ben kei - _ - ne Heimath mehr, wir miis-sen $\left(\frac{a}{b}+2\right.$ की Vög - _ - lein travern sehr: wir ha-ben kei - - - ne Heimath mehr, wir müs-sen

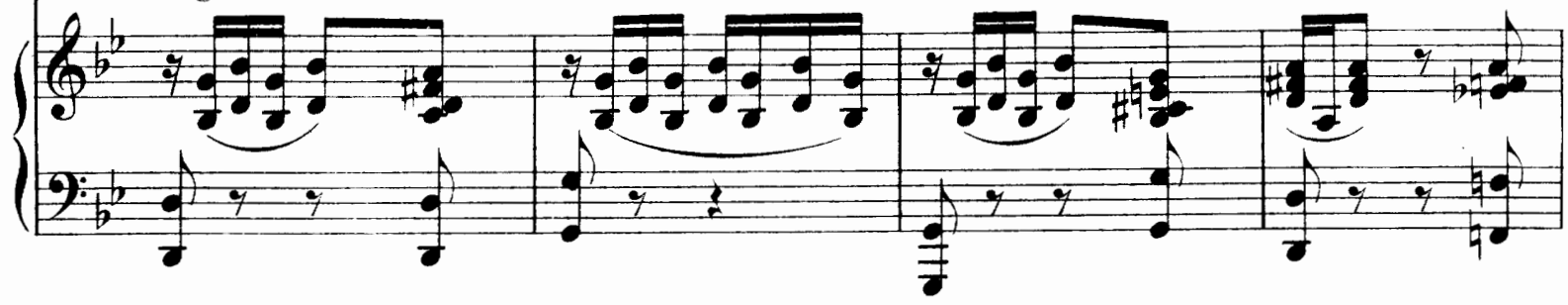

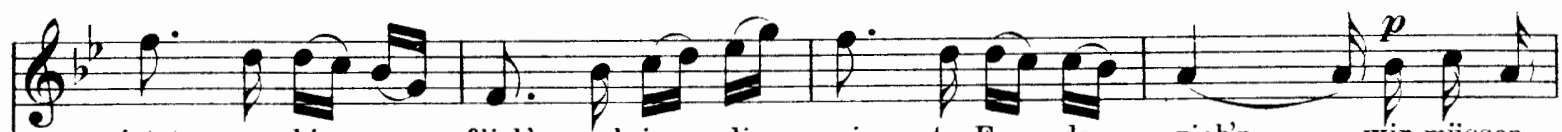
jetzt von hin-nen flieh'n und in die wei - te Frem-de zieh'n, __ wir müssen

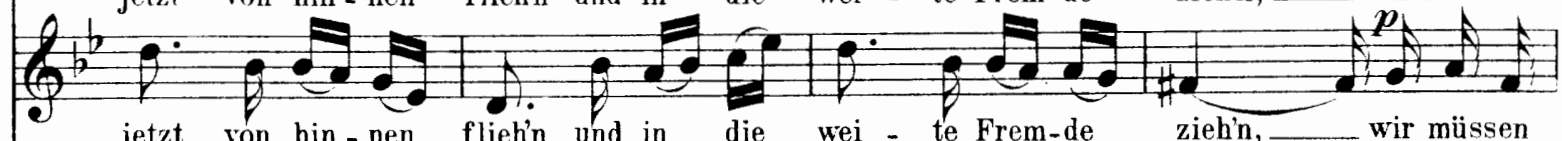

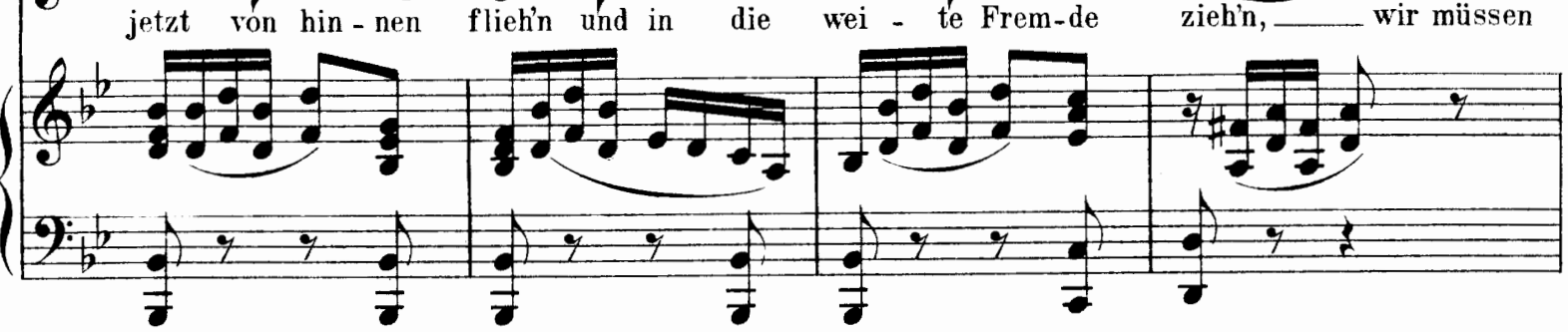

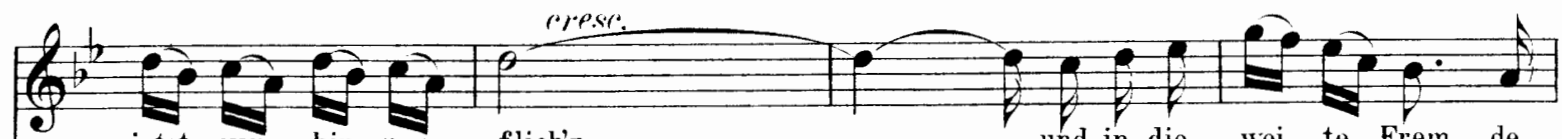
jetzt ron hin-nen flieh'n___ und in die wei - te Frem - de

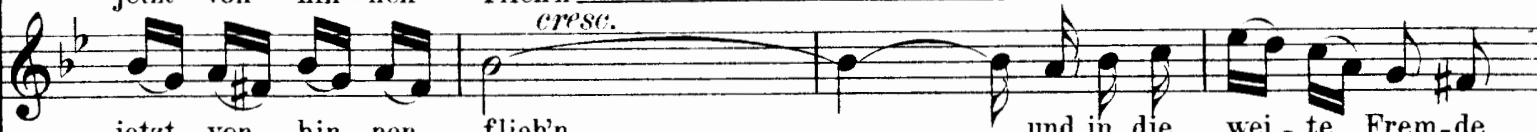
jetzt von hin - nen flieh'n

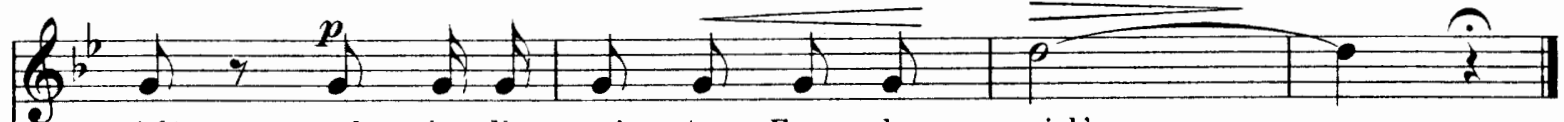
ziehn, und in die wei - te Frem-de

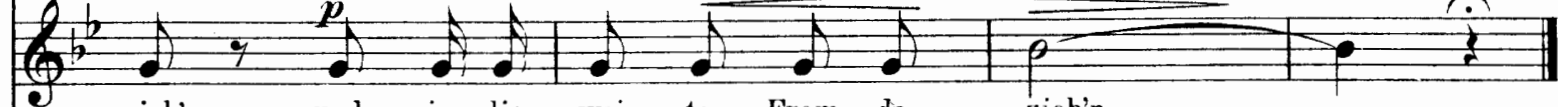
Edition Peters. 
Teneramente, non lento.

Op.63 Nr. 3.

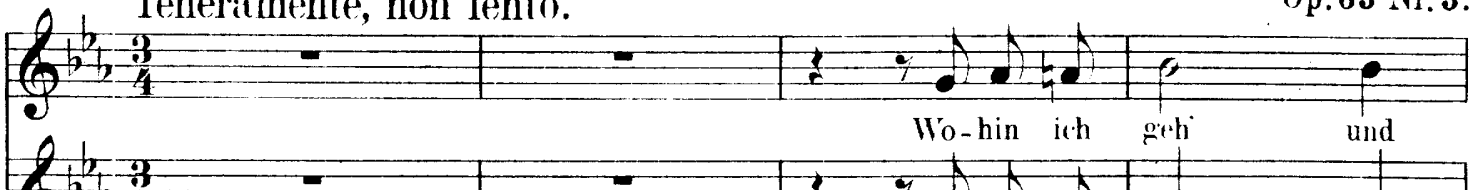

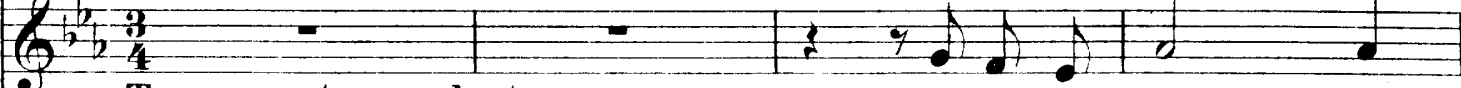

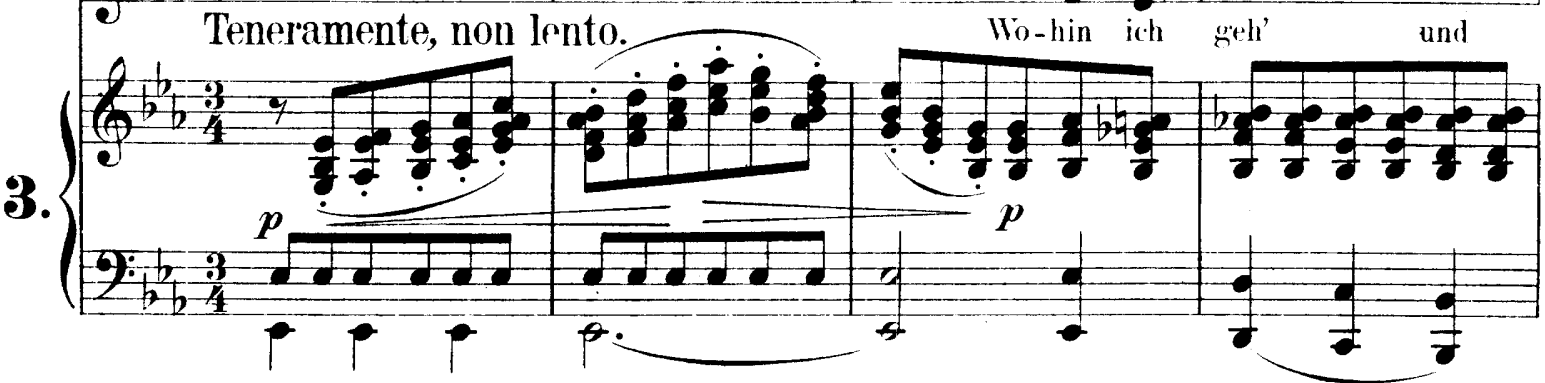

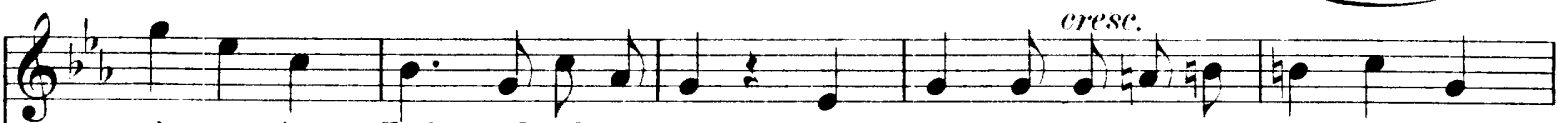
schau-e, in Feld undWald und Thal, vom Hü-gel hin anf die Au - e, rom

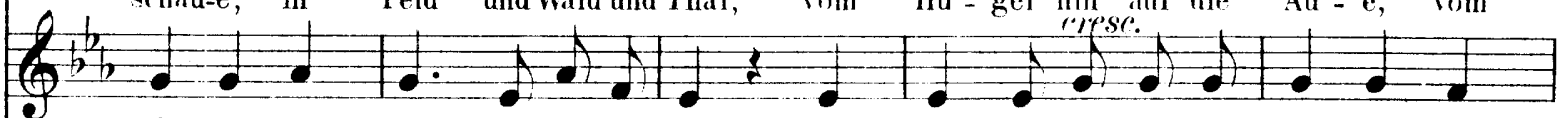
schau-e, in Feld und Wald und Thal, rom Hii - grel hin anf die Au - e, vom

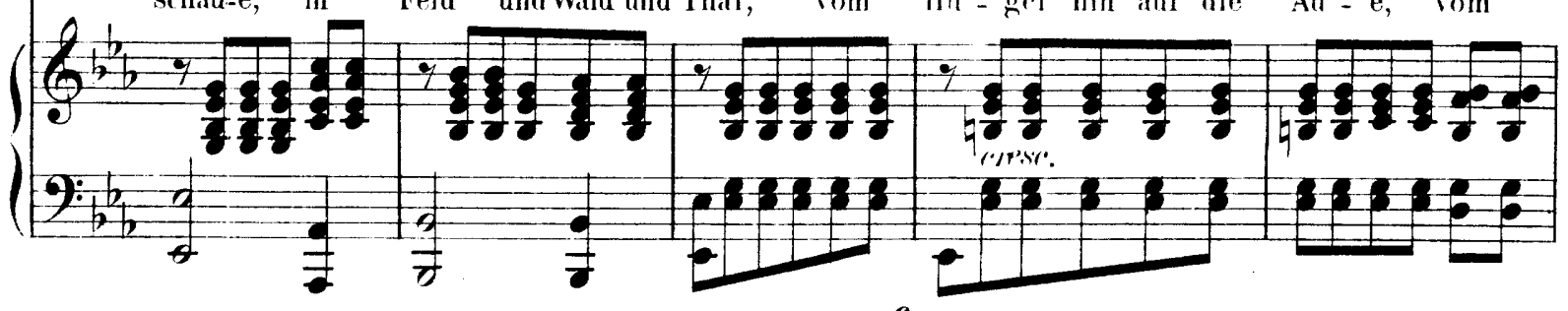

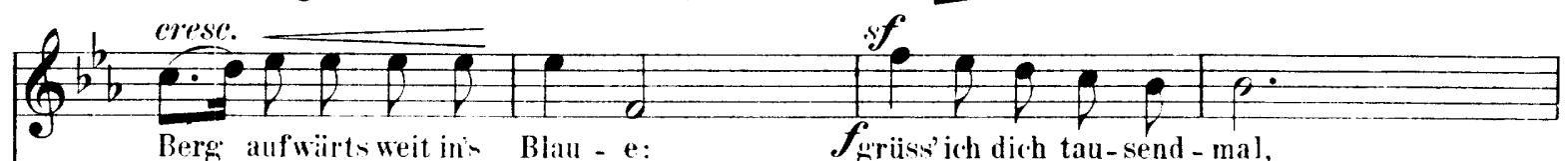
Berg; aufwirts weit ini Blau - e:

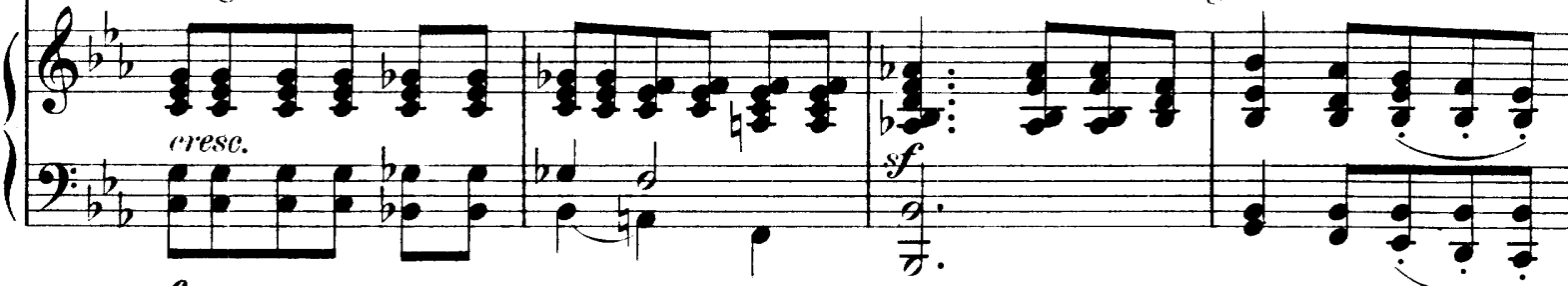
$\left(\frac{b^{b} f^{2}}{2}+9+9\right.$ grüss' ich dich tau-send-mal, grüss'__ ich dich tall - send-mal.

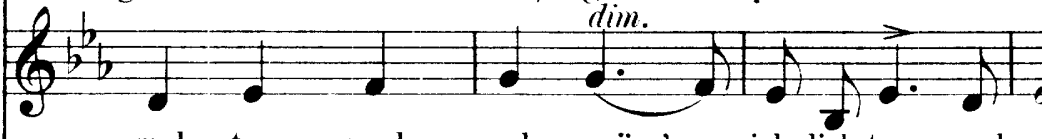

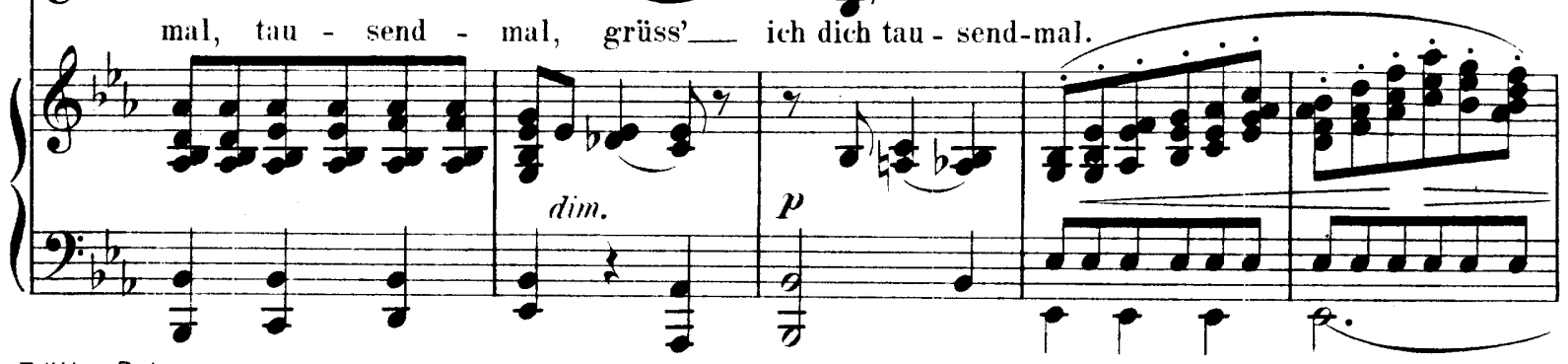

Edition Peters. 


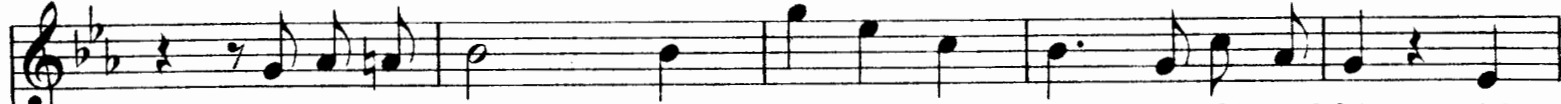
In mei_nem Gar - - - ten find' ich viel Blu - men,schön und fein, viel

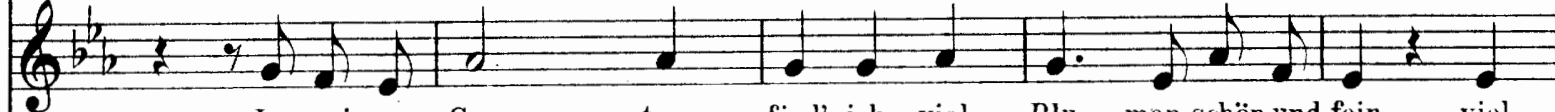

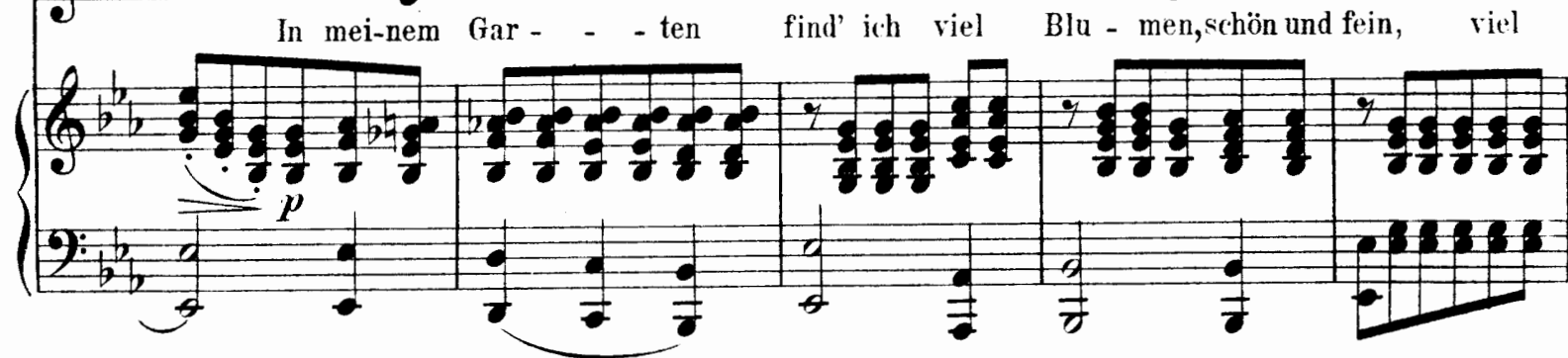

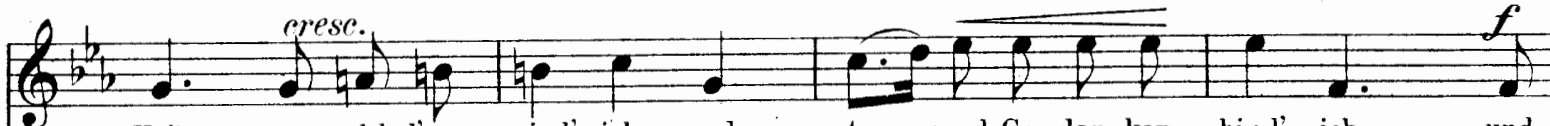
Krän - ze wohl draus wind' ich und tau - send Ge-dan-ken bind' ich und

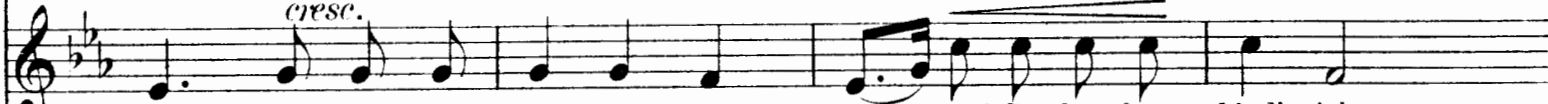
Krän - ze wohl d'raus wind' ich und tau - send Ge-dan-ken bind' ich

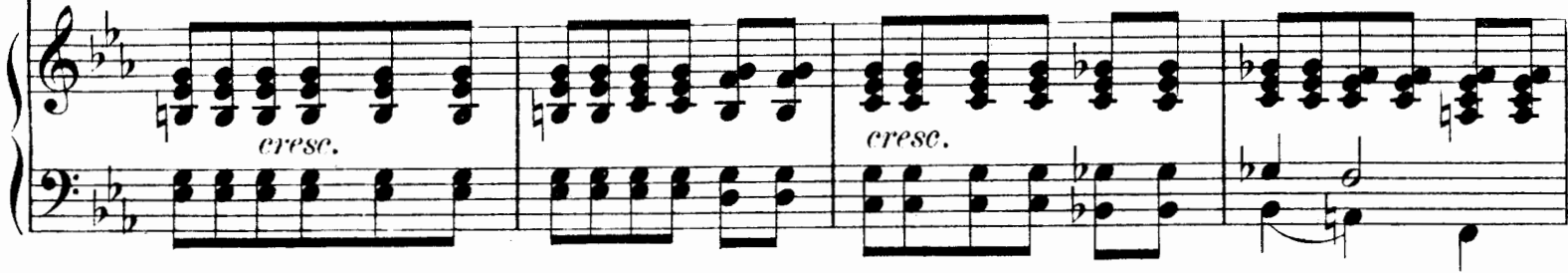

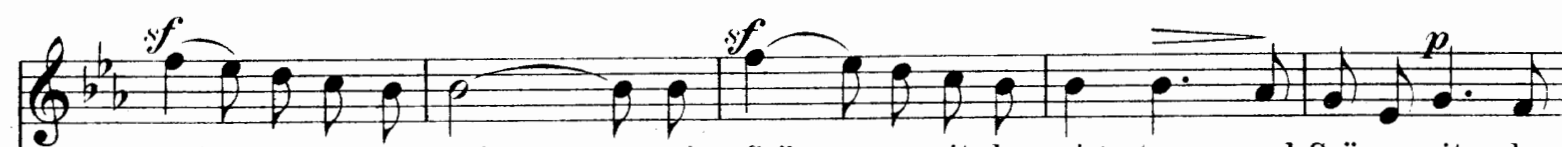
Grü - sse mit da - rein, und Grü - sse mit da - rein, tau - send Grüsse mit da -

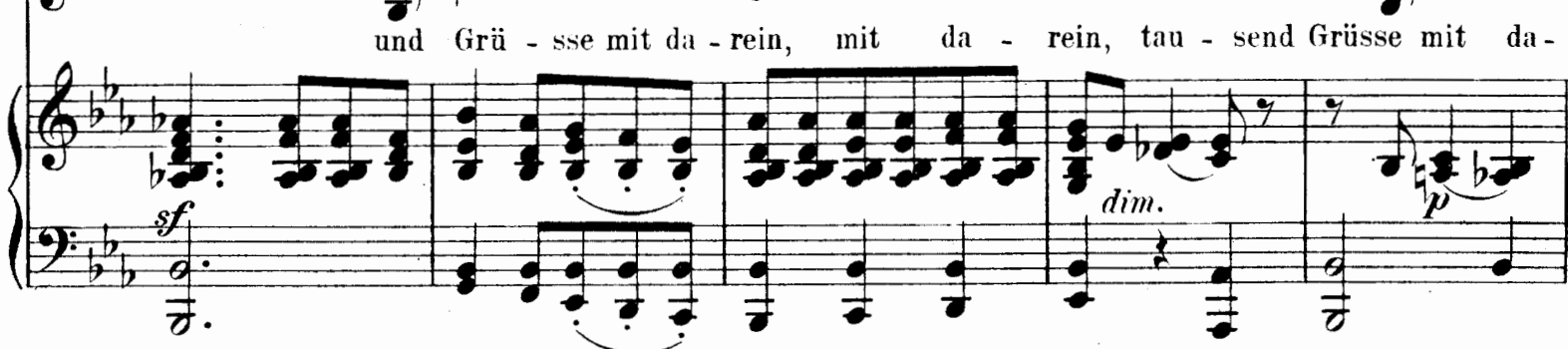

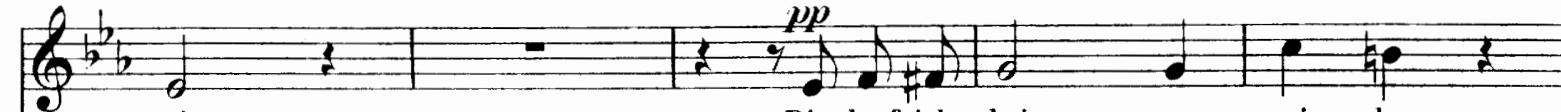
rein.

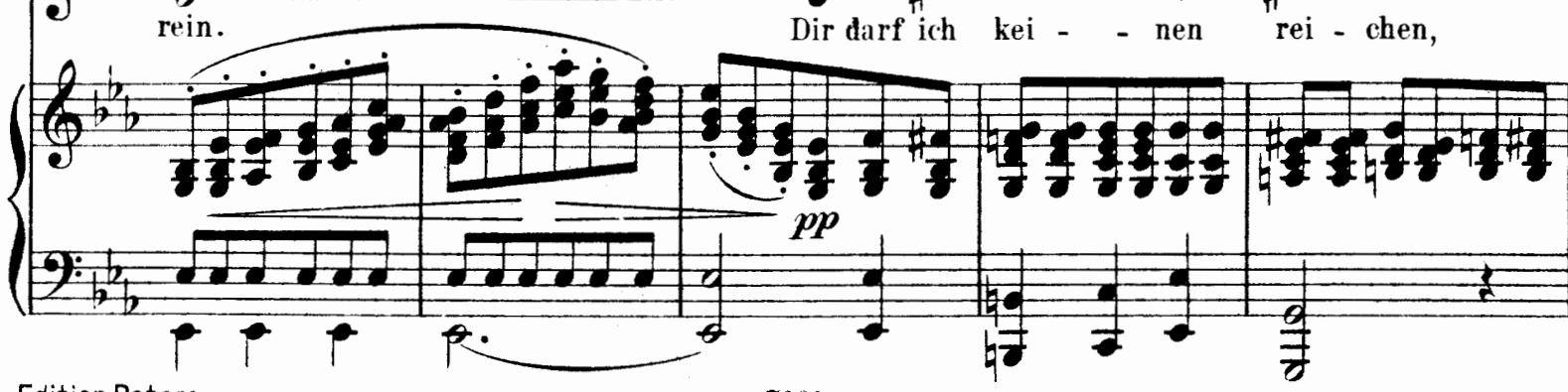
Edition Peters 


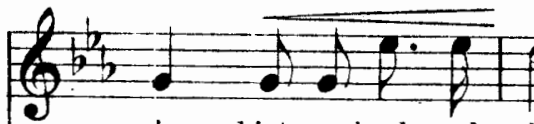

du bist zu hoch und schön,

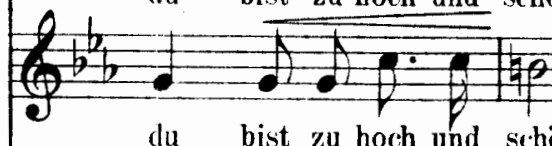

¿lu bist zu hoch und schön, sie müs - sen zu bald ver - blei - chen,

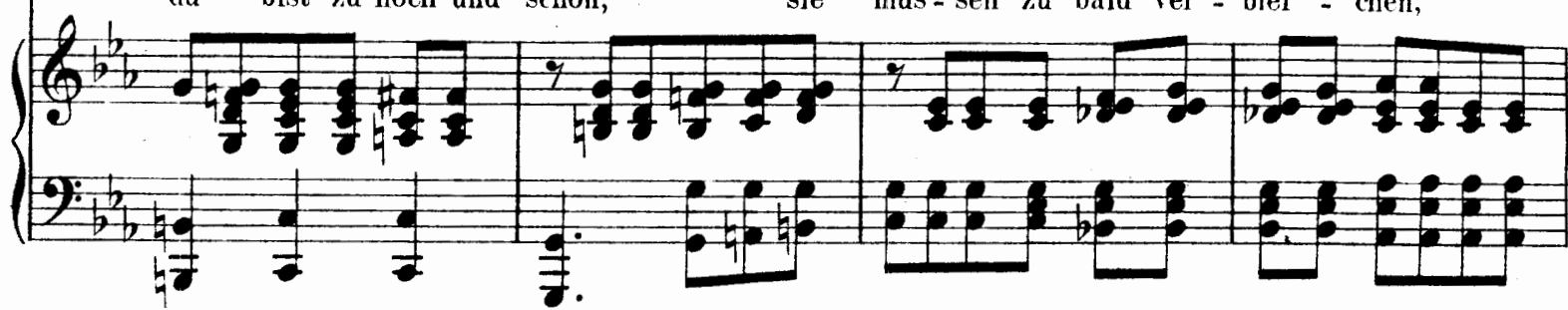

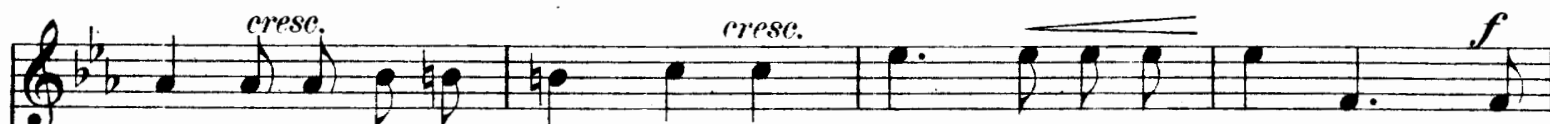

müs - sen zu bald ver - blei - chen, die Lie - - be oh-ne Glei - chen bleibt

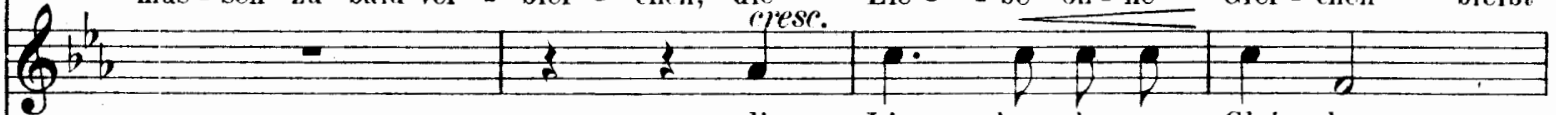

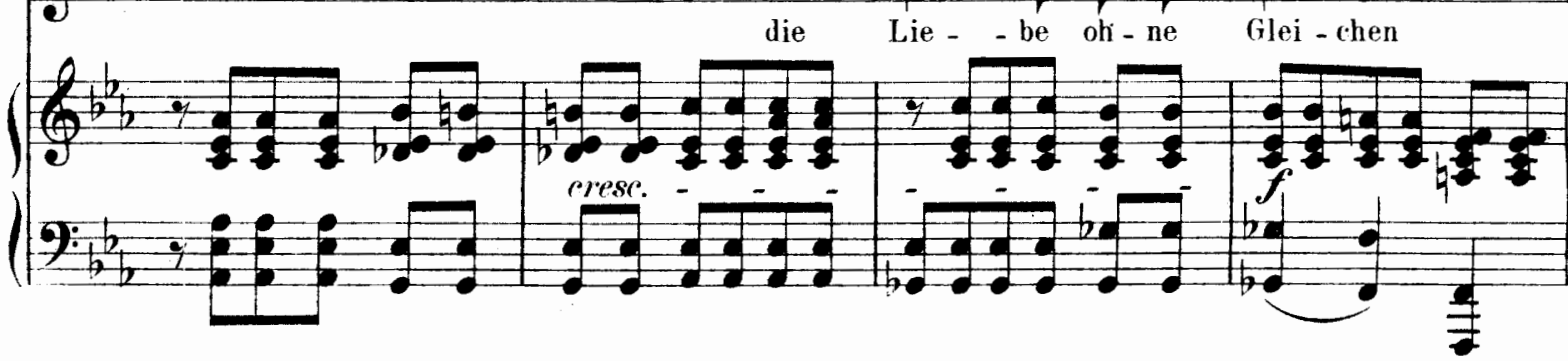

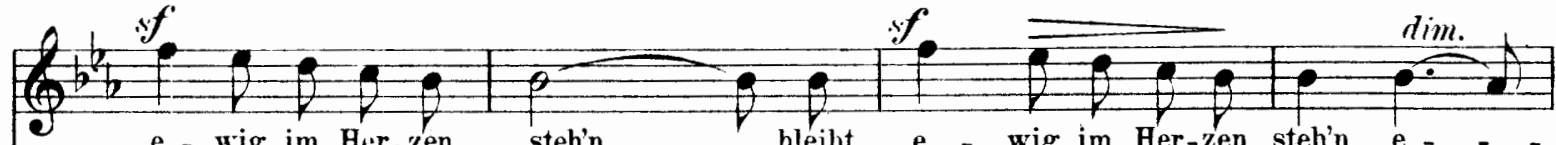
e - wig im Her-zen steh'n, bleibt e - wig im Her-zen steh'n, e - - -

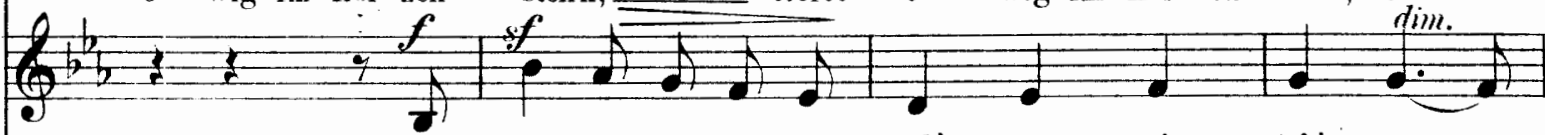

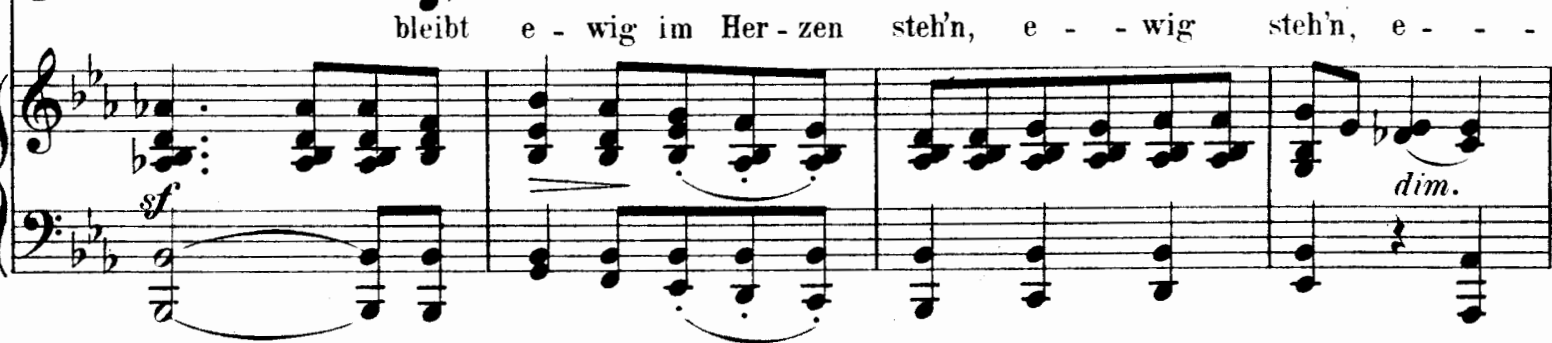

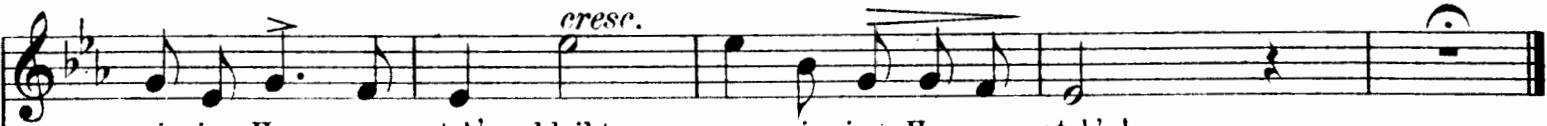
wig im Her - zen steh'n, bleibt crese. e - wig im Her-zen steh'n! wig im Her - zen steh'n, bleibt e - wig im Her-zen stehin!

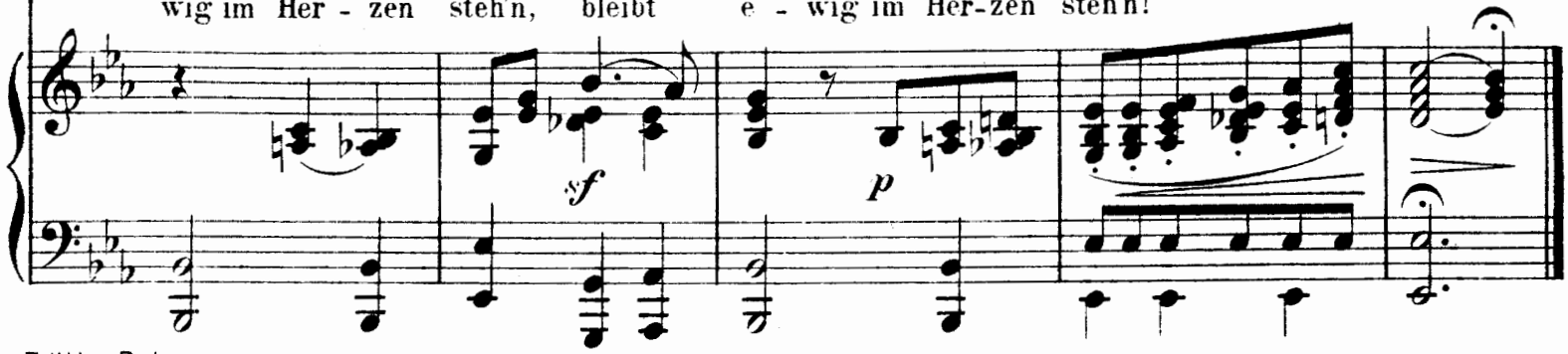

EditionPeters. 
(Klingemann.)

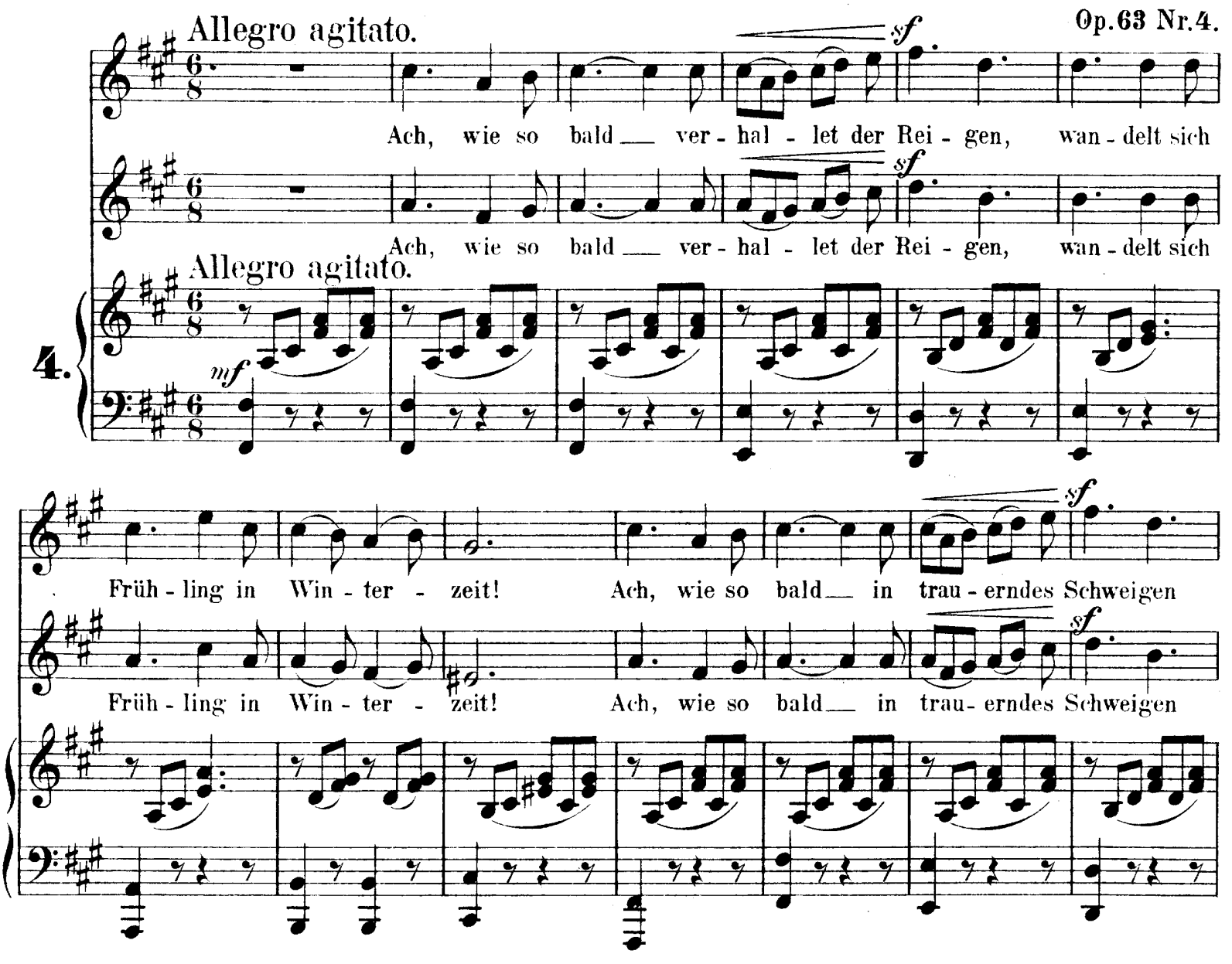

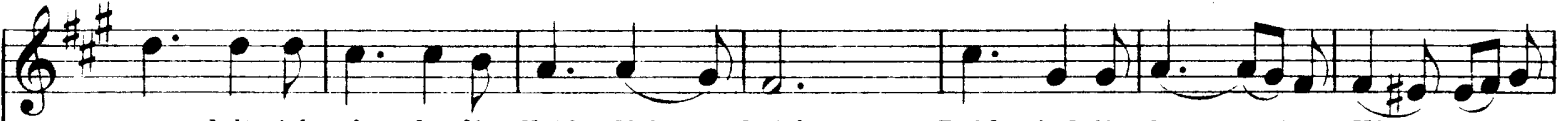

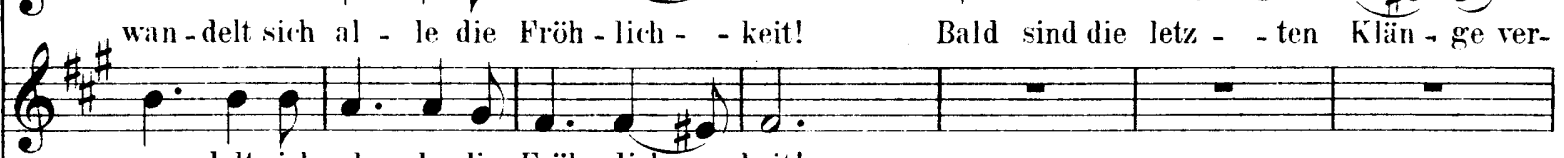

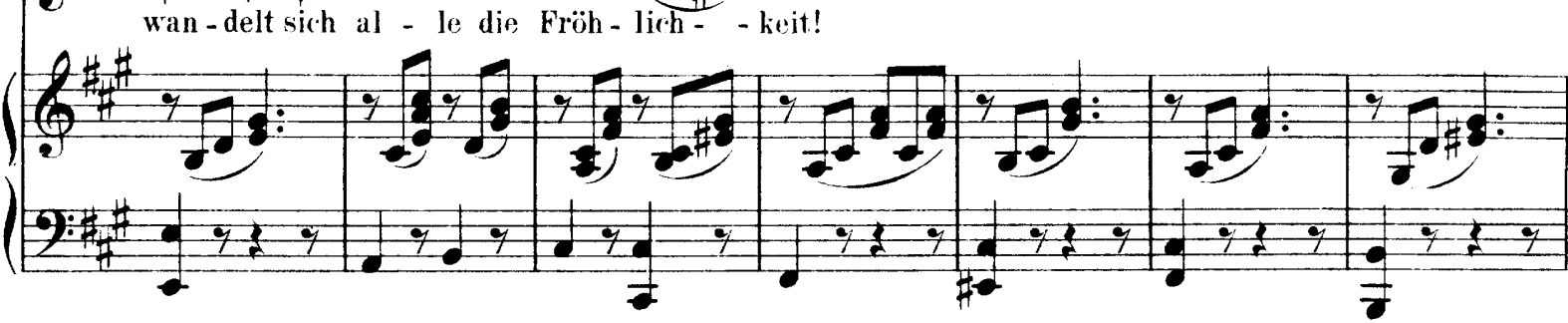

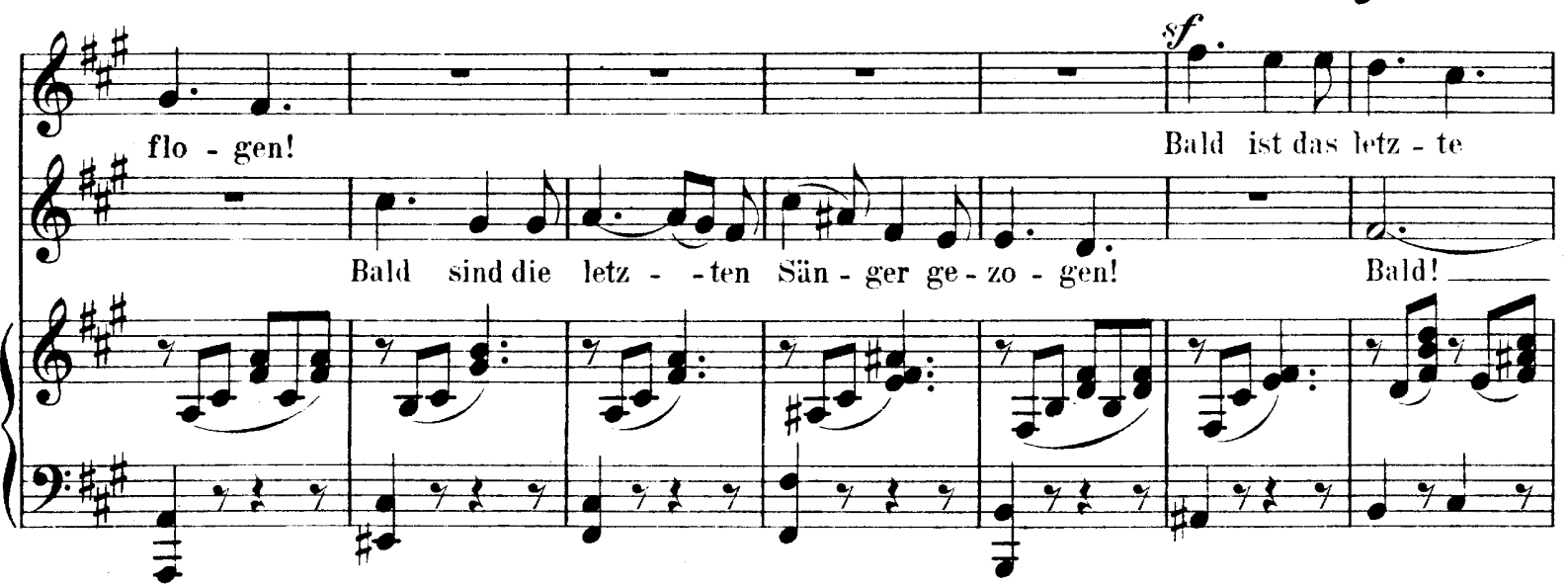




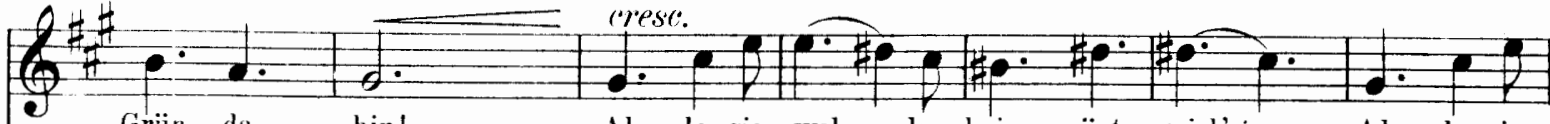

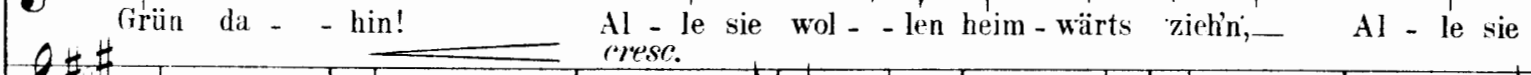

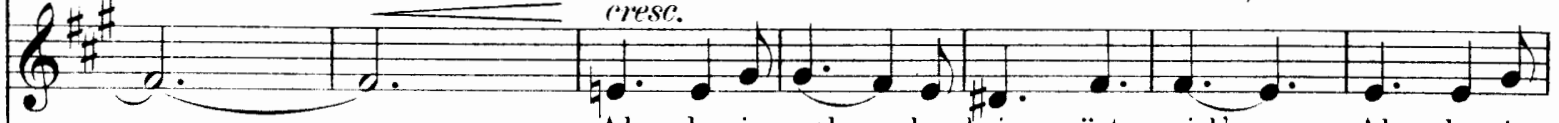

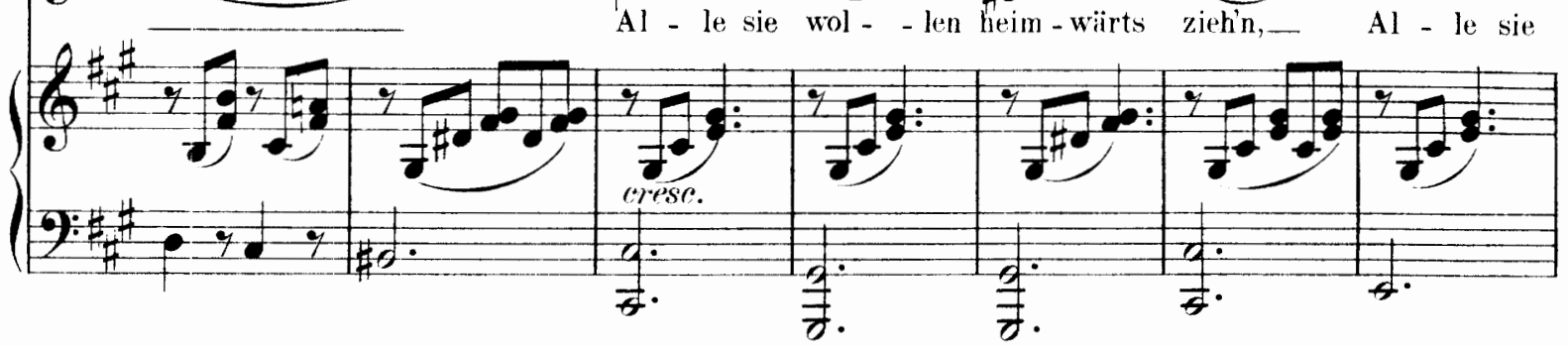

(6) O ${ }^{*}$ wol - - len heim - wärts zieh'n, bald ist das letz - - te Grün da - hin!

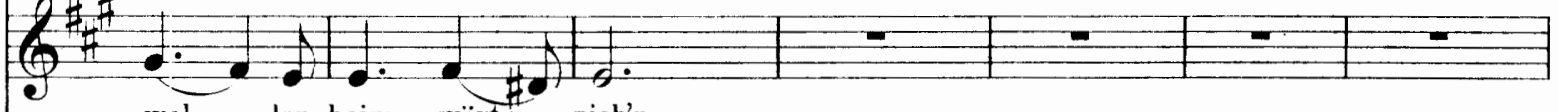

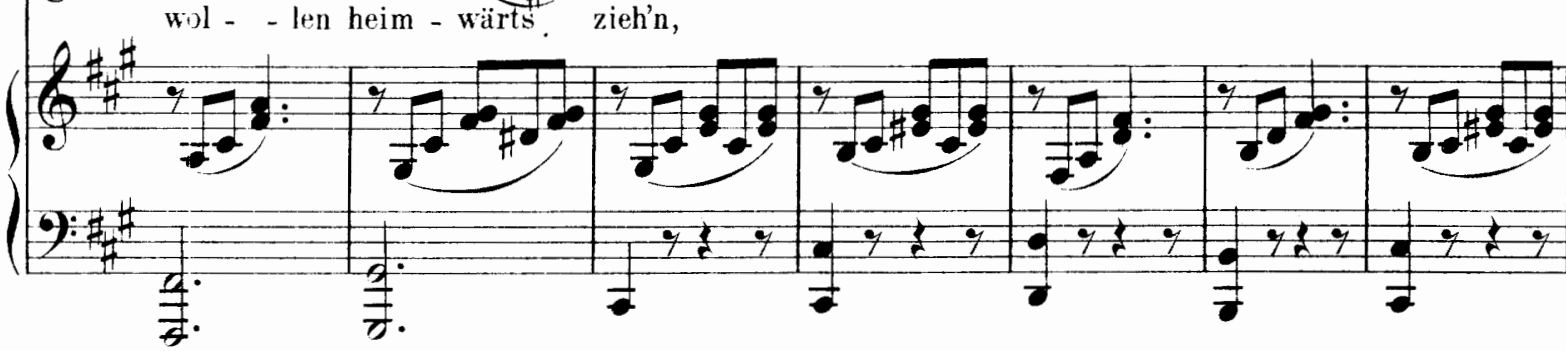

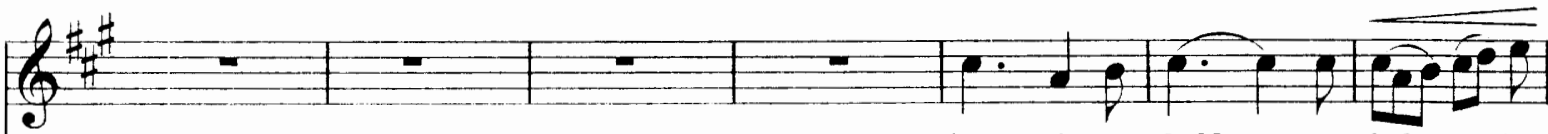
Ach, wie so bald _ ver - hal - let der (6) Al - - le sie wol - - len heim - wärts zieh'n! Ach, wie so bild__ ver - hal - let der

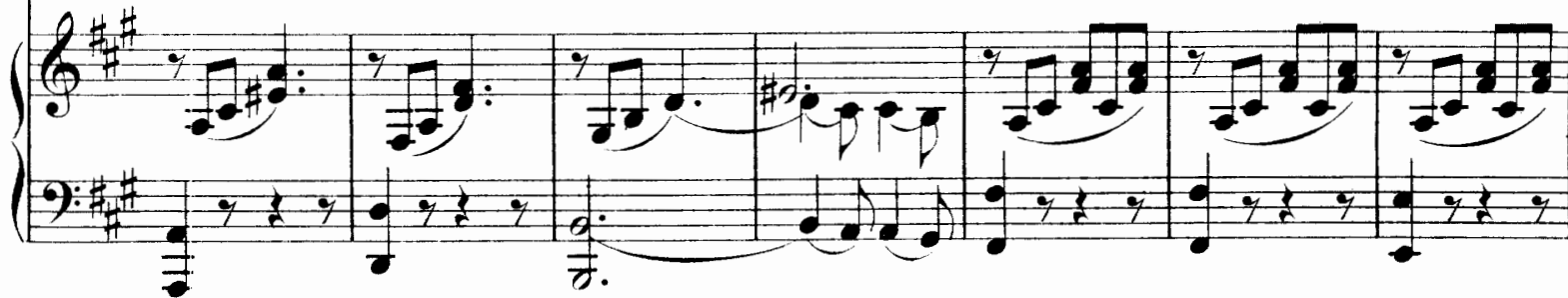

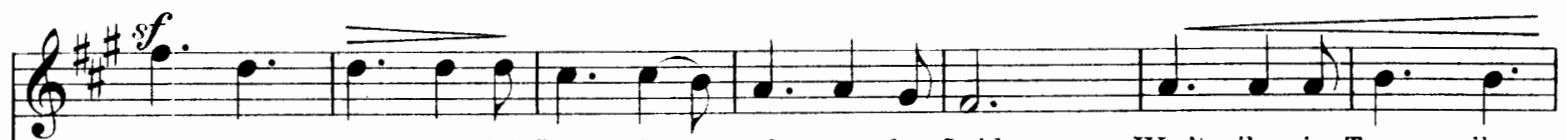
Rei-gen, wan-delt sich Lust in___ seh-nen-des Leid. War't ihr ein Traum, ihr

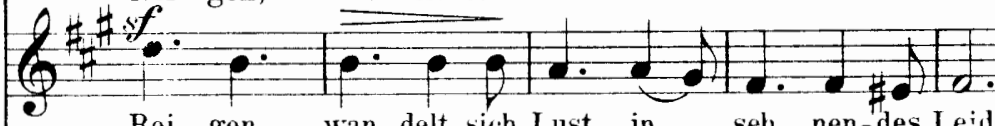
Rei-gen, wan-delt sich Lust in _ seh-nen-des Leid.

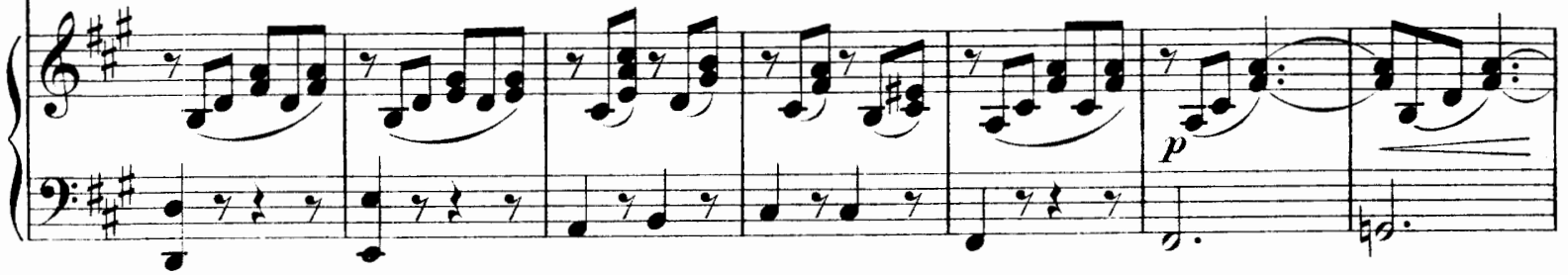




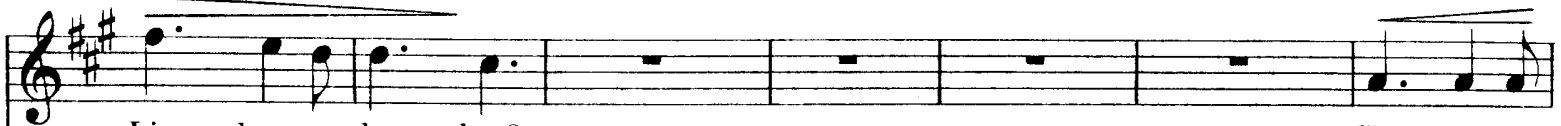
60 Lie - bes-ge-dan - ken?

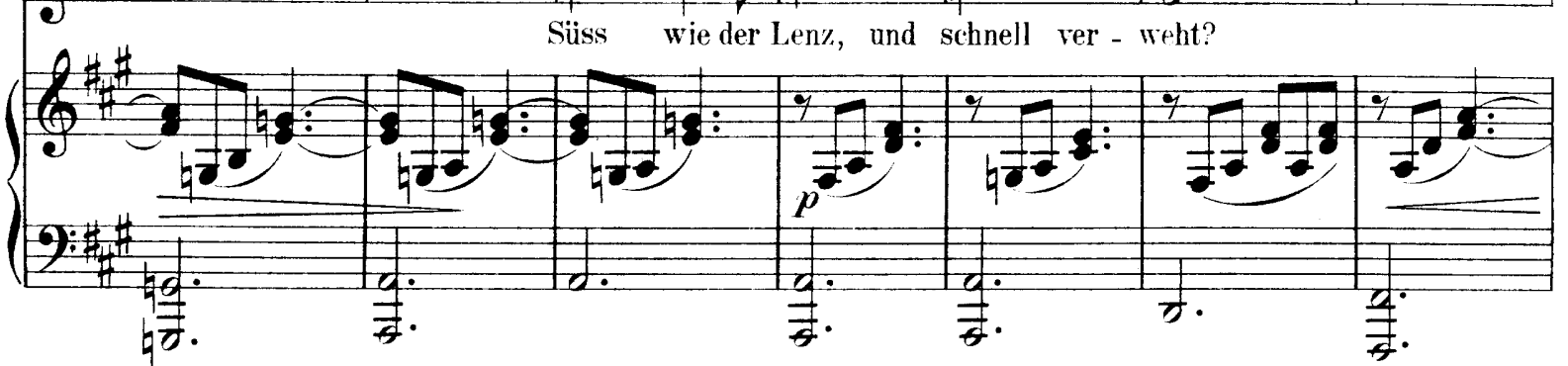

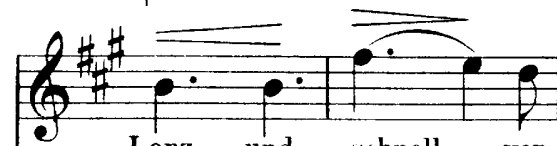
Lenz, und schnell_ ver-weht?

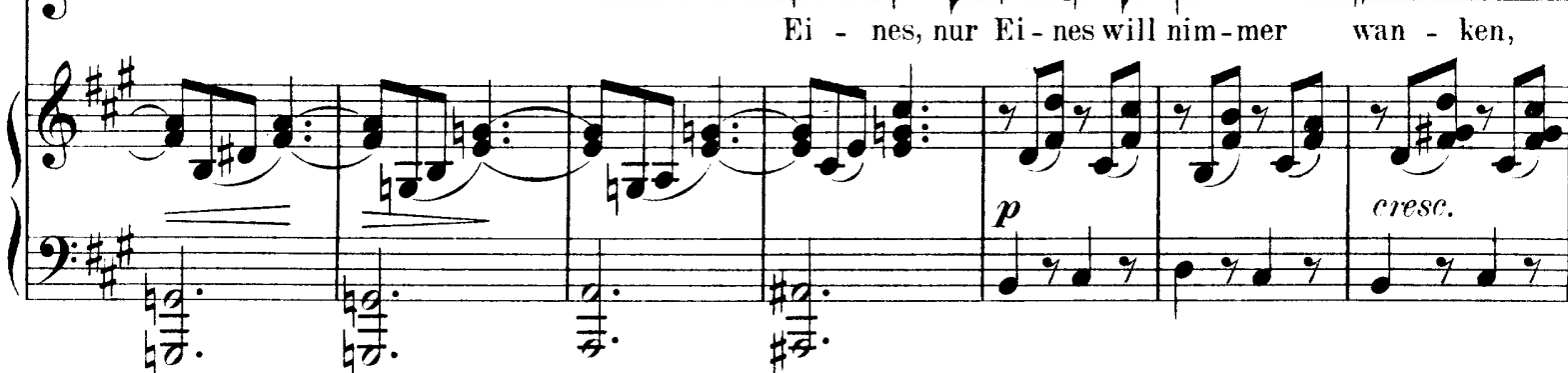

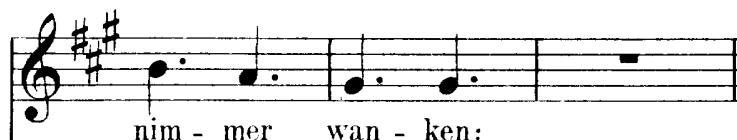
\begin{tabular}{l} 
nim - mer wan-ken: \\
\hline coresc. \\
\hline
\end{tabular} cresc. $e$ riten.

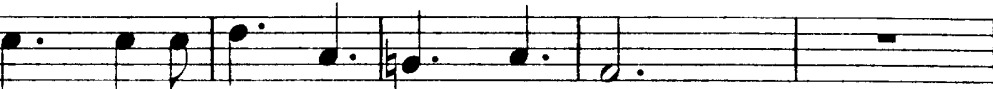

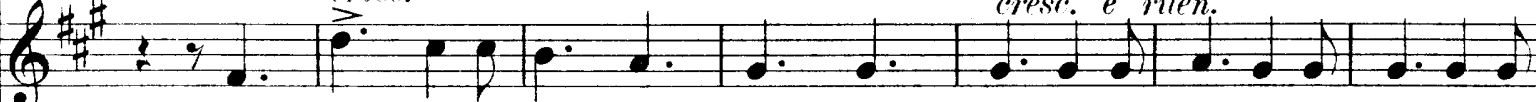

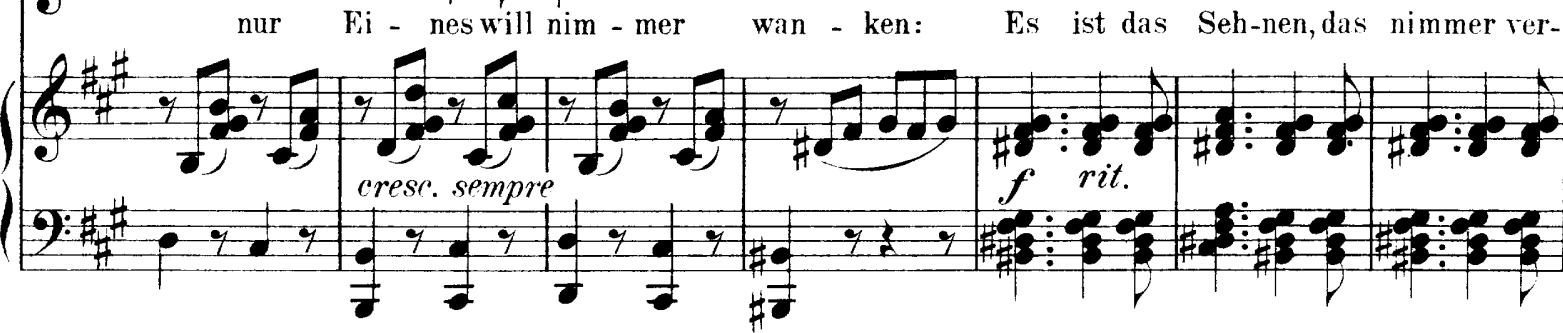

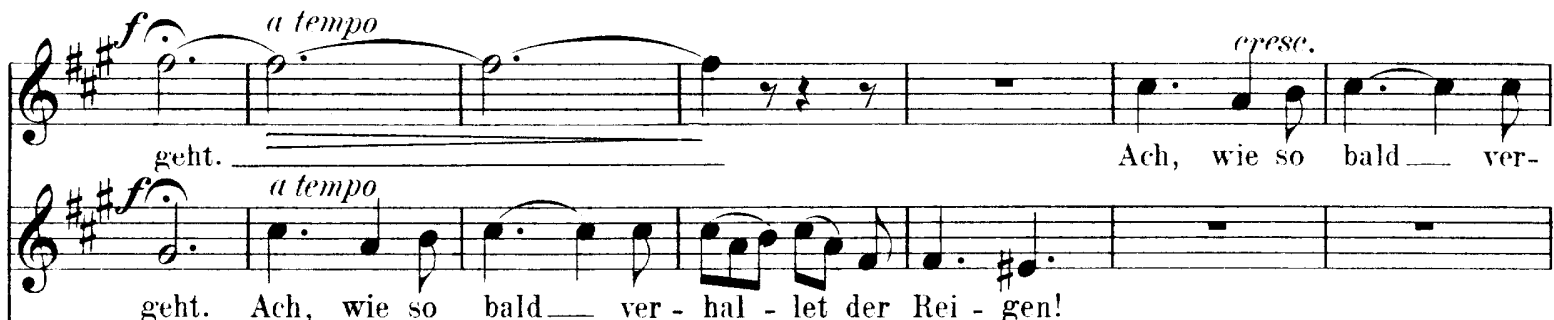
geht. Ach, wie so bald___ ver - hal - let der Rei - gen!

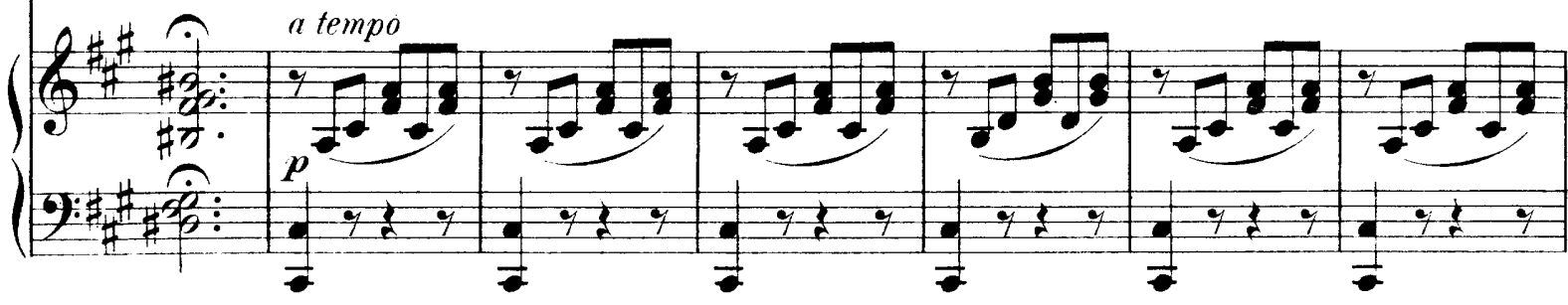




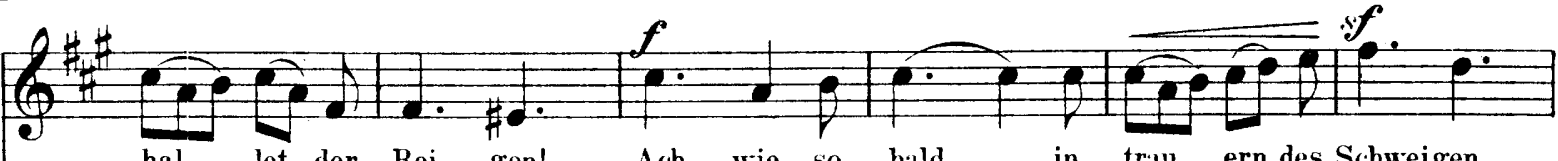
hal _ - let der Rei - gen! Ach, wie so bald ___ in trau - ern-des Schweigen

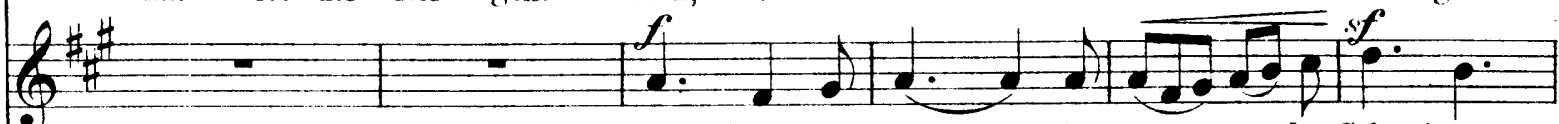
Ach, whe so bald___ in trau - ern-des Schweigen

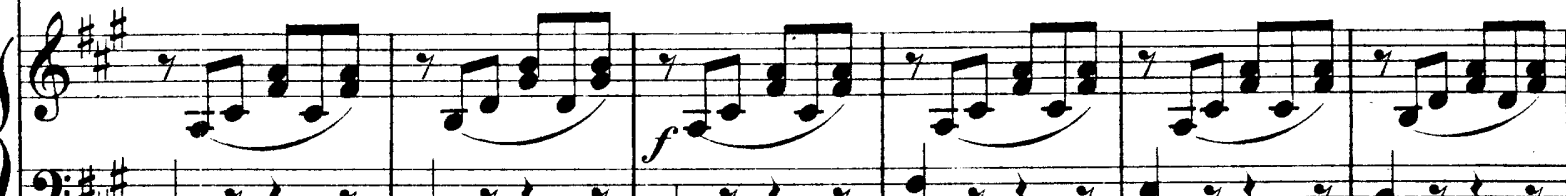
Q2:

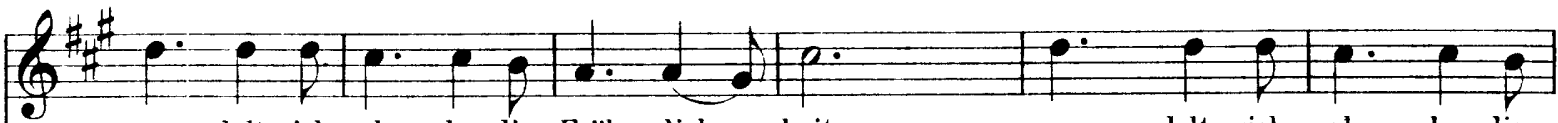
Wan - delt sich al - le die Fröh - lich - keit, wan - delt sich al - le die

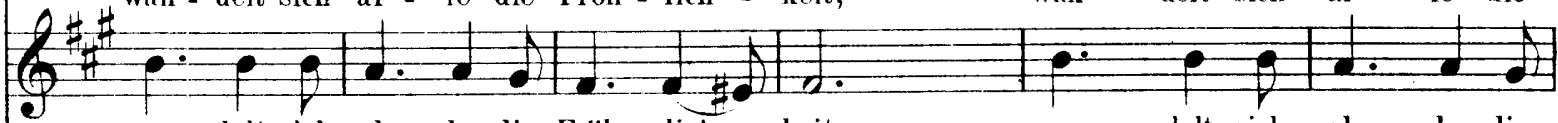
wan - delt sich al - le die Fröh - lich - keit, wan - delt sich al - le die

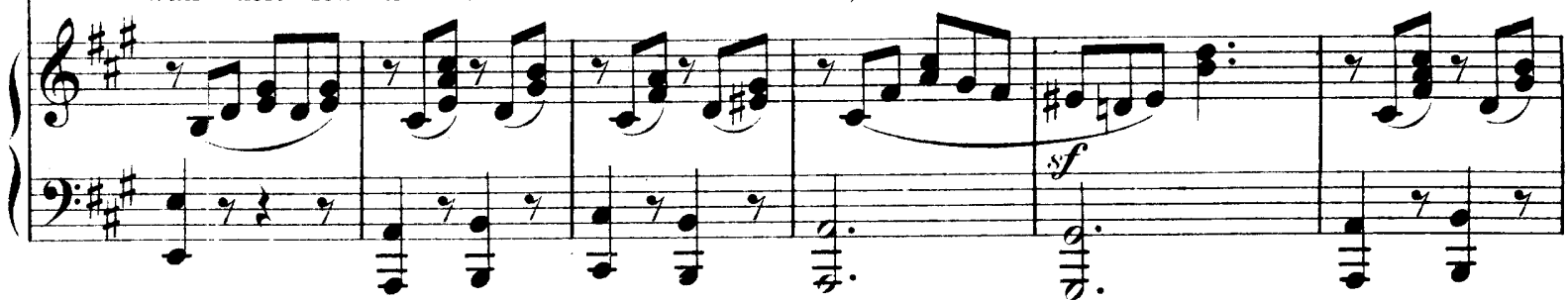
(6) Cröh - lich - keit! Ach, wie so_ bild! $p_{7} \quad$ Ach, wie so_

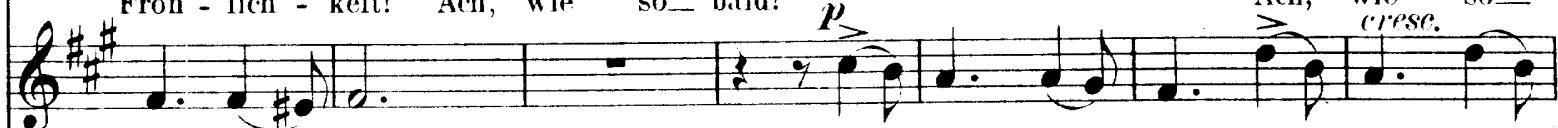
Fröh - lich - keit! Ach, wie so _ bald! Ach, wie so -

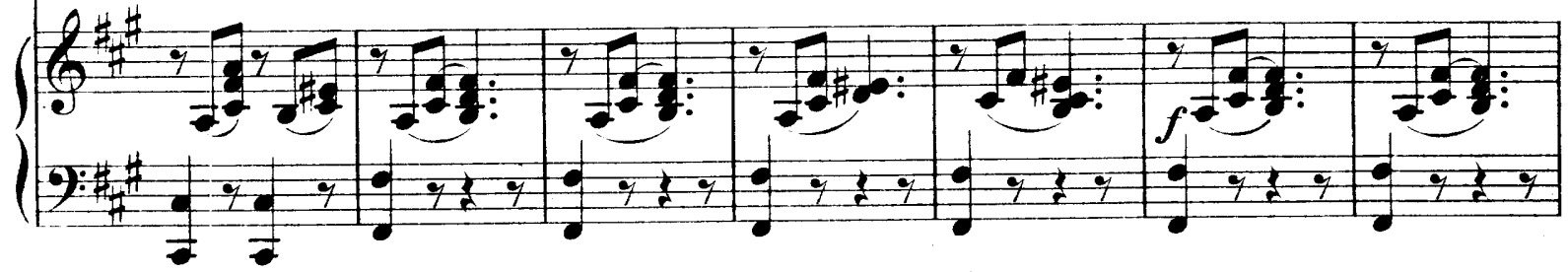

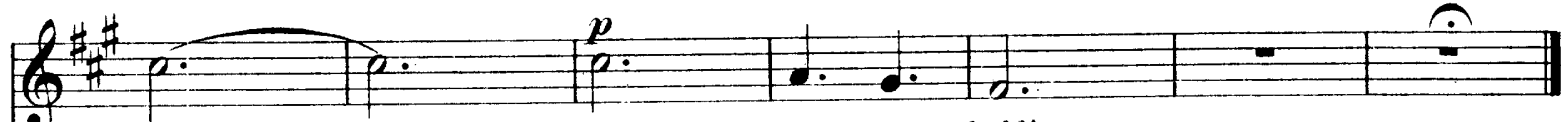

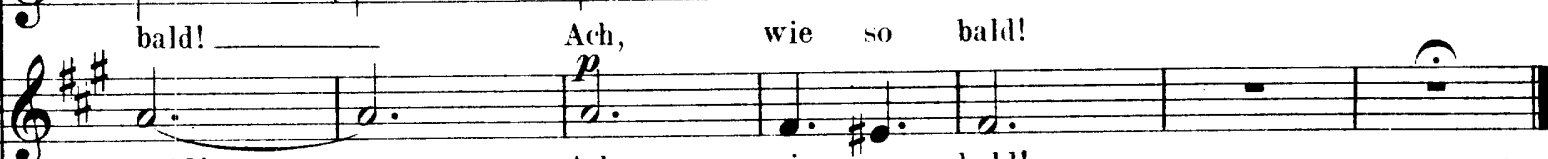
bald! Ach, wie so bald!

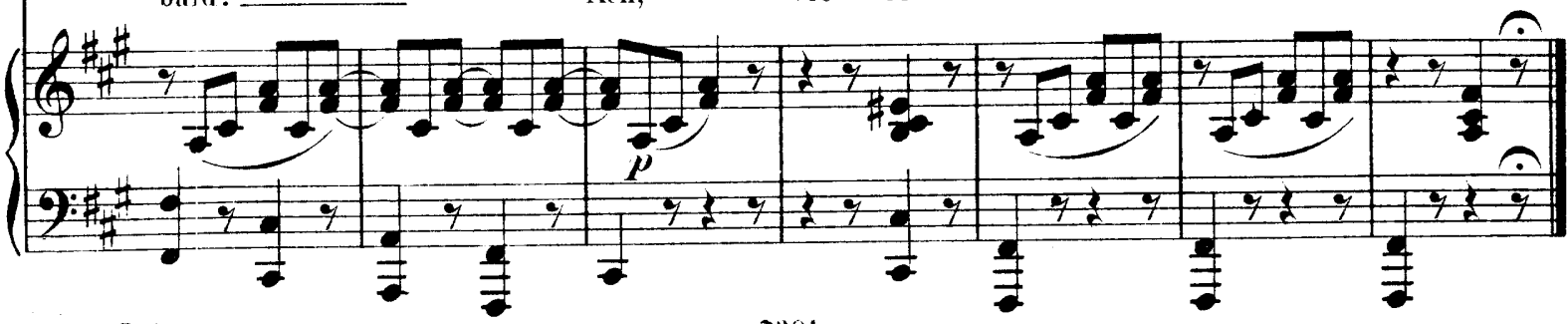
Edition Peters. 
Andante.

Op.63 Nr.5.

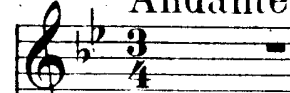

$+-5+c=$ (e

0 sïh' ich auf der Haide dort im

$\frac{a^{b} \cdot 3}{a^{b-4}}$

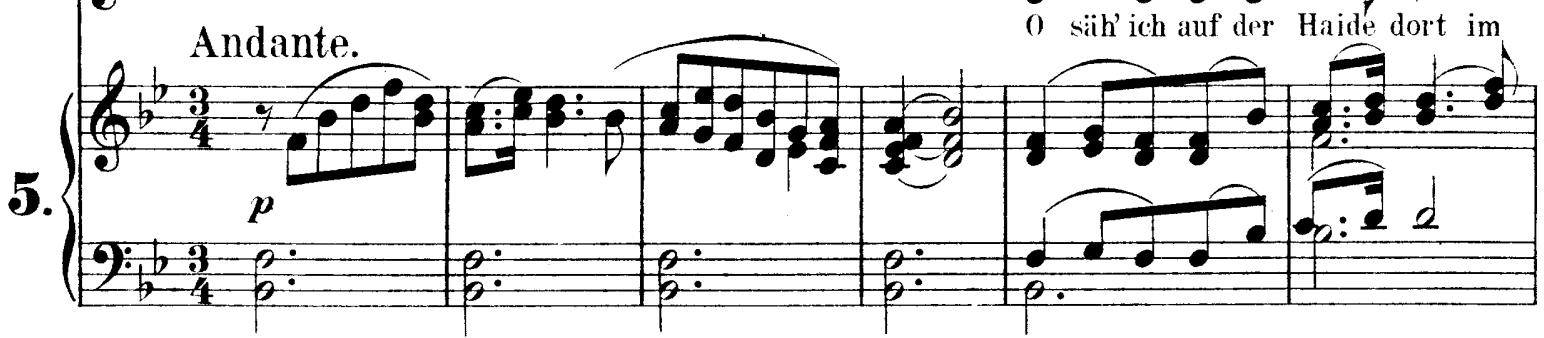

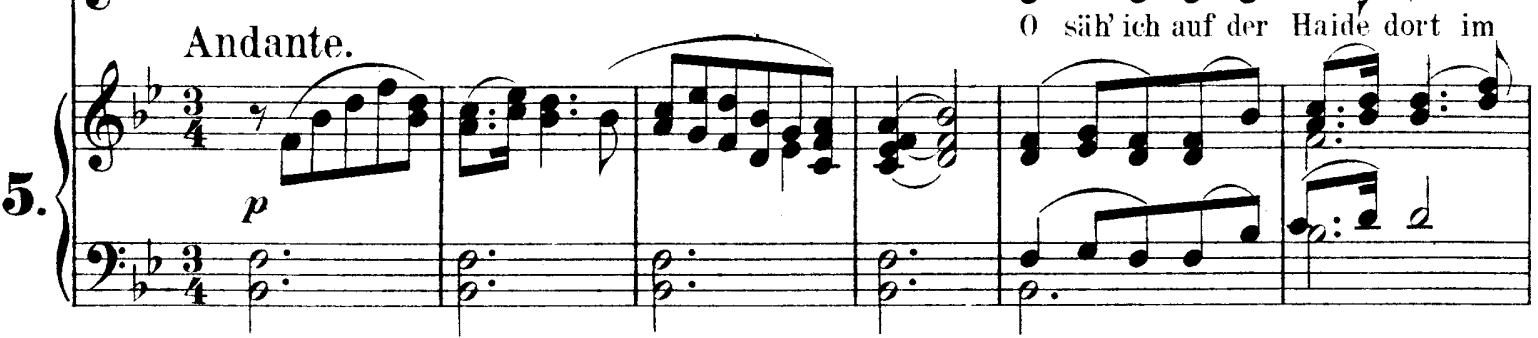

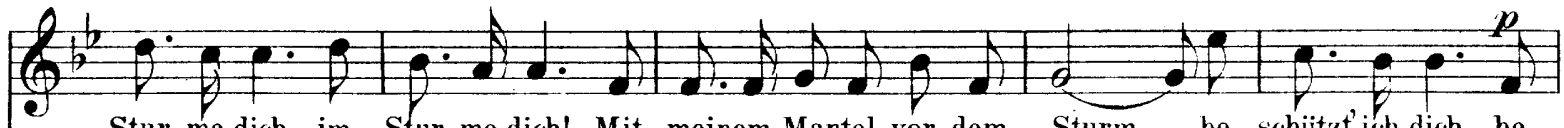

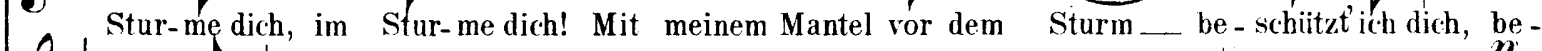

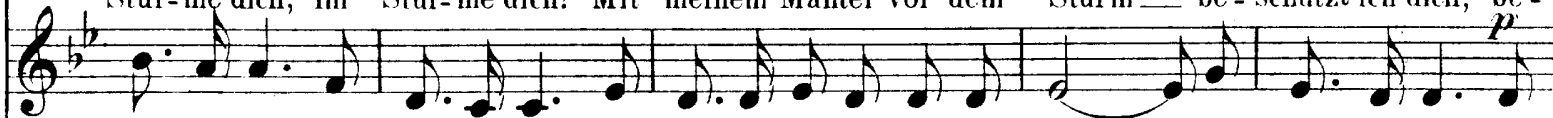

Stur-me dich, im Stur-me dich! Mit meinem Mantel vor dem Sturm _ be - schützt'ich dich, be _

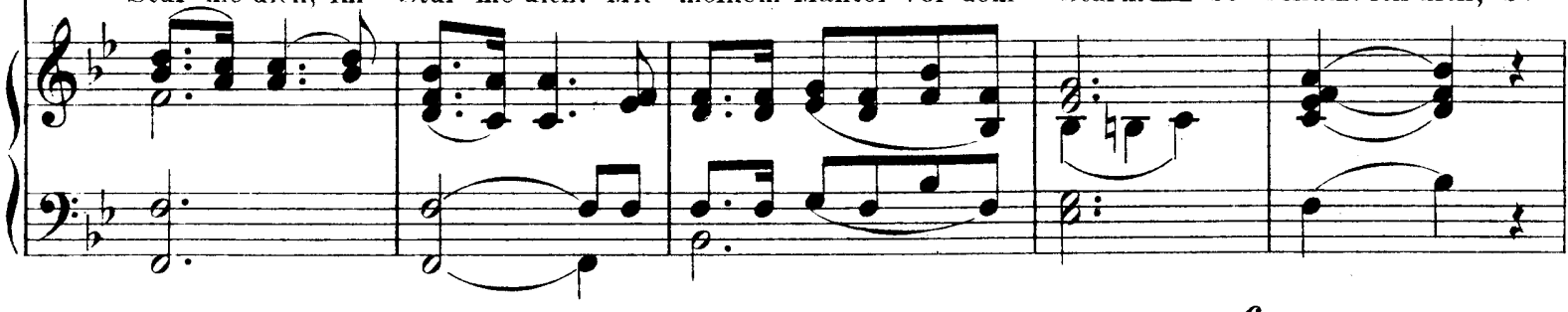

0 b cresc.

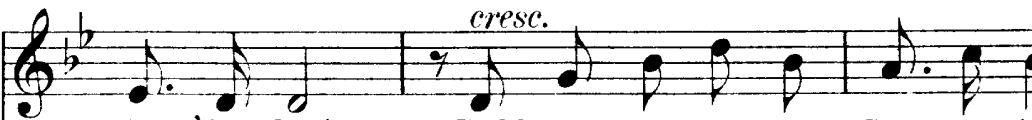

sf

Tnd kommt mit sei-nem Stur-me je dir Un-gliick nah' dir

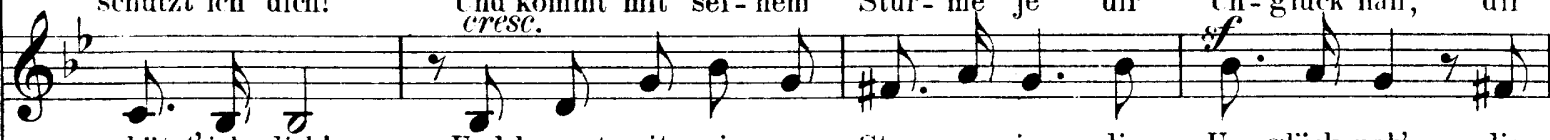

schützt' ich dich! Und kommt mit sei-nem Stur-me je dir Un-glück nah', dir

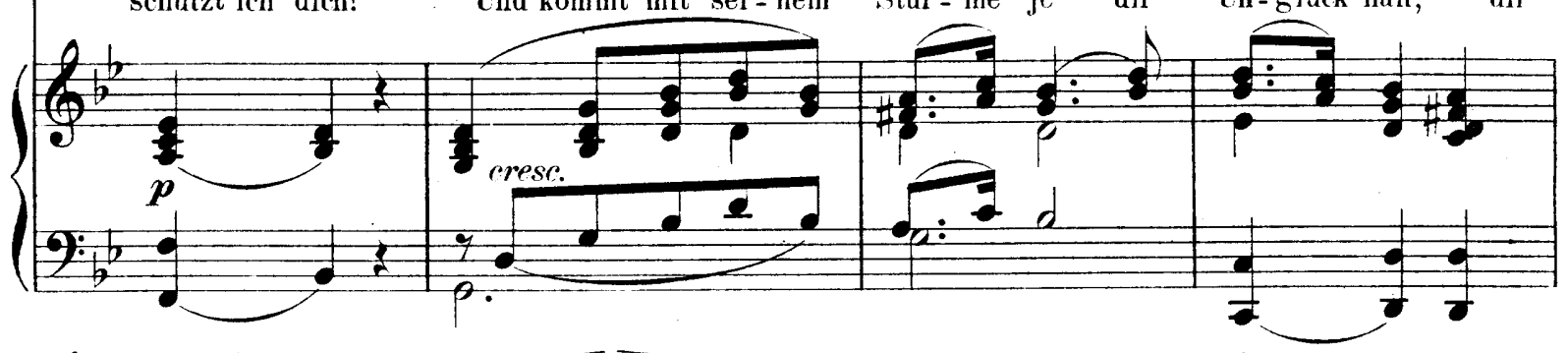

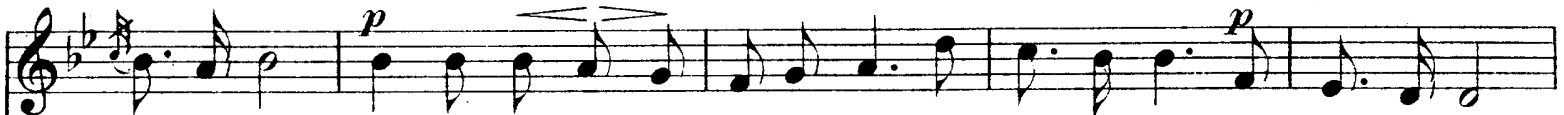

Un-glück nah', dann wär' dies Herz dein Zufluchtsort, gern theilt' ich's ja, garn theilt' ich's ja!

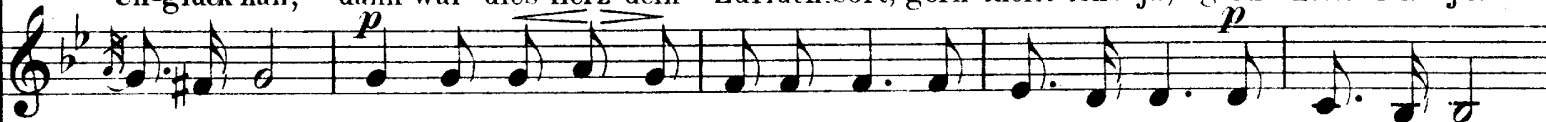

Un-glück nah', dann wär' dies Herz dein Zufluchtsort, gern theilt' ich's ja, gern theilt' ictis ja!

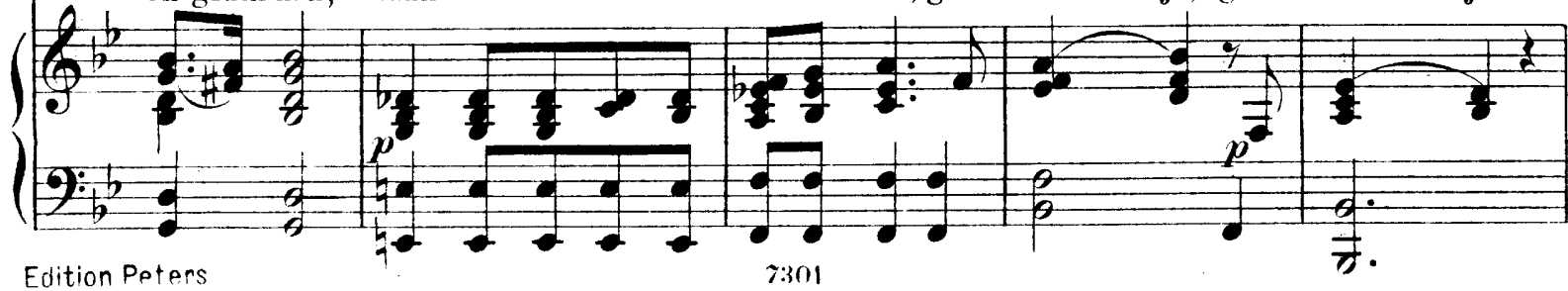



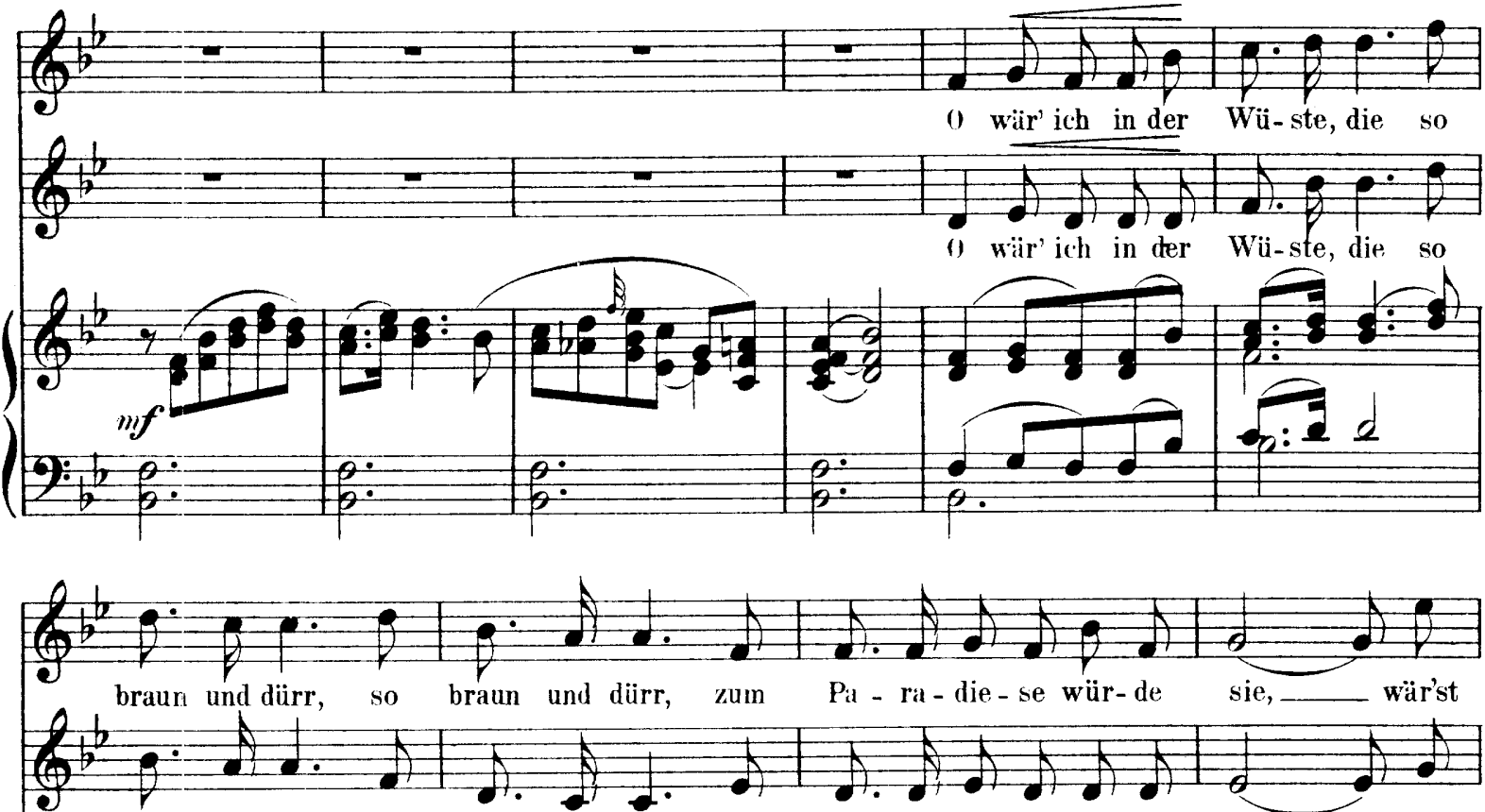
braun und dürr, so braun und dürr, zum Pa-ra-die-se wür-de sie,_ wär'st
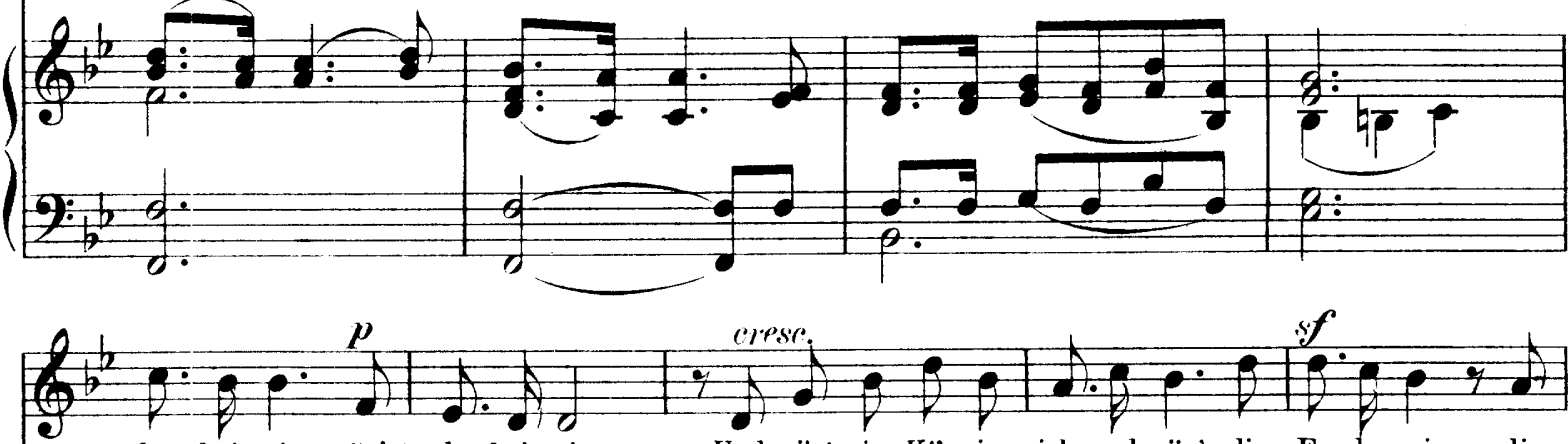
du bei mir, wär'st du bei mir. Und wär' ein Kö-nig ich, und wär' die Er-de mein, die

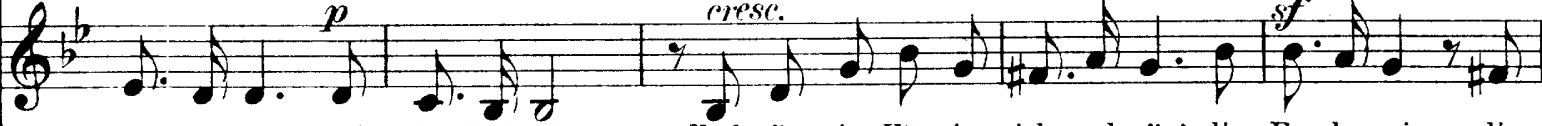
du bei mir, wär'st du bei mir. [ind wär' ein Kö-nig ich, und wär' die Fr-de mein, die

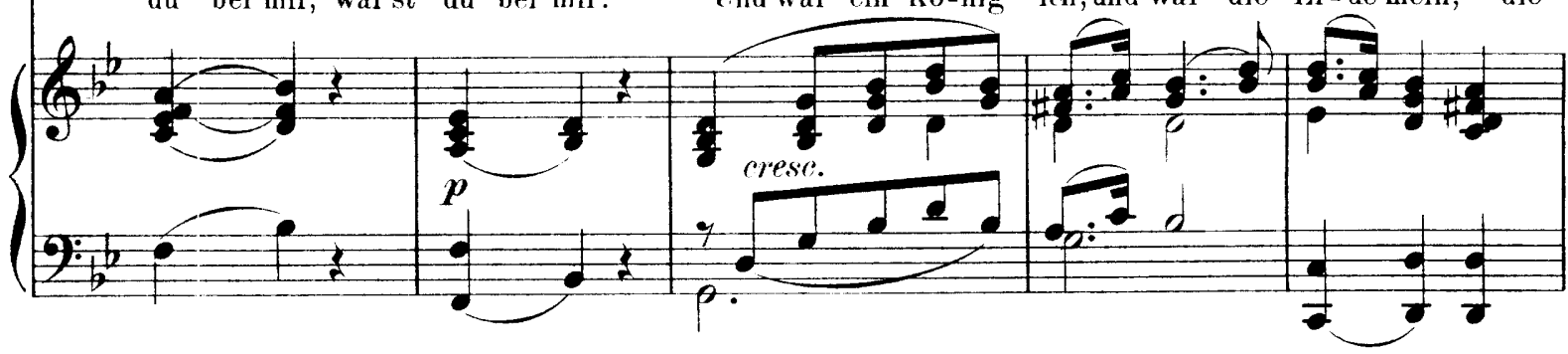

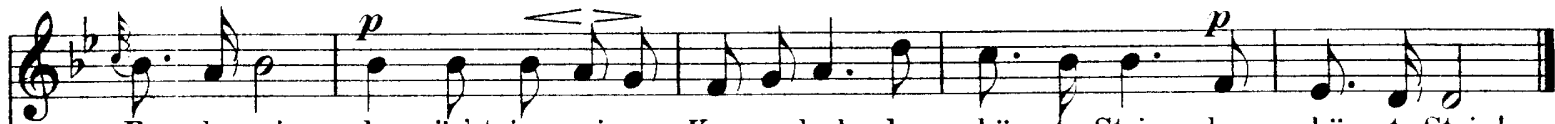
$\mathrm{Er}$.. de mein, du wär'st in meiner Kro-ne doch der schön-ste Stein, der schön-ste Stein!

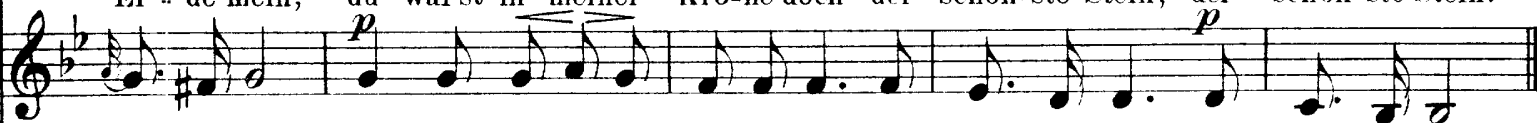
Fr .. de mein, du wär'st in meiner Kro-ne doch der schön-ste Stein, der schön-ste Stein!

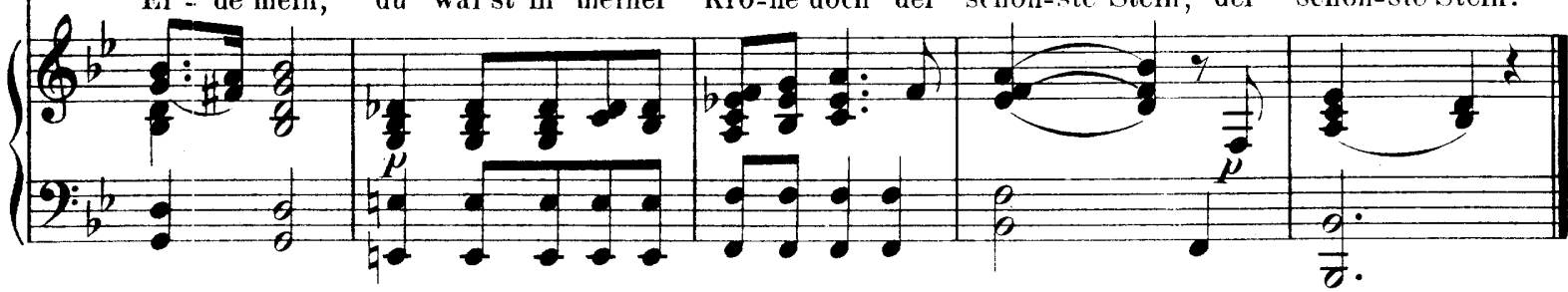




\section{Maiglöckchen und die Blümelein.}

(Hoffmann von Fallersleben.)

Allegro vivace.

Op.63 Nr.6.

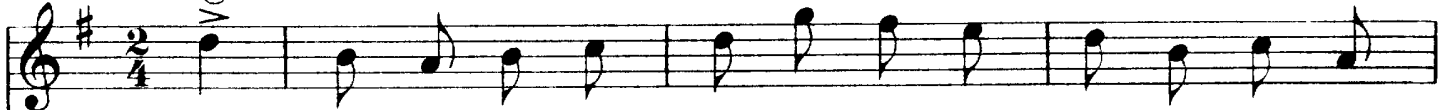

Mai - glöck-chen läu - tet in dem Thal, das klingt so hell und

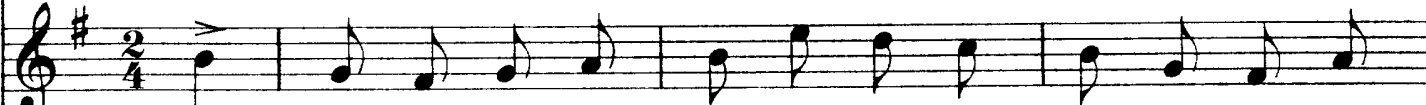

Mai - glöck-chen liiu - tet in dem Thal, das klingt so hell und

Allegro vivace.

6.
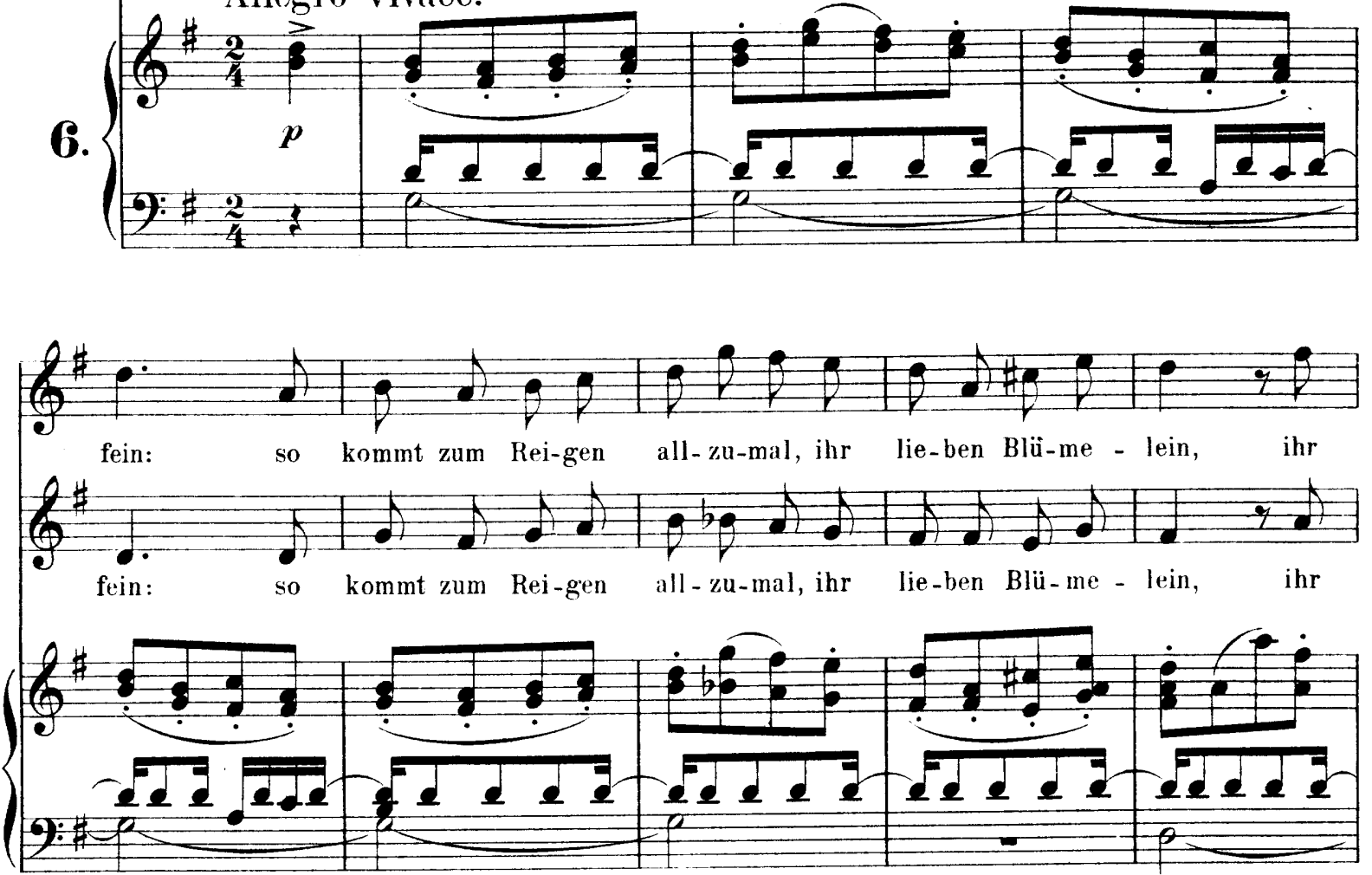

Po.
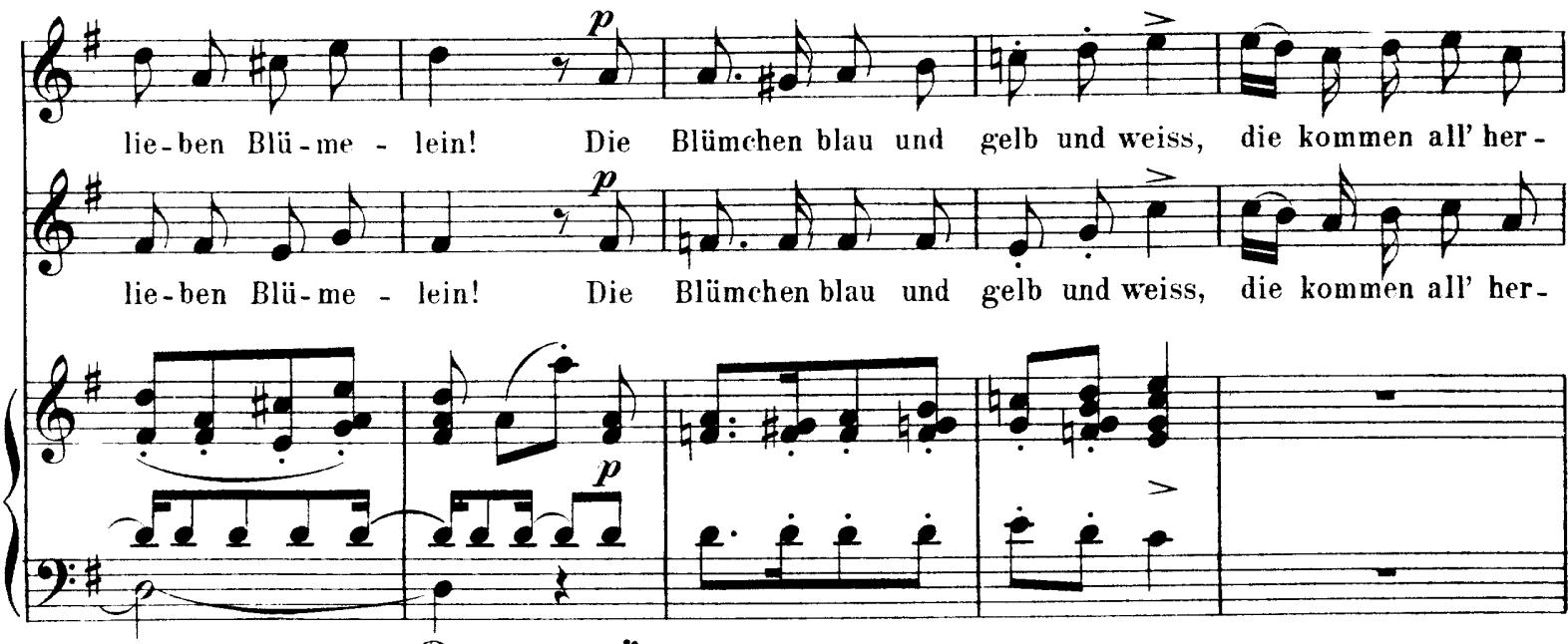

$*$ To. * 
(6) aei,

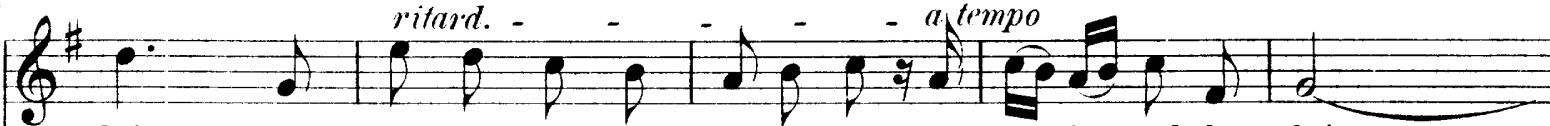
bei, Ver - giss-mein-nicht und Fh-ren-preis und Veil-chen sind da - bei, (2)

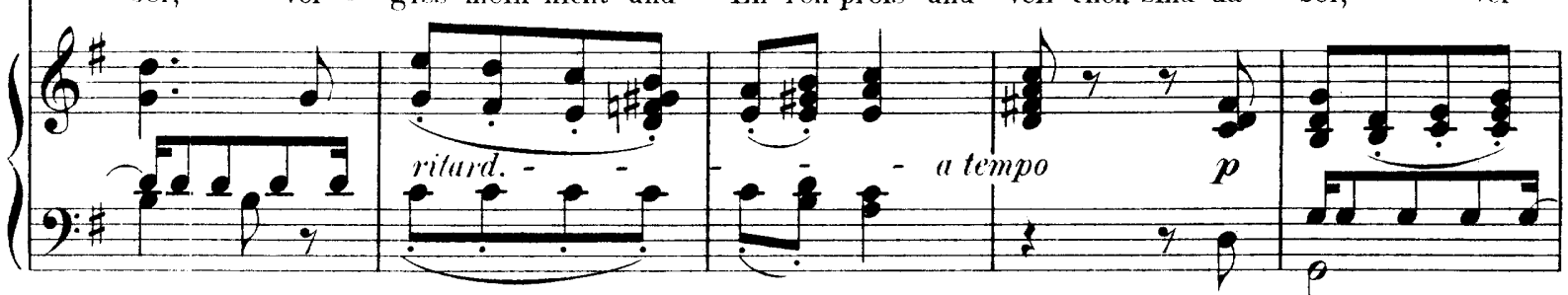

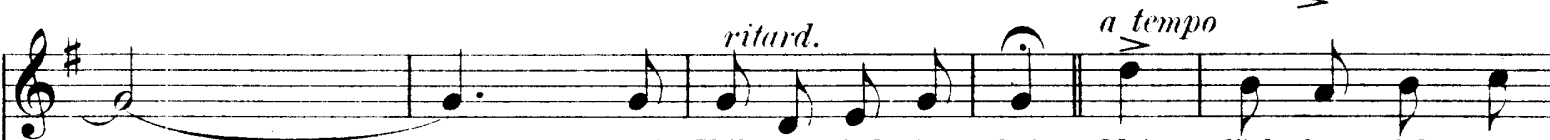
und Veil-chensind da - bei. Mai - glöck-chen spielt zum giss-mein-nicht und Eh-ren-preis und Veil-chen sind da - bei. Mai - glörk-chen spielt zum

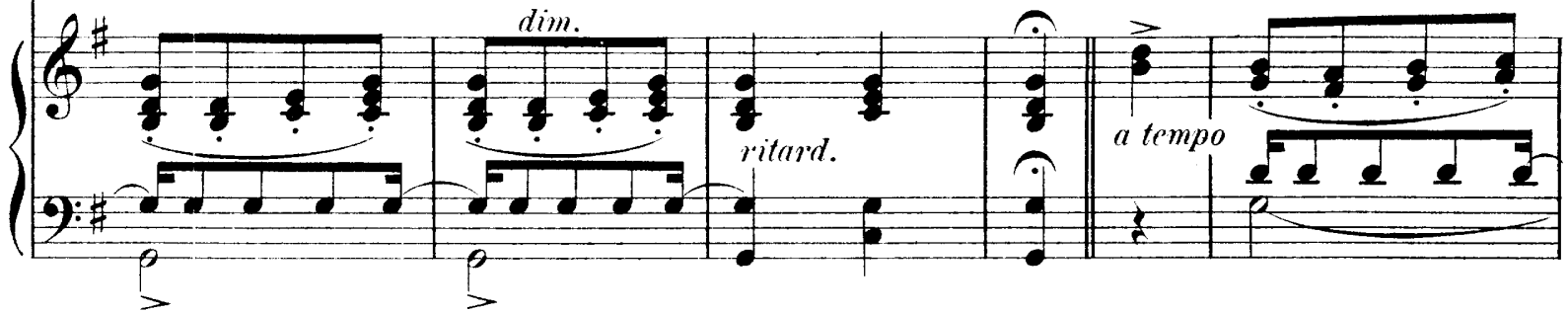

Q⿻肀丷 Tanz im $\mathrm{Nu}$ und

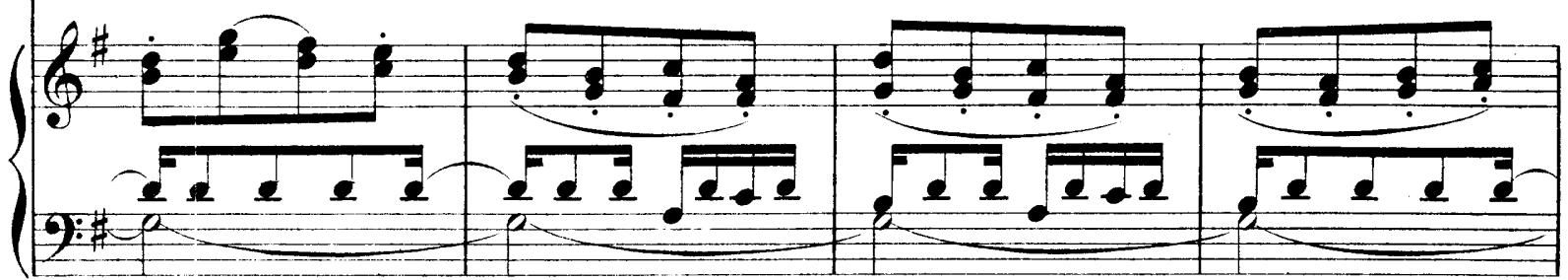




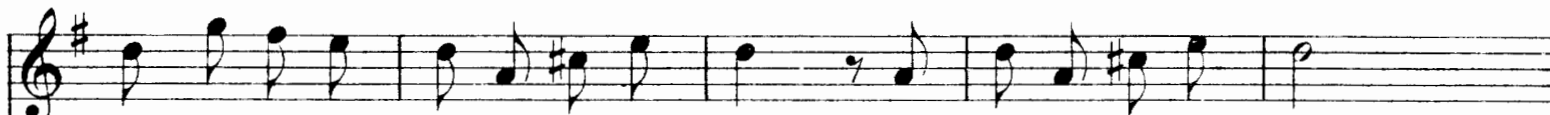
freund-lich zu, hat sei-ne Freu-de d'ran, hat sei-ne Freu-de d'ran.

(6) freund-lich $z u$, hat sei-ne Freu-de d'ran, hat sei-ne Freu-de dran.

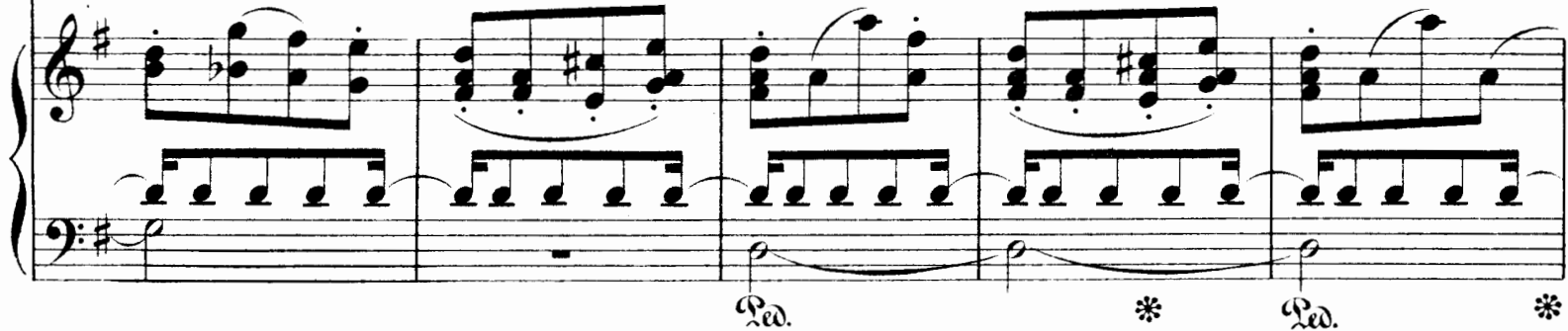
(6) Den Jun-ker Reif ver-drosi das sehr, er kommt in's Thal hin - ein: _

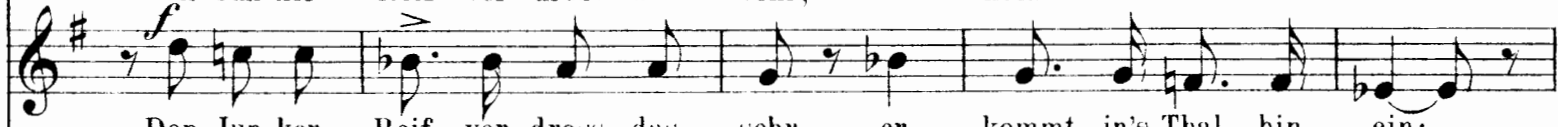
Den Jun-ker Reif ver-dross das sehr, er kommt in's Thal hin - ein:

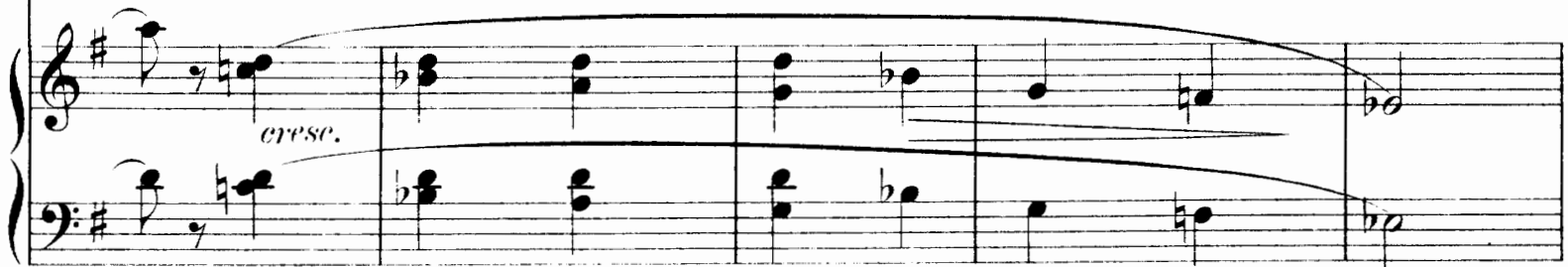

$(6, p p$ Mai-glöck-chen spielt zum Tanz nicht mehr,

(6) Mai-gröck-chen spielt zum Tanz niche mehr, fort sind die Blii-me - lein,

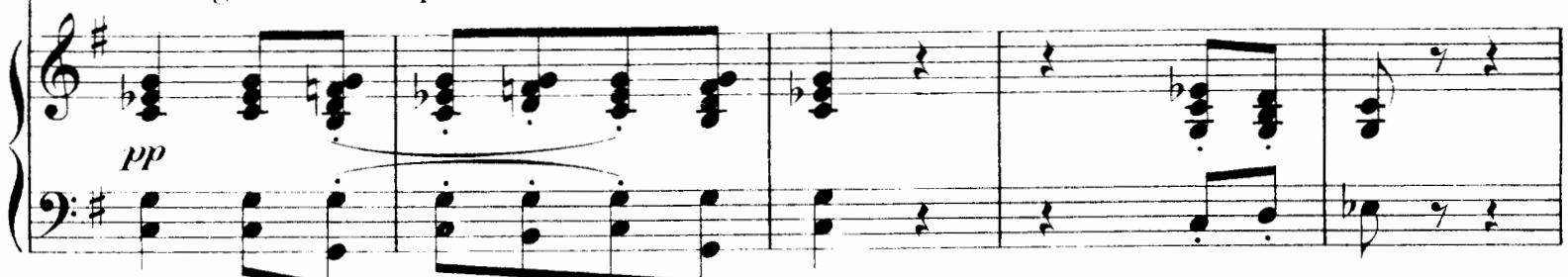

$(6$ मी गे sind die Blü-me - lrin, fort sind die Blü-me-lein, die Blü - me - lein.

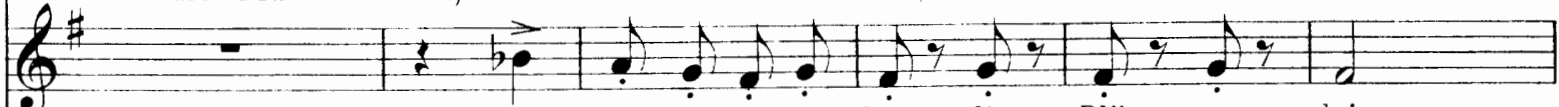
fort sind die Blü-me-lein, die Bï̈ - me - lein.

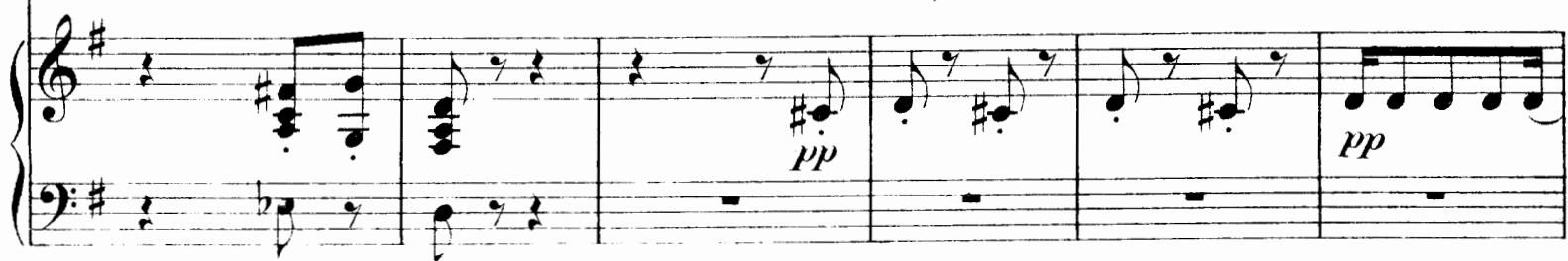



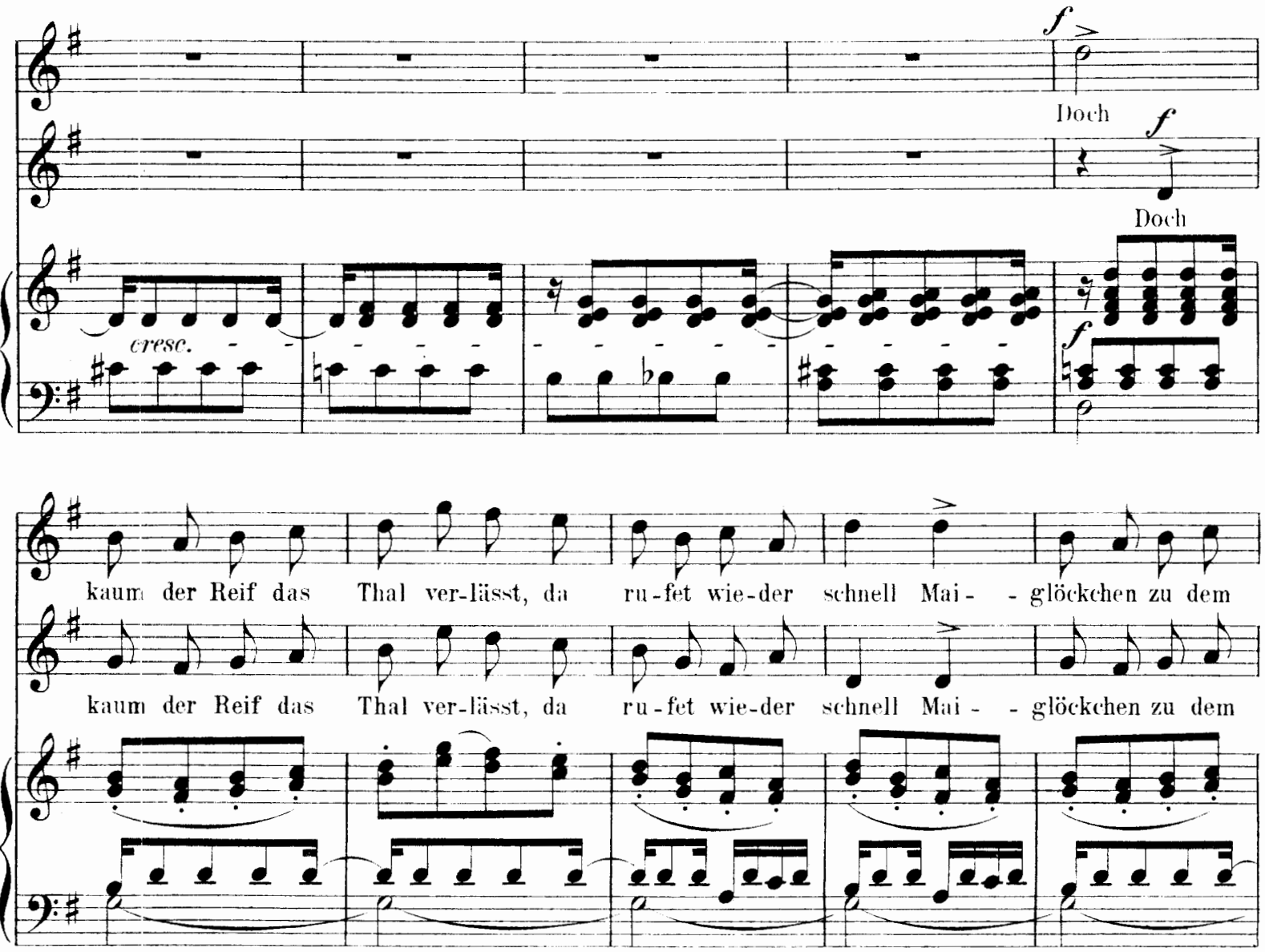

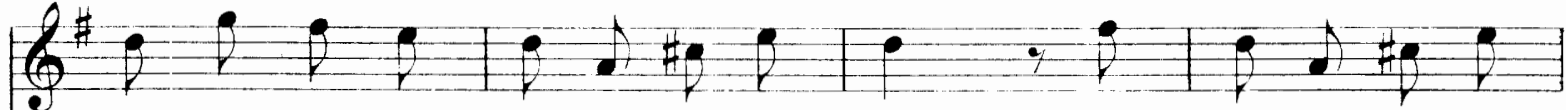
Früh-lings-fest und läu-tet dop-pelt hell, und läu - tet dop-pelt

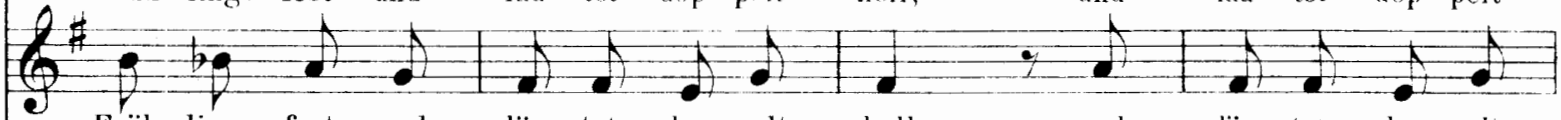
Früh-lings-fest und läu-tet dop-pelt hell, und lialu-tet dop-pelt
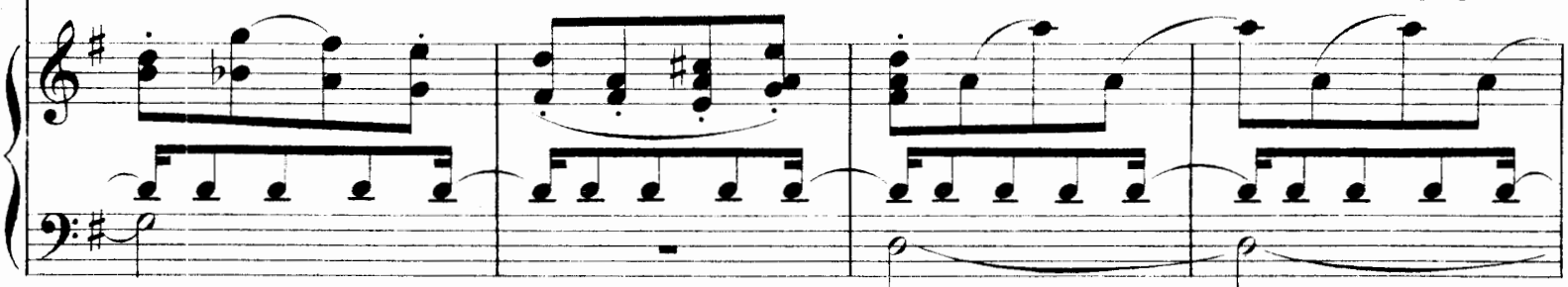
so.

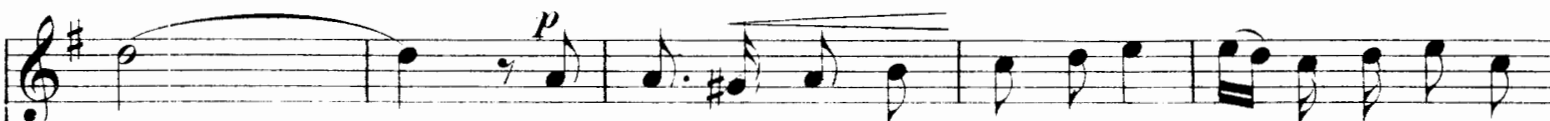
hell. Nun hïlt's auch mich nicht mehr zu Haus, Maiglöckchen ruft auch

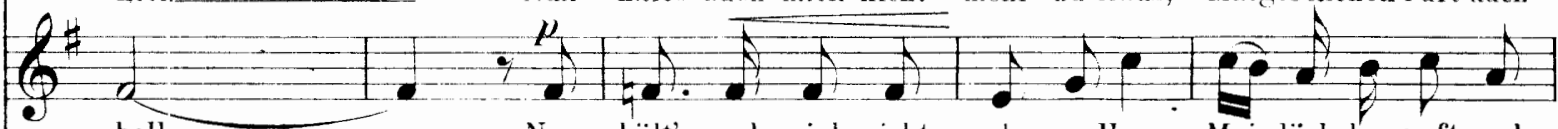
hell Nun hält's auch mich nicht mehr zu Haus, Maigglöckchen ruft auch

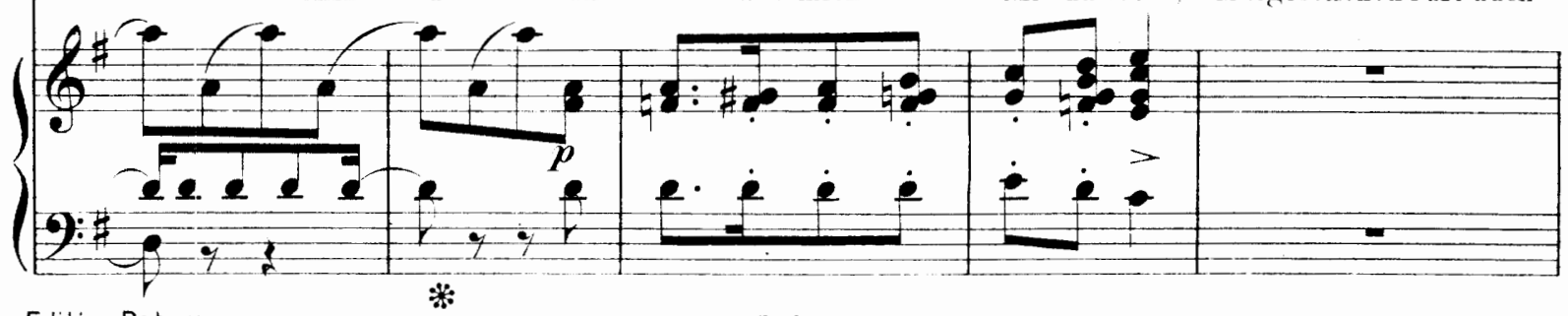




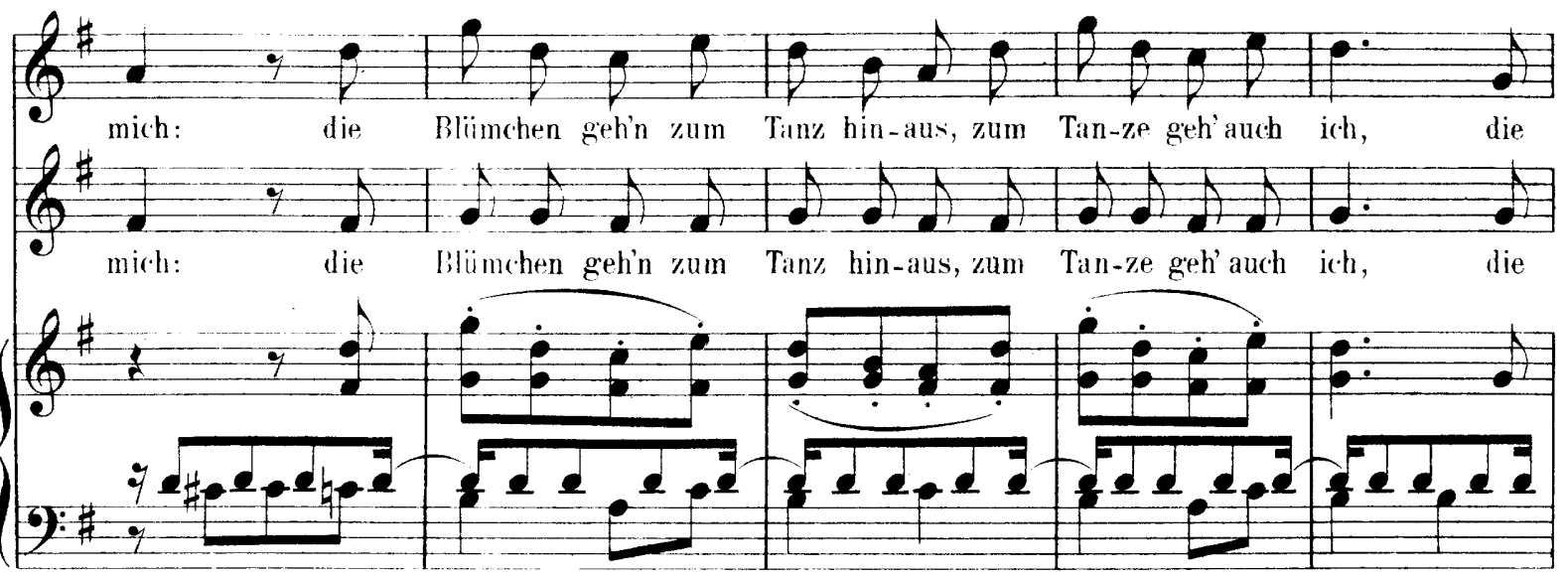

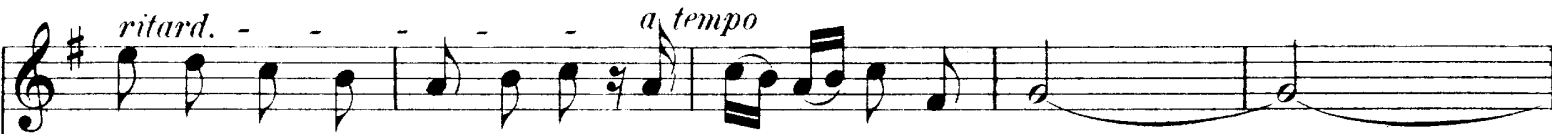
Blïmchen geh'n zum Tanz hin-aus, zum Tan-ze geb'auch ich,

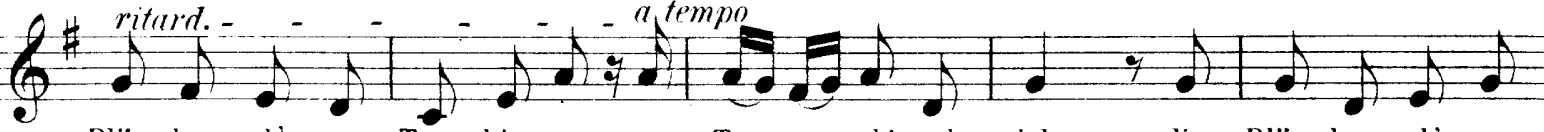
Blümchen geh'n zum Tanz hin-aus, zum Tan-ze geh'auch ich, die Blümchen geh'n zum

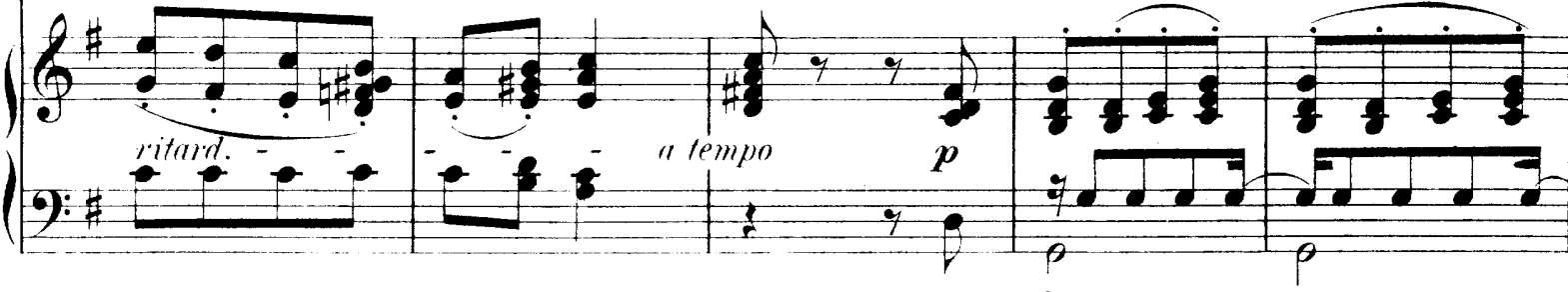

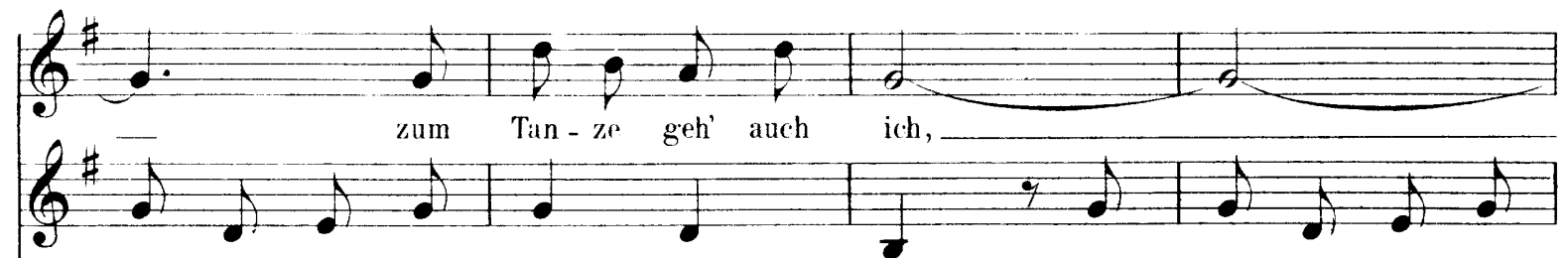
Tanz hin - aus, zum Tanz hin - - - aus, die Blüm-chen geh'n zum

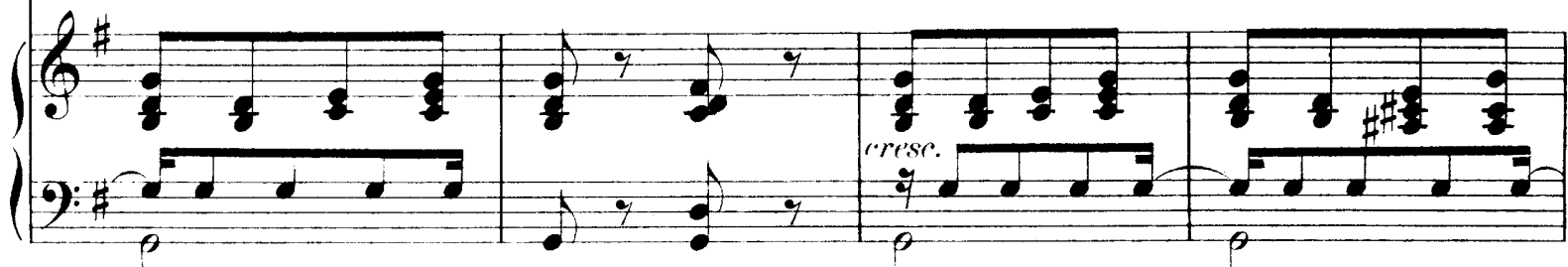

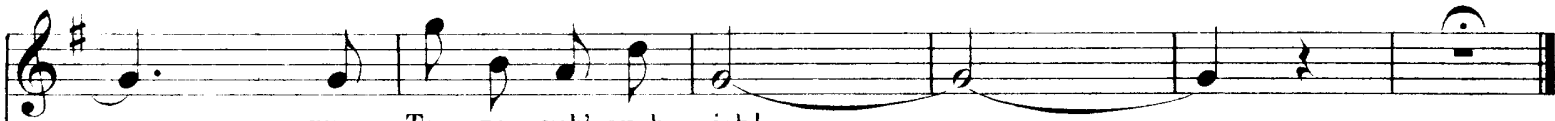

$\left.\frac{6}{6}+1\right)$ of

Tanz hin-aus, zum Tan-ze geh aluch ich!

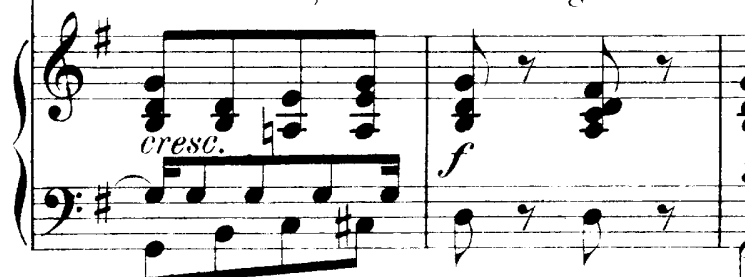

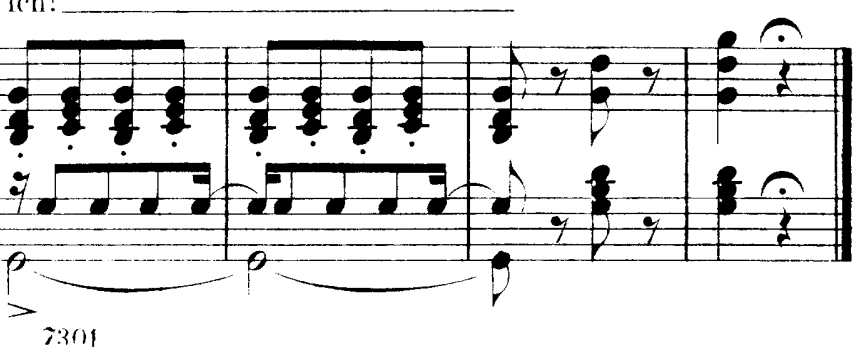




\section{Sonntagsmorgen.}

(Lbland.)

Andante sostenuto.

Op.77 Nr.1.
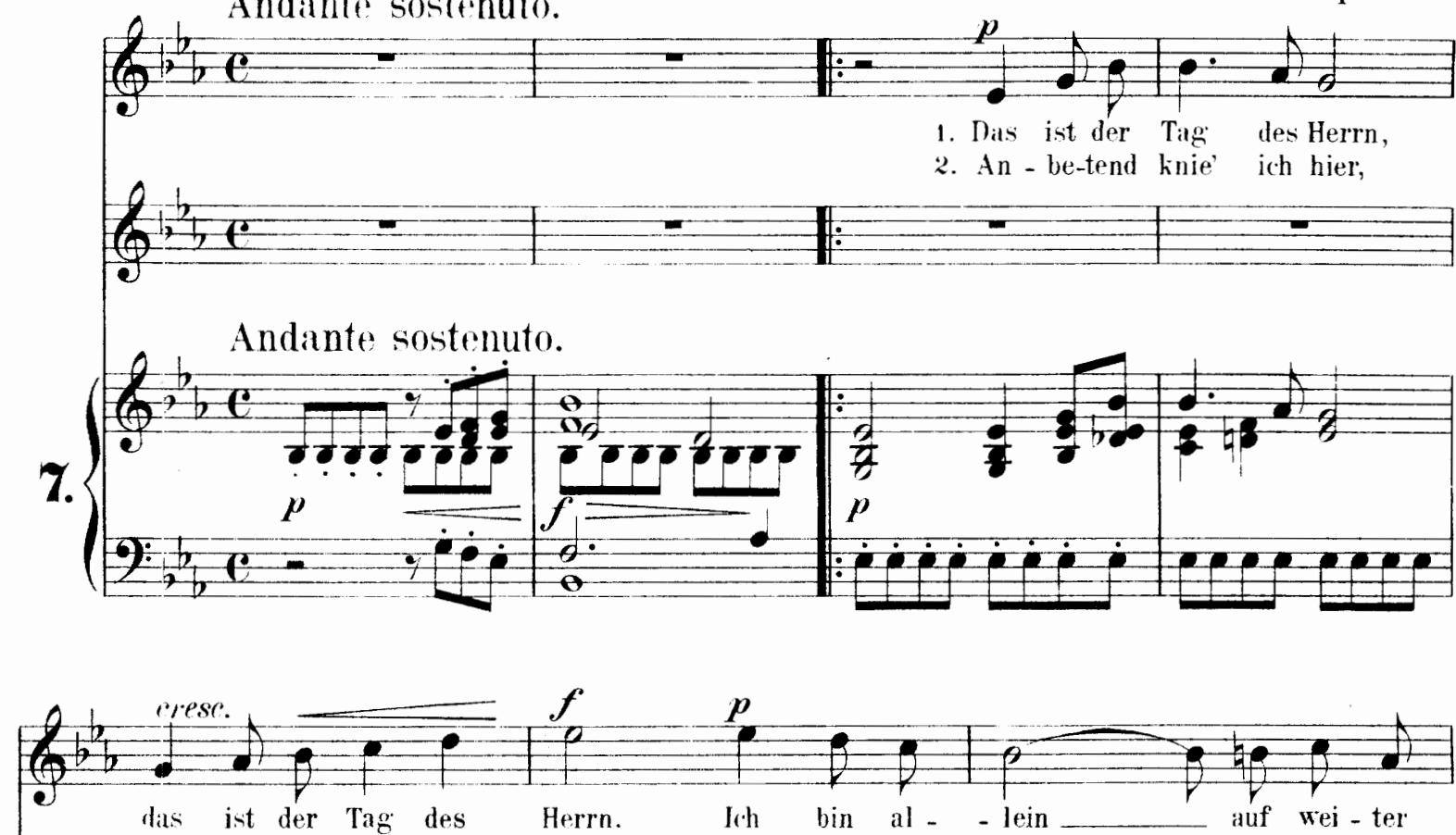

an - be -tend knif' ich hier. 0 sii - sies Grau'n!__ (ie - hei - mes

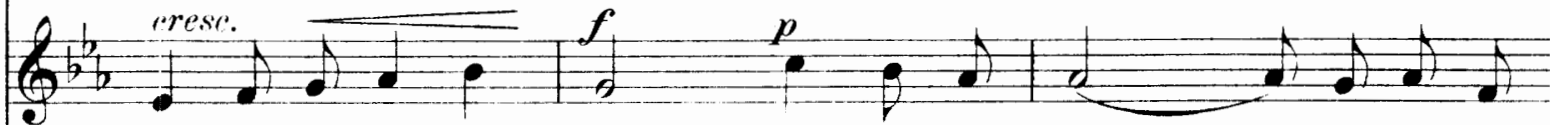

1. Dis ist der Tag des Herrn. Ifh bin al - - lein___ auf wei-ter

2. An - be-tend knie' ich hier. 0 sii-sses Graun! —_ Ge-hei-mes

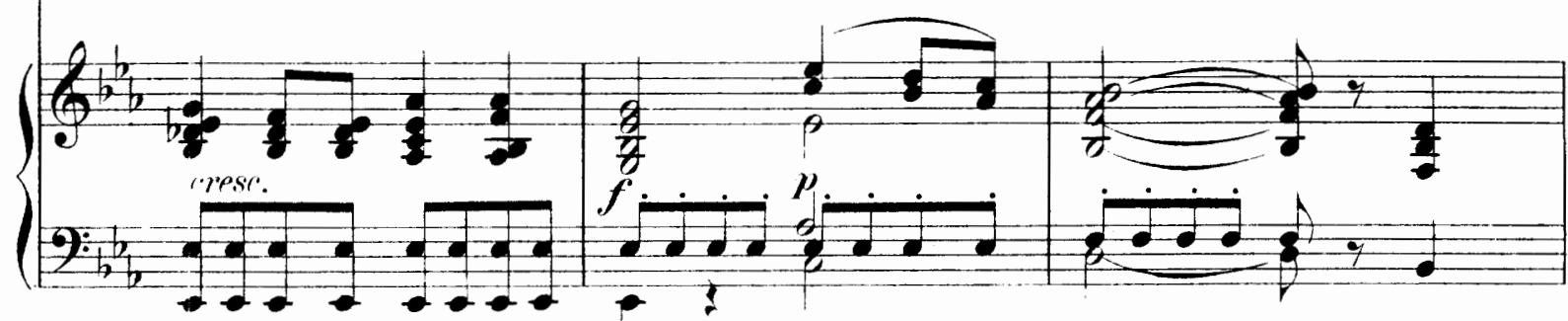

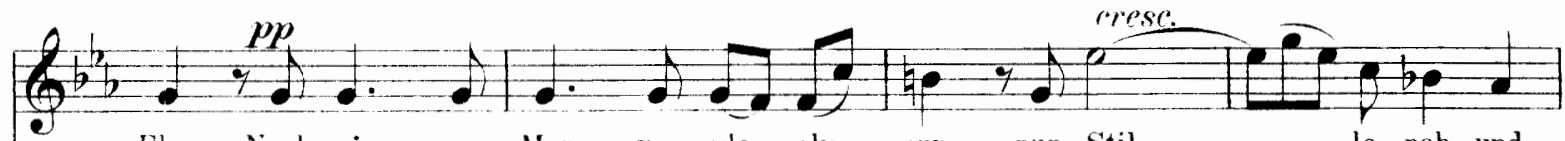

Flur. Noch ei - - ne Hor - gen - glo - rke nur, nun Stil - _ - - le nah und

Wehn! Als knie - trin Vip - le un - ge - swhn und be - - - - te - ten mit

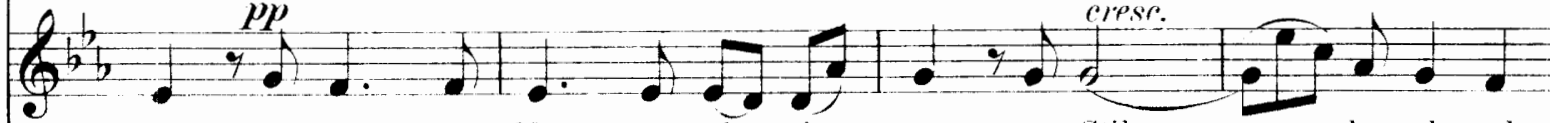

Flur. Yorh ei - - ne Mor - grn - glo - rke nur, nun stil - _ - - le nah und

Wehn! Als knie - ten lie - le un - ge - setin und be - - - - te -ten mit

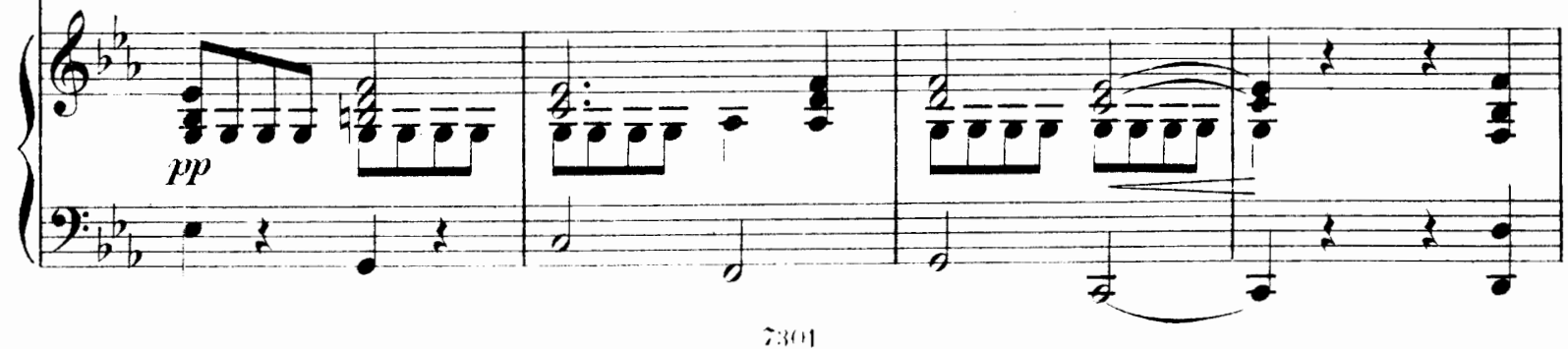




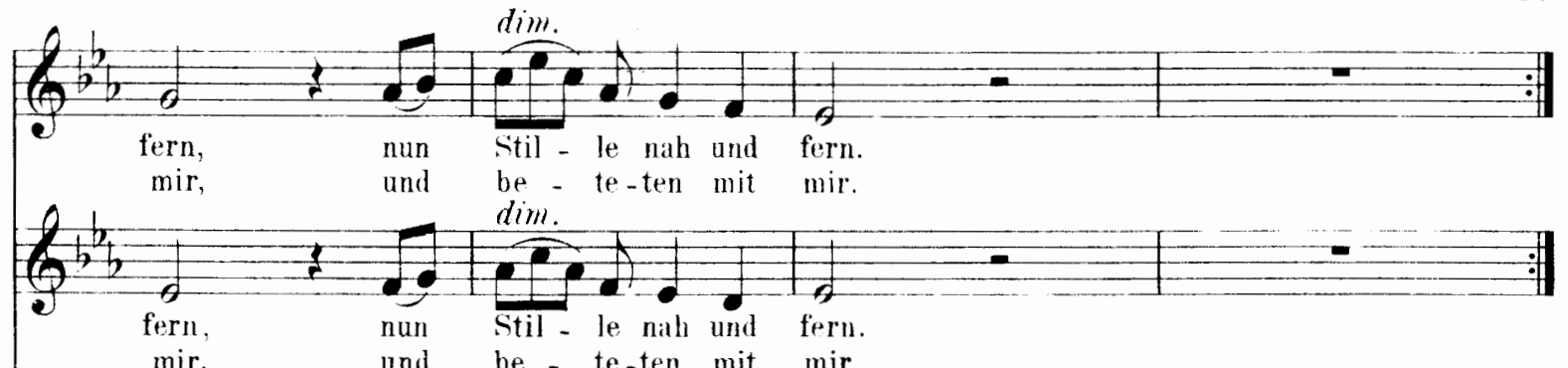

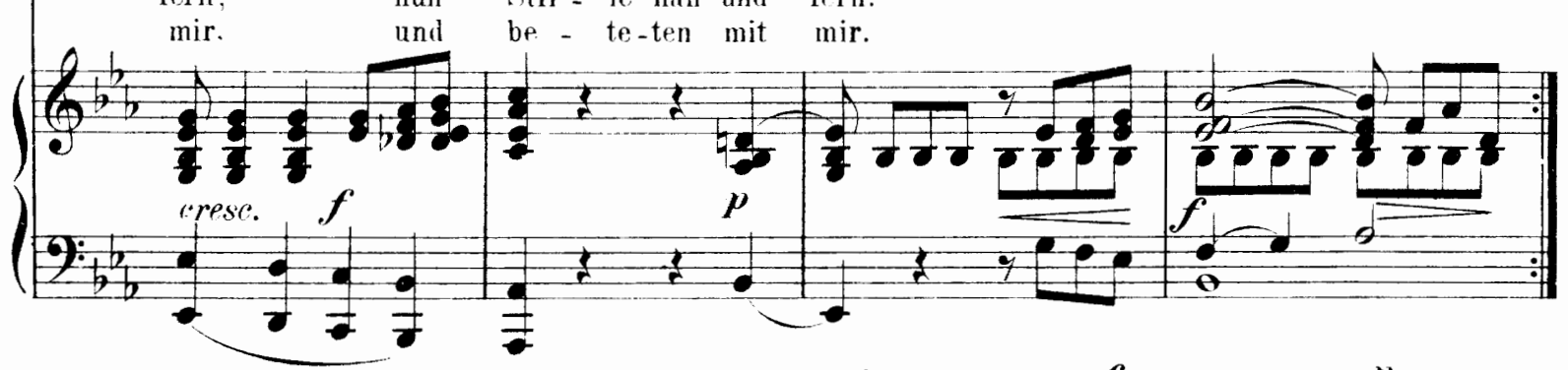

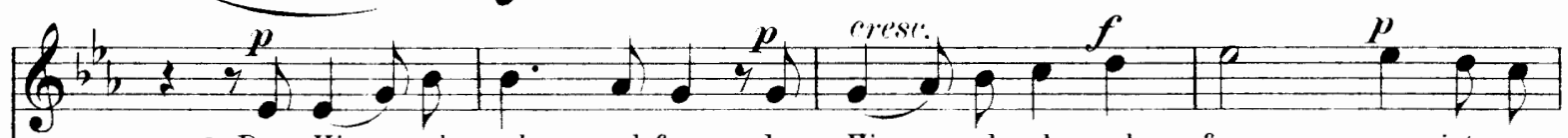

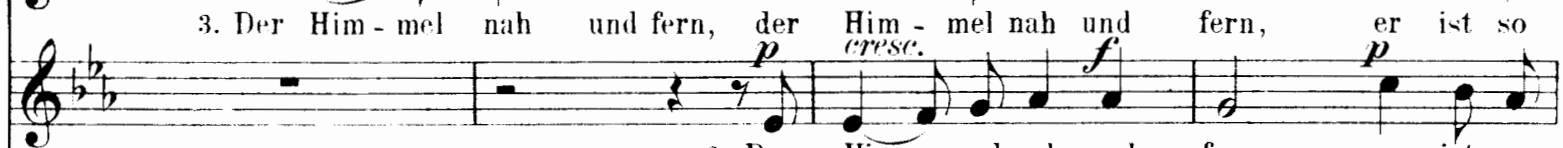

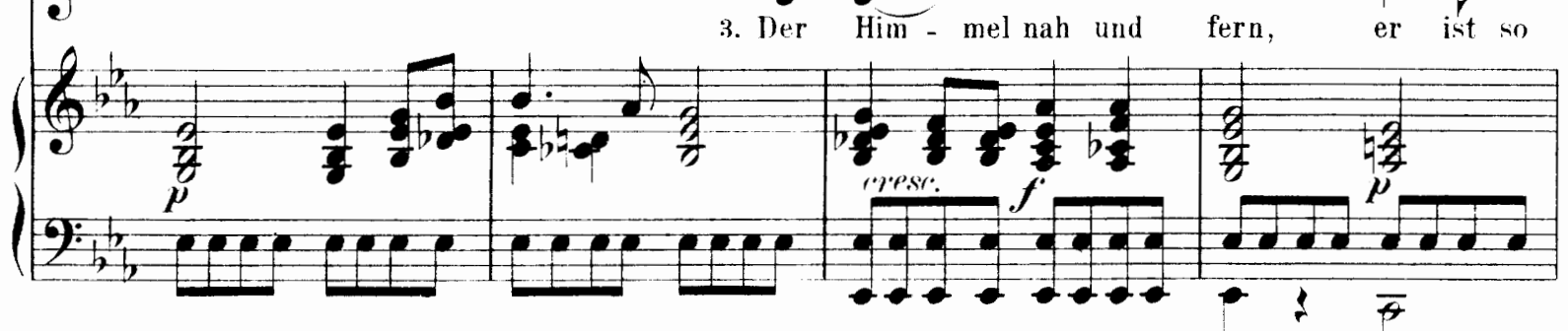

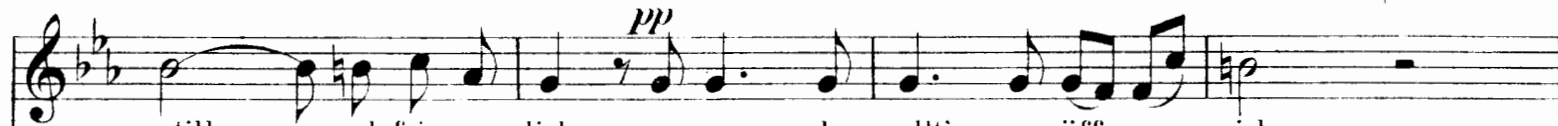
und fer - lich, so wank als wollt er öf-nen sich.

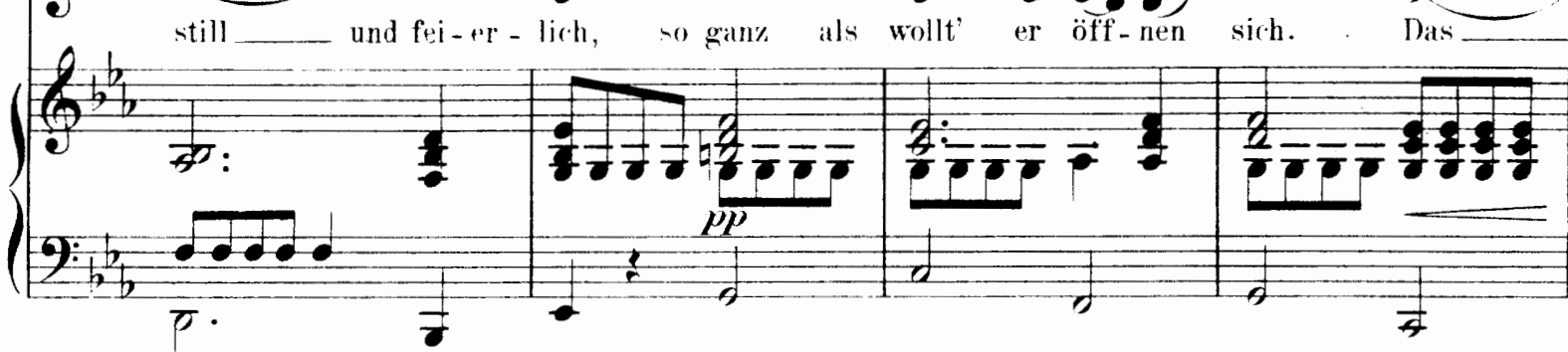

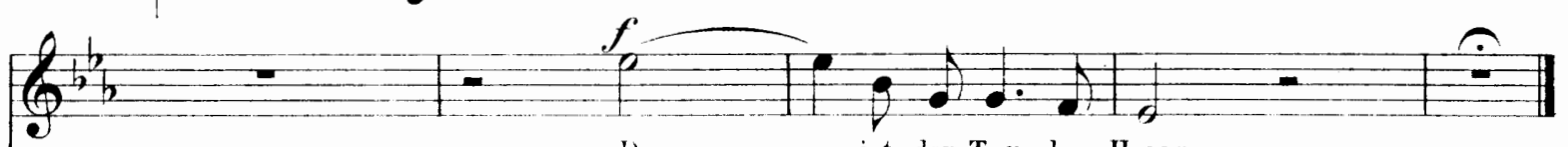

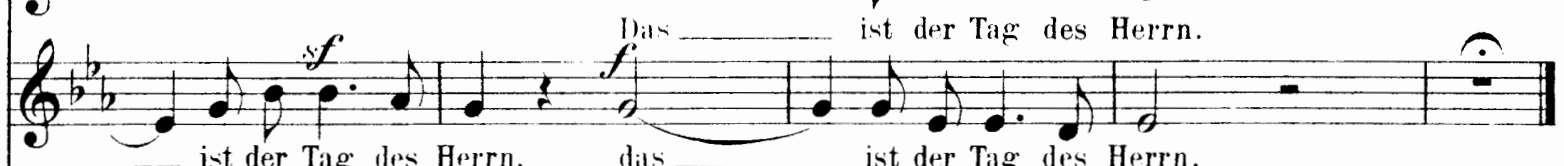

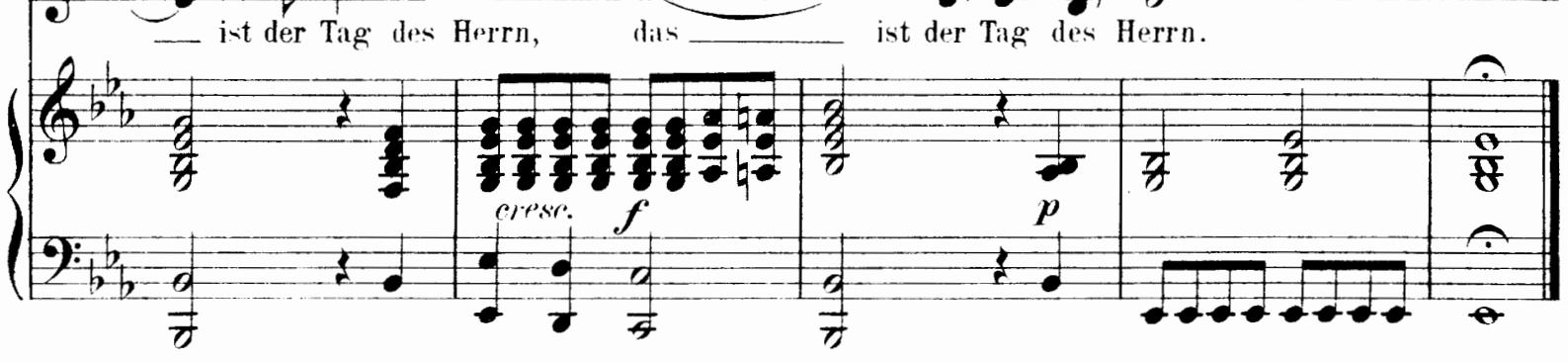




\title{
Das Aehrenfeld.
}

\author{
Hoffmann ron Fallersleben.)
}
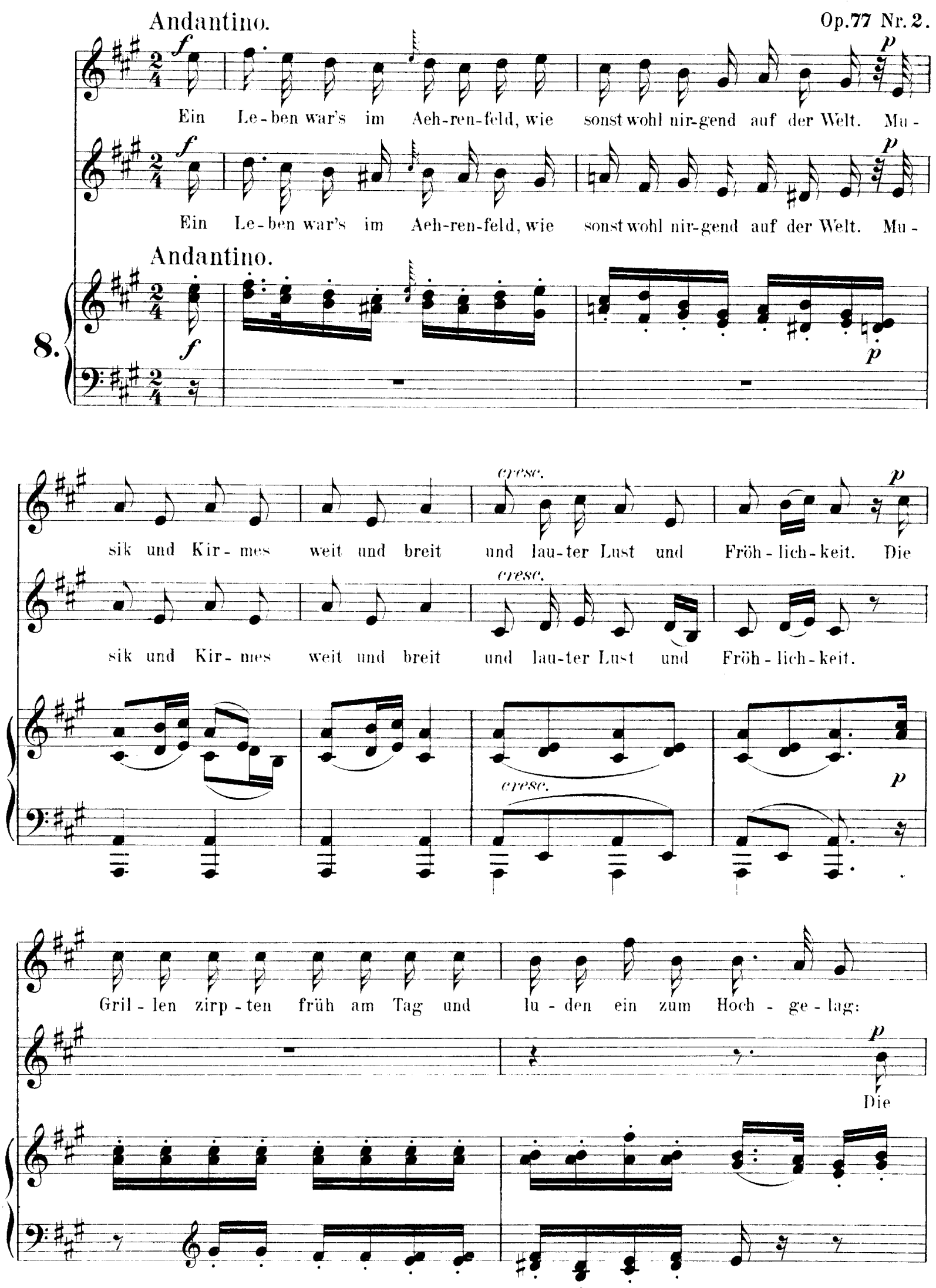
$Q^{\# \#+\cdots}$

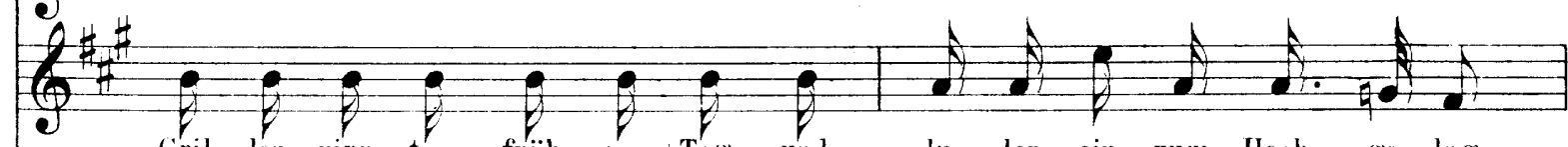
(iril - len zirp-ten früh am Tig und lu - den ein zum Hoch - ge-liag:

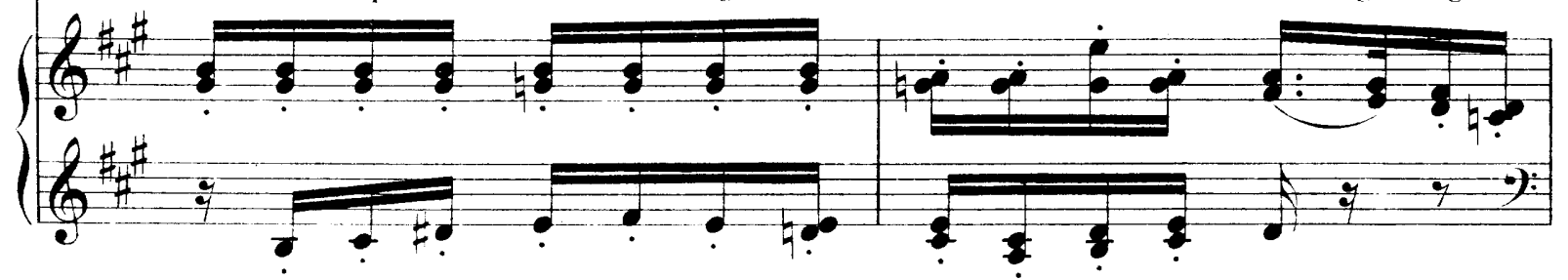

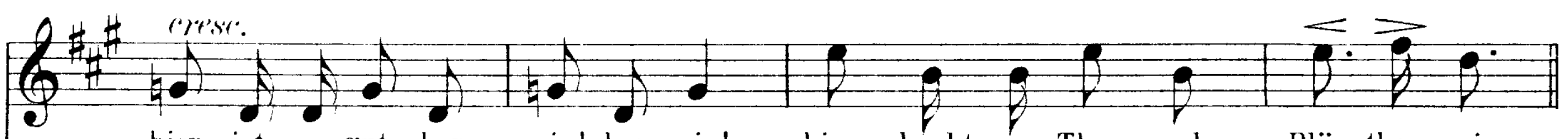
hier int es gut, her - ein! her - ein! hier schenkt man Thau und Blii - then-wein.

2:

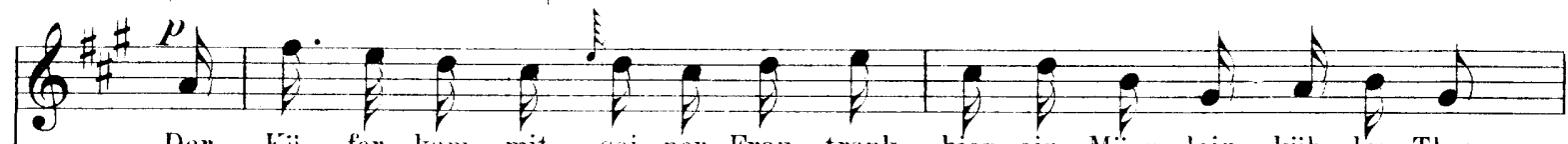
Q $*$ Ner kii - fer kim mit sei-ner Frau, trank hier ein Mïm-lein küh-len Thau,

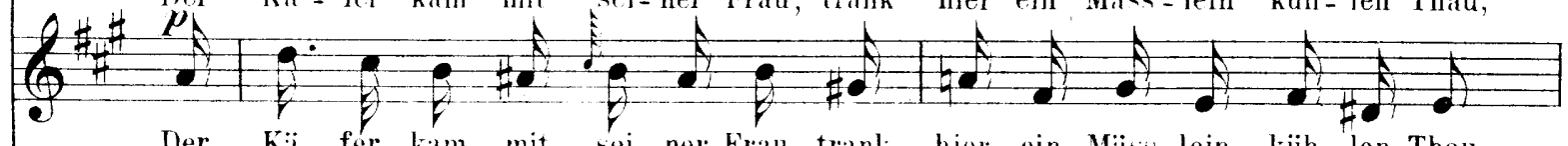

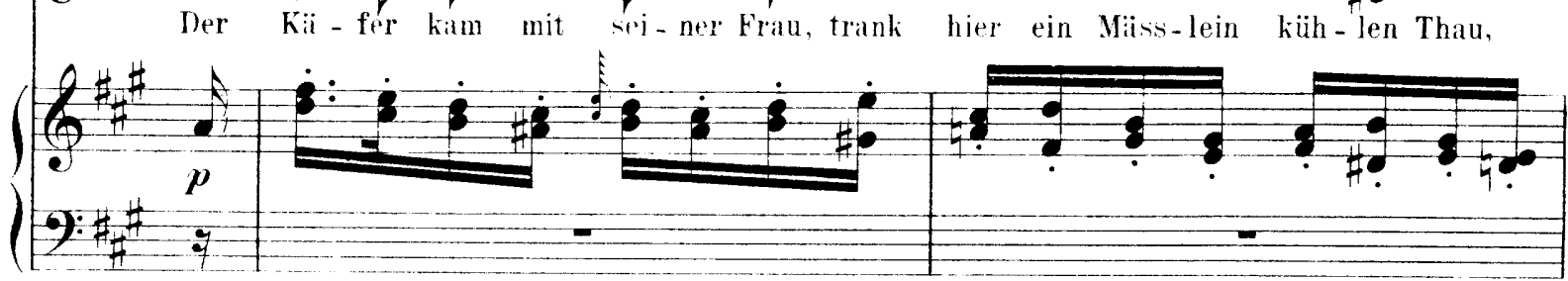

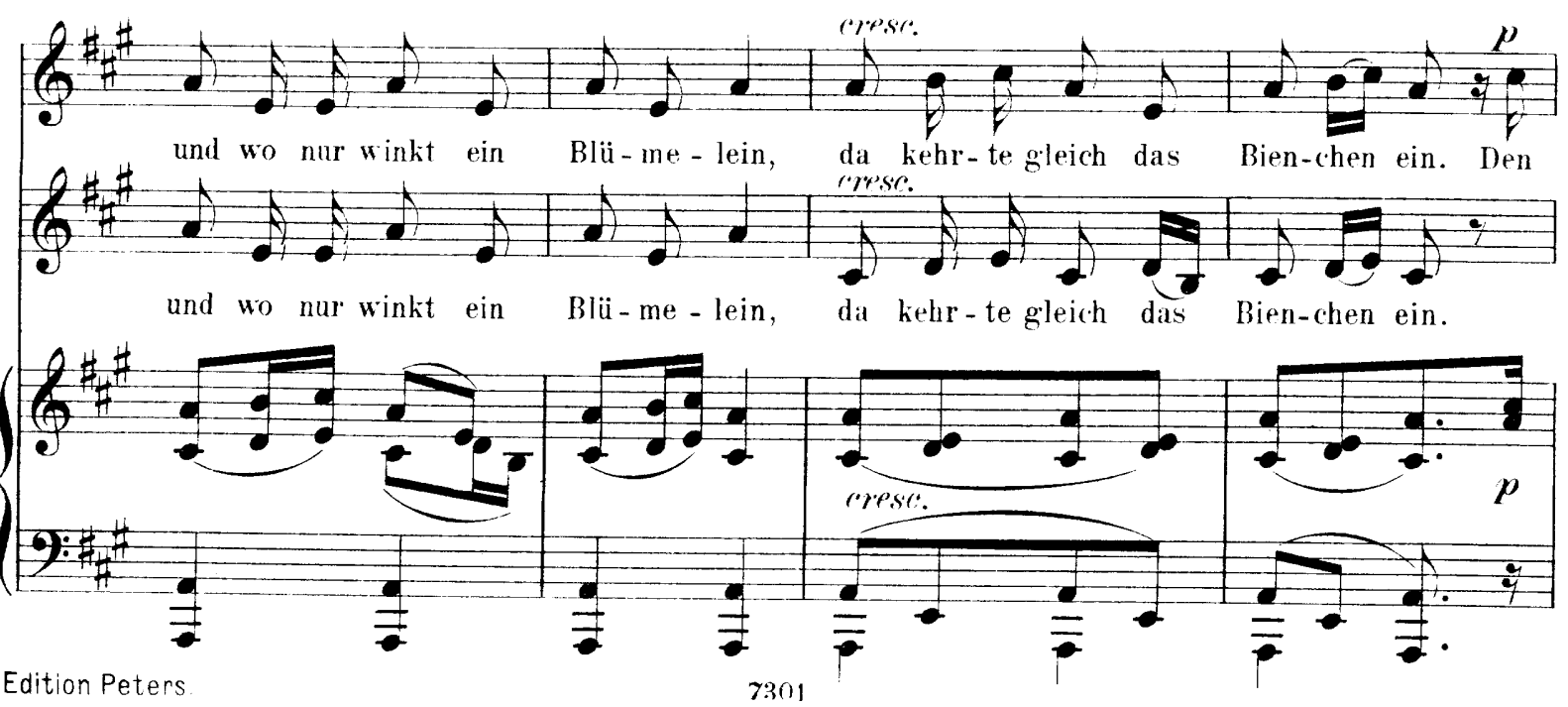

Edition Peters 
(6) Flie - gen ward die Zeit nicht lang, sie summ-ten man-chen fro - hen Sang,

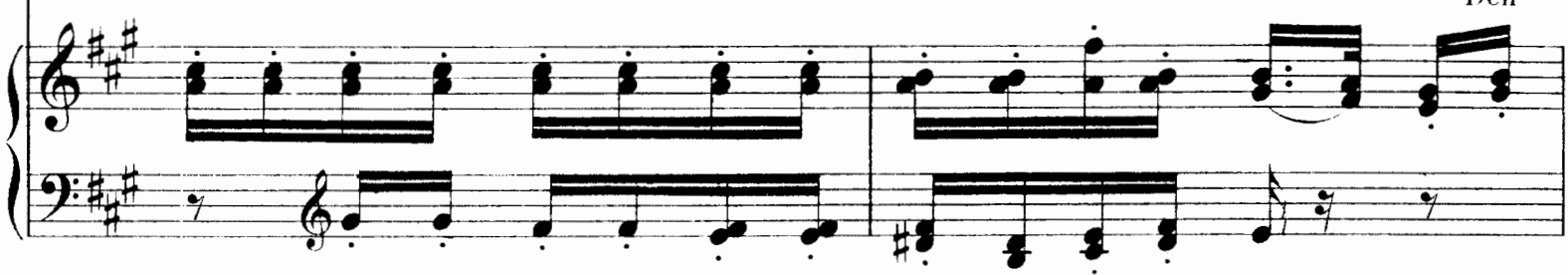
$(6+$ $(6)$

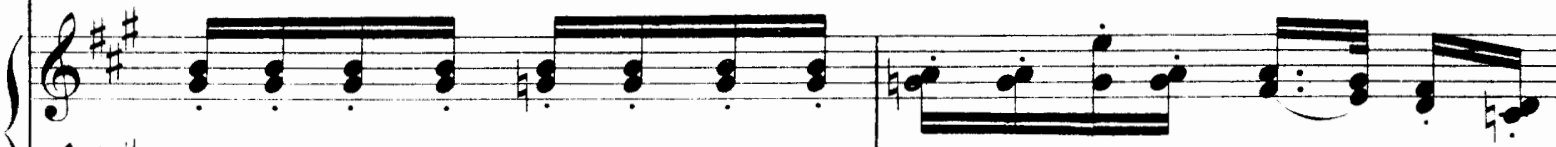

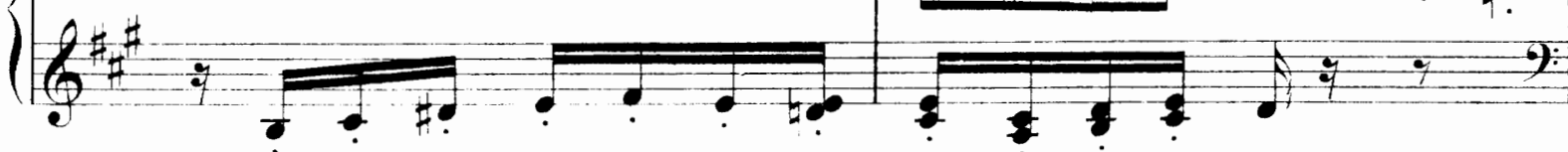

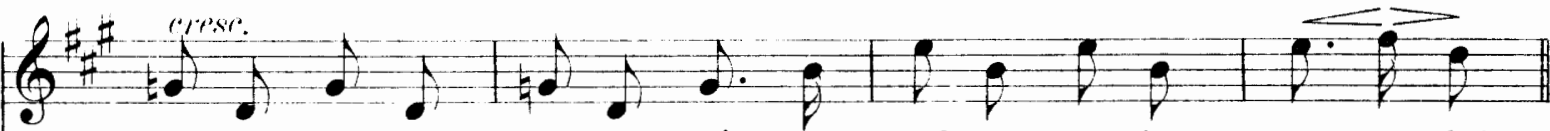
Mü-cken tanz-ten ih-ren Reih'n, wohl auf und ab im son-nen-schein. (6) Mii-cken tanz-ten ih-ren Reilin, wohl auf und ab im Son-nen-schein.

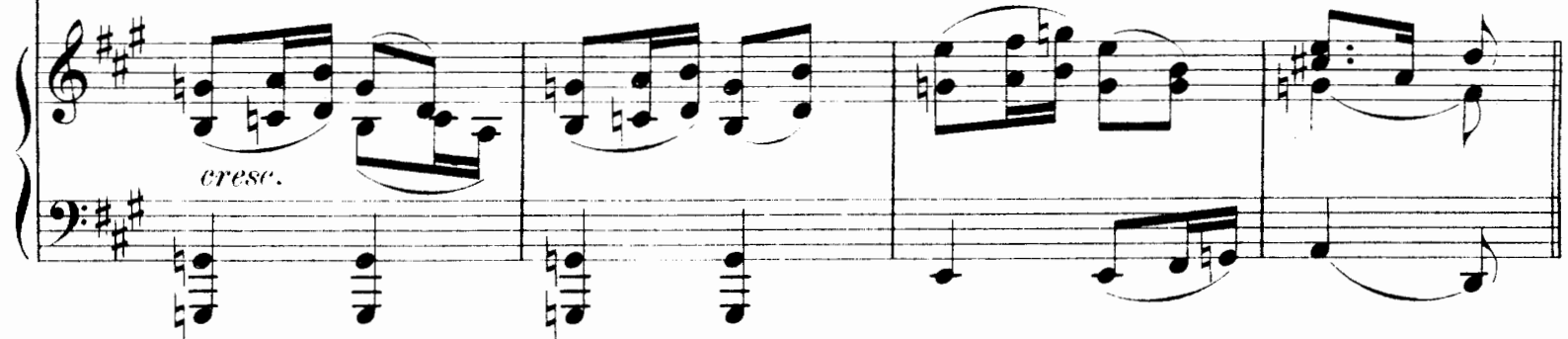
(6)

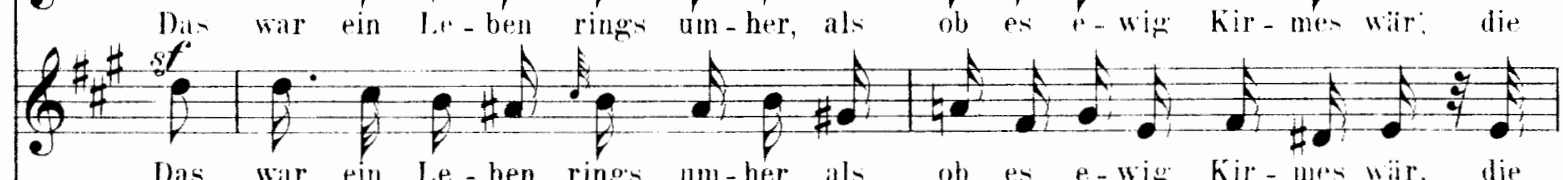

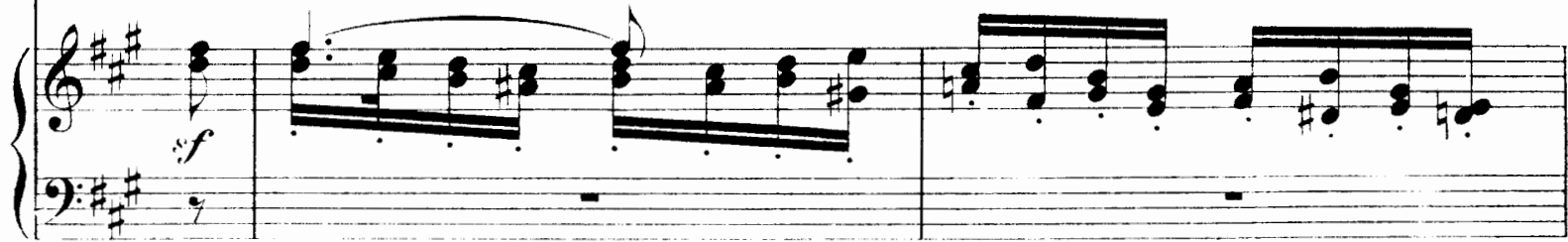


$(6)$ poco a poro ritard. Gï - - ste zo - gen poco rius und ein und lie - sen sich's gar (2) und ein und lie - ssen sich's gar

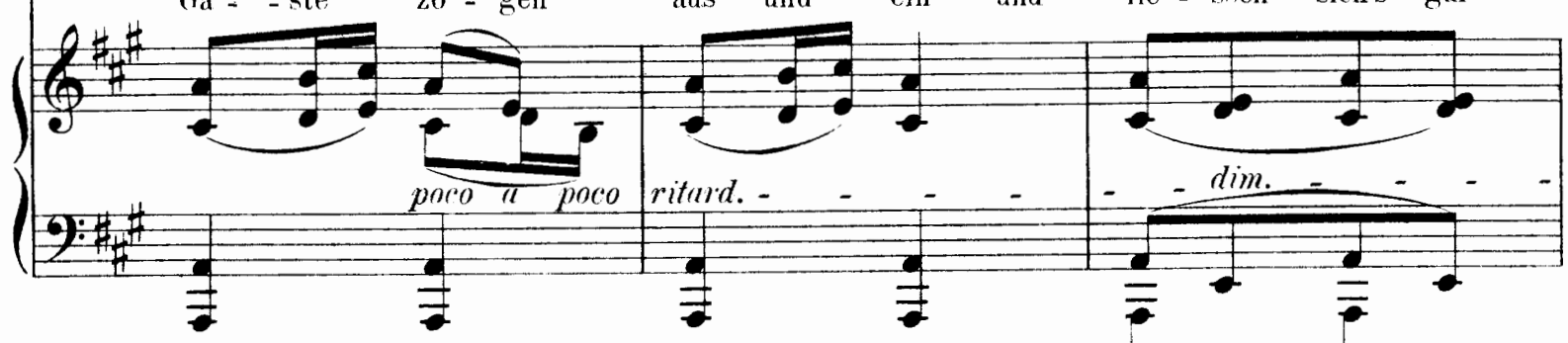
wohl

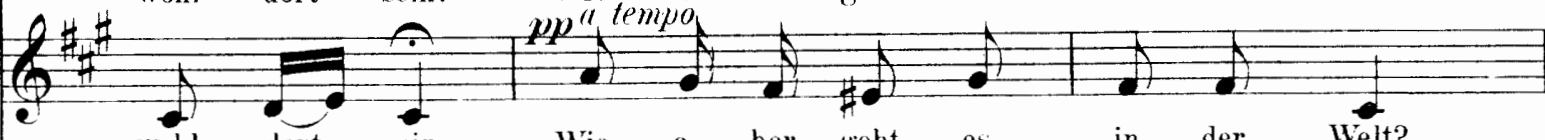

wohl dort srin. Wie a - ber geht es in der Welt?

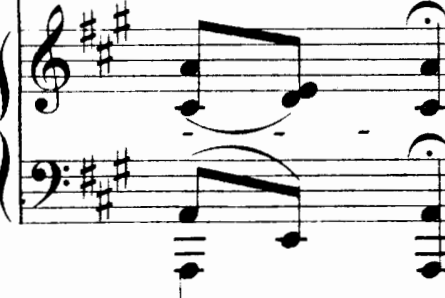

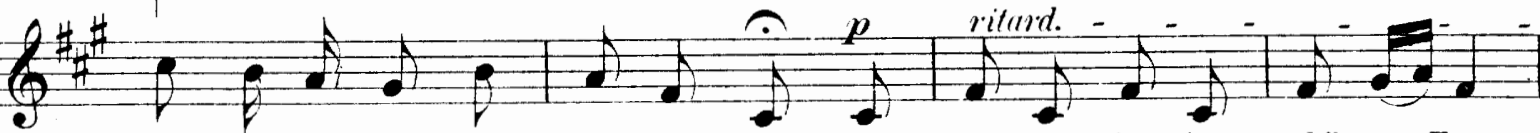
Heut' ist ge-mïht das Aeh-ren - feld. Zer - stö-ret ist das schö-ne Hius

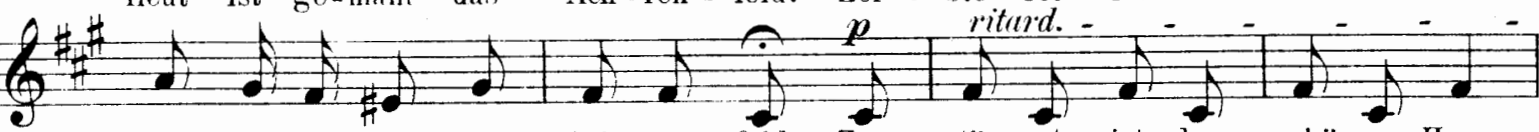
Heut' ist ge-müht das Aeh-ren-feld. Zer - stö-ret ist das schö-ne Haus

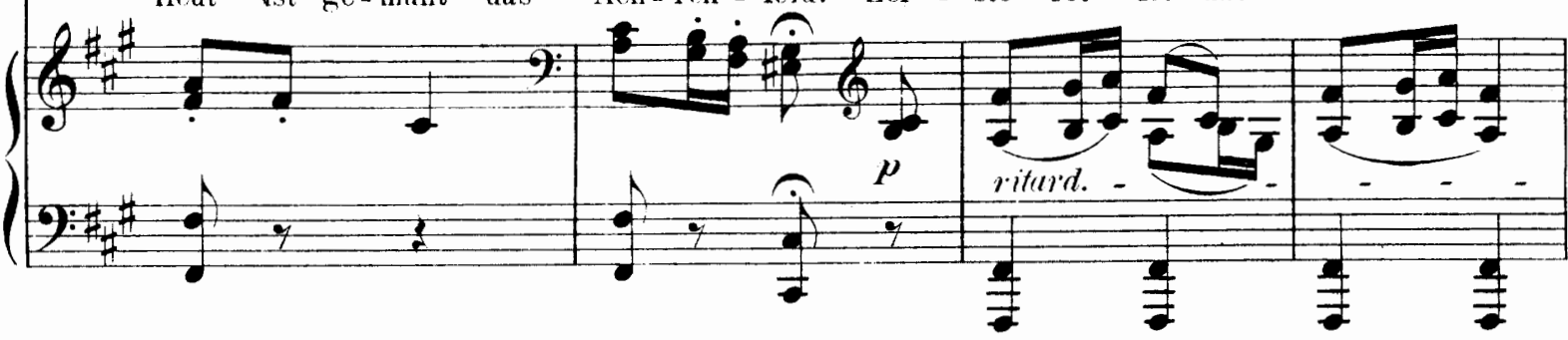

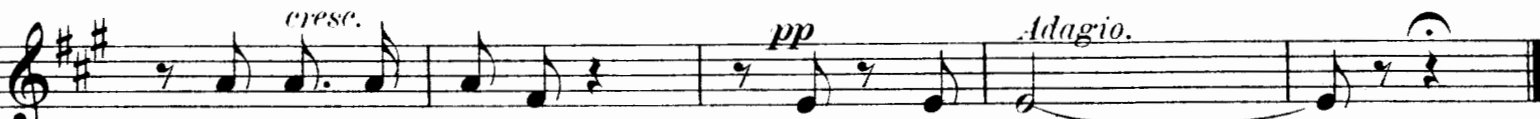

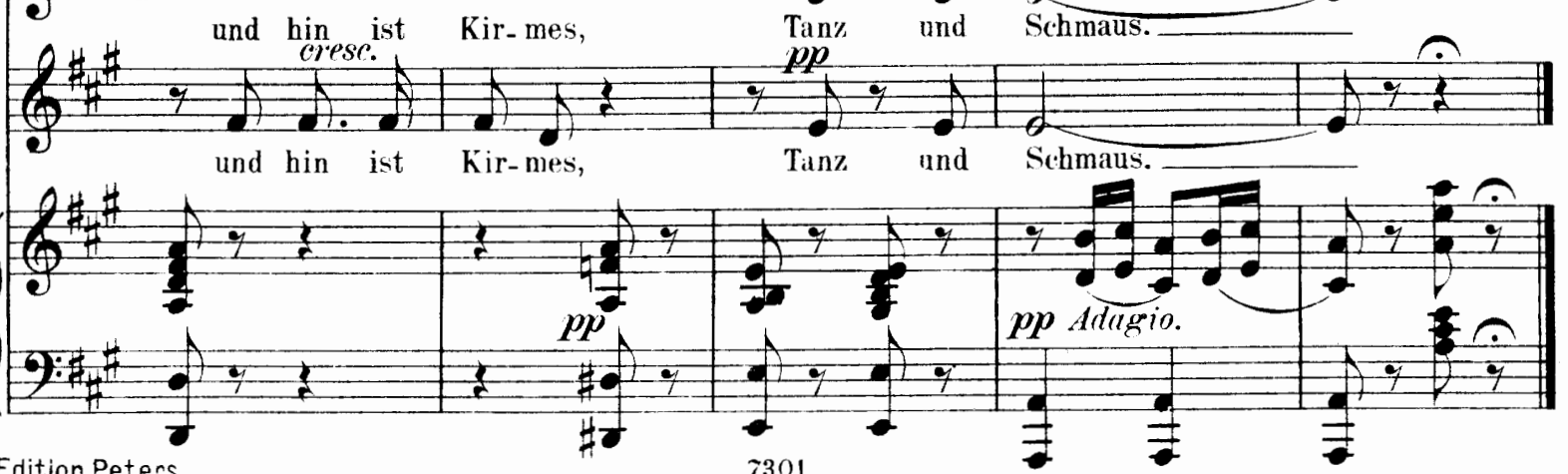




\section{Lied aus Ruy Blas.}

(Victor Hugo.)

Op.77 Nr. 3 .
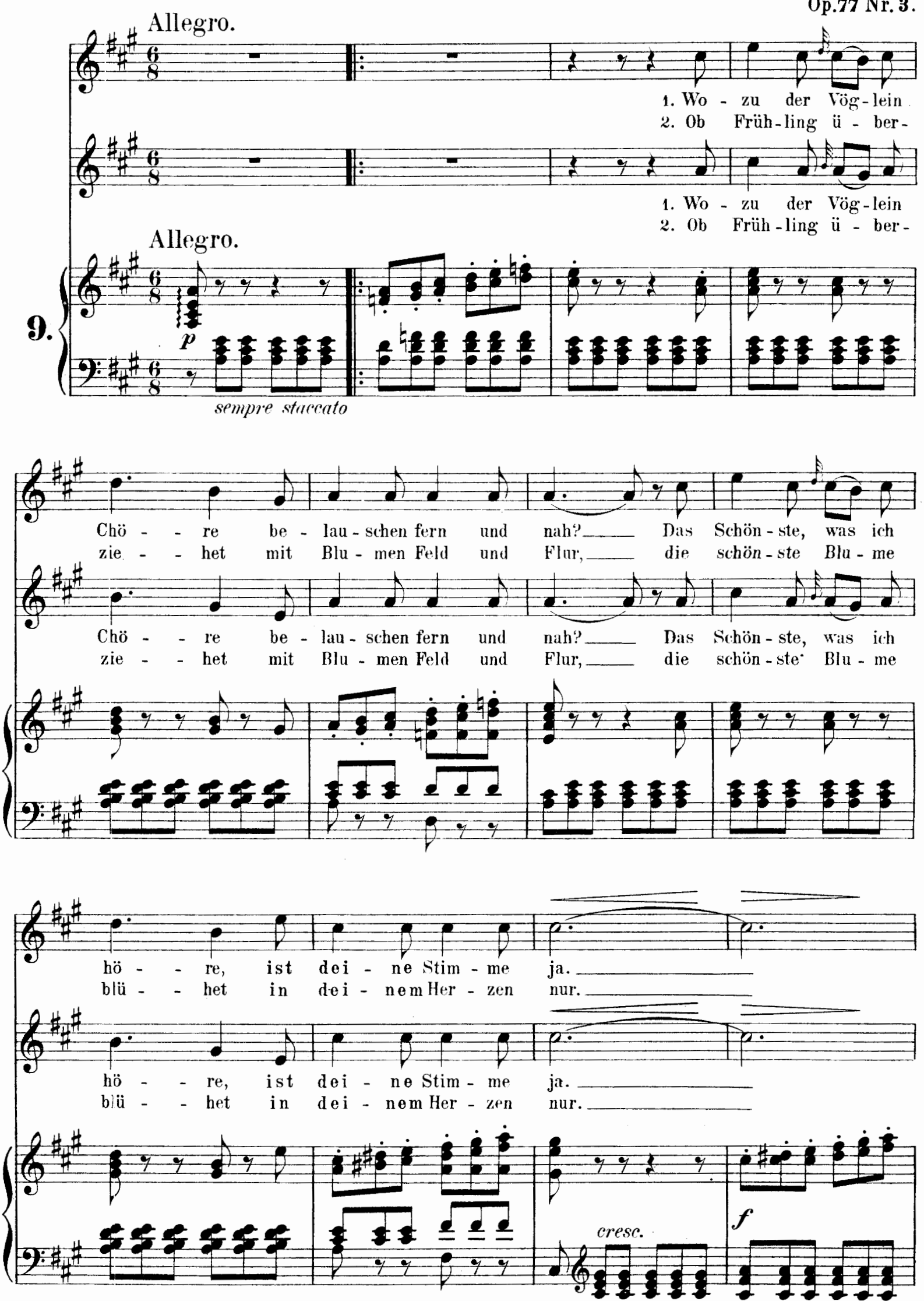

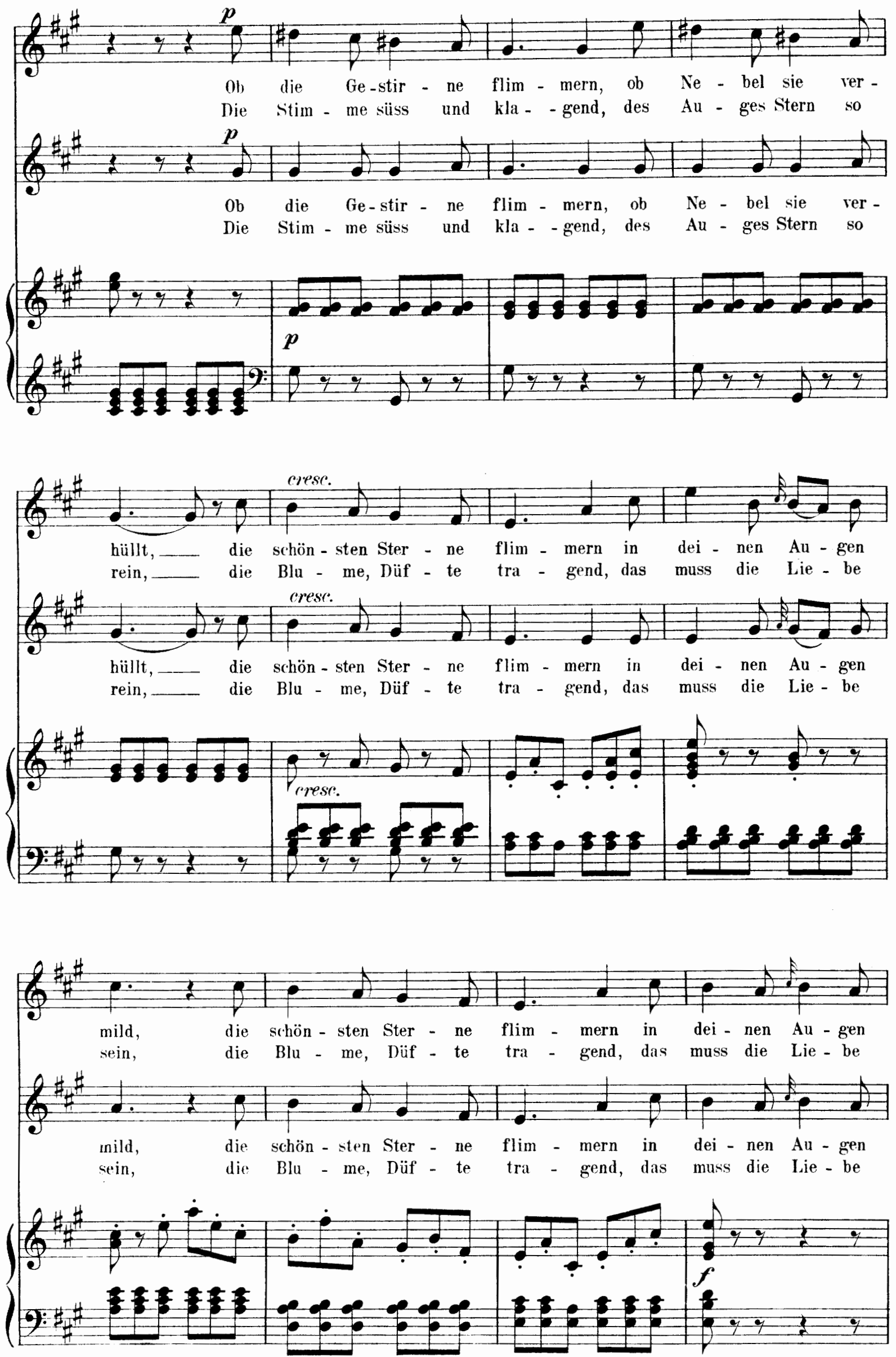

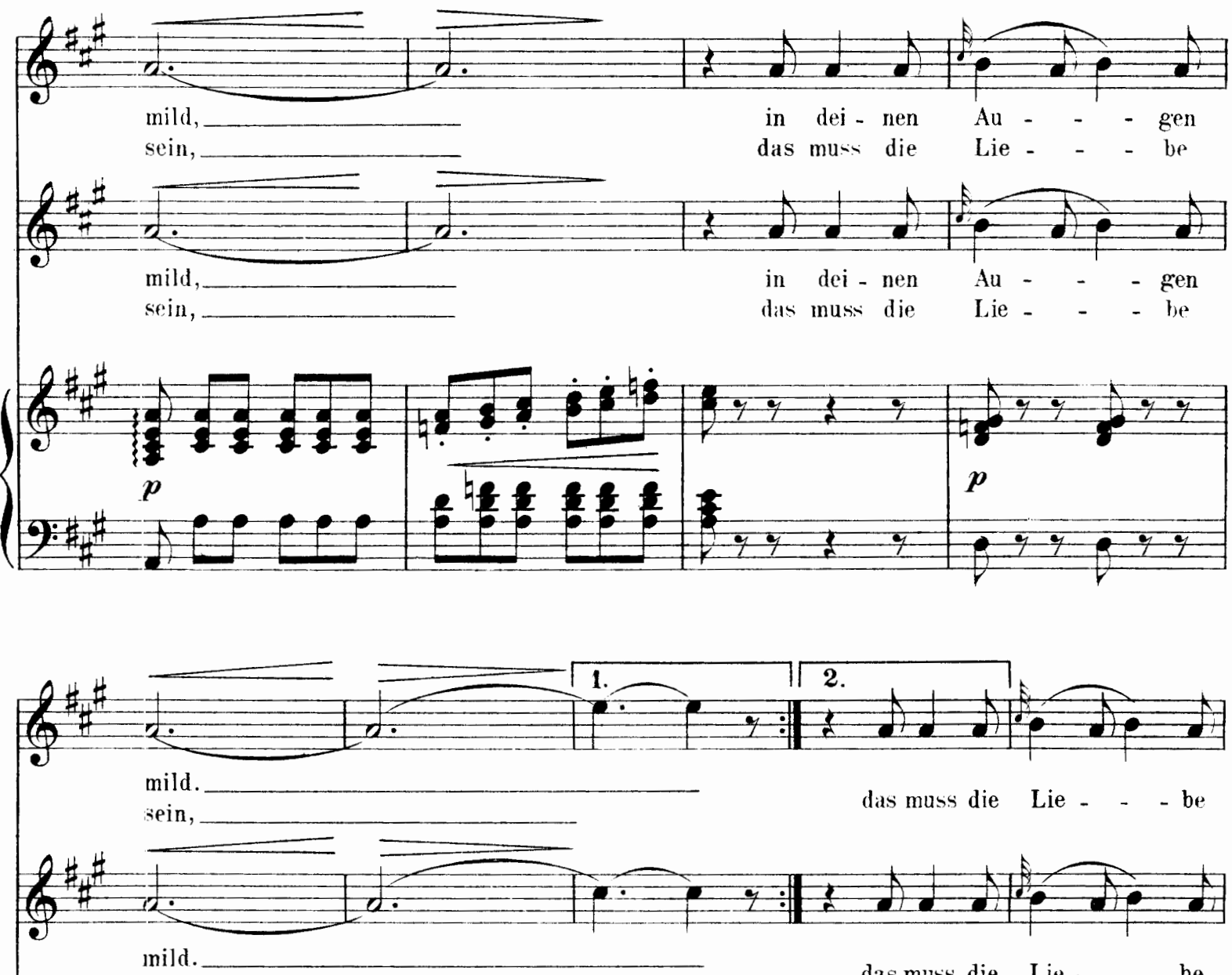

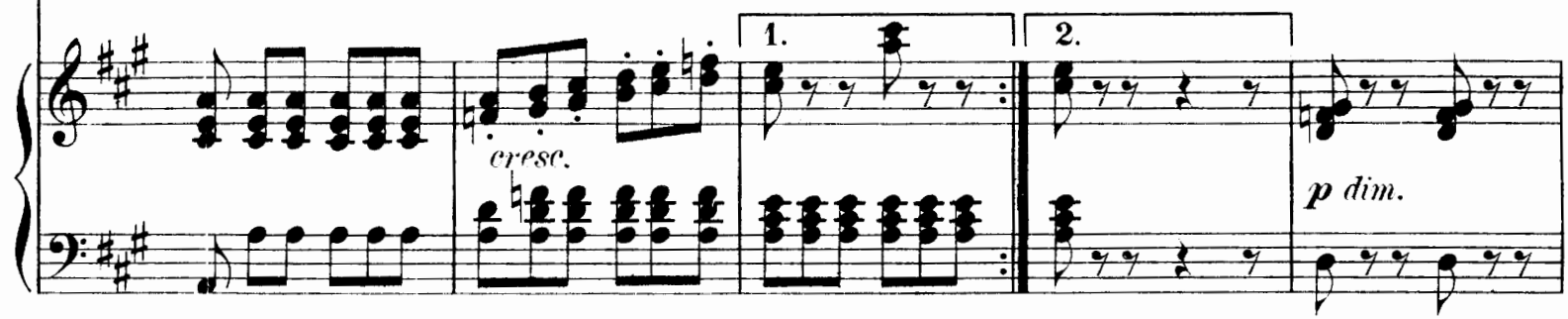
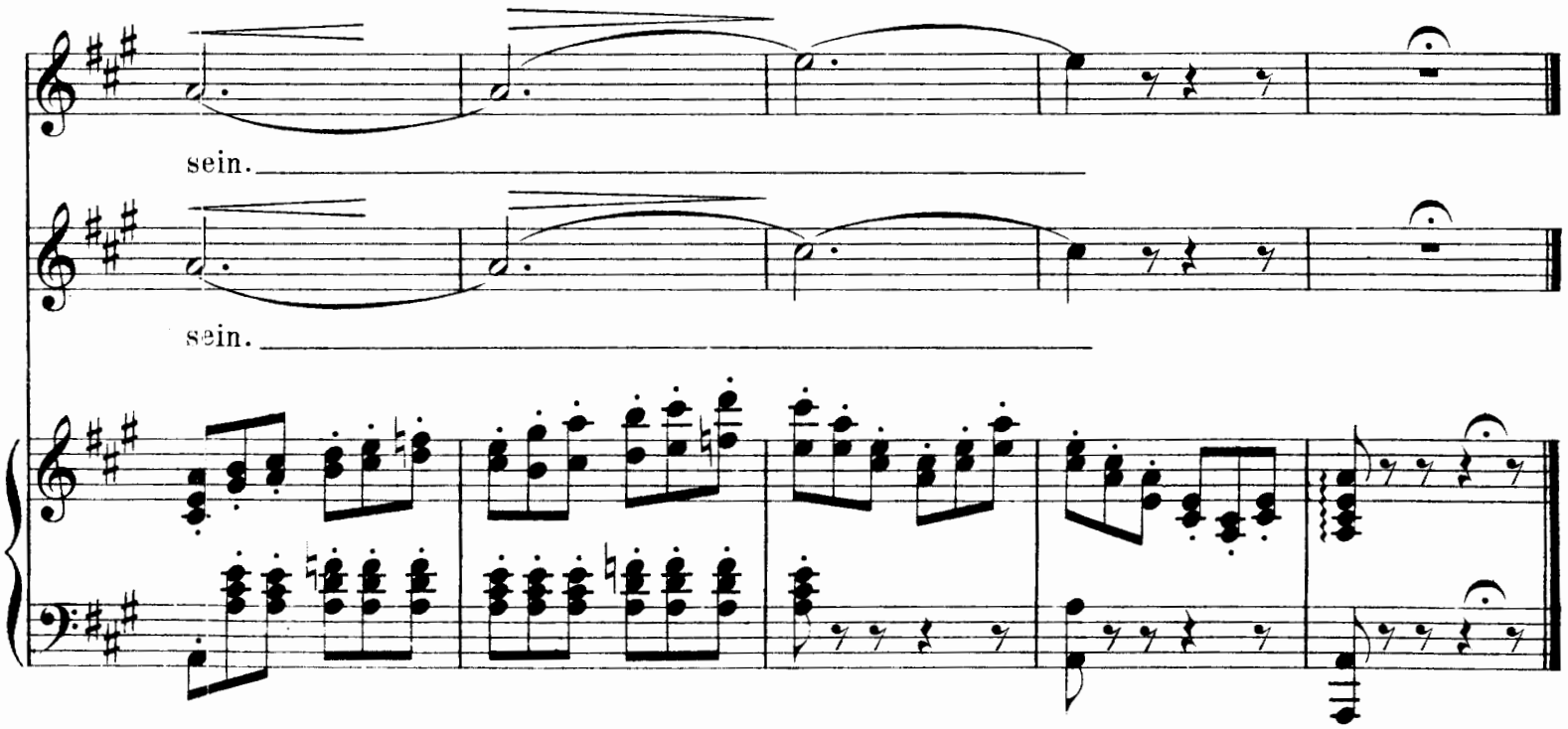
(Ph. Kaufmann.)

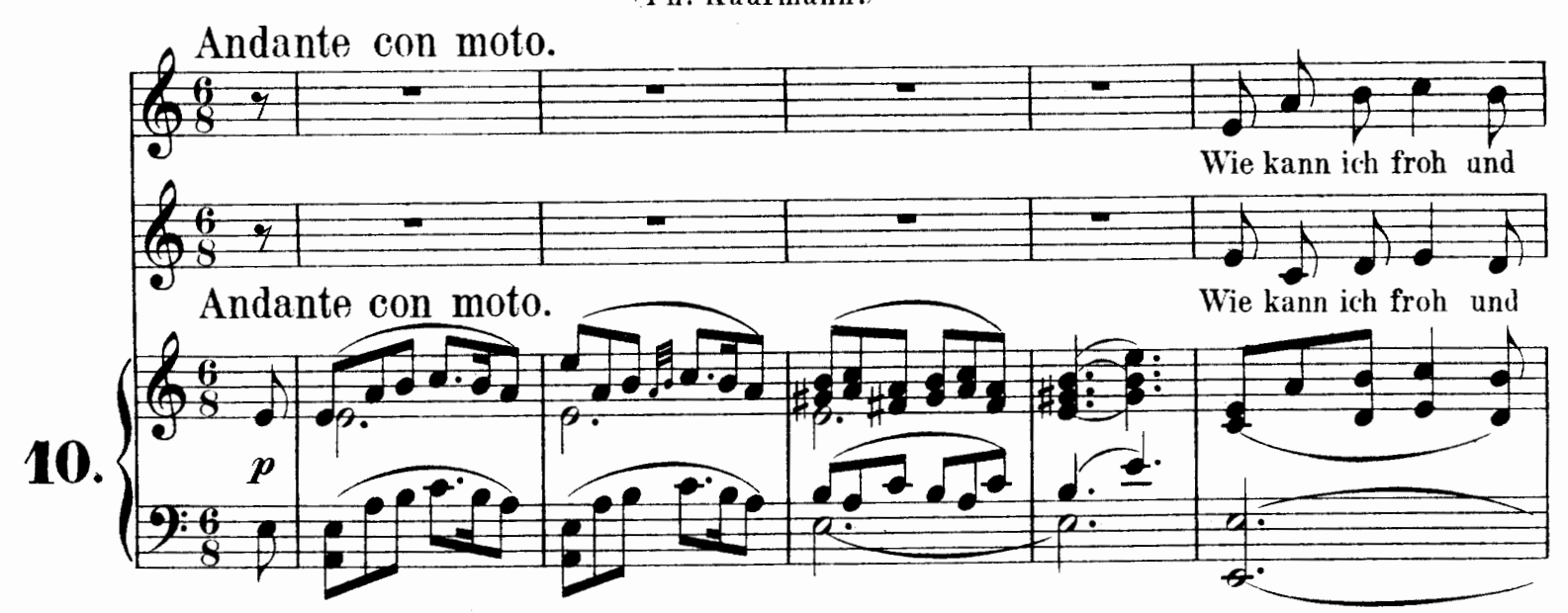

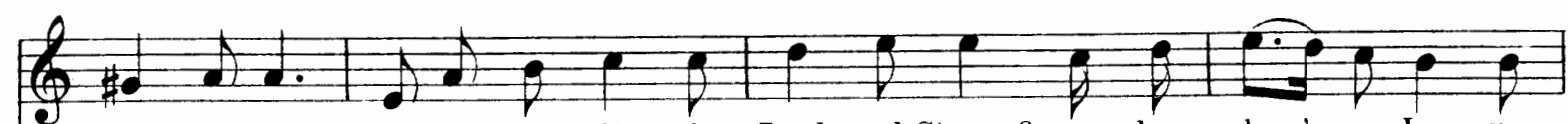
lu - stig sein? wie kann ich geh'n mit Band und Strauss? wenn der herz'-ge Jun - ge,

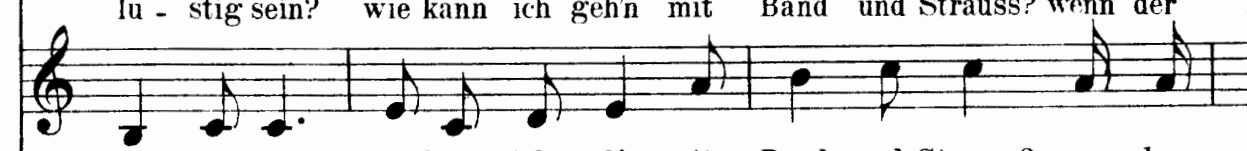

lu - stig sein? wie kann ich geh'n mit Band und Strauss? wenn der herz' - ge Jun - ge,

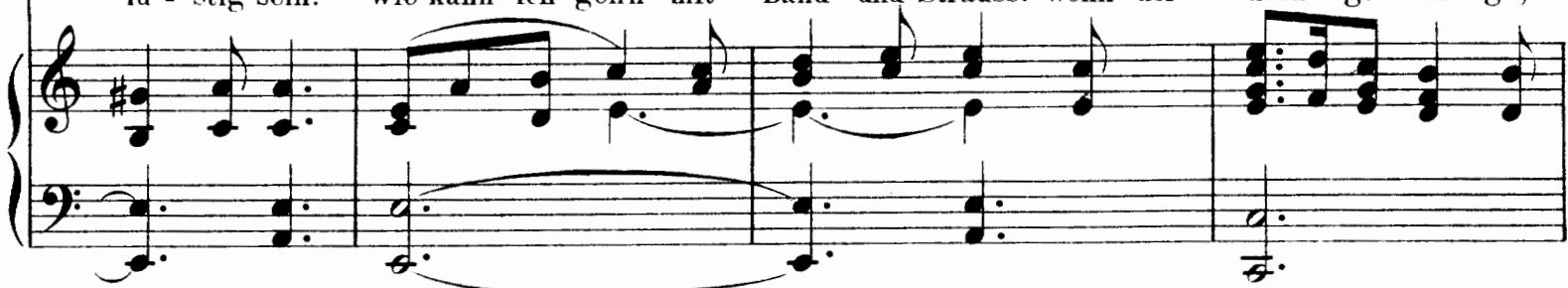

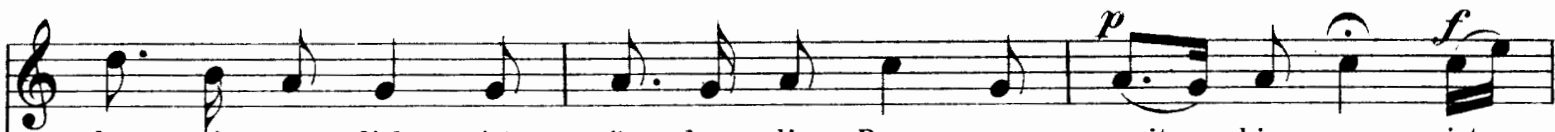
der mir so lieb, ist $\ddot{\mathrm{u}}-$ ber die Ber - ge
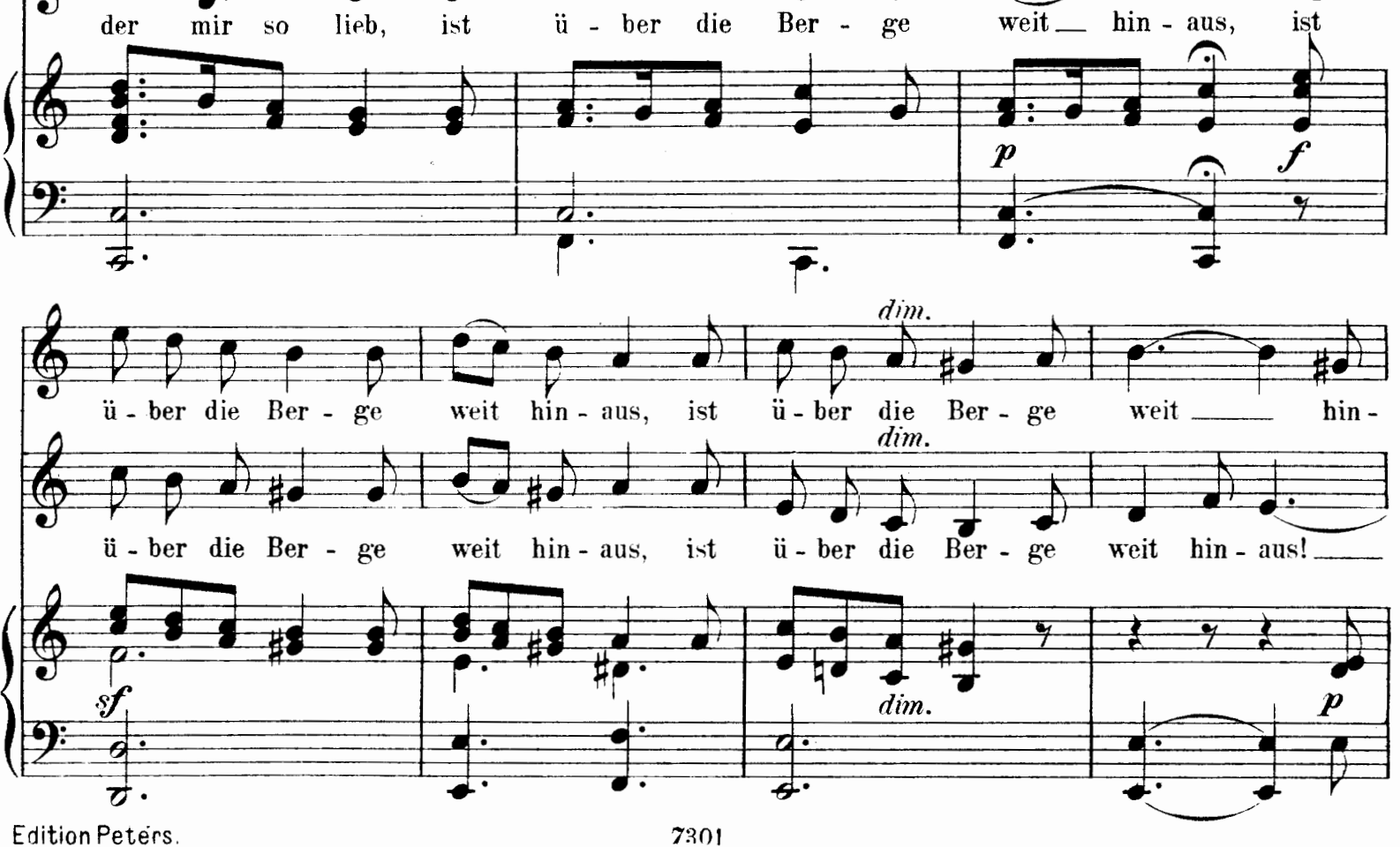

Edition Petérs. 


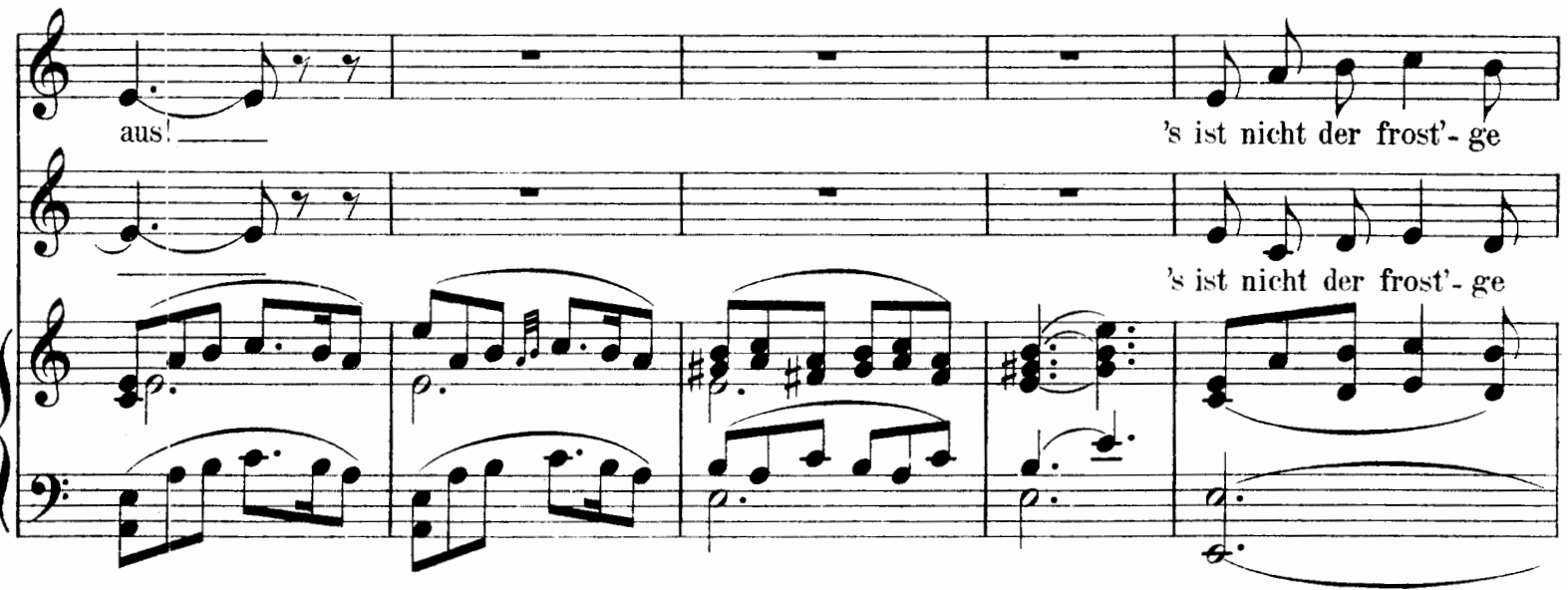

(6) Win - ter-wind, 's ist nicht der Schnee und Sturm und Graus, doch im - mer kom-men mir

Win - ter-wind, 's ist nicht der Schnee und Sturm und Graus, doch im - mer kom-men mir

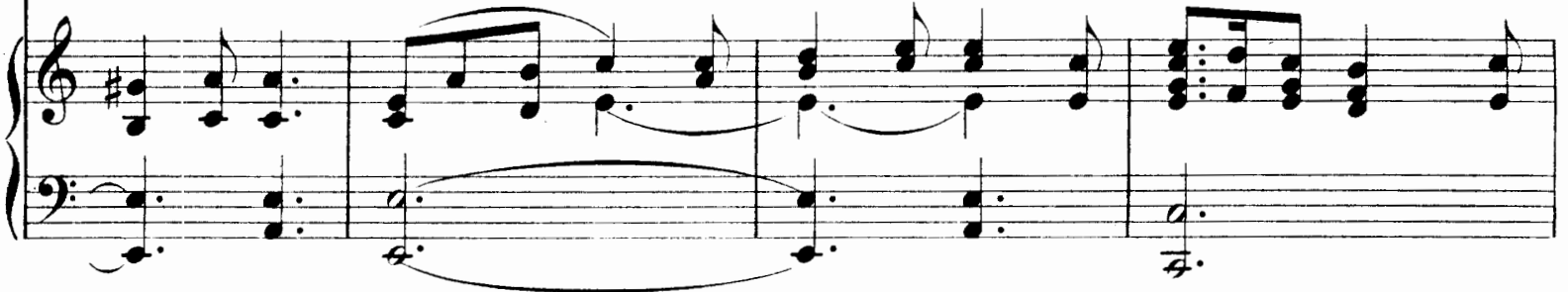

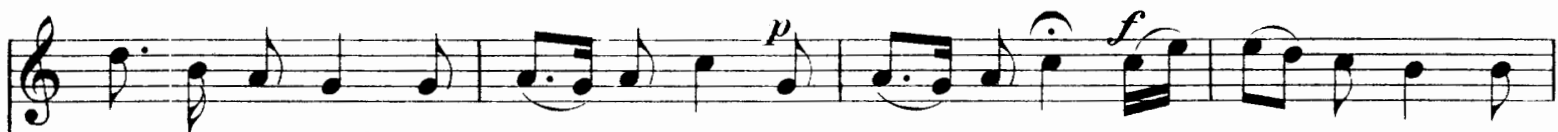
Thrä-nen in's Aug', denk' ich an ihn, der weit hin-aus, denk' ich an ihn, der

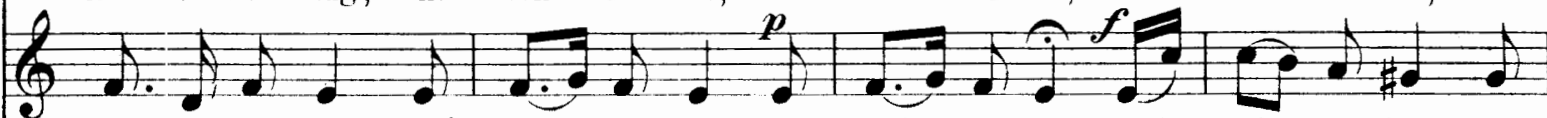
Thrä-nen in's Aug', denk' ich an ihn, der weit hin-aus, denk' ich an ihn, der

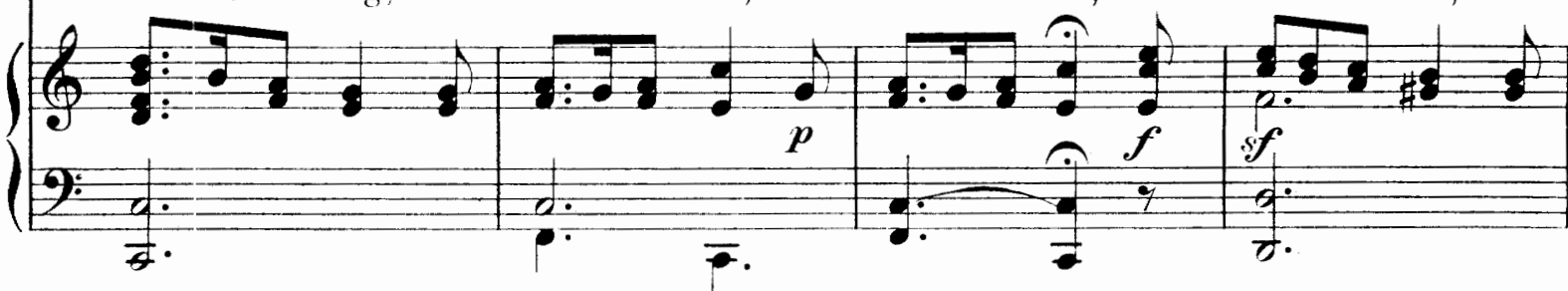

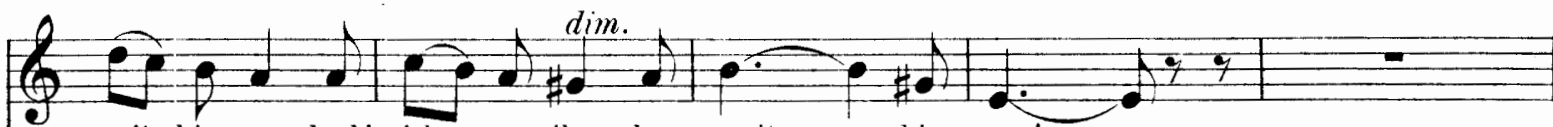
weit hin-aus, denk' ich an ihn, dır weit__ hin - aus! _

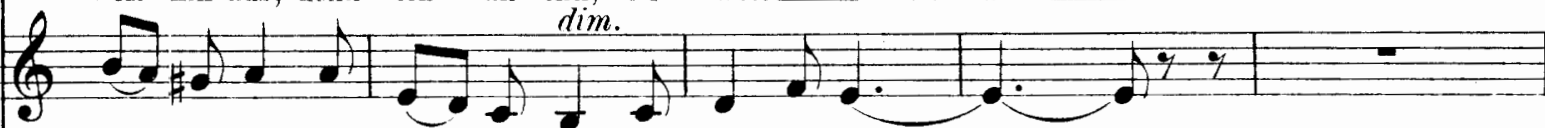

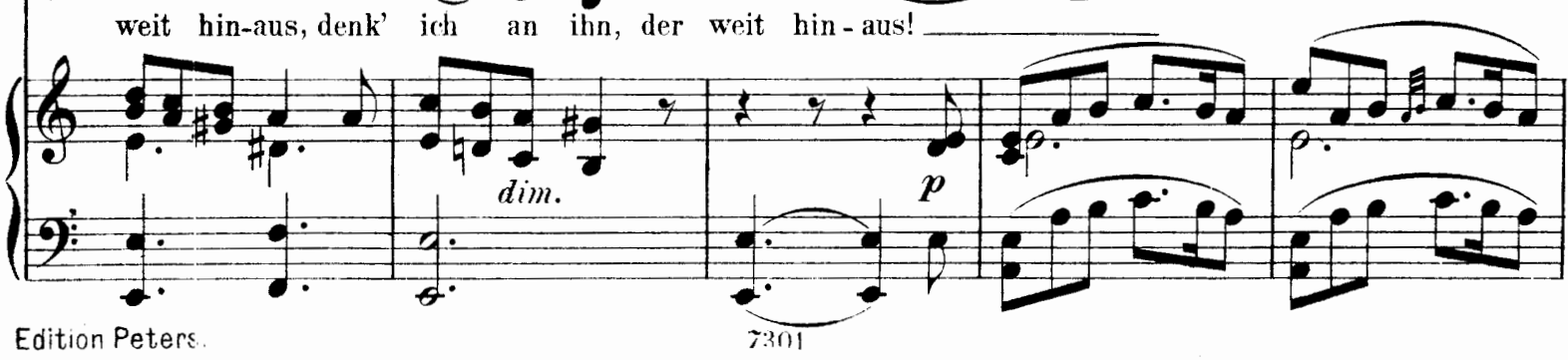



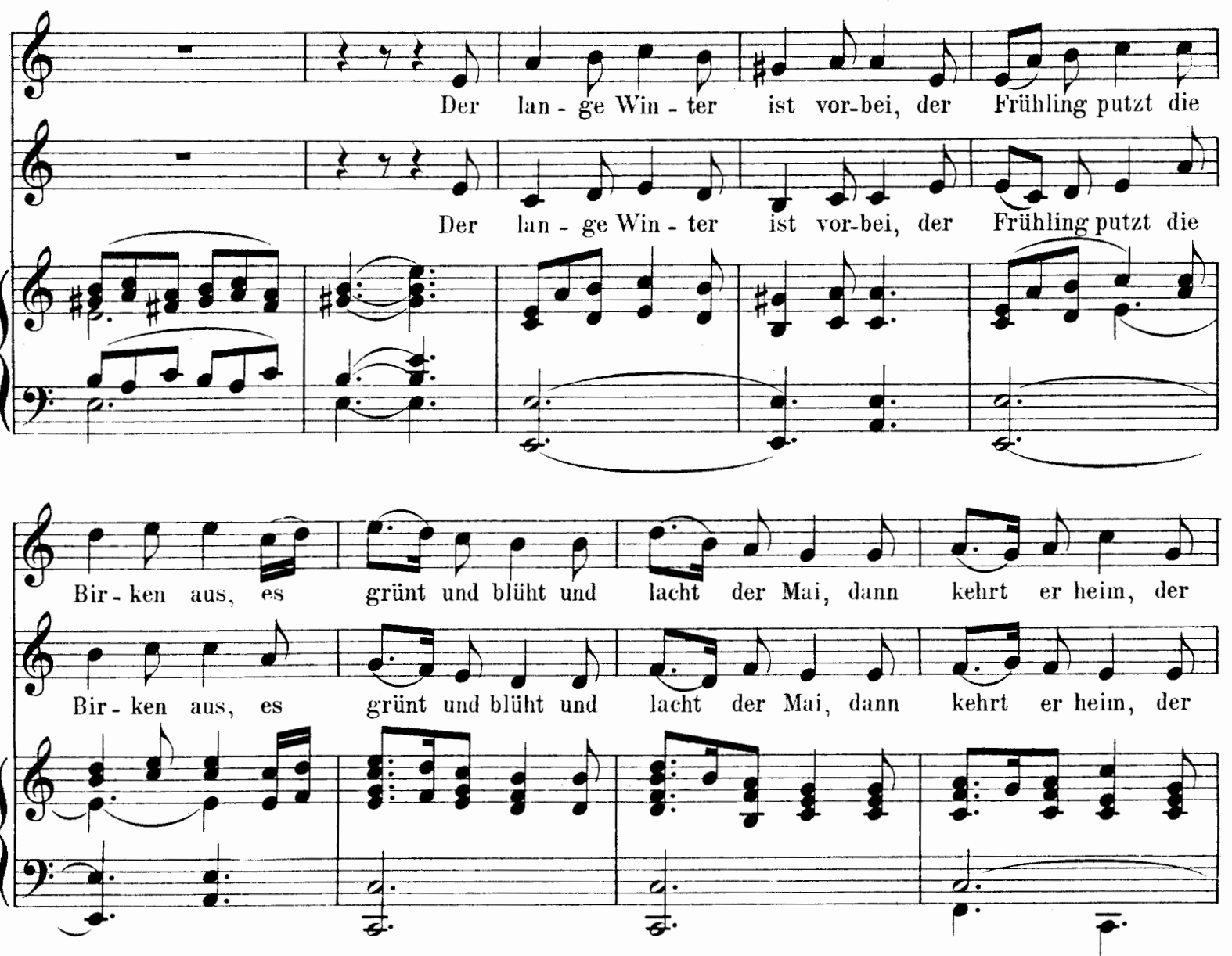

(4) (6)

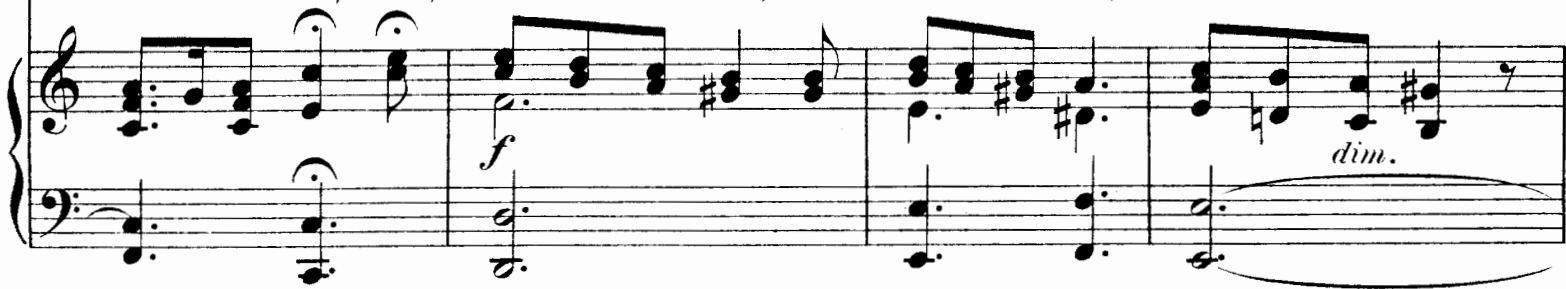

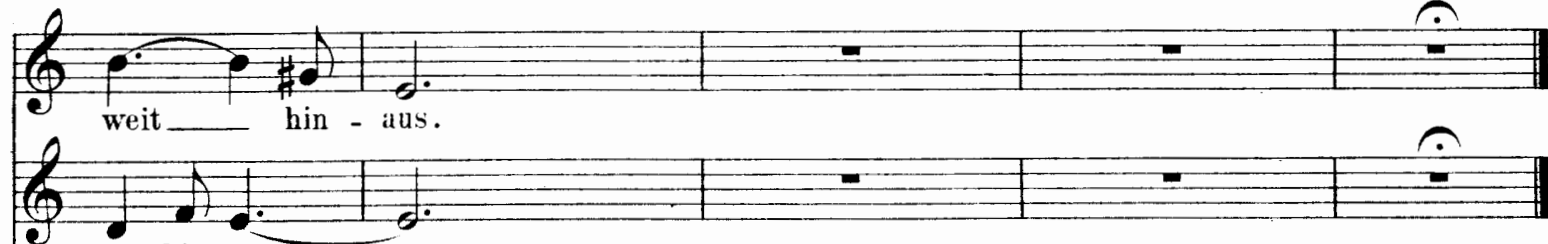

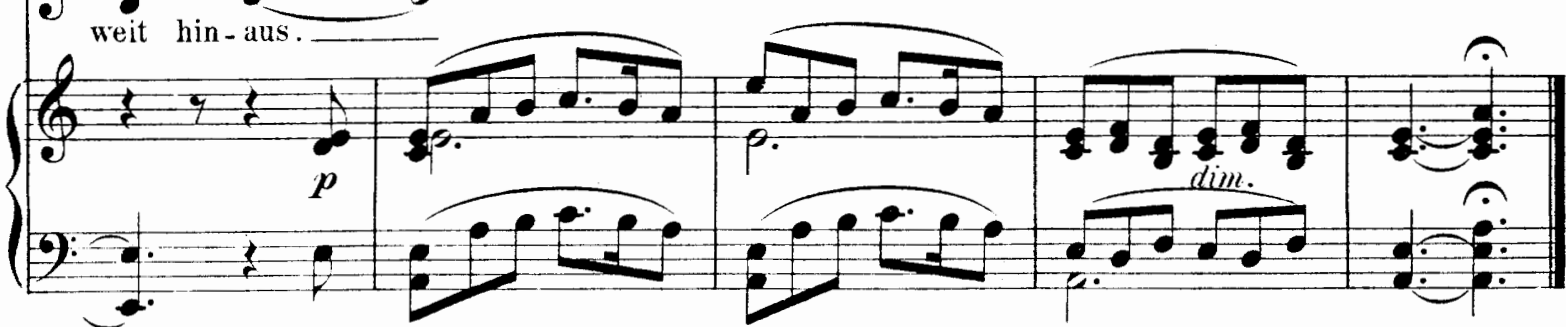
Edition Peters. 
Abendlied .

(H.Heine.)

Andante tranquillo.

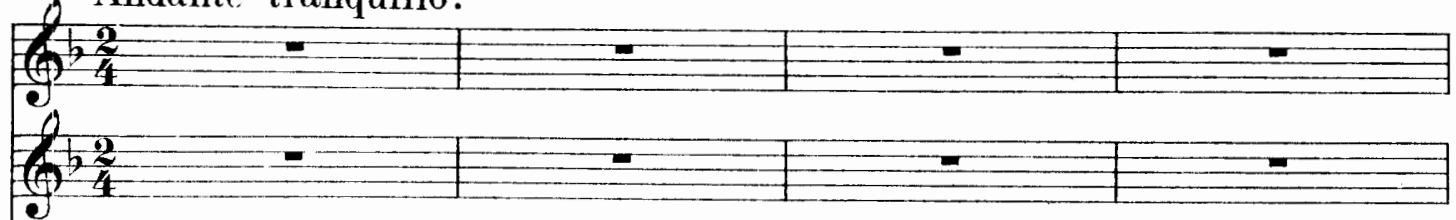

Andinte tranquillo.

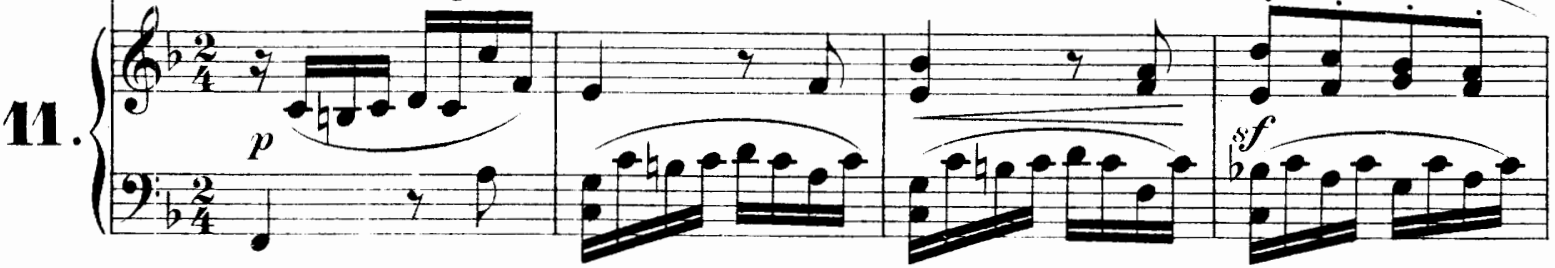

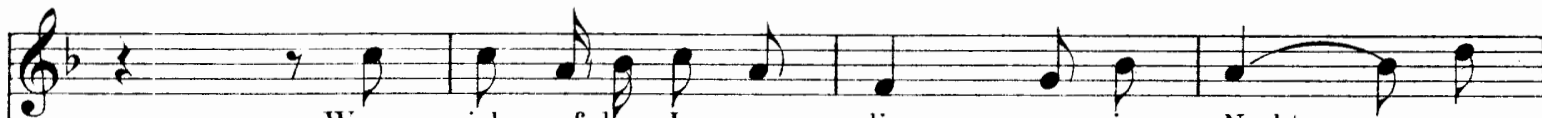
Wenn ich auf dem La -ger lie - - ge, in Nacht_ ge -

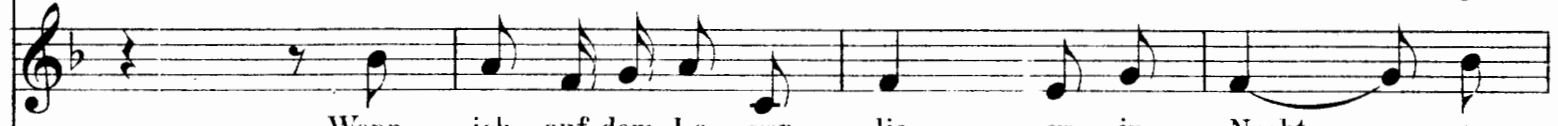

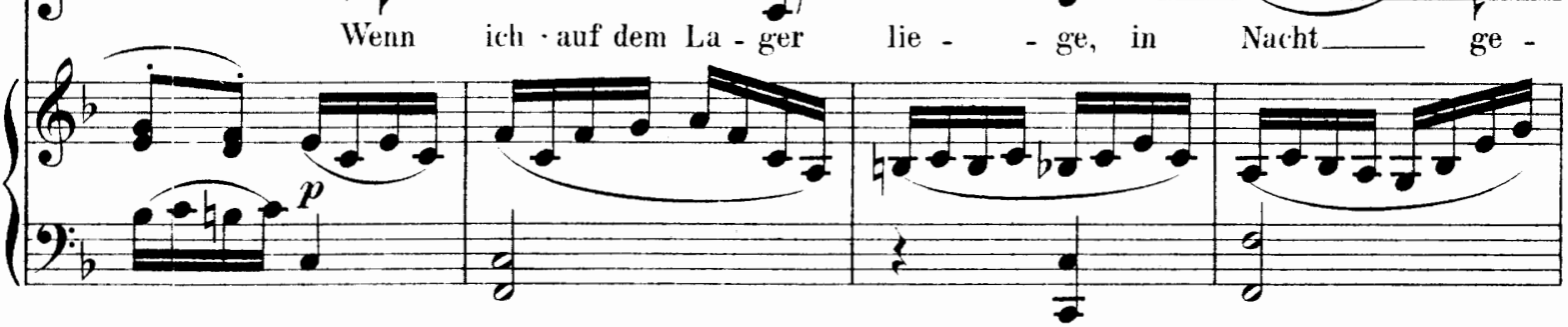

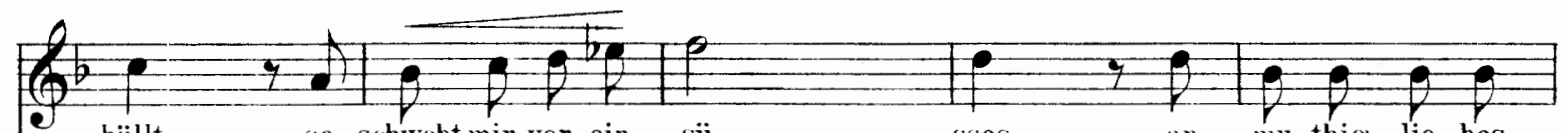
hüllt, so schwebtmir vor ein sü - $\quad$ - $\quad$ - sses, an - mu-thig lie-bes

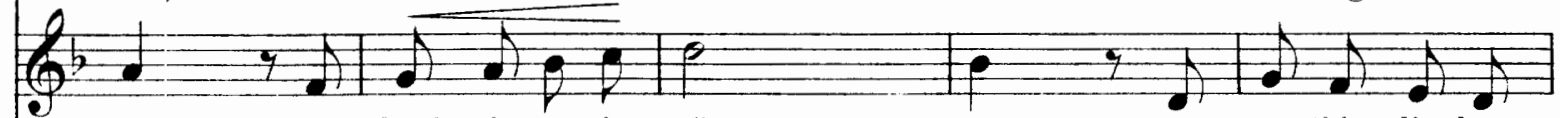

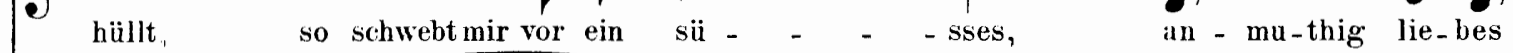

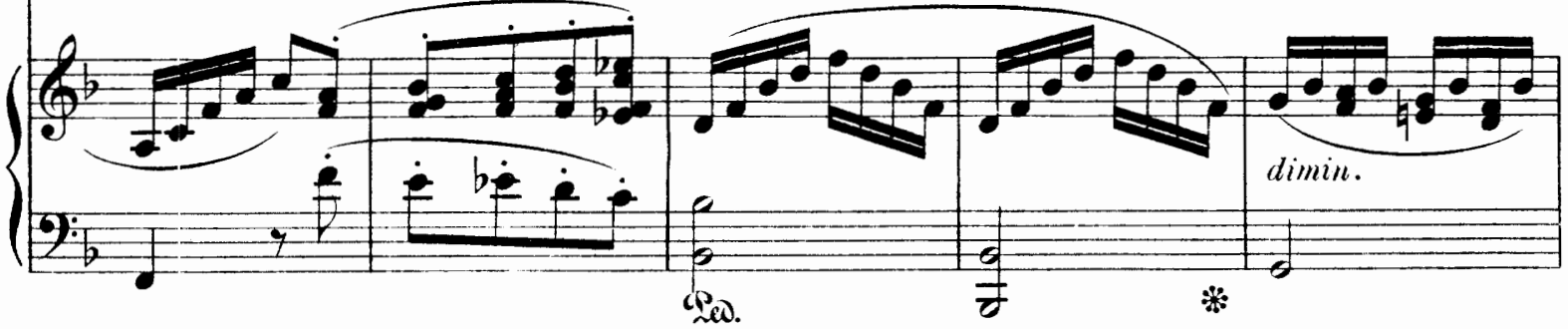

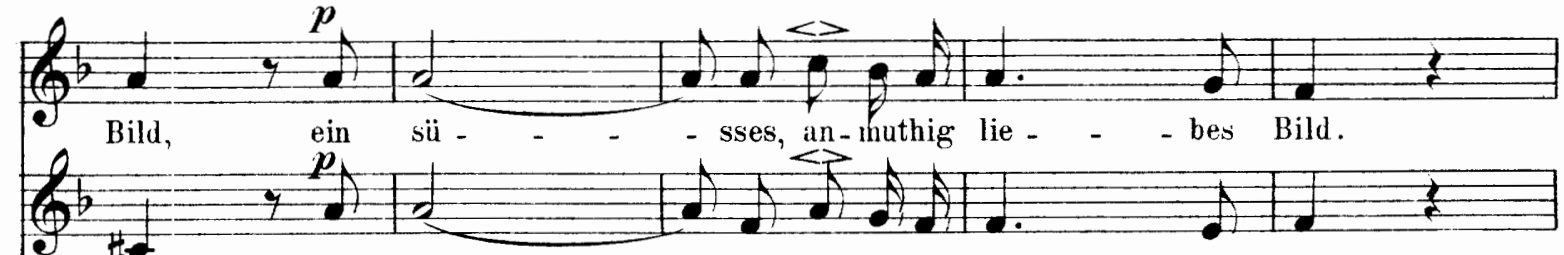

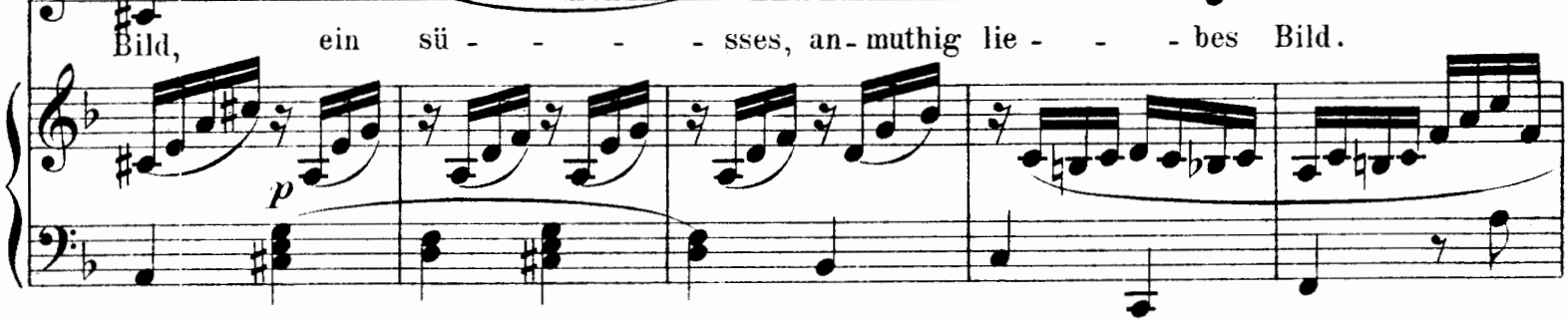

Edition Peters. 

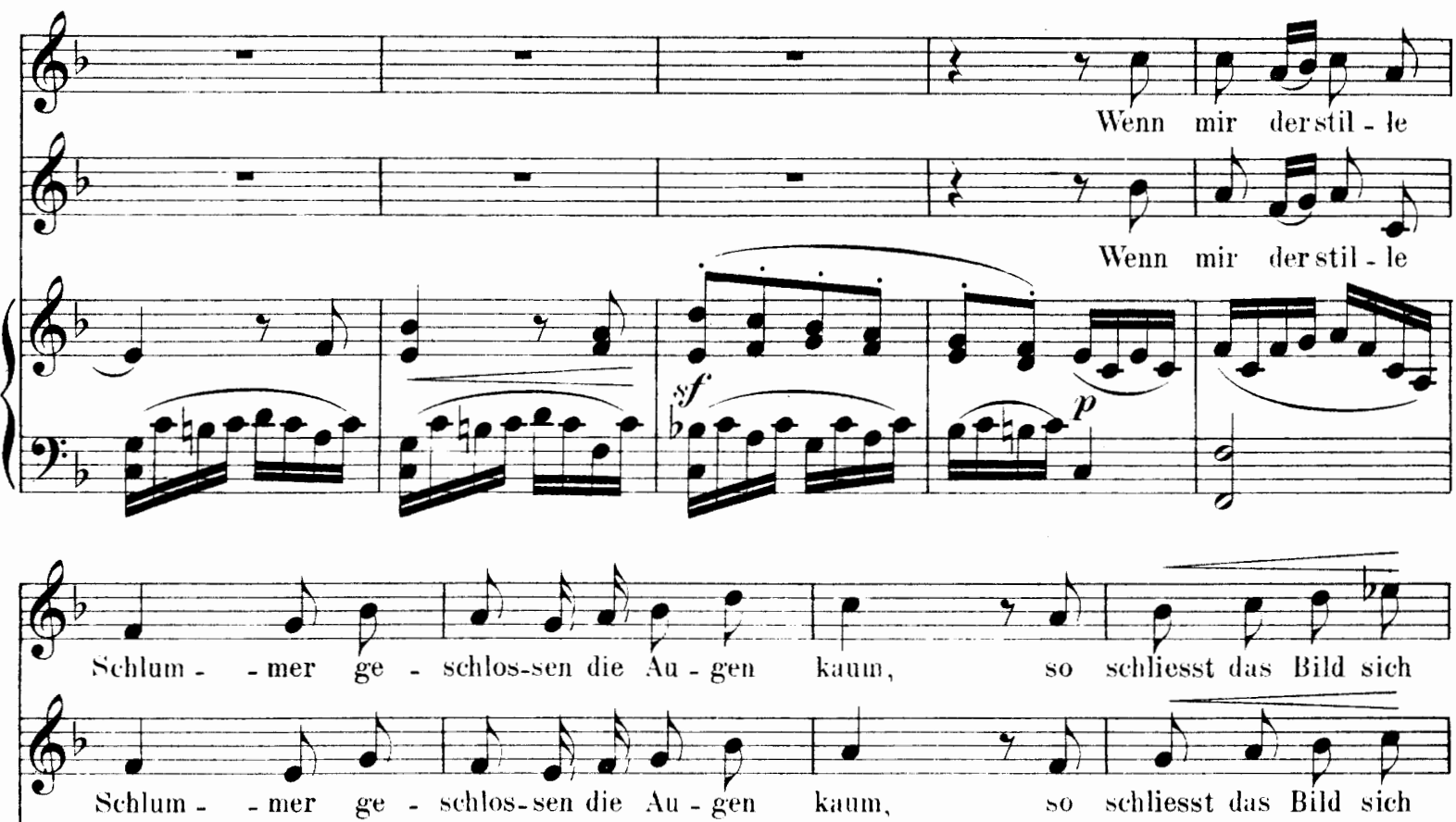

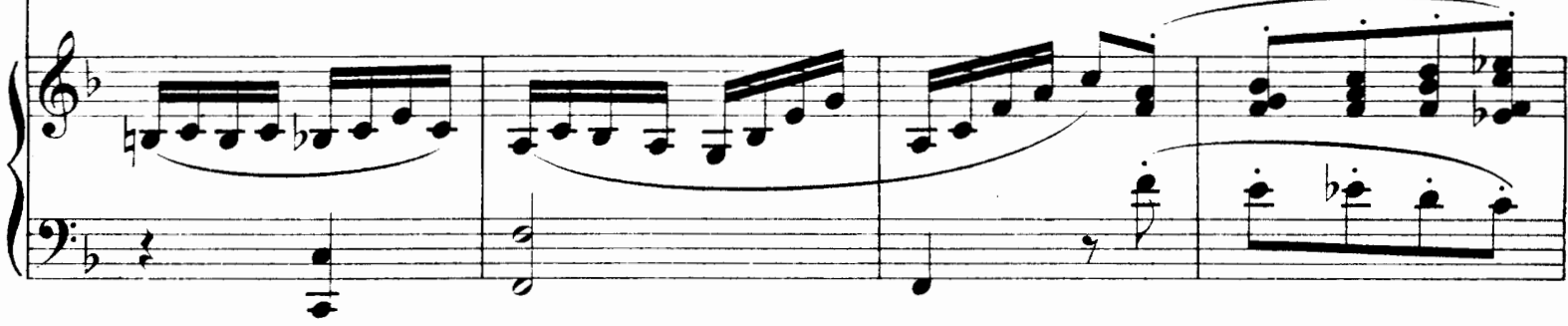

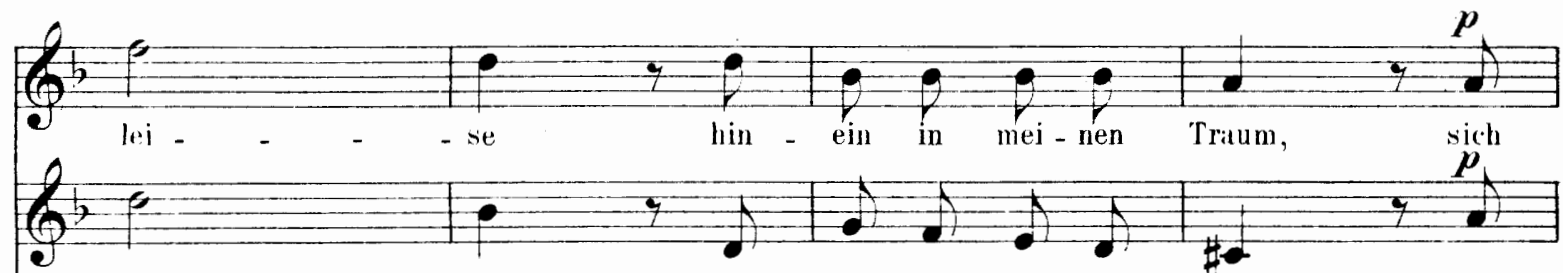
lei - - - - se bin - ein in mei - nen Traum, sich

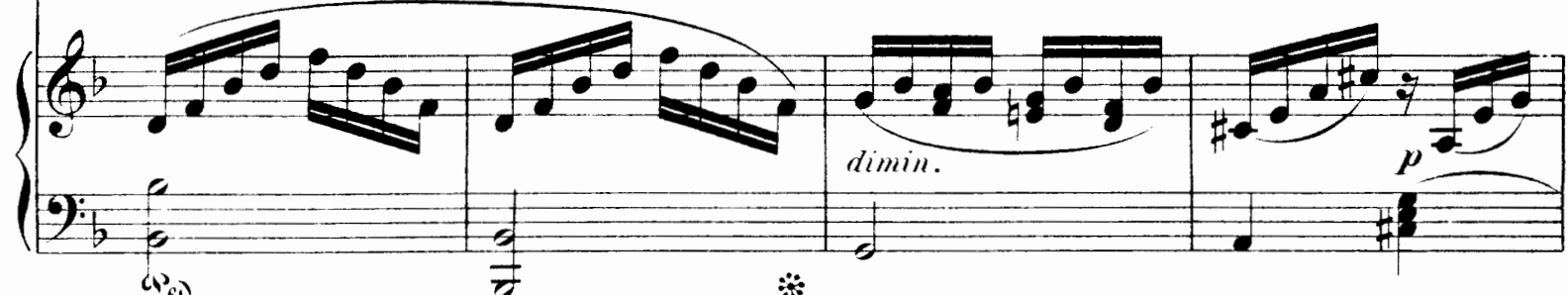
aso. ث

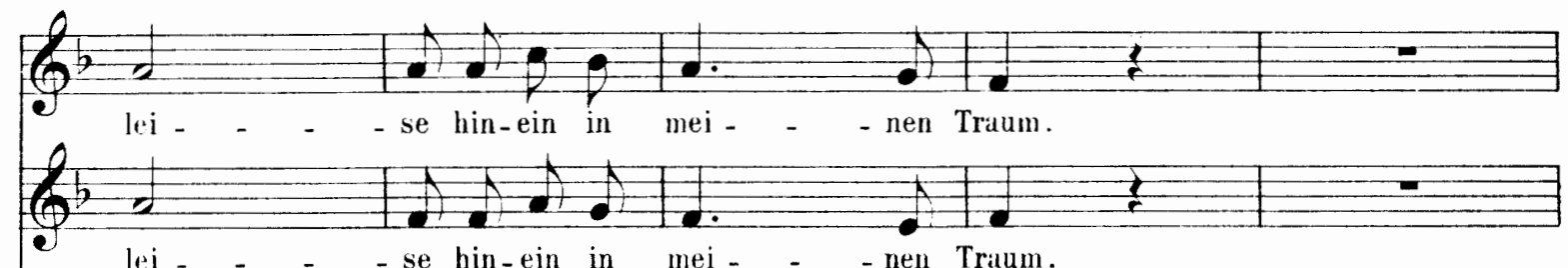

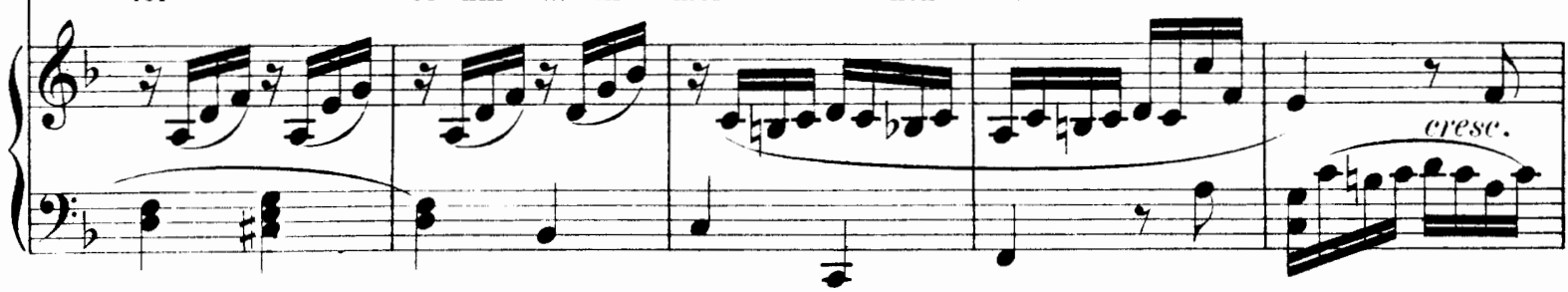




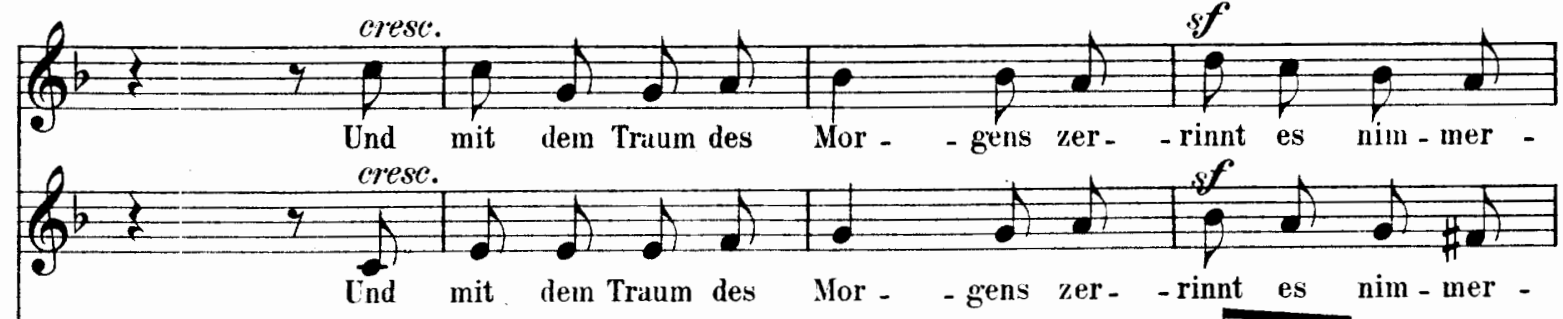

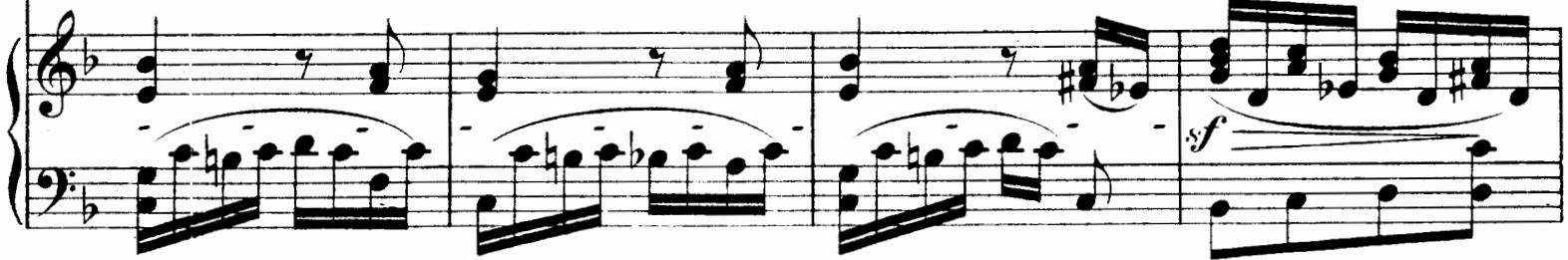

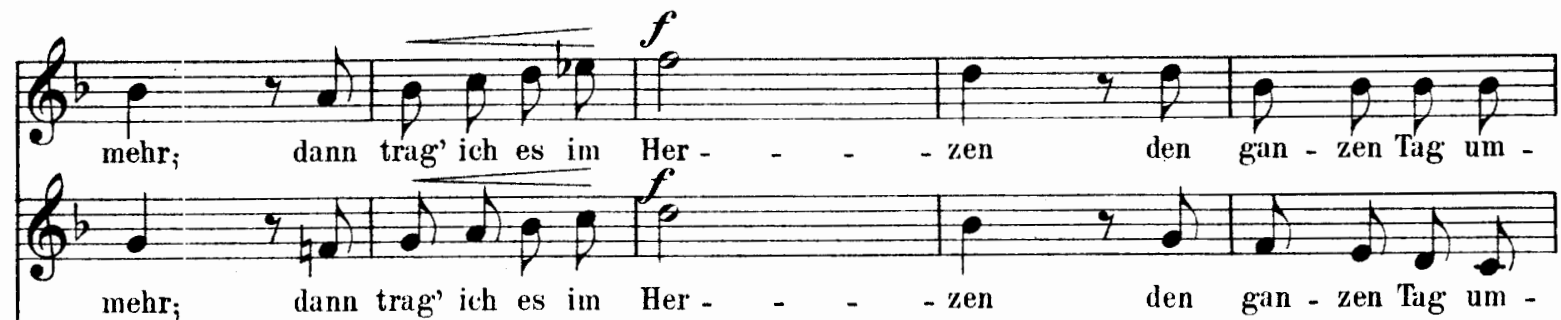
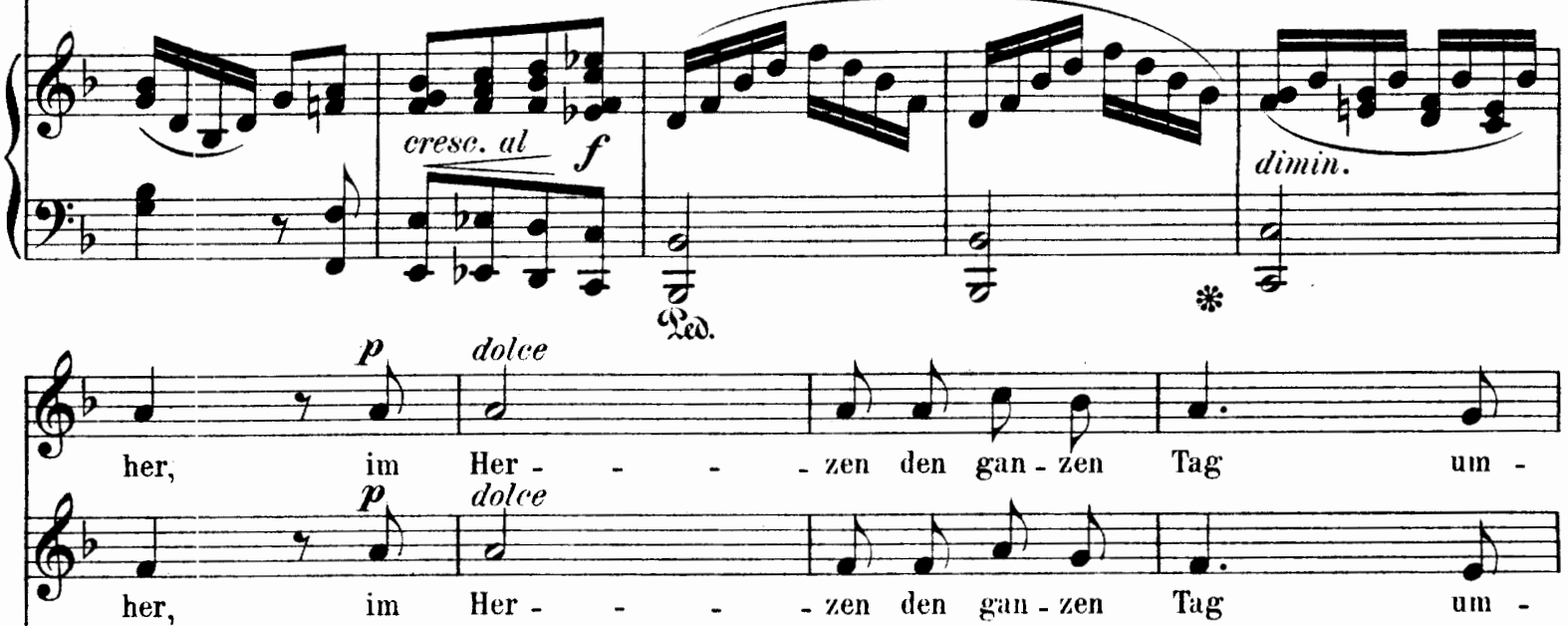

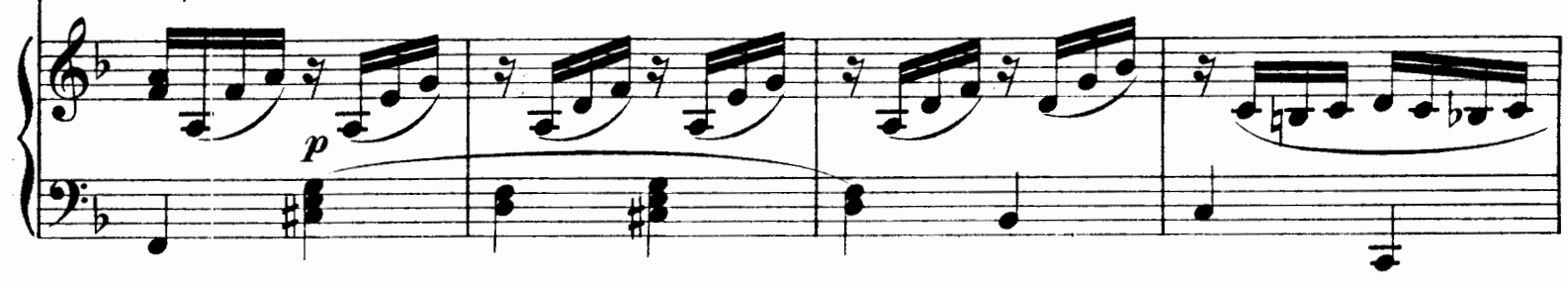

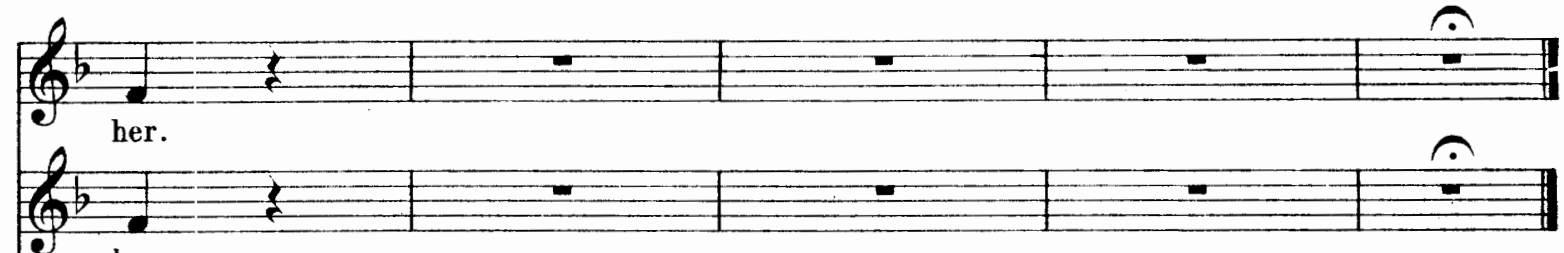

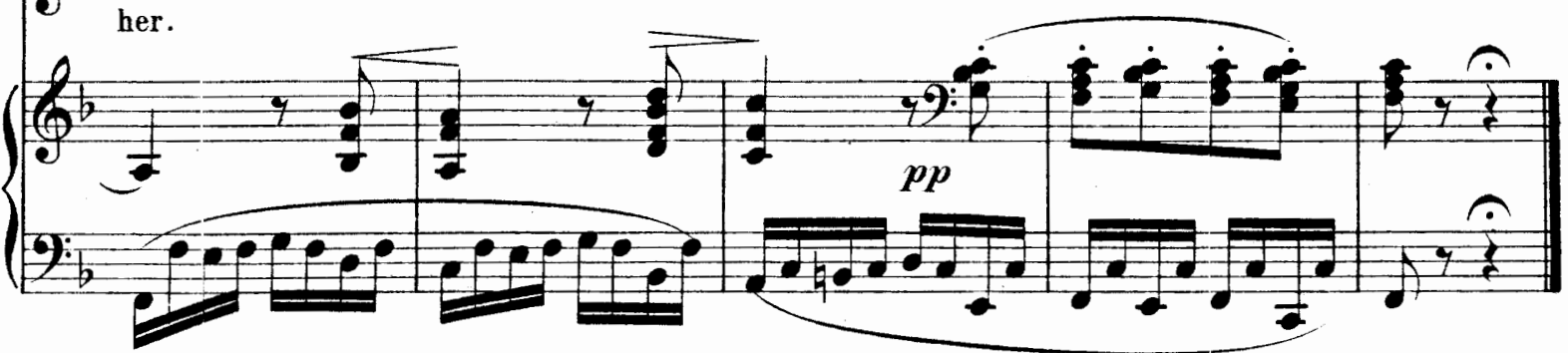
Edition Peters. 


\section{Wasserfahrt.}

(H. Heine.)
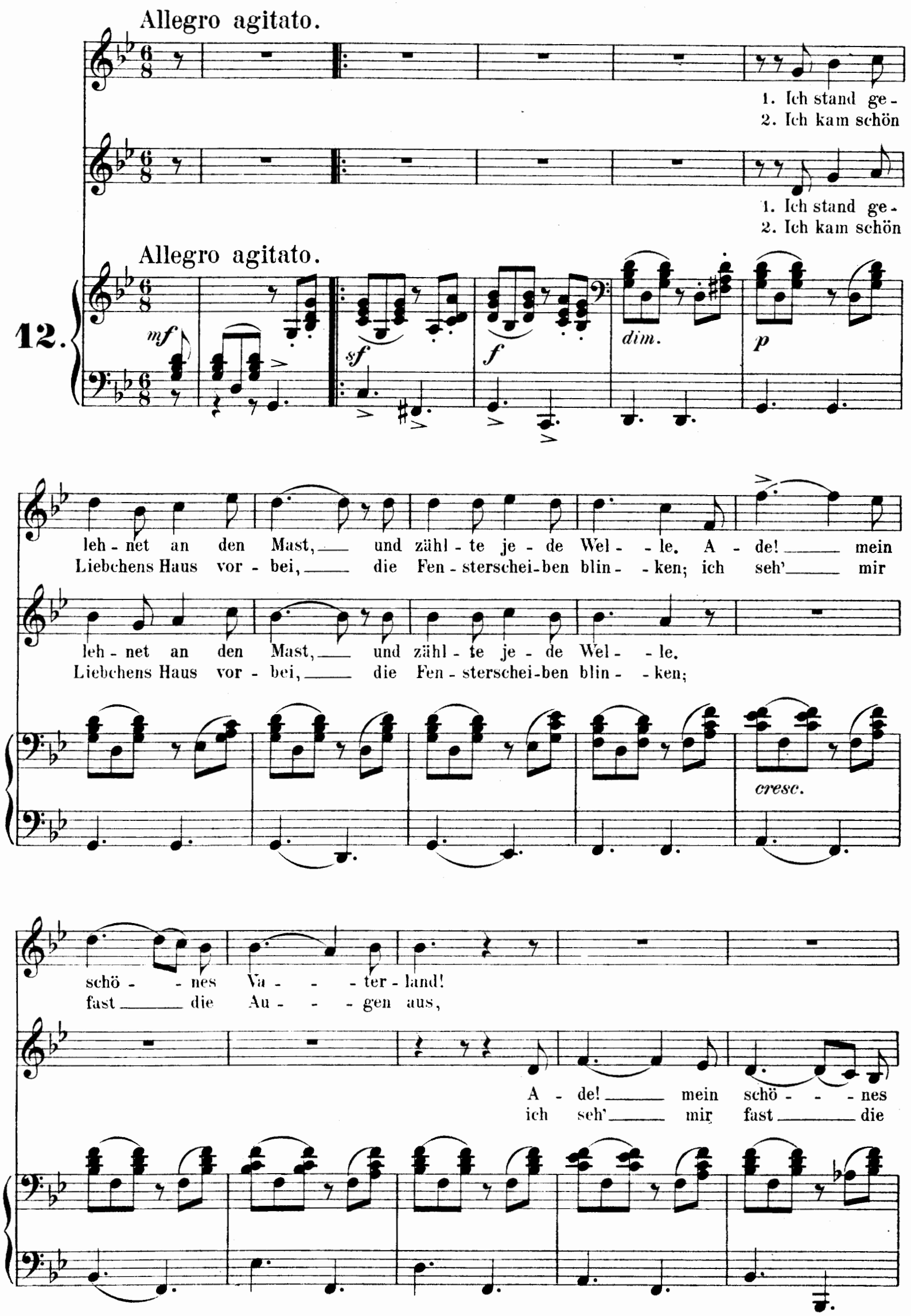


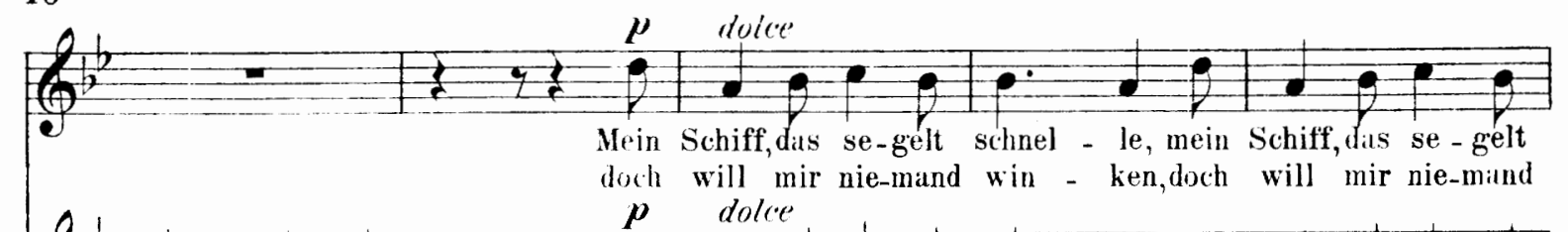

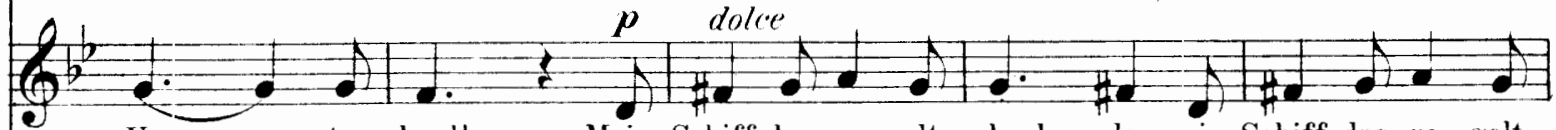

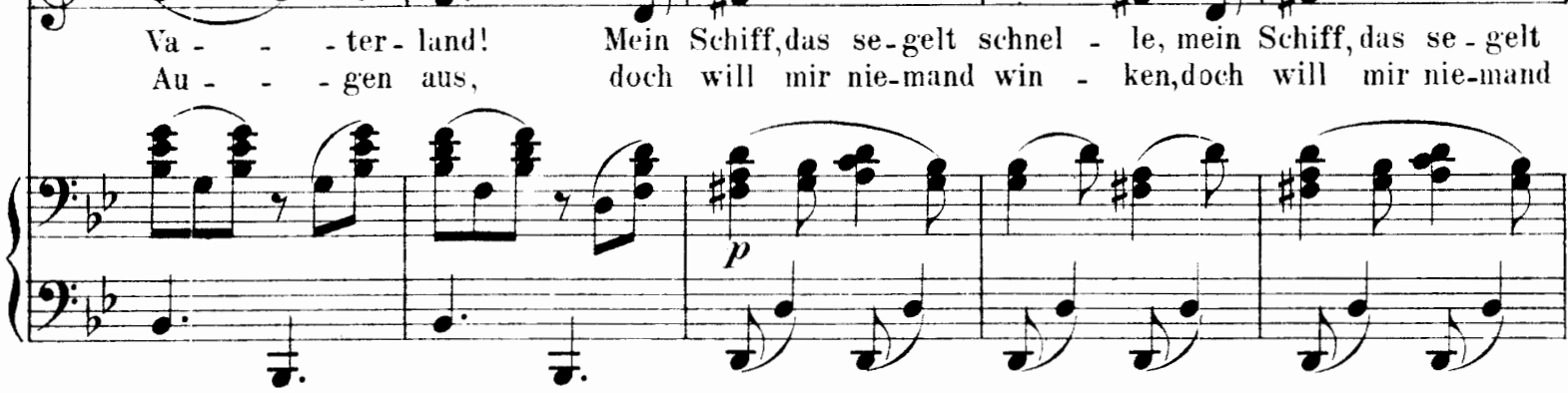

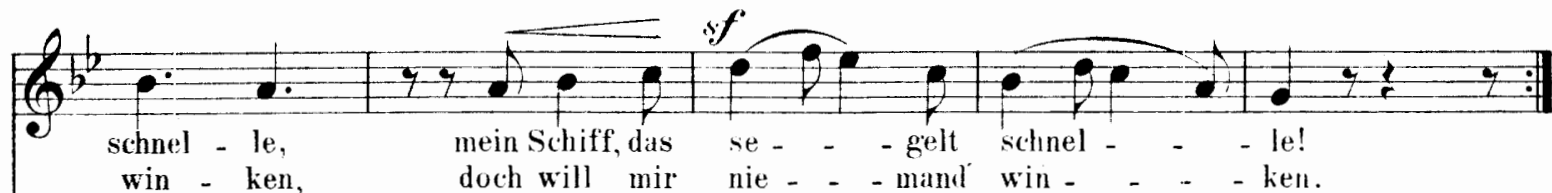

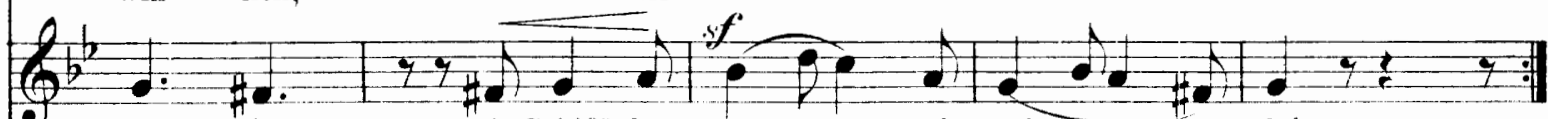
schnel - le, mein Schiff, das se - - - gelt schnet- - - le! win - ken, doch will mir nie - - - mand win- - - - ken.

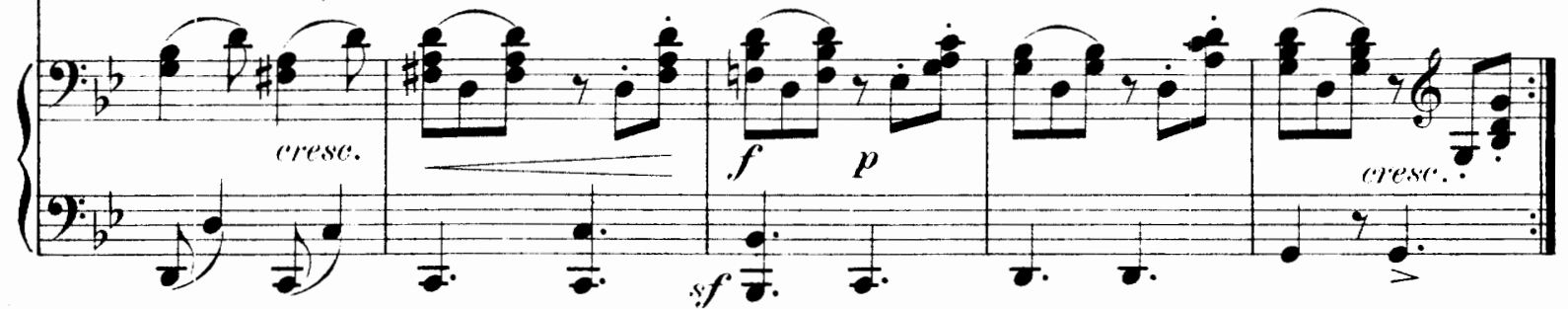

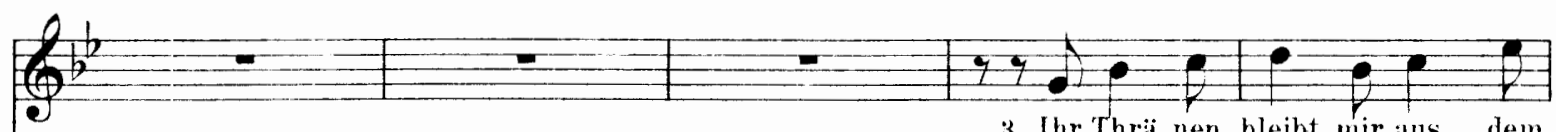
$a^{\frac{b}{2}}=-1$

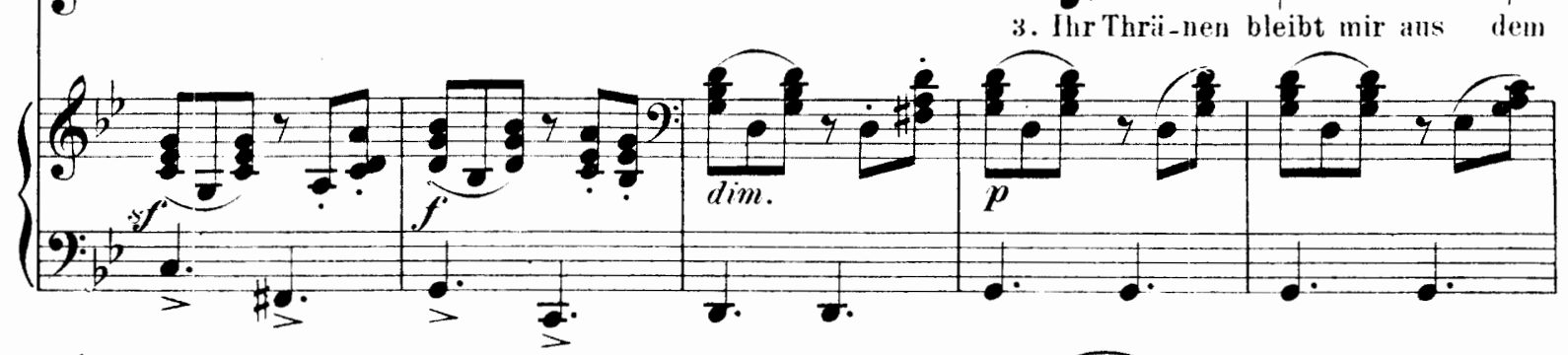

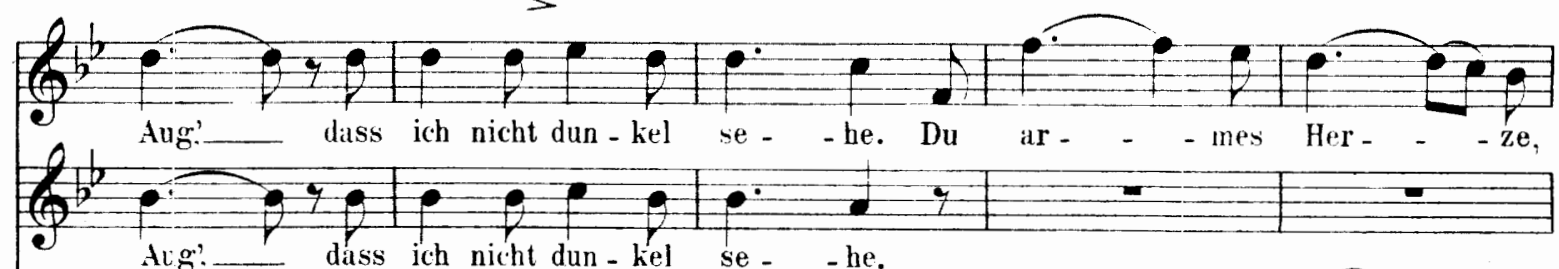

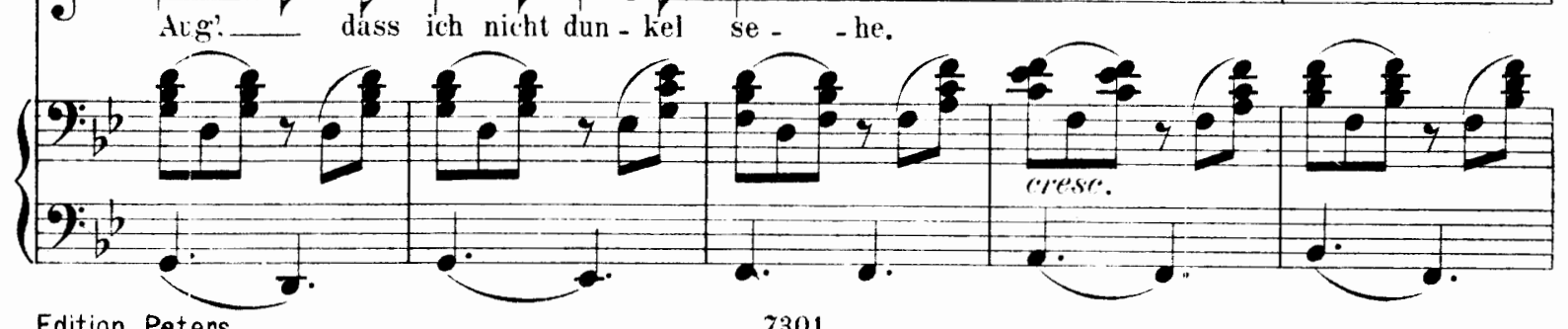
Edition Peters. 


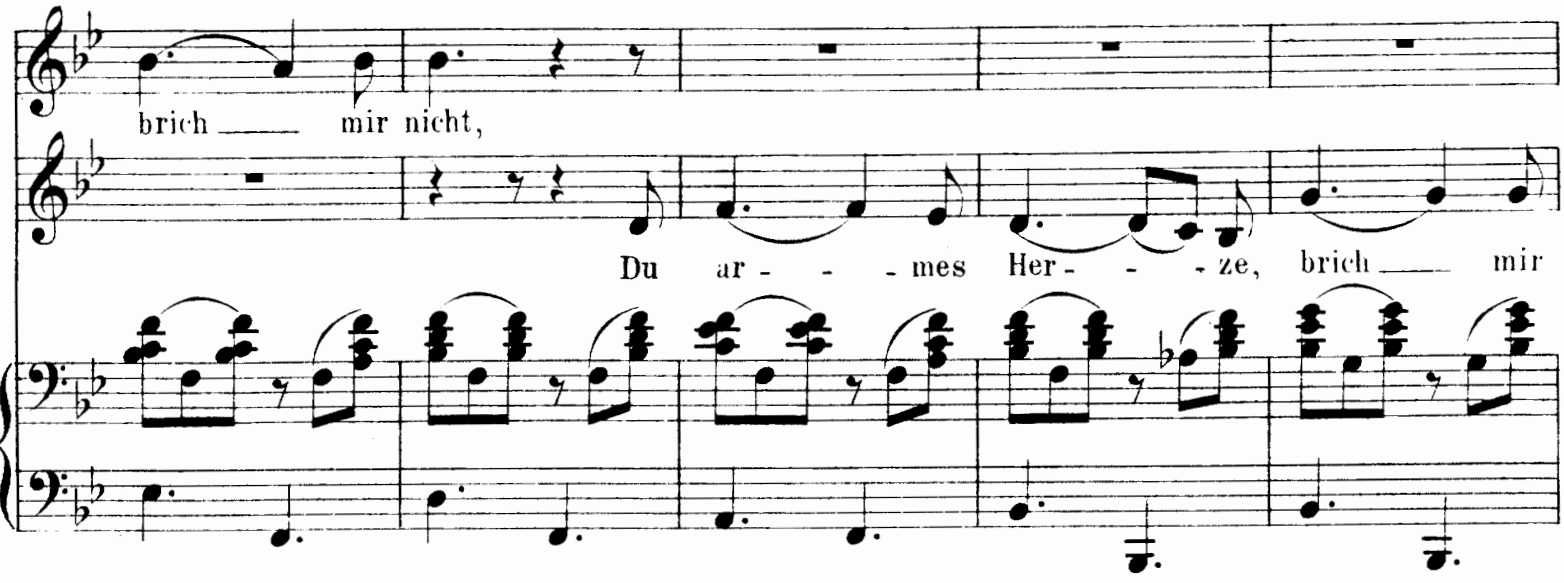

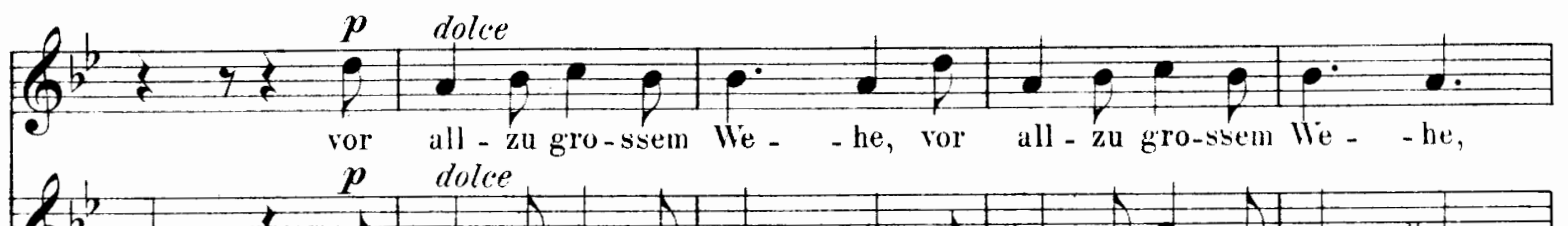
$\left(e^{b^{2}}+2\right.$

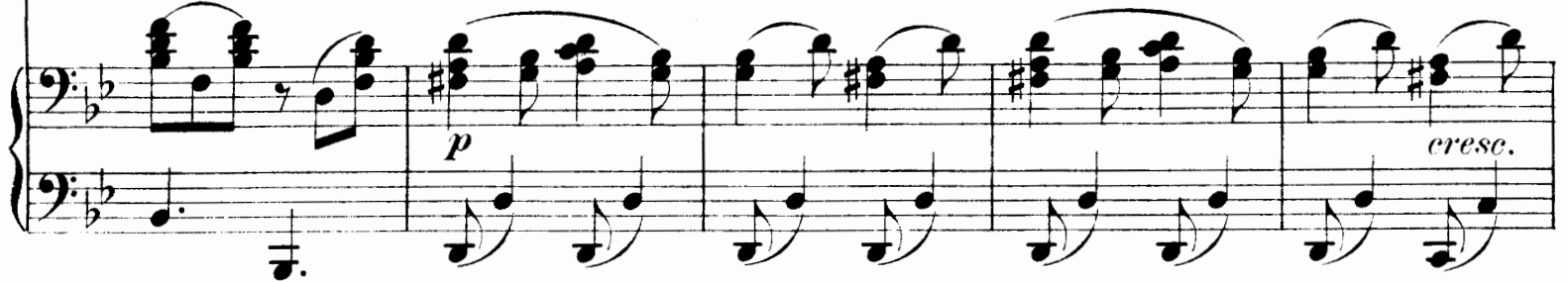

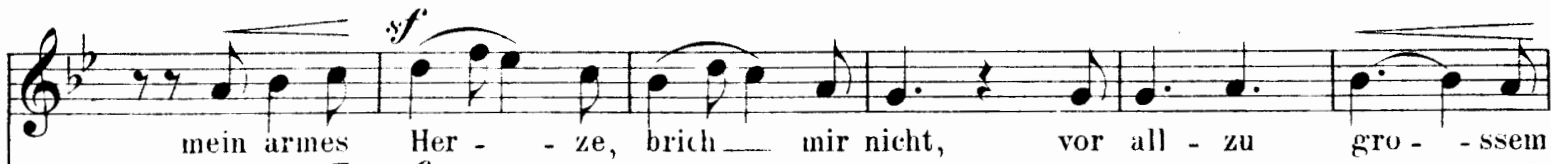

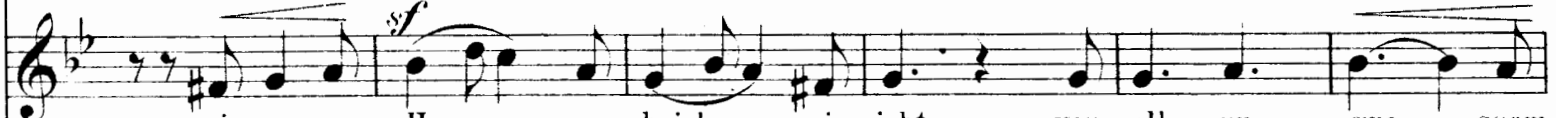
mein armes Her - - ze, brich__ mir nicht, vor all - zu gro- - ssem

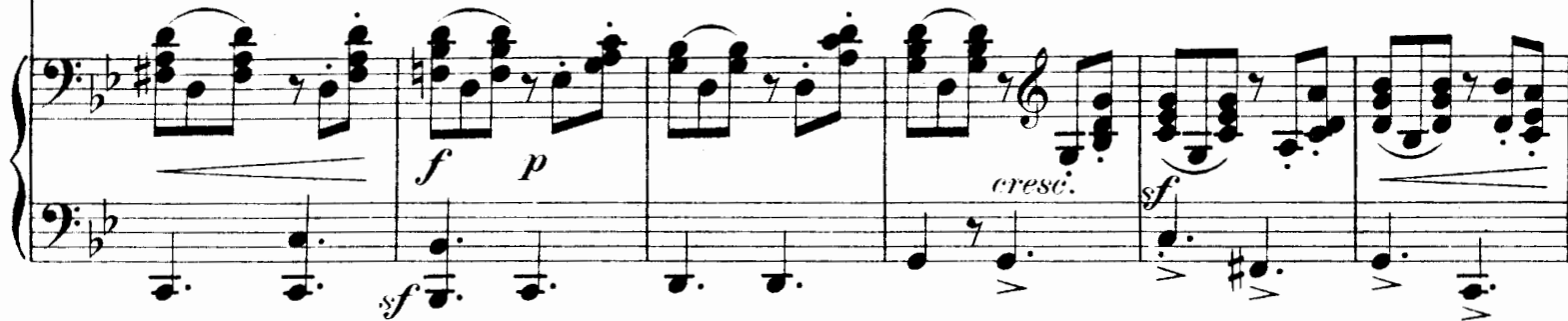

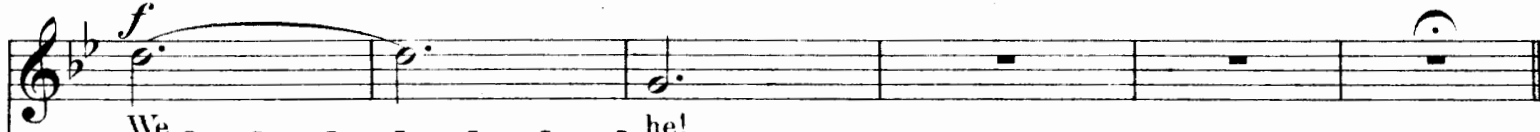

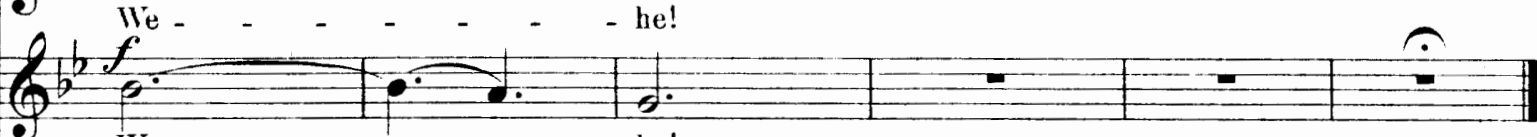

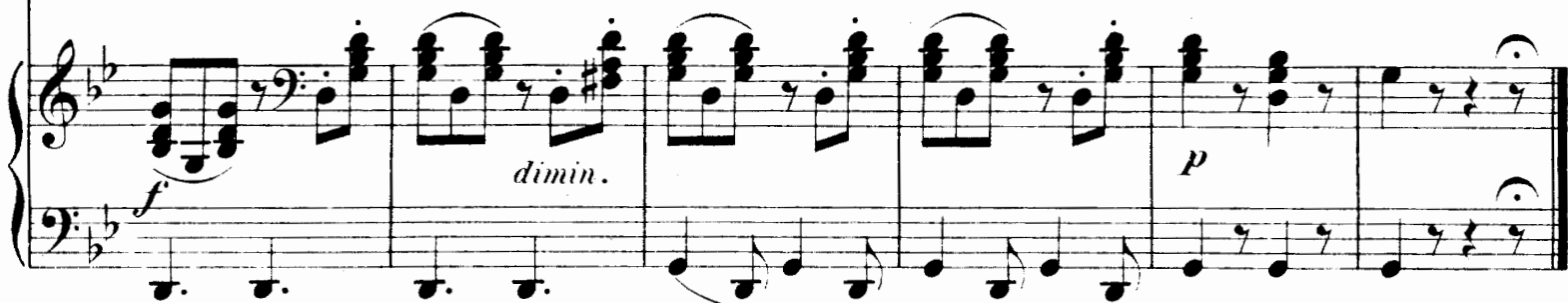
Edition Peters 


\section{Suleika und Hatem.}

Allegretto.

(Goethe.)

Suleika.

Componirt von Fanny Mendelssohn-Bartholdy, 0p.8 Nr.12.
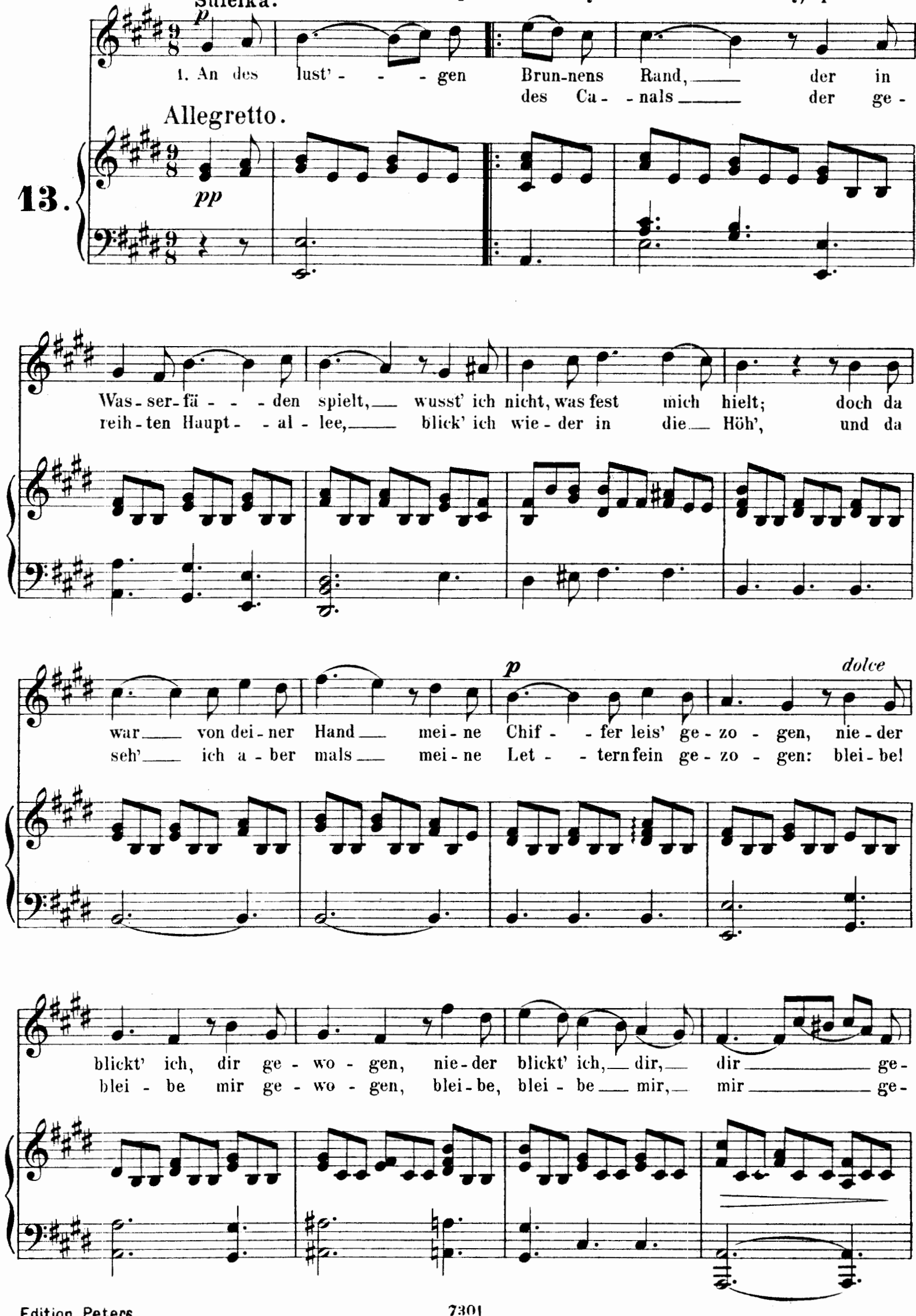


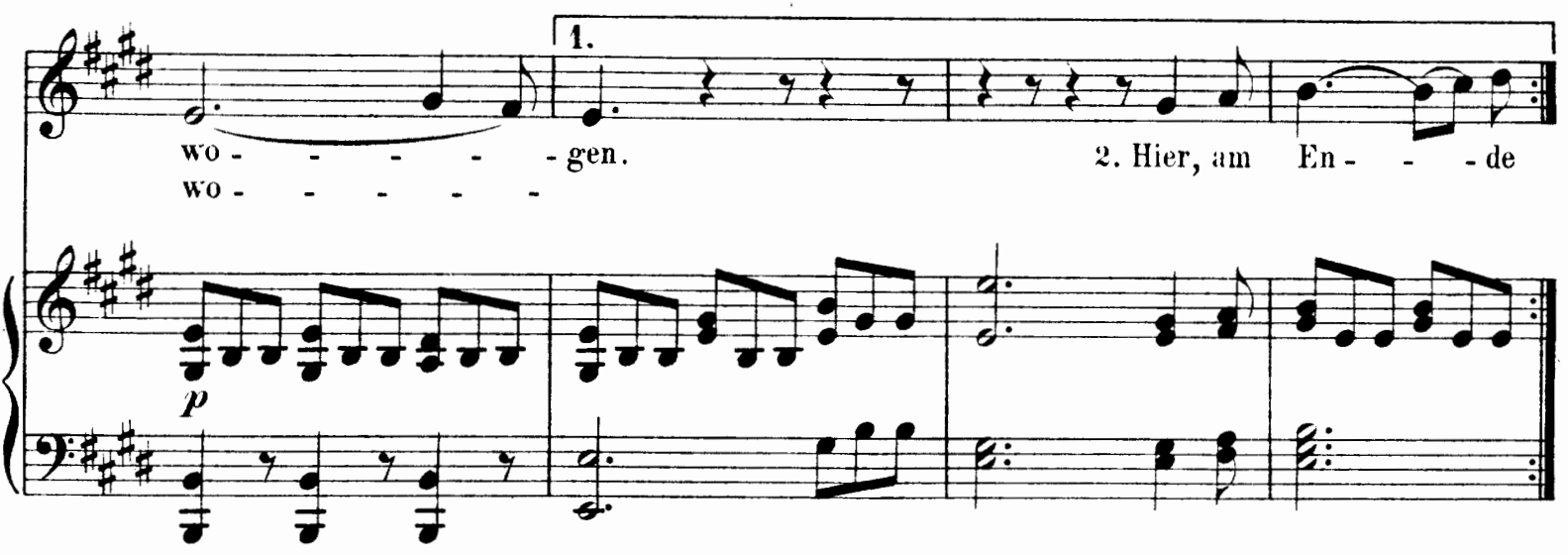

Più mosso.

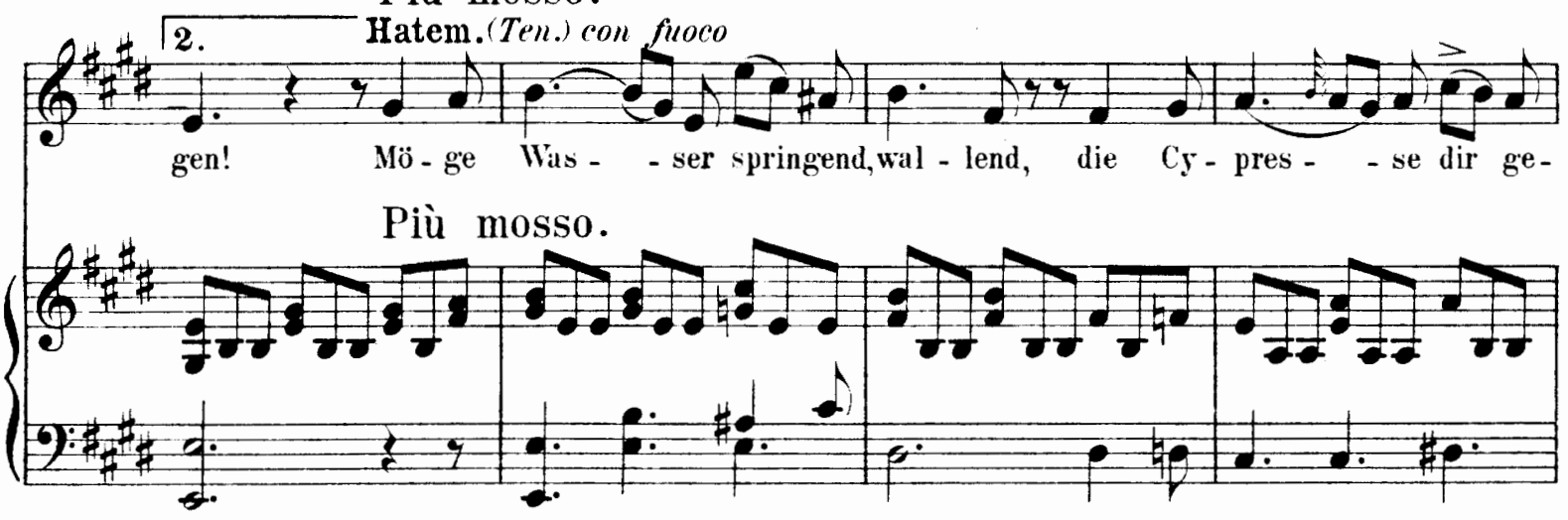
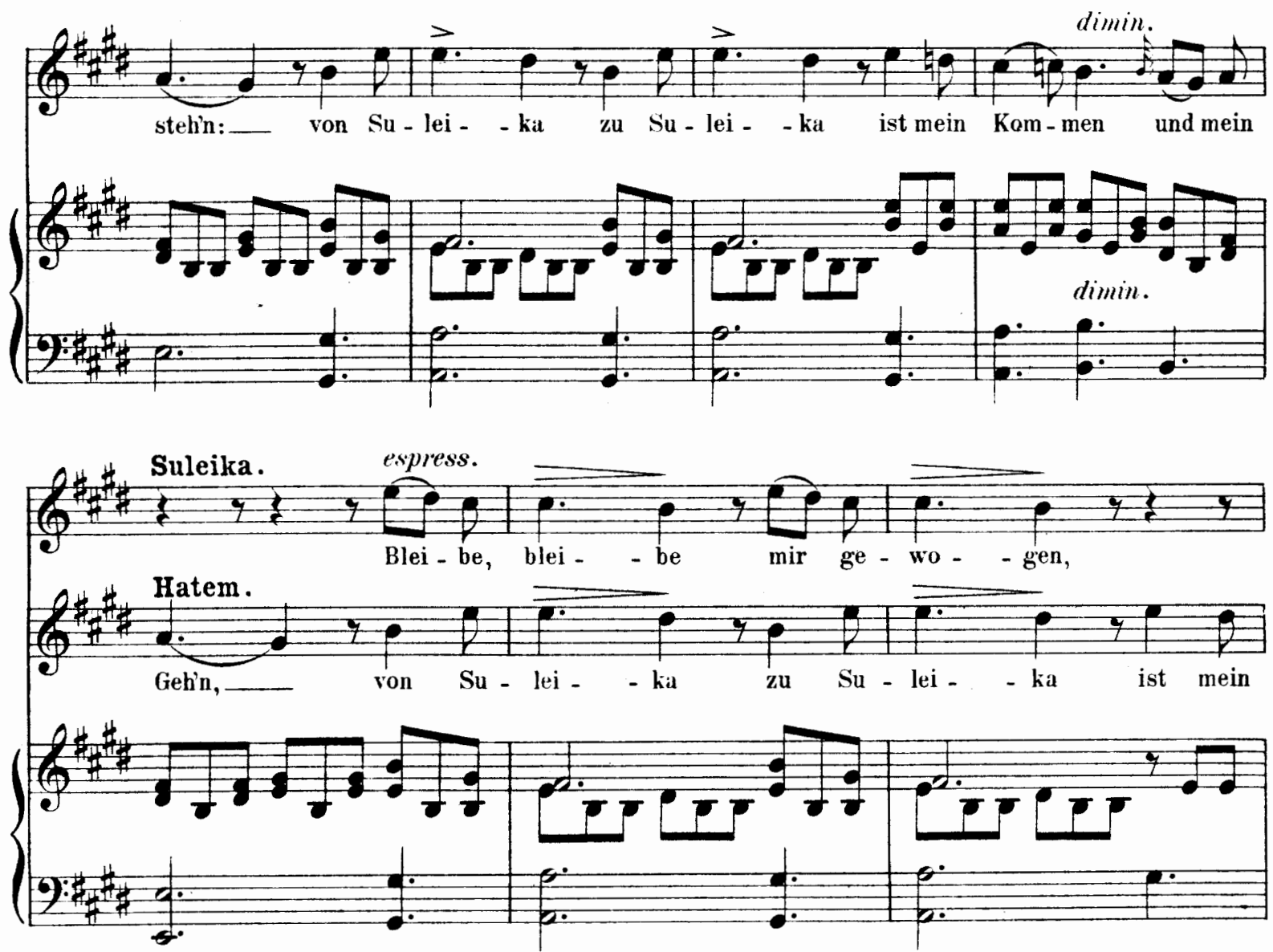


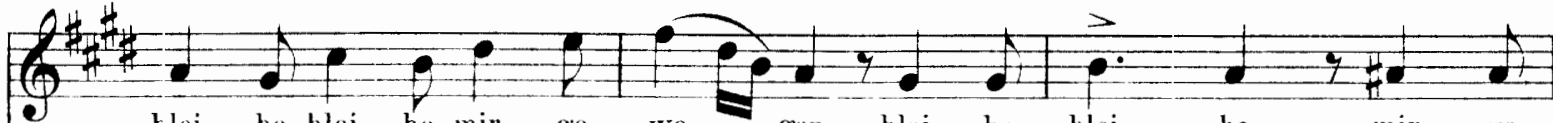
klei - be, blei - be mir ge - wo - - gen, blei - be, blei - - be mir ge -

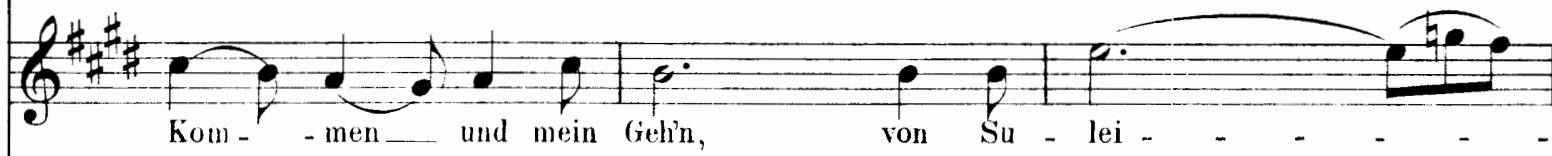

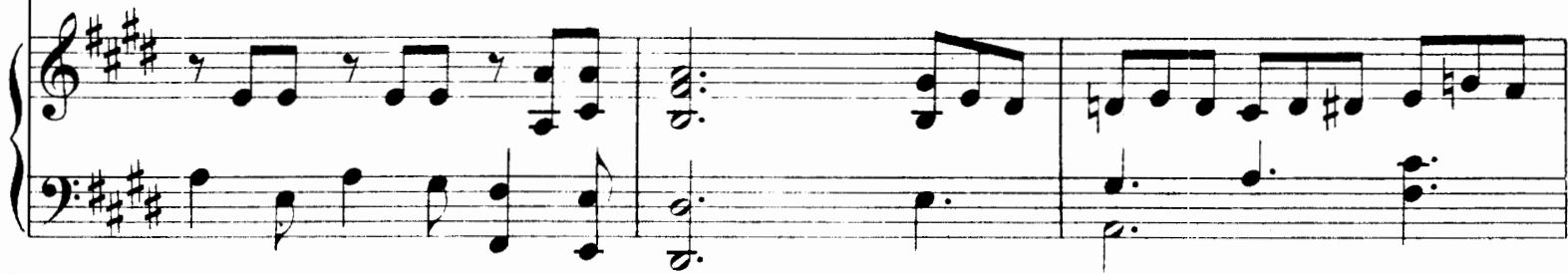

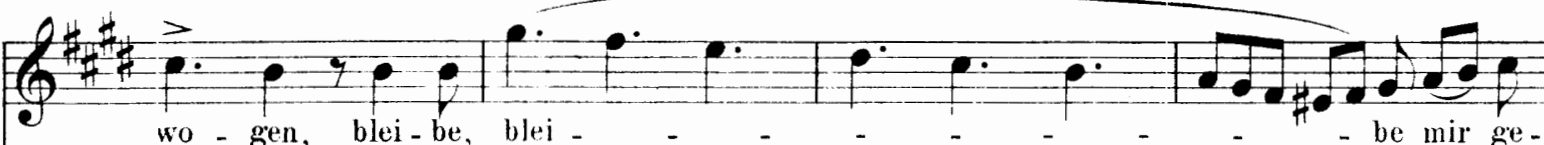
6 wo - gen, blei - be, blei -

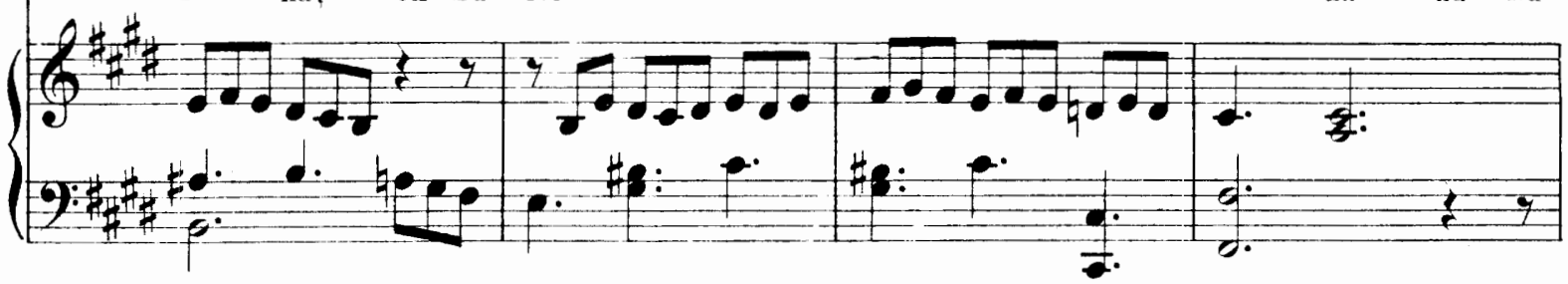

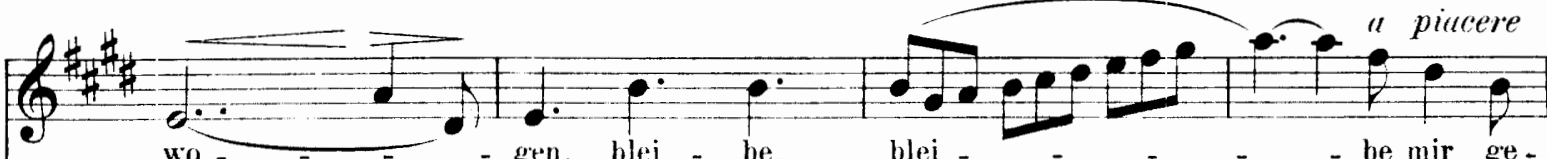
wo - - gen, blei - be, blei - - - - - be mir ge

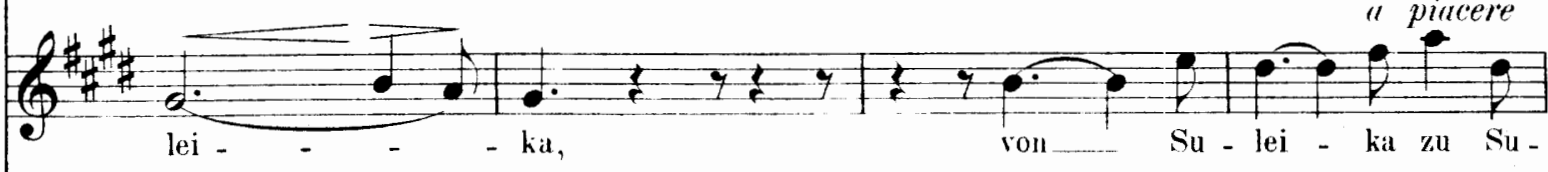

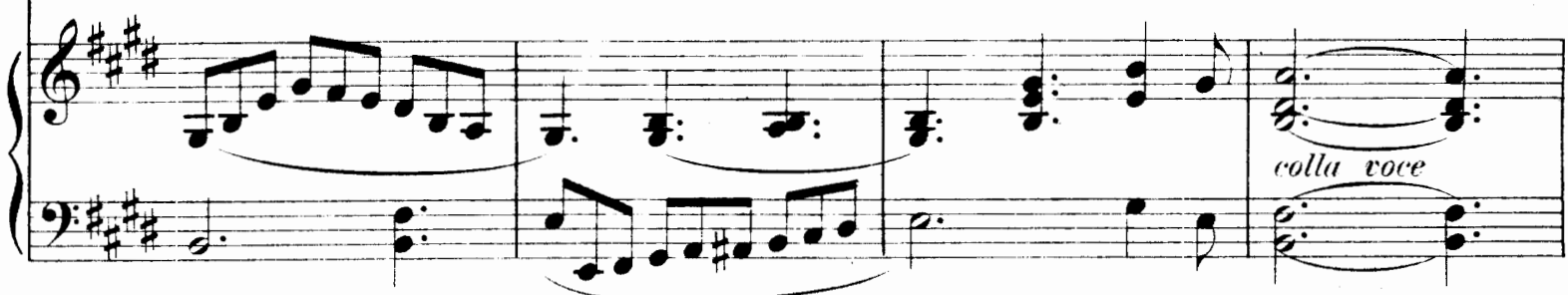

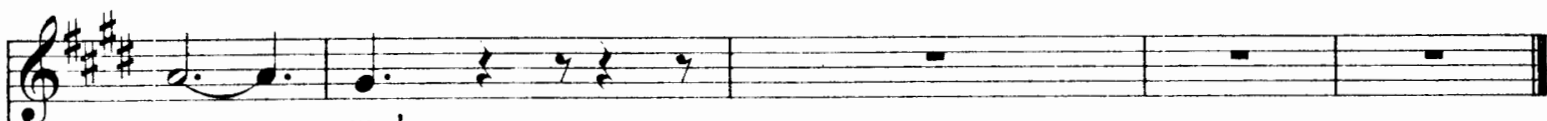

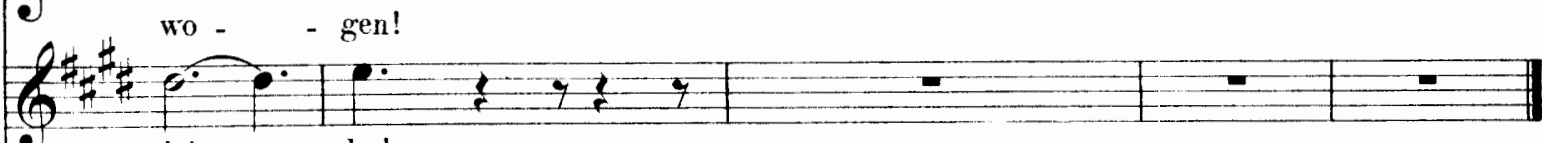

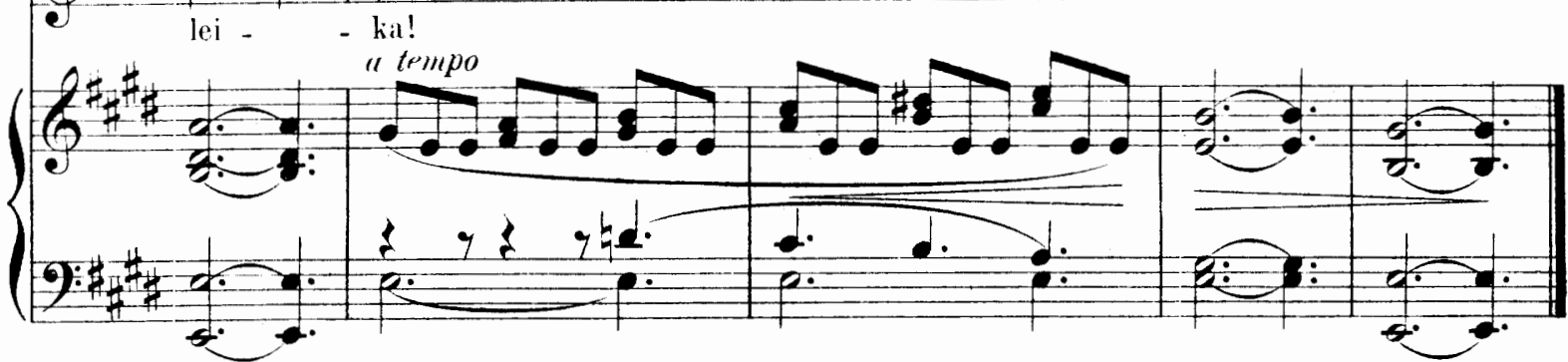




\section{Aus Psalm 95.}

Con moto. $d=\mathbf{7 6}$.

Opus 46.

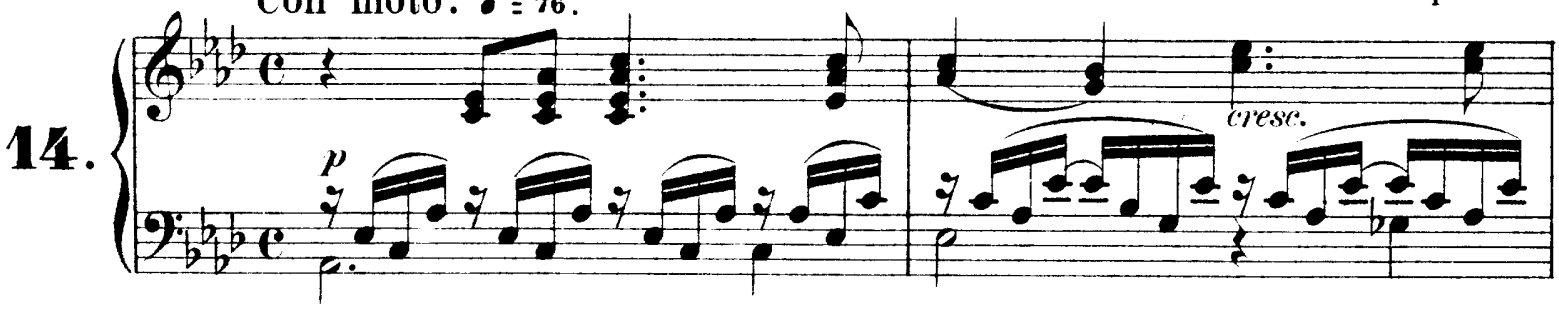
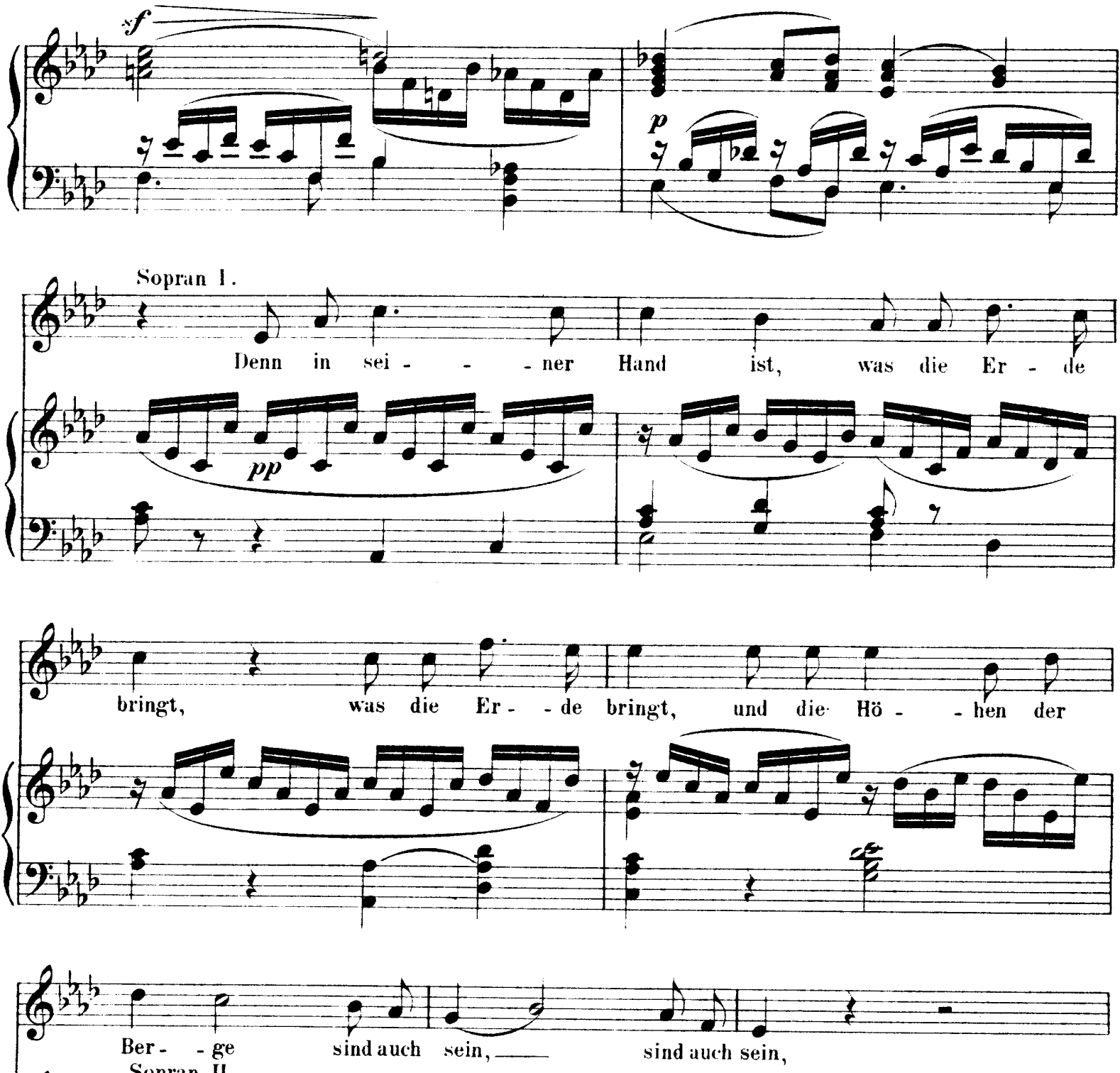

$G_{b} b$ Sopran II.

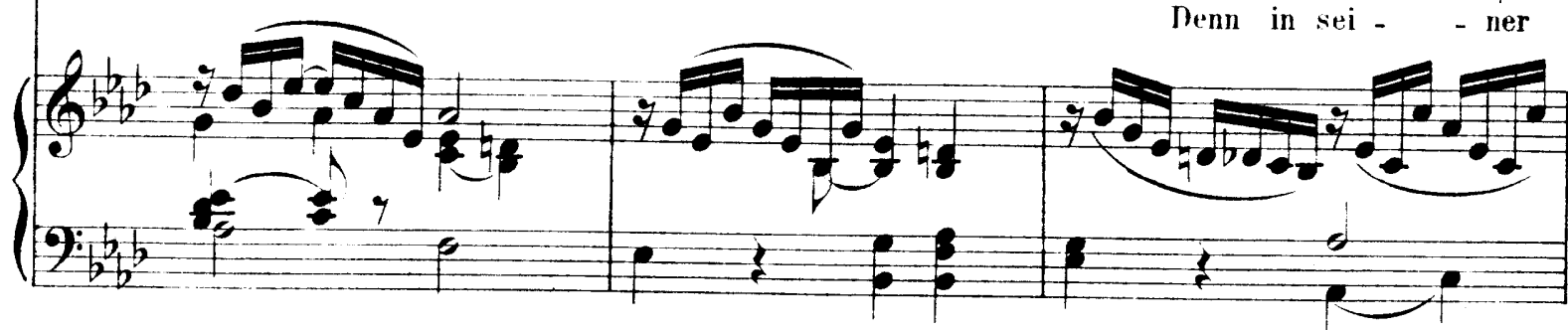



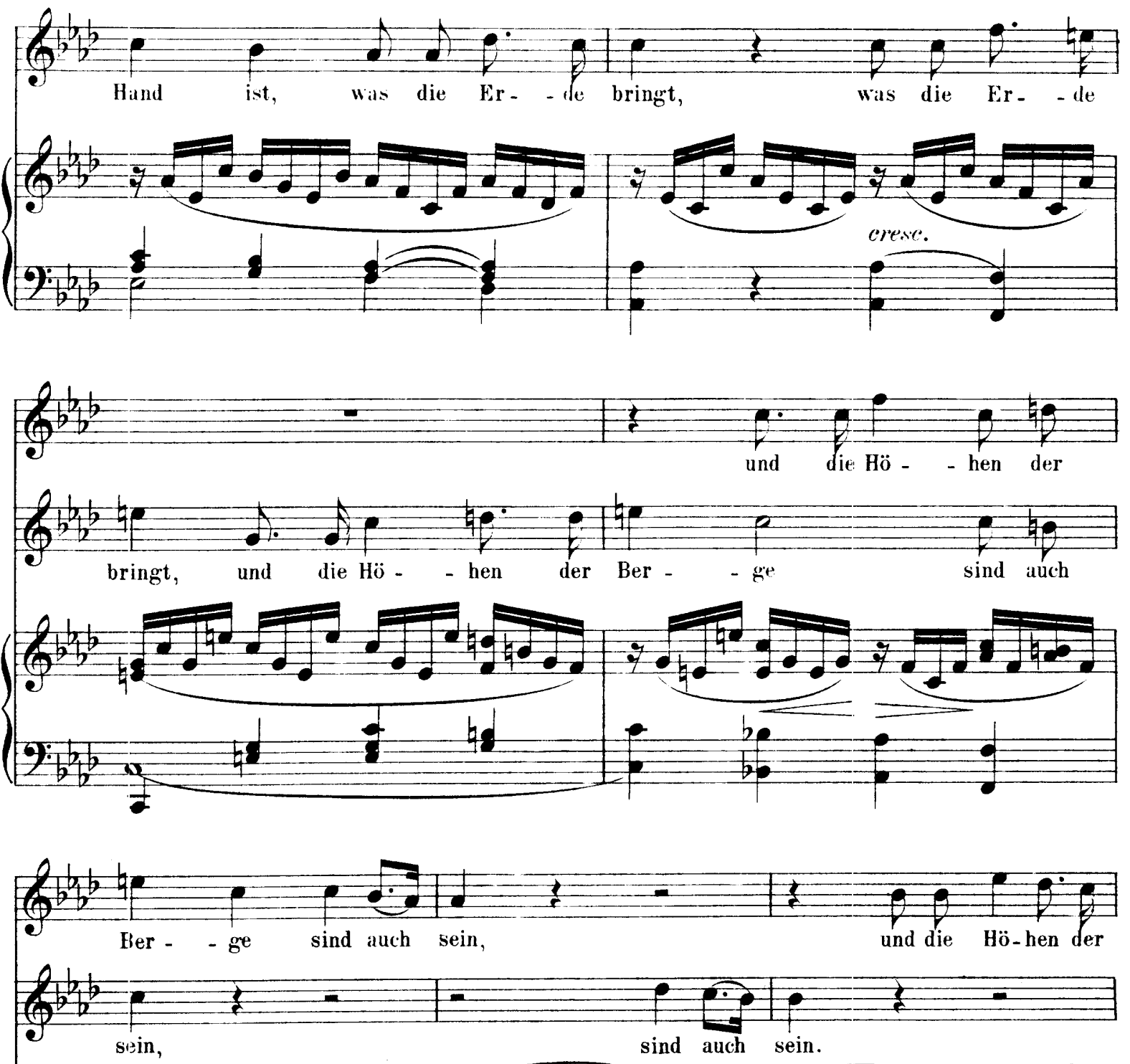

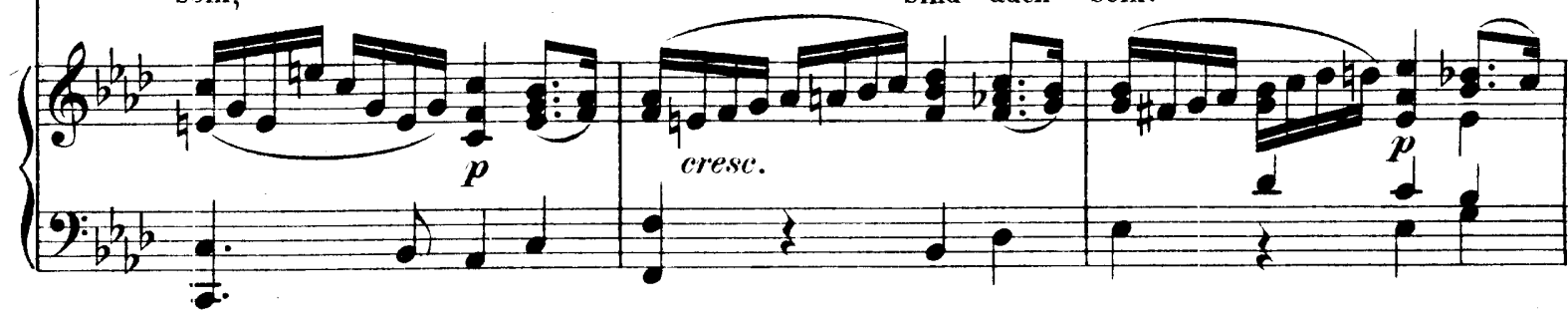

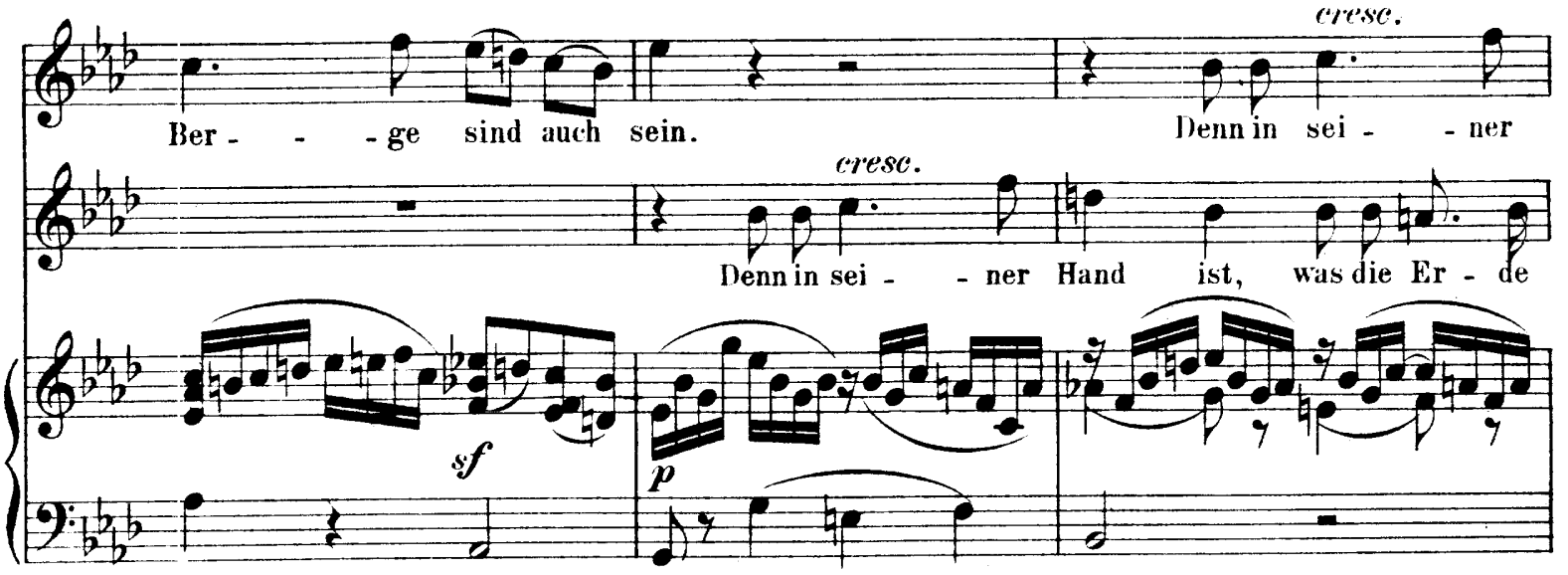



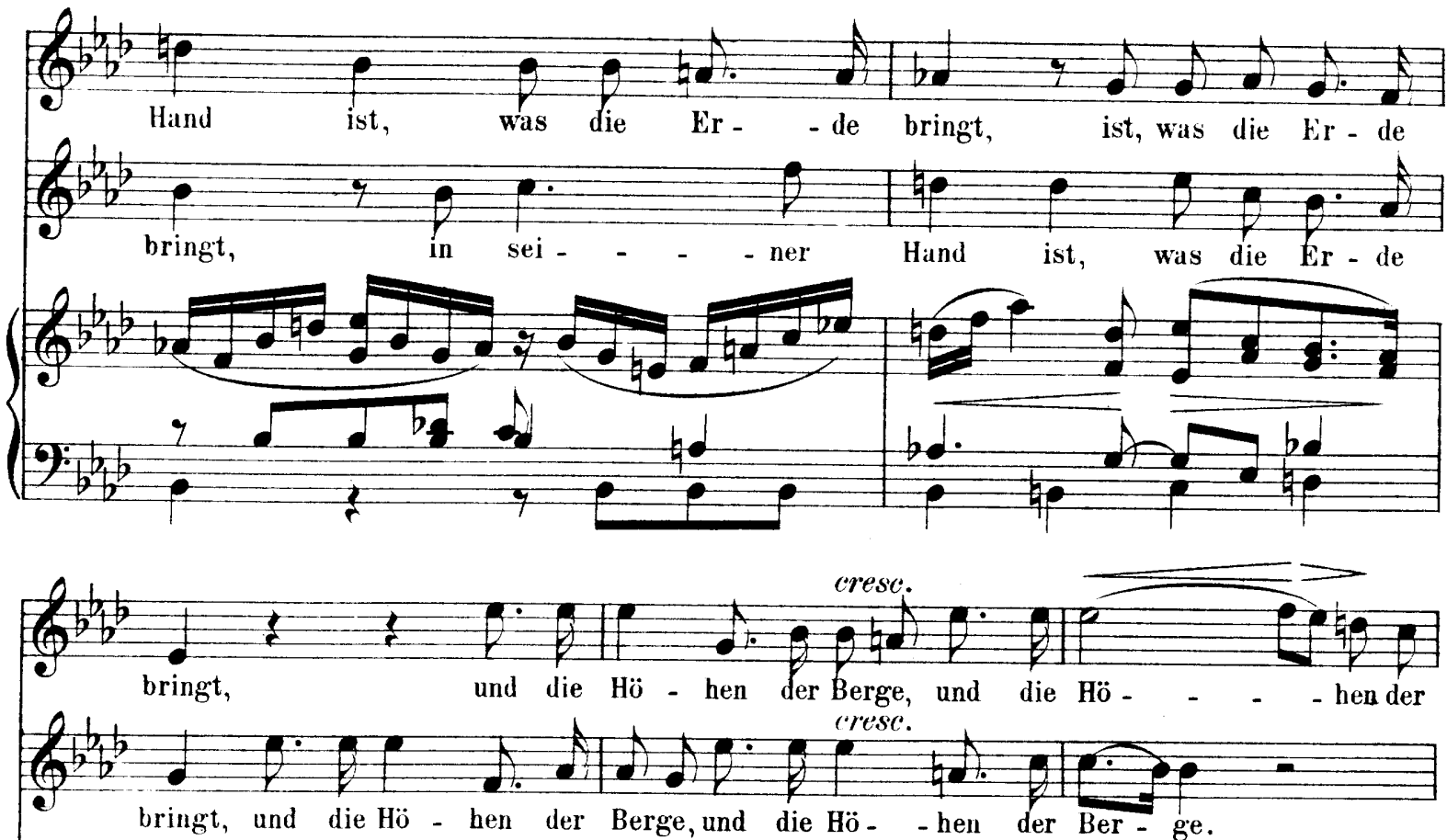

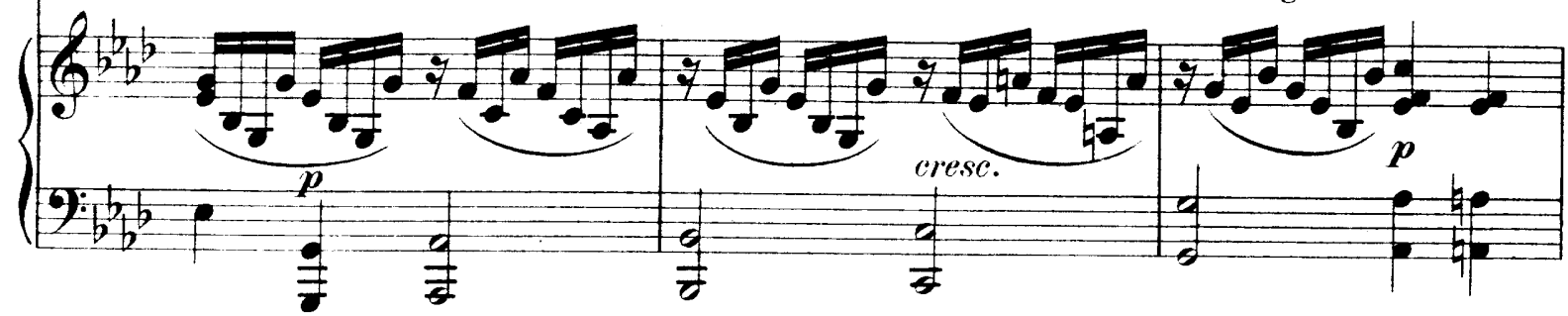

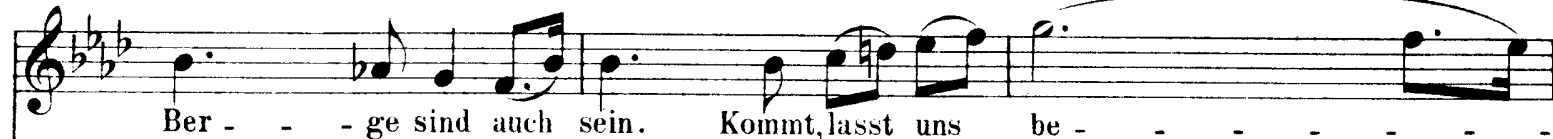

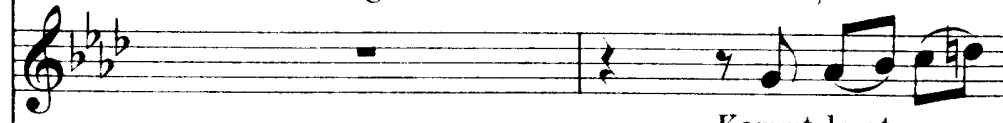

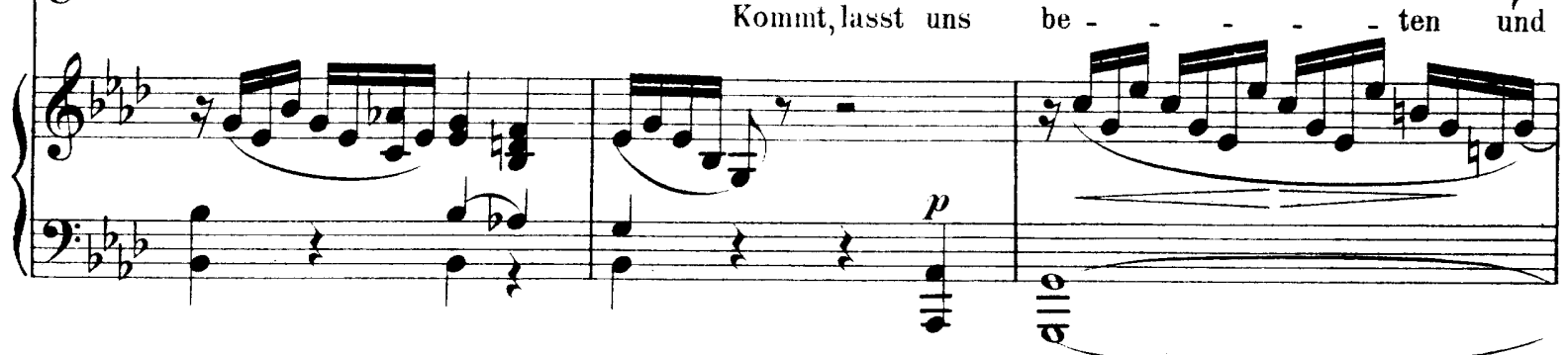

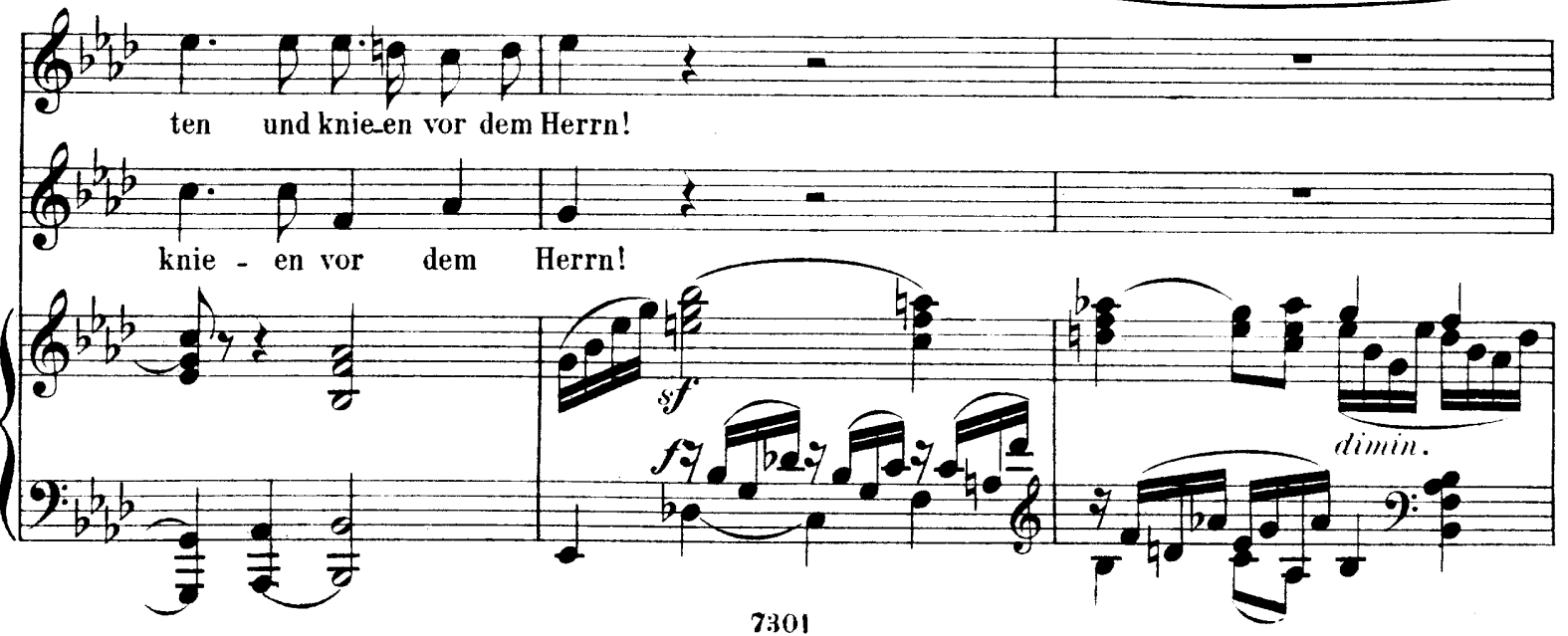



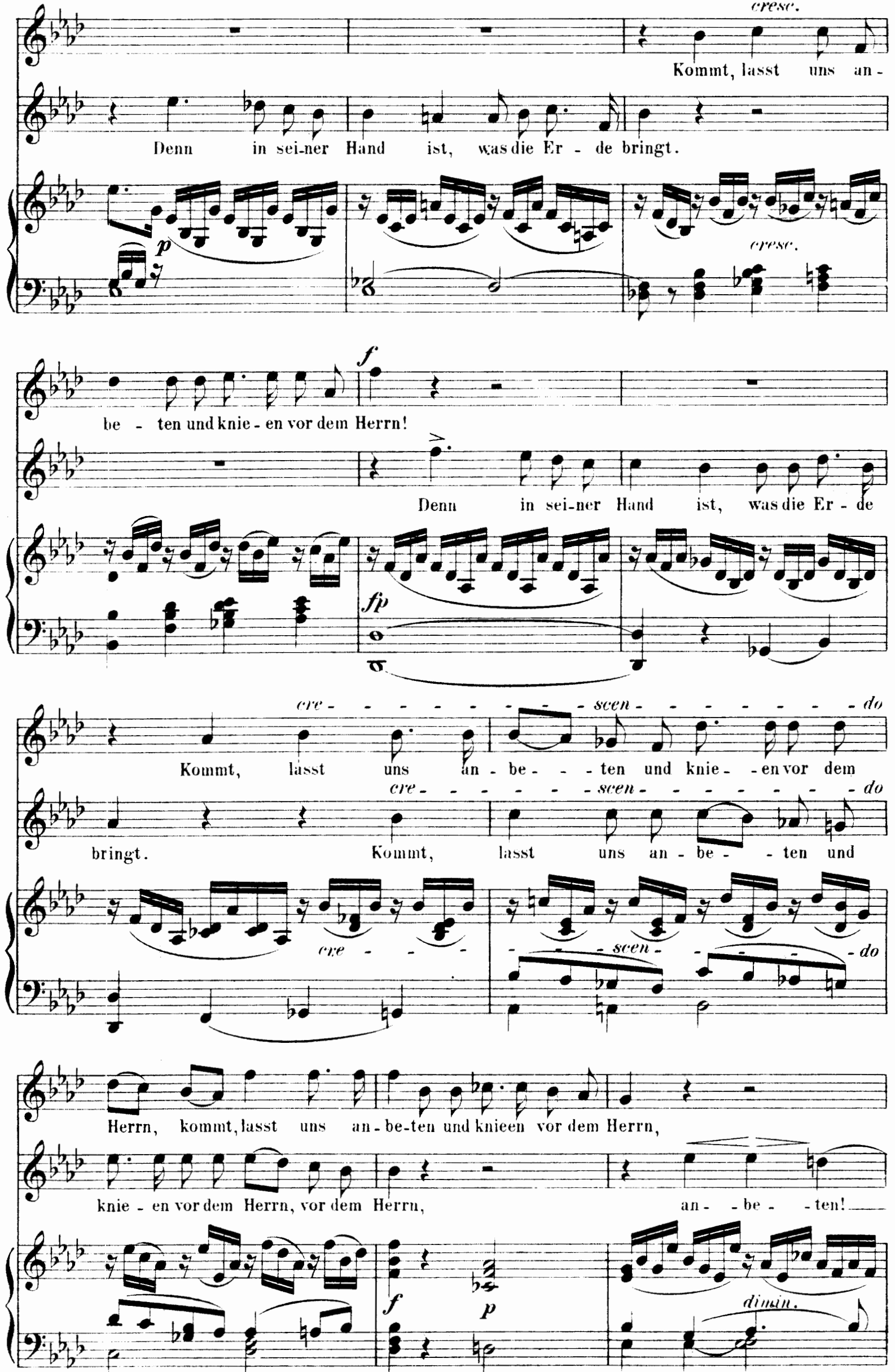
and knie-en vor dem Herrn! Denn in sei

(6) and knie-en vor dem Herrn! Denn in sei

$\left(2+\frac{b}{2}+1=\right.$

+

- ner Hand int, was die Er-de

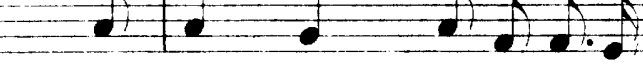

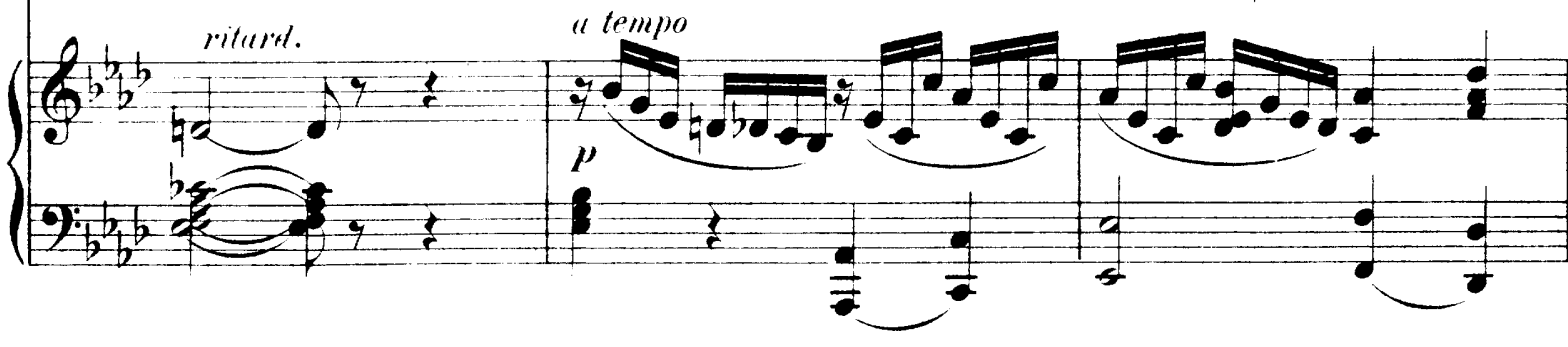
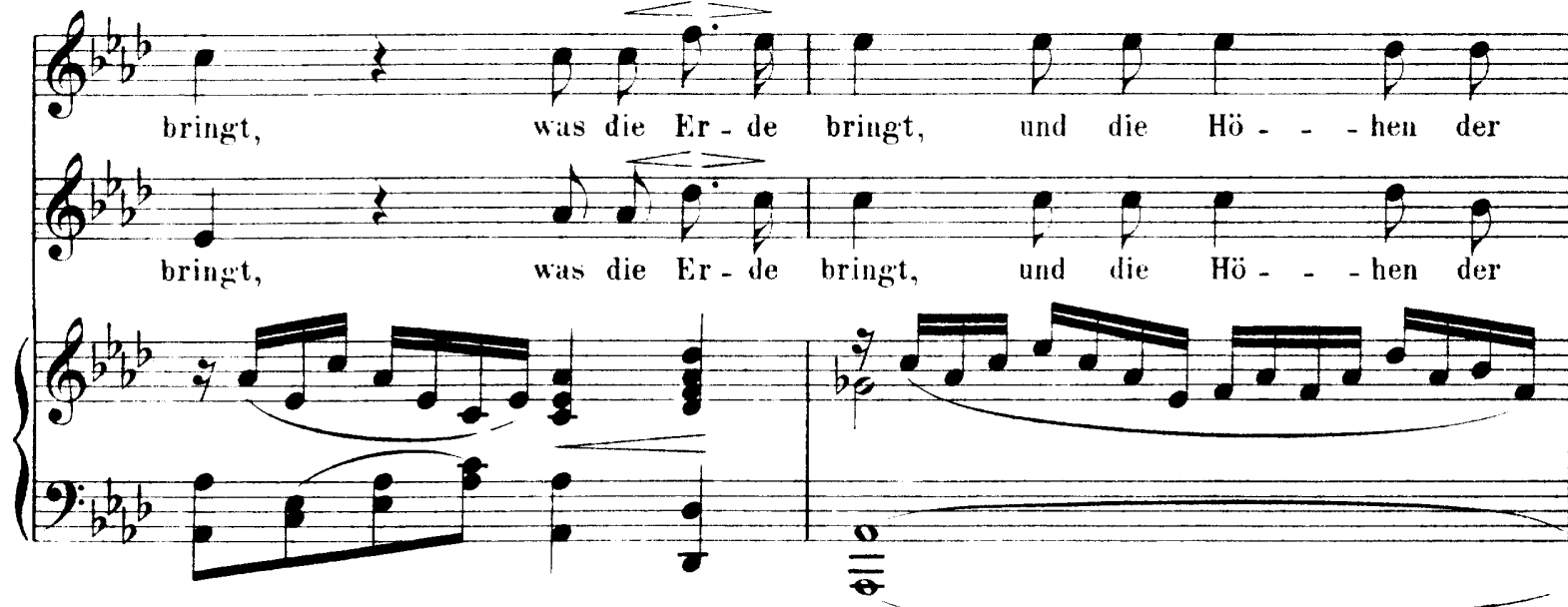

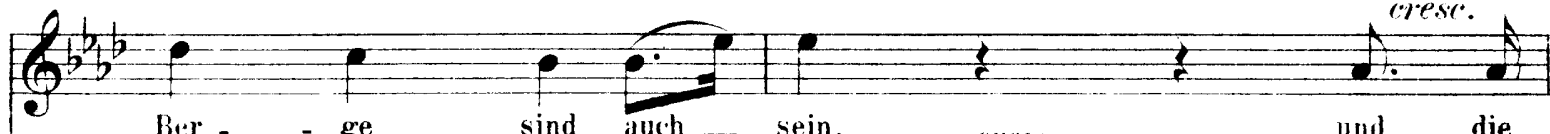

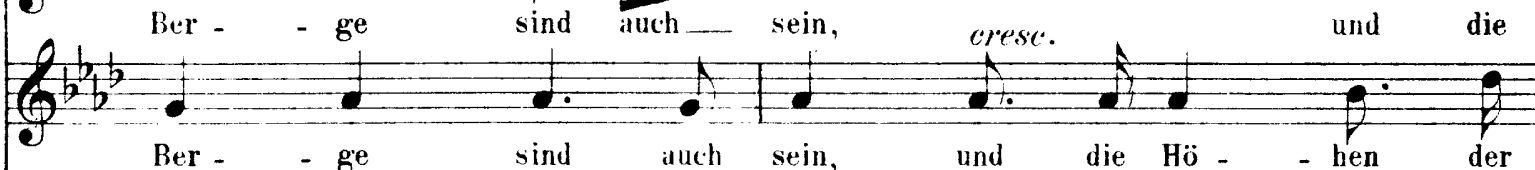

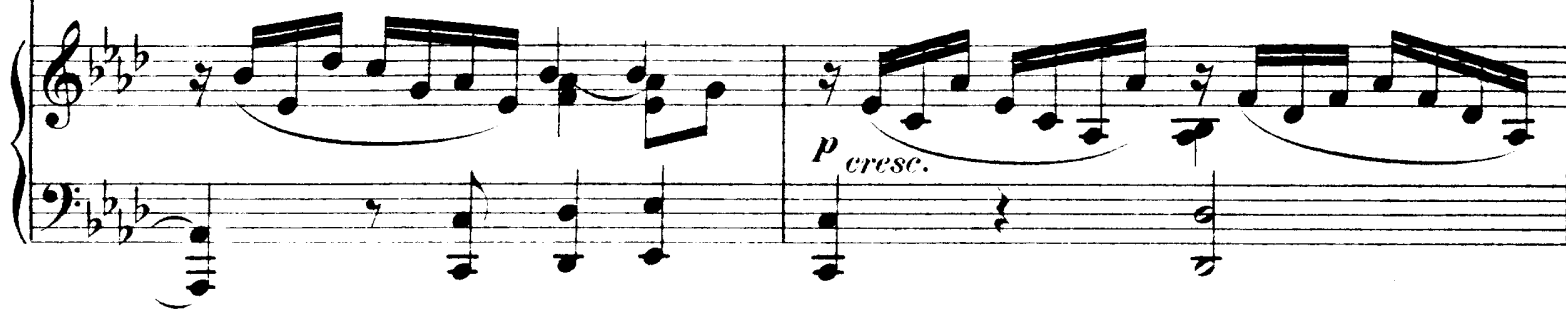

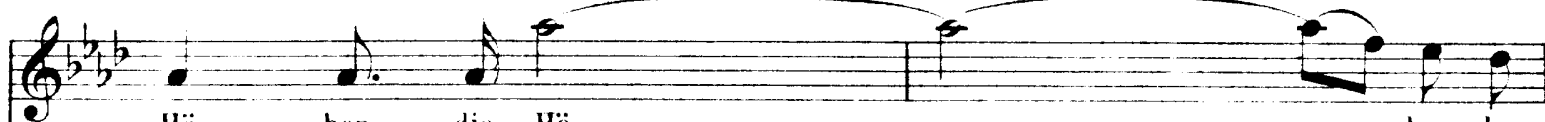

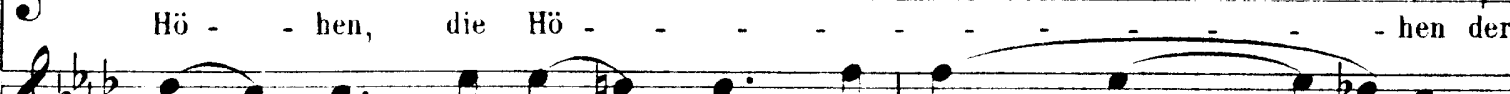

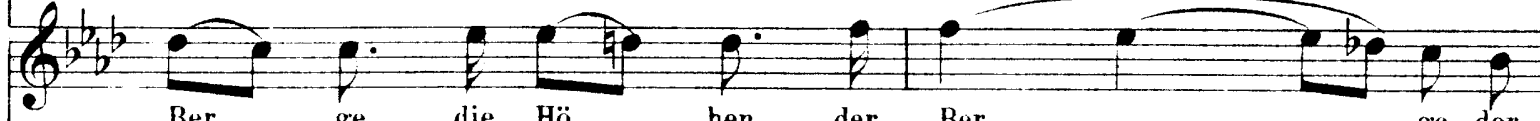

Eaition Peters 
$\left(e^{b} b_{\text {Ber - - ge sind auch }}^{b}\right.$

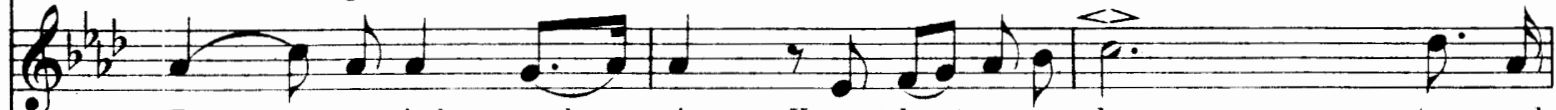
S

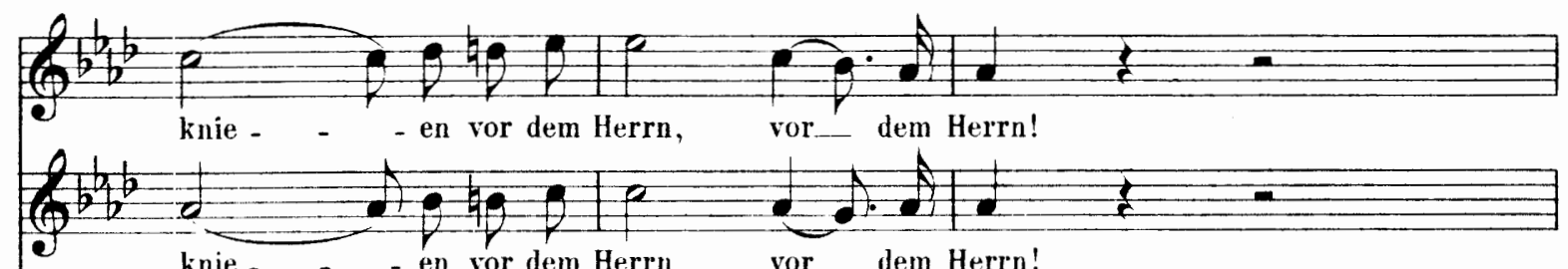
(9) knie - - - en vor dem Herrn,

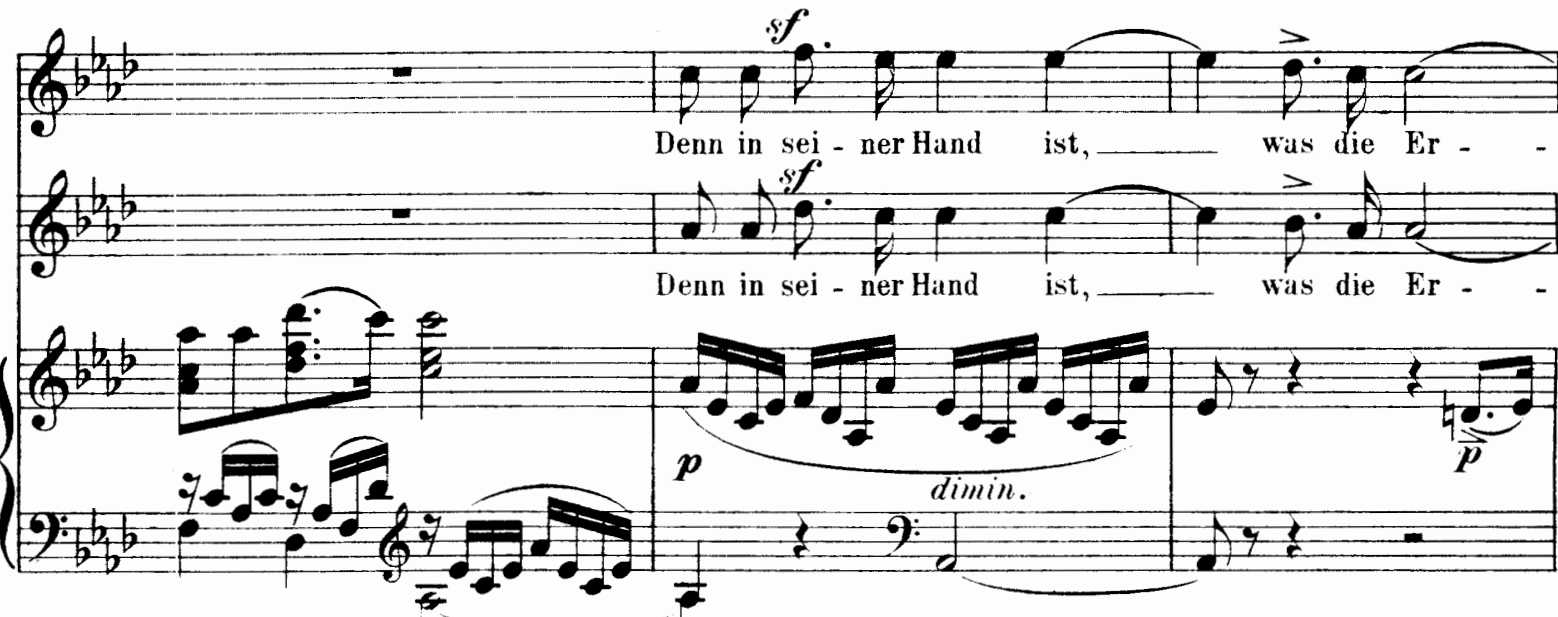

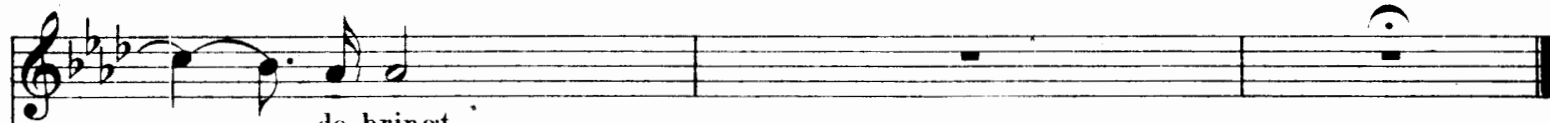
$Q_{b} b^{-}-{ }^{-}-$de bringt. $\biguplus^{b b}=2$ ती (a) 


\section{Aus dem , Lobgesang.“}
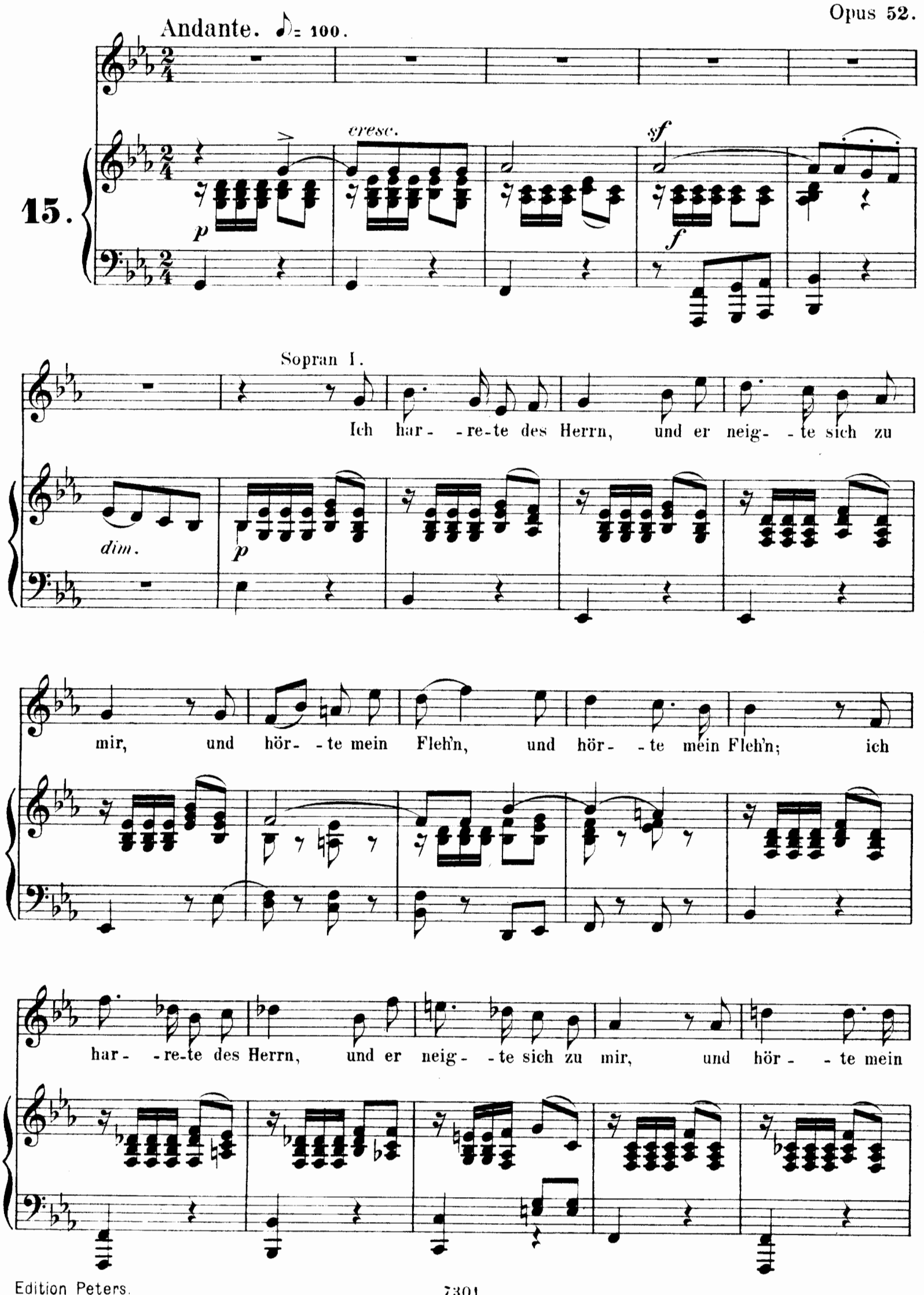


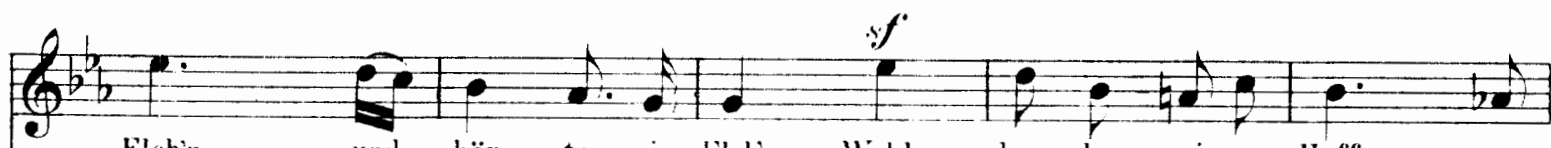
Fleh'n, und hör - te mein Flehin. Wohl dem, der sei - ne Hoff - - nung

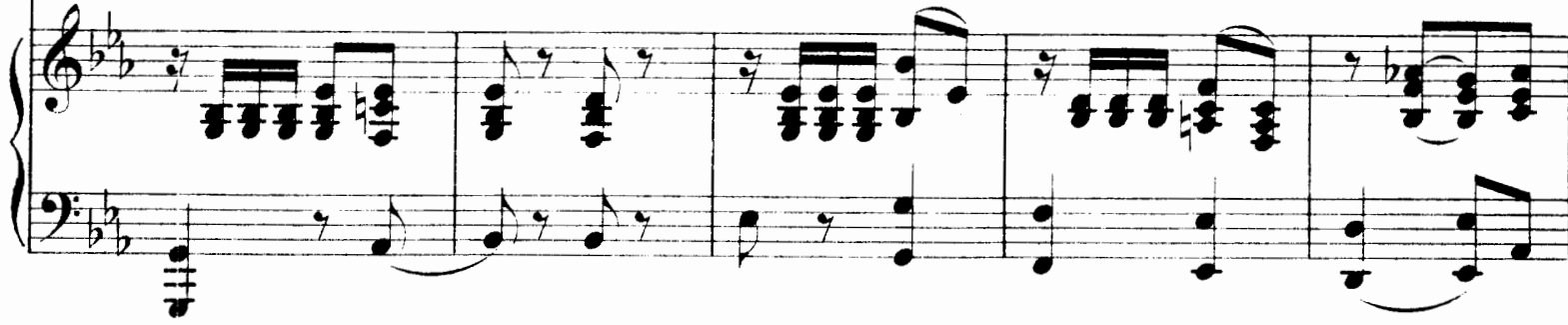

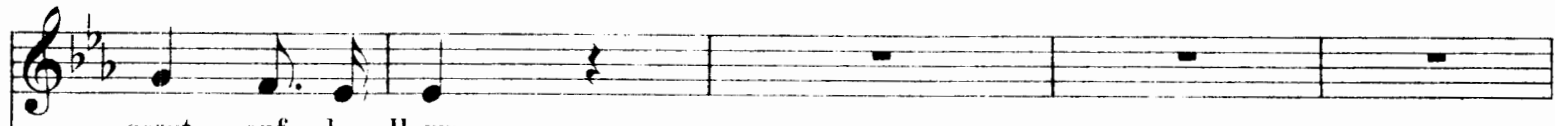
se:zt auf den Herrn.

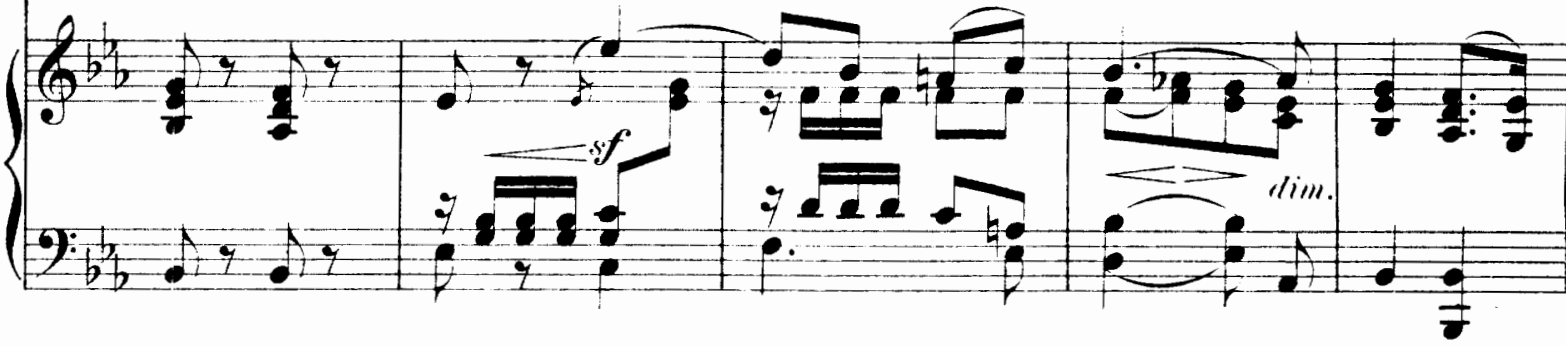

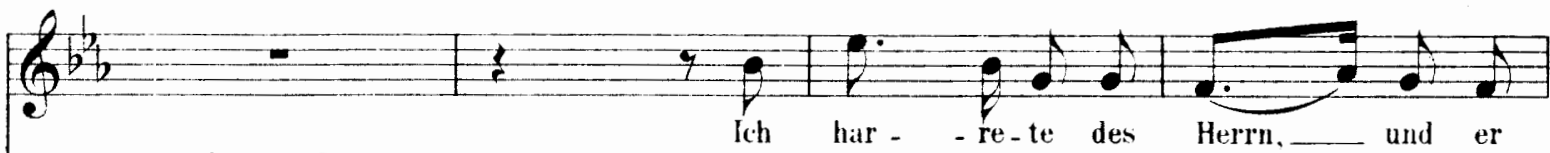

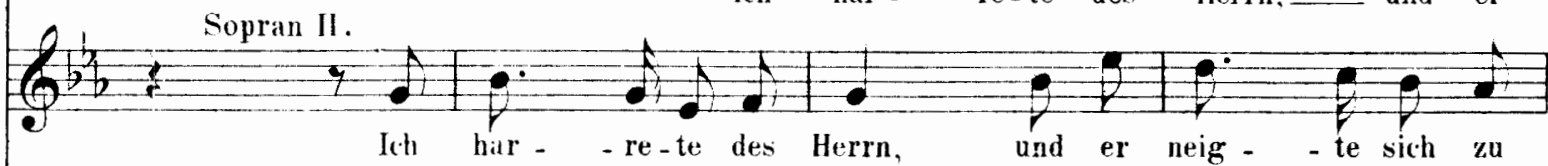

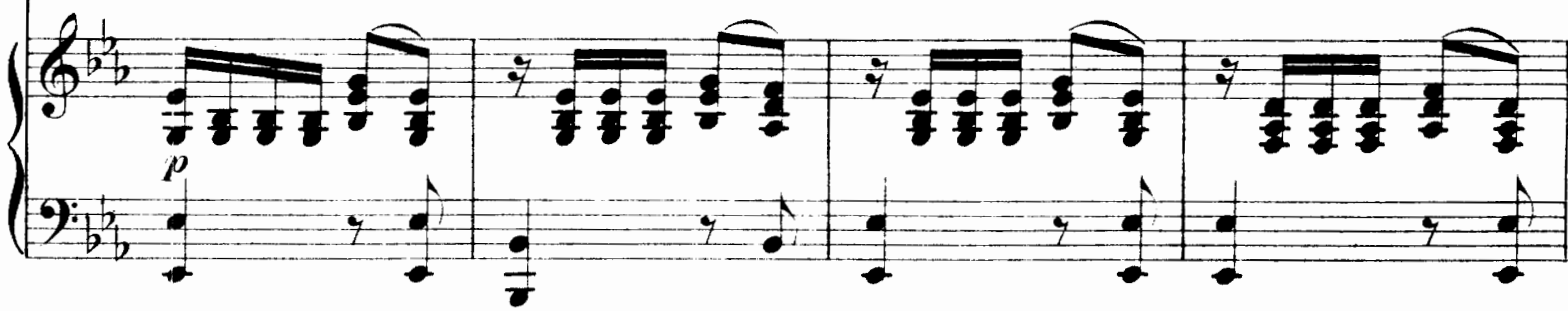

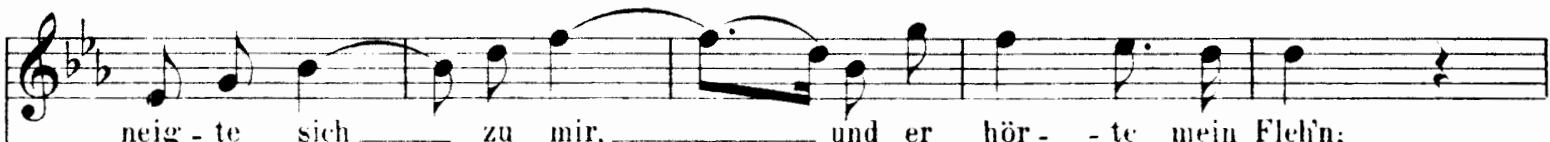

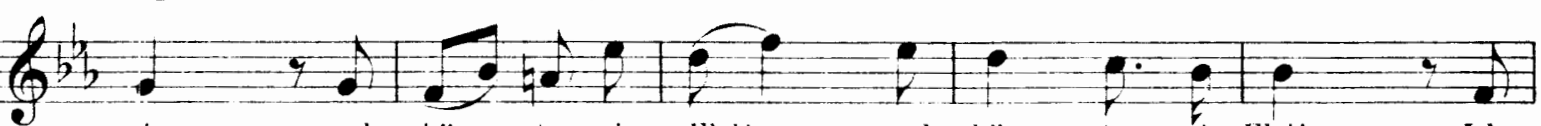
mir, und hör- - te mein Flebin, und hïr- - te mein Fletin. Ich

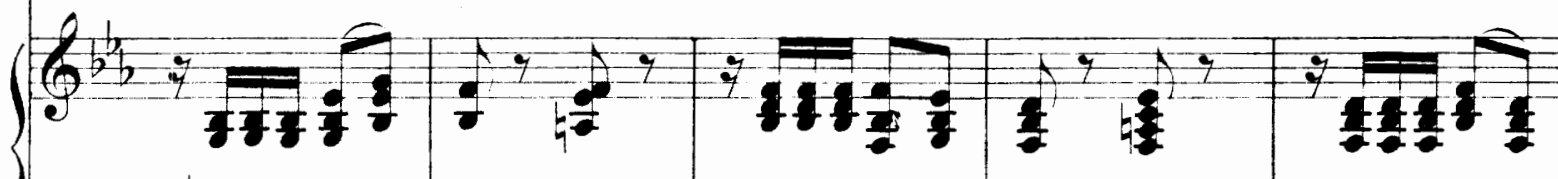

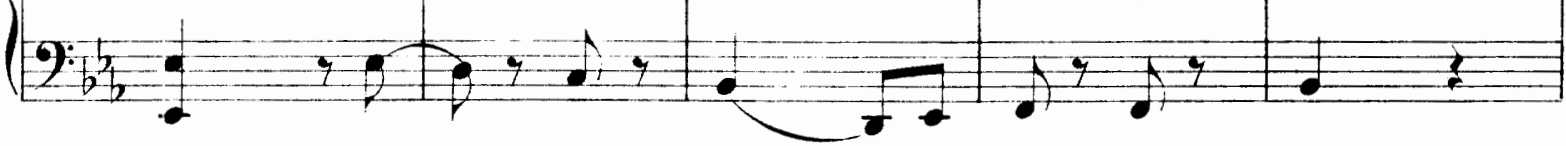
Edition Pejers 


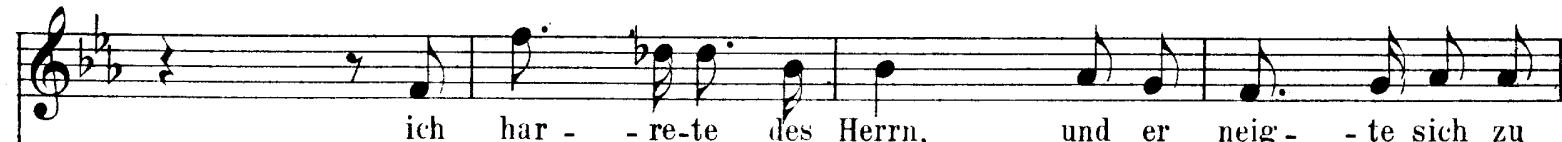
har - - re-te des Herrn,

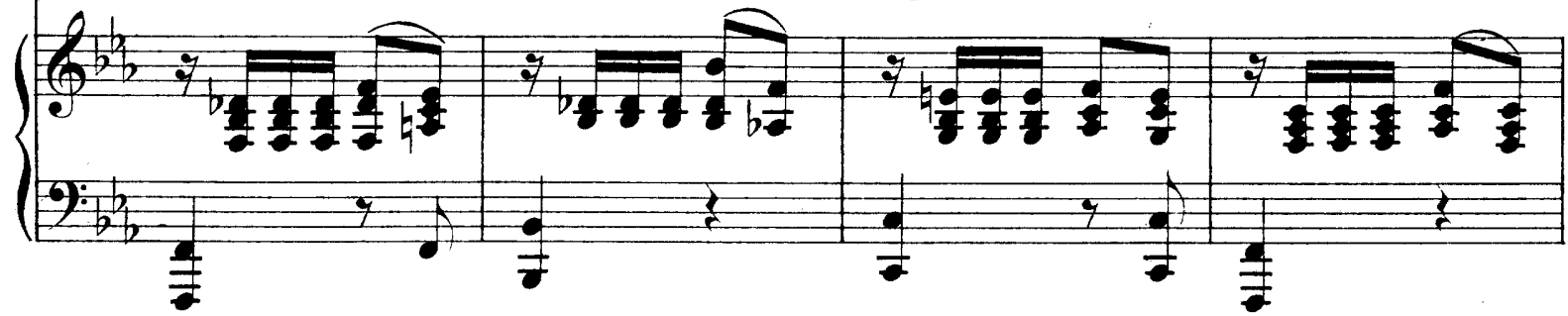

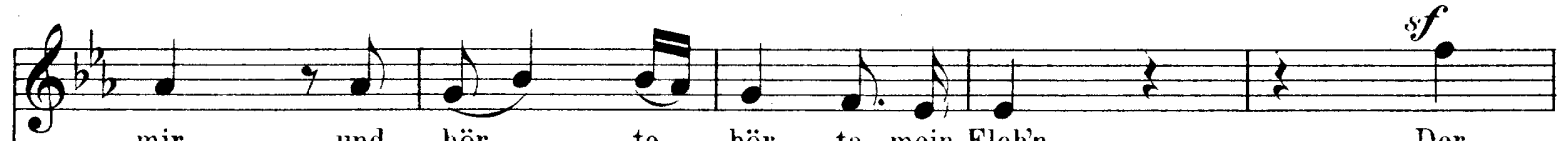
hör - - te mein Flehn,

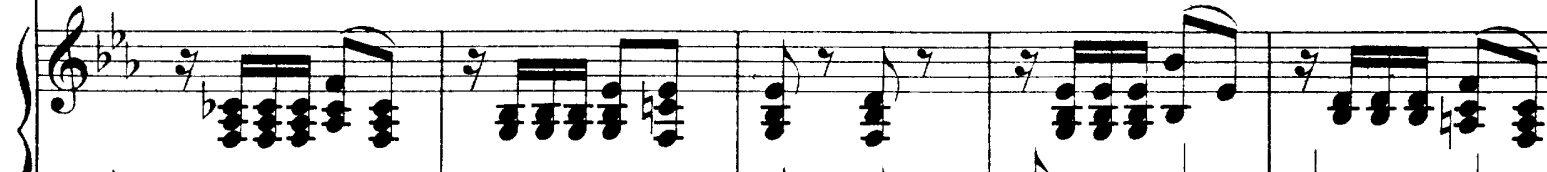

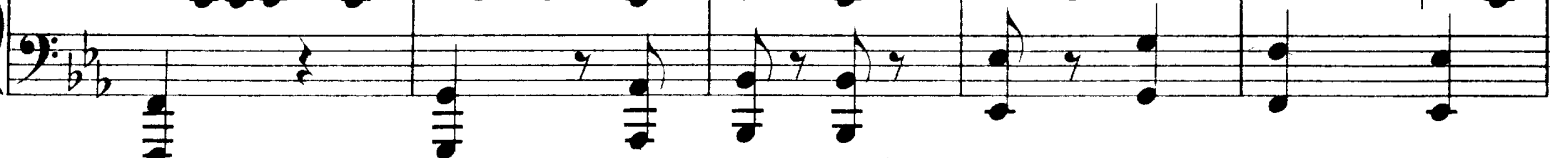

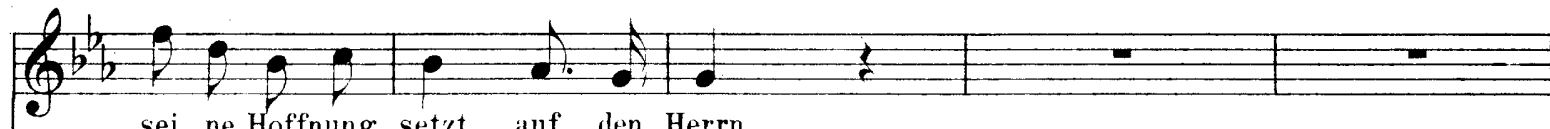
Q sei-ne Hoffnung setzt auf den Herrn,

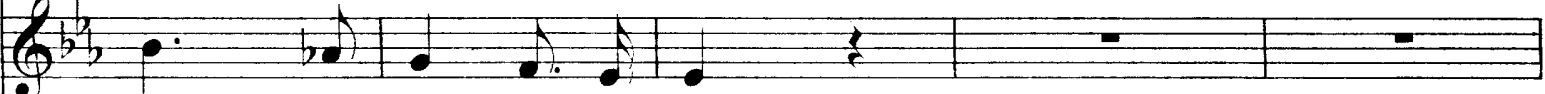

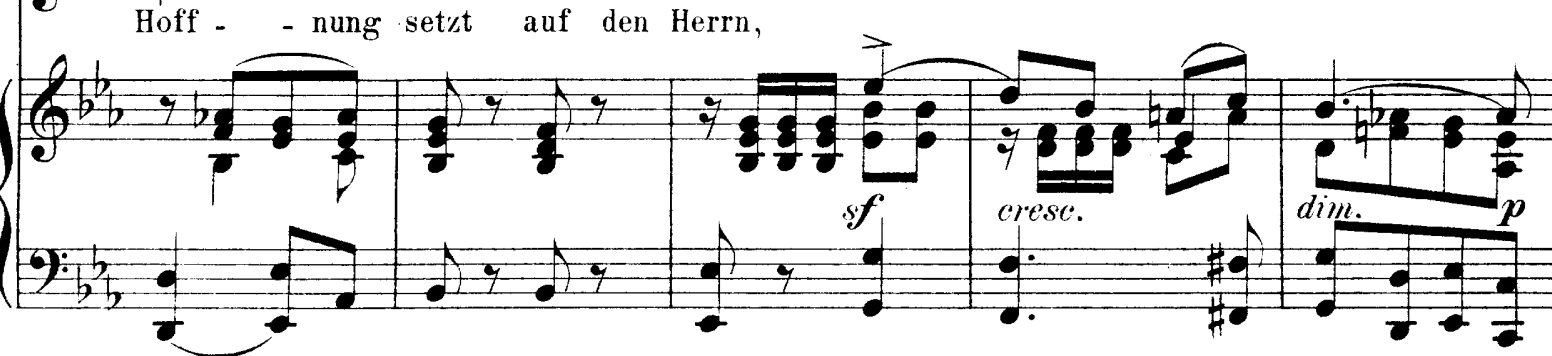
der ${ }_{\text {sei - ne }}^{2}$

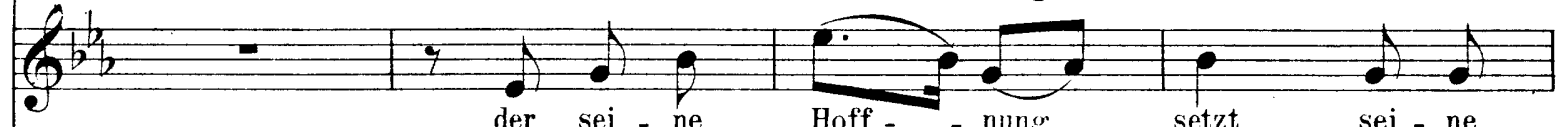
Edition Peters. 


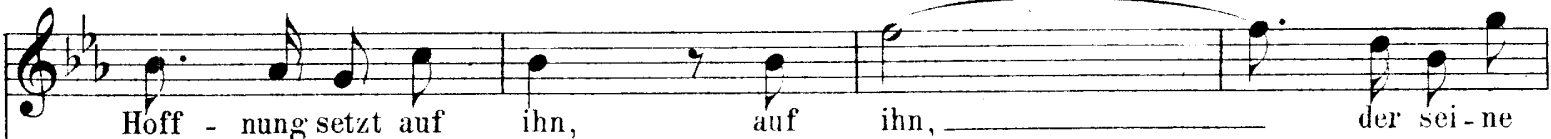

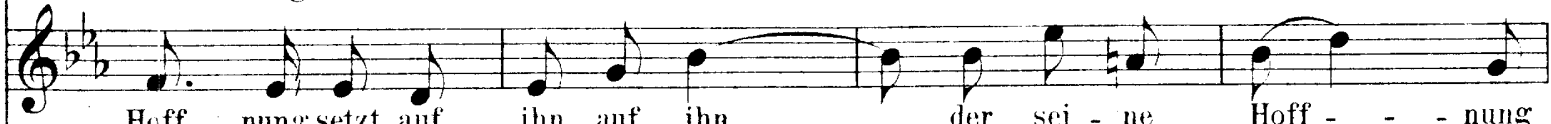
Heff - nungsetzt auf ihn, auf ihn,___ der sei - ne Hoff - - - nung

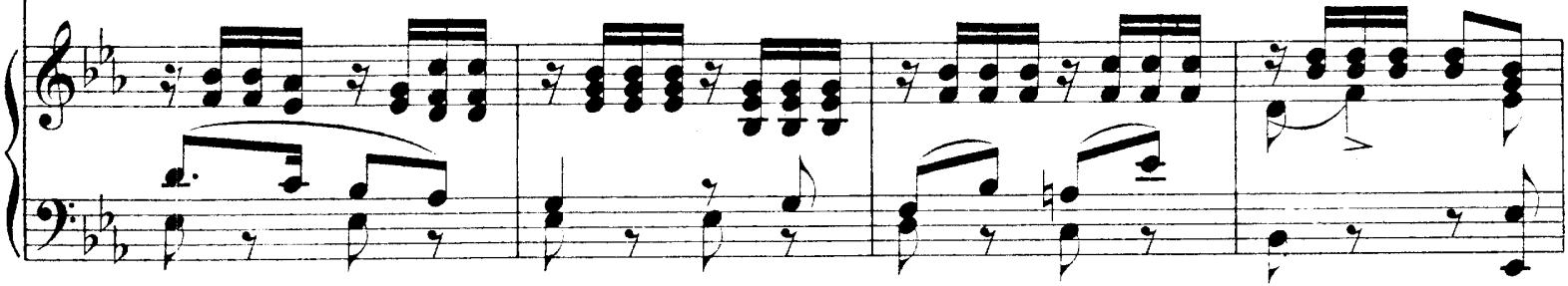
$\left(a^{\frac{1}{2}+0}=0\right.$

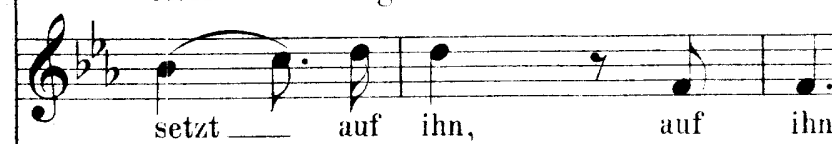
$+\mid \frac{b e}{r}+\infty$

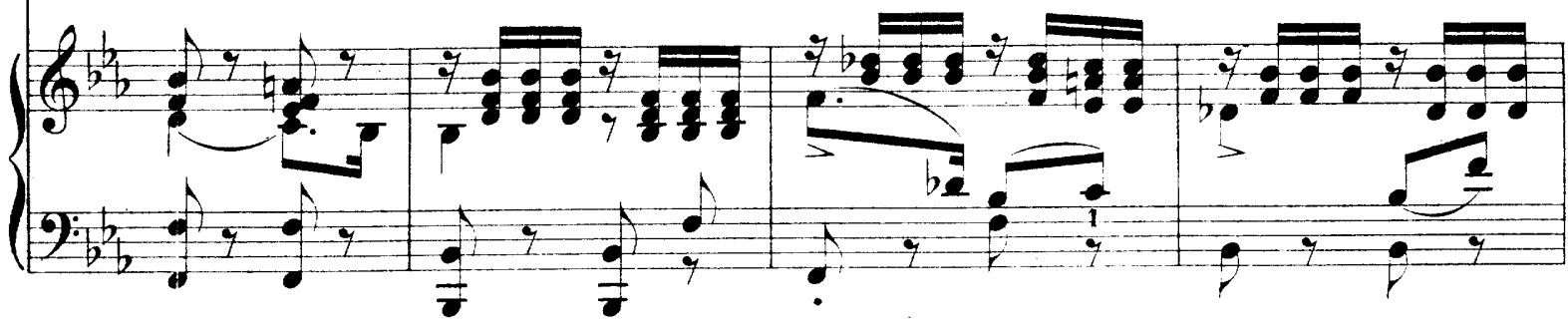

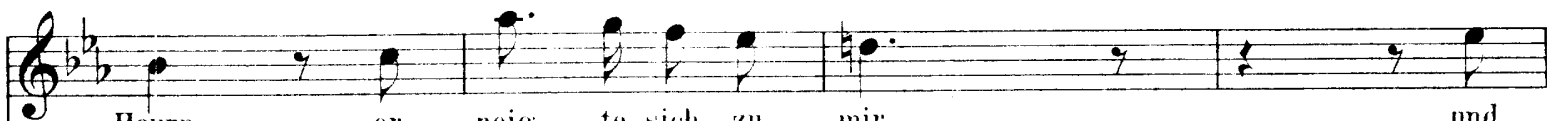
Herrn,

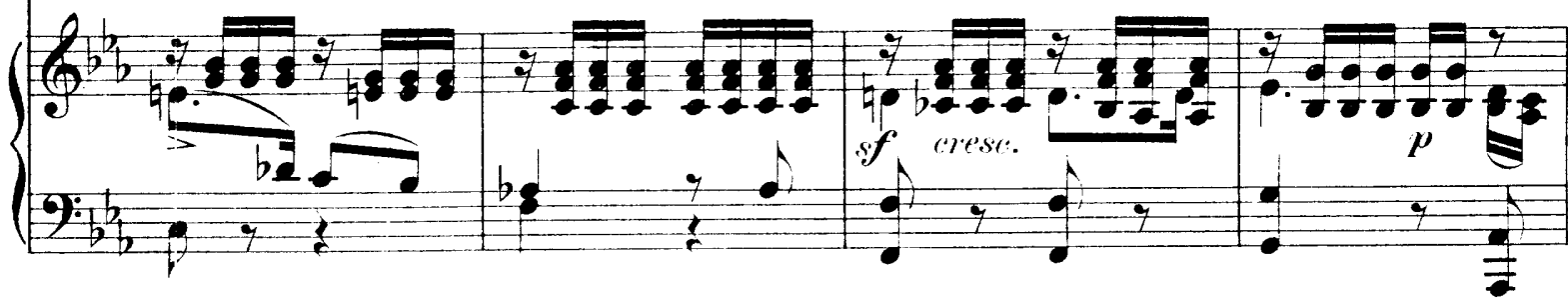

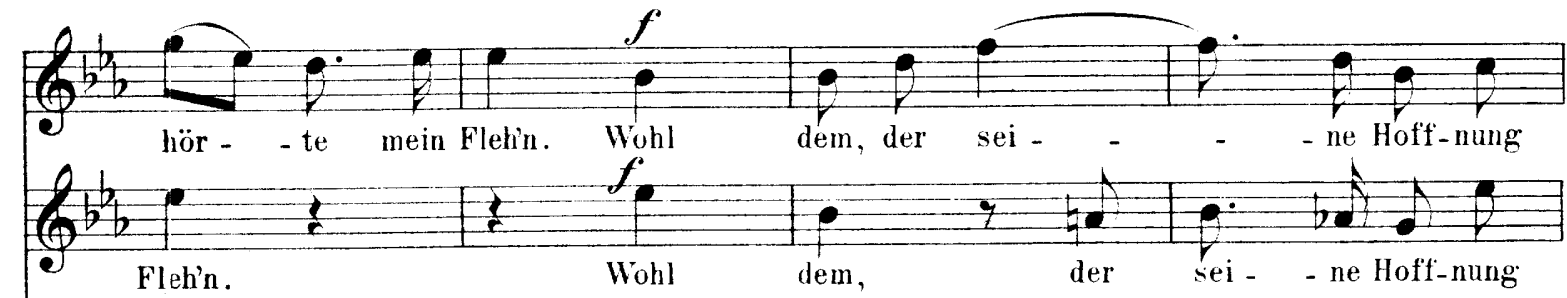

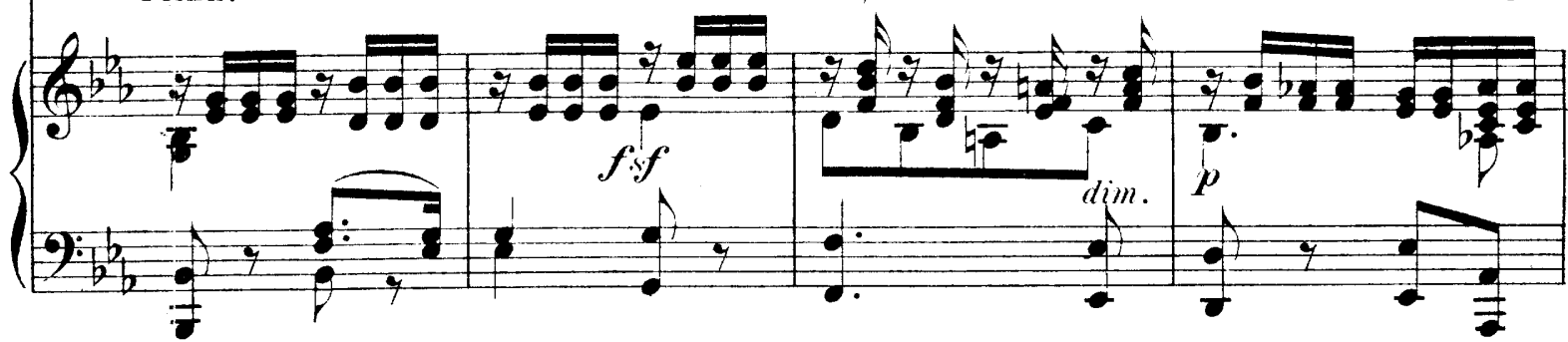
Edition Peters. 


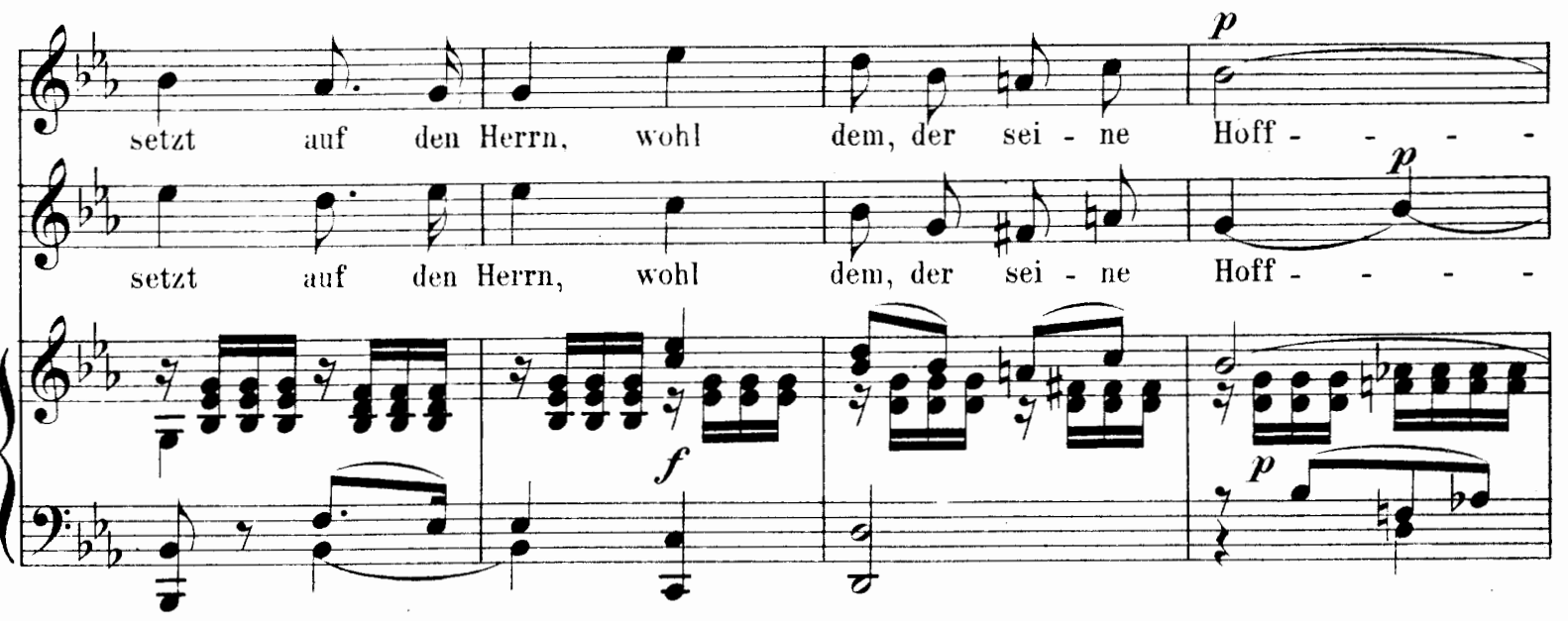

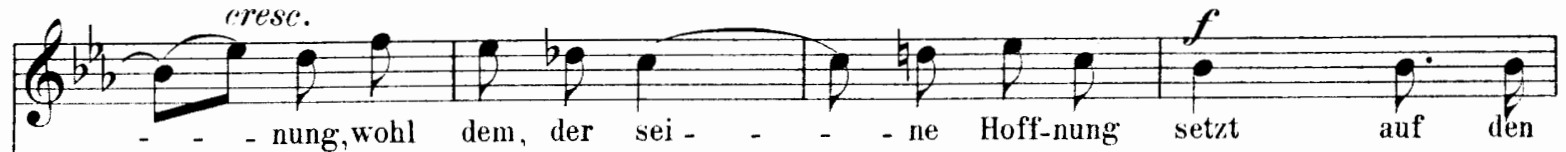
$\left(a^{b}-20\right.$ bो

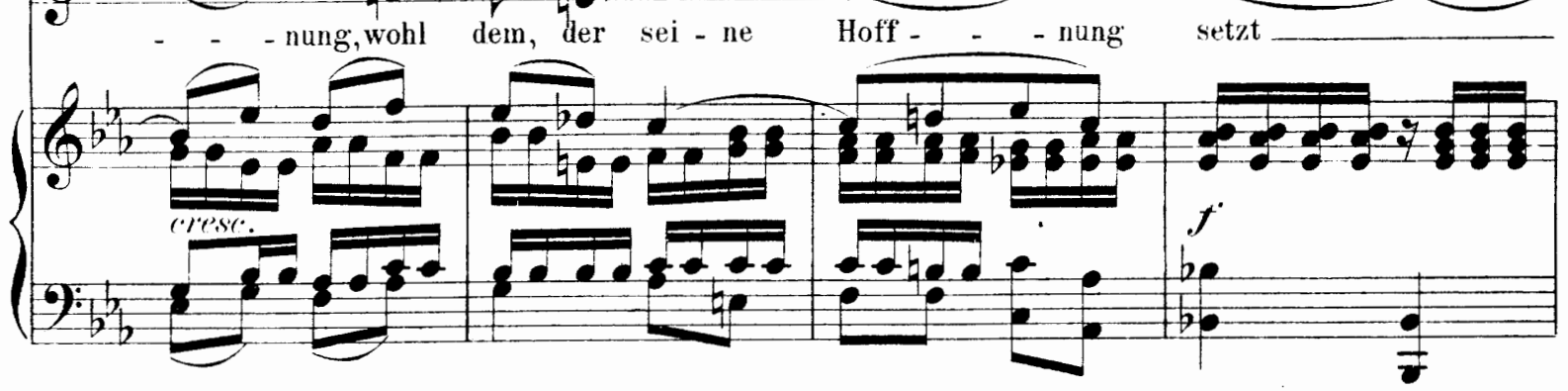

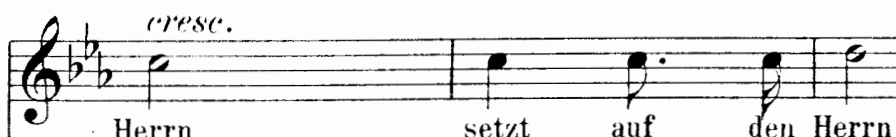
$f f$ setzt auf den Herrn, setzt auf den

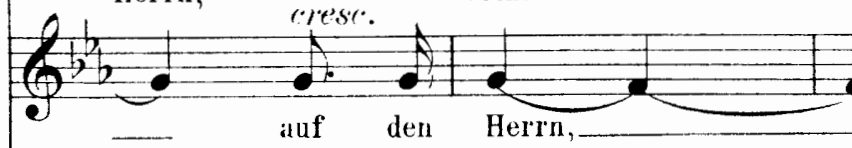

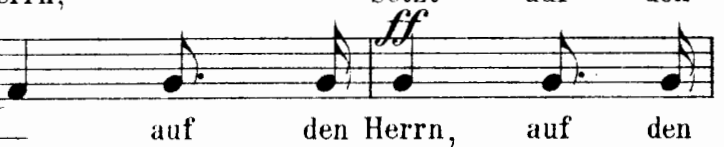

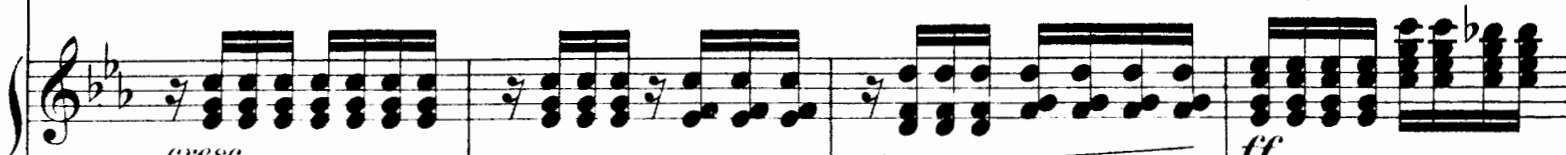

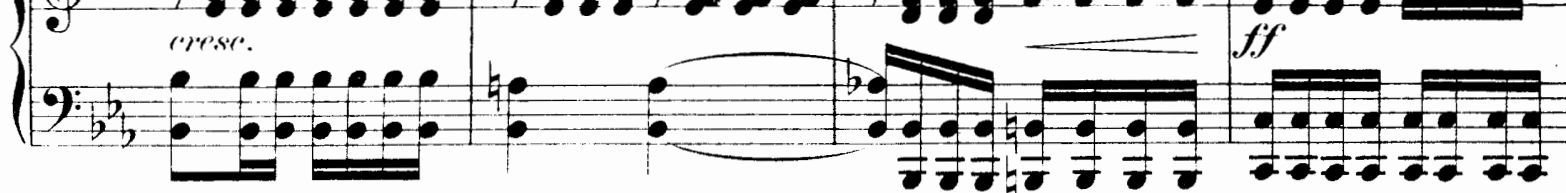

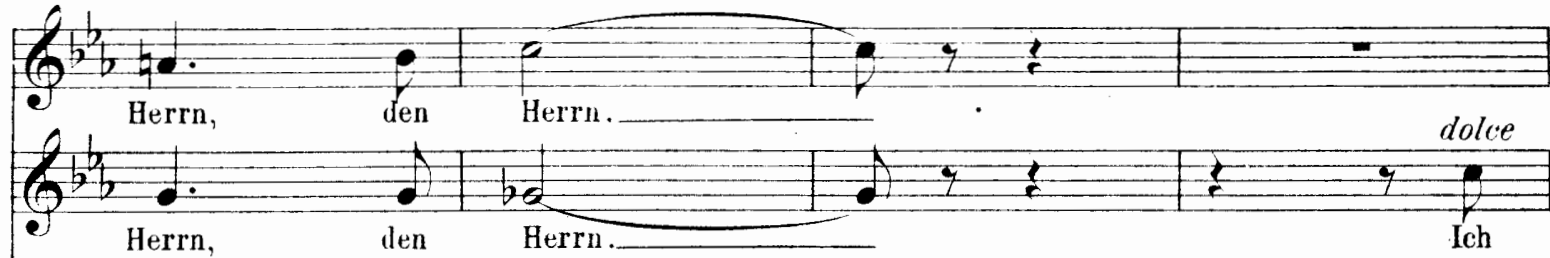

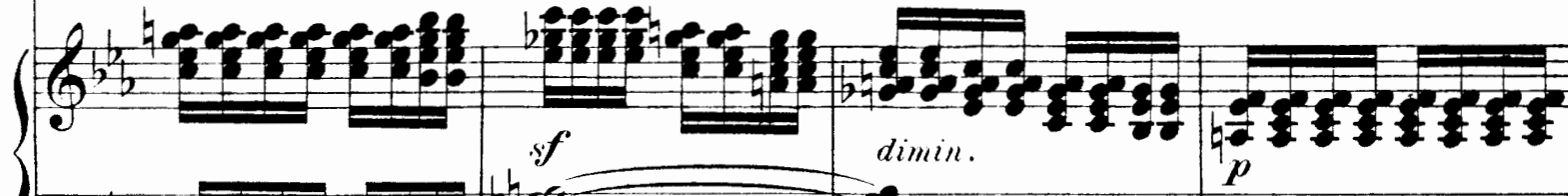

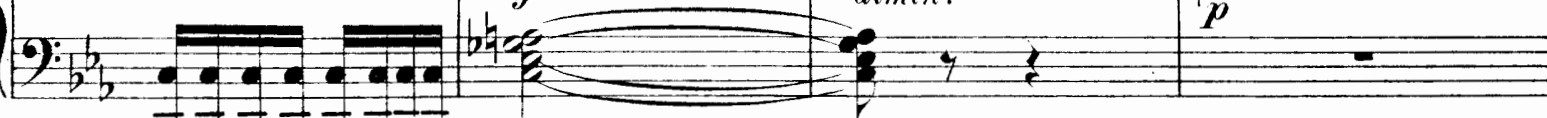
$\frac{1}{2}=\frac{1}{2}=2$ 


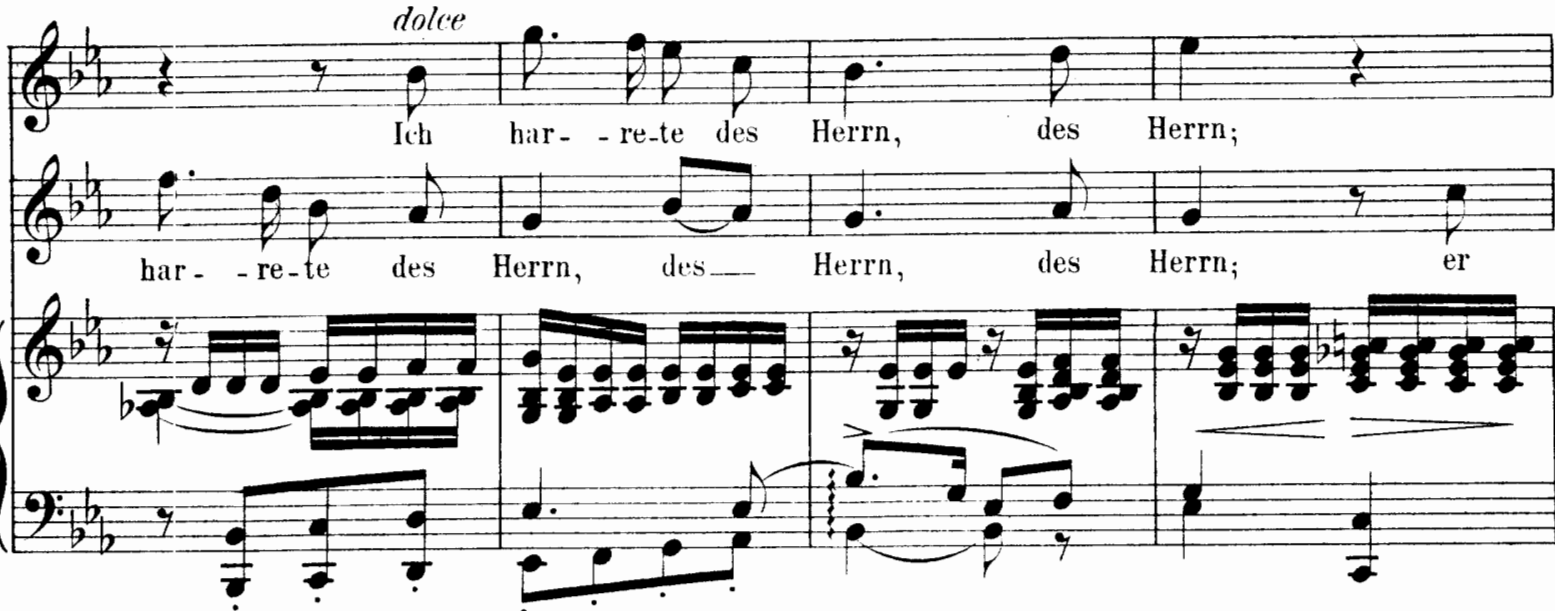

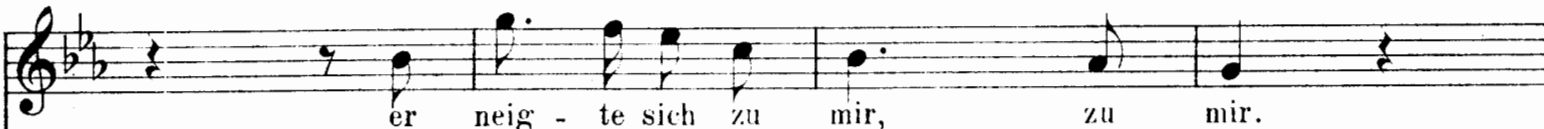

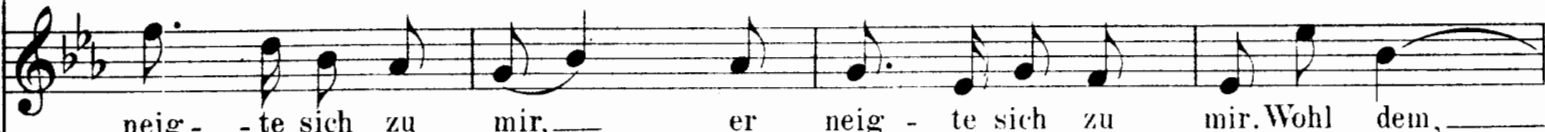

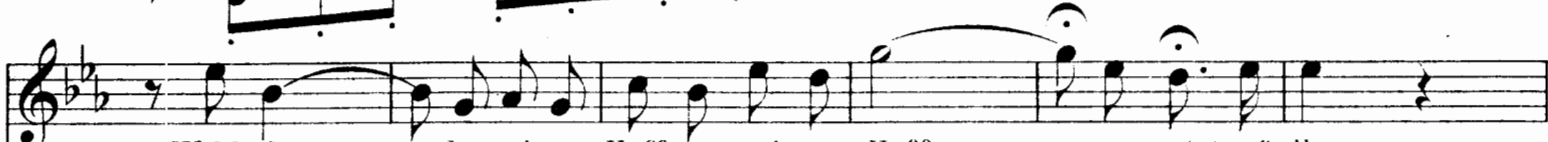
Wohl dem, ___ der sei-ne Hoffnung,sei-ne Hoff _ _ _ nung setztauf ihn.

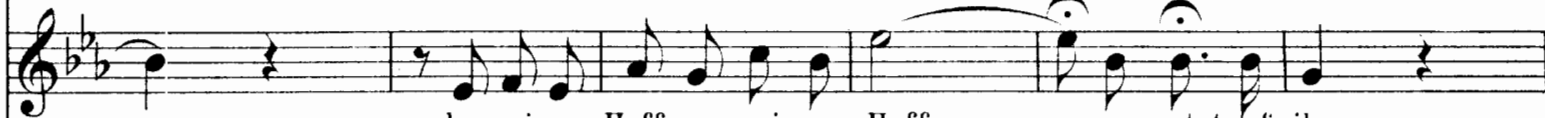

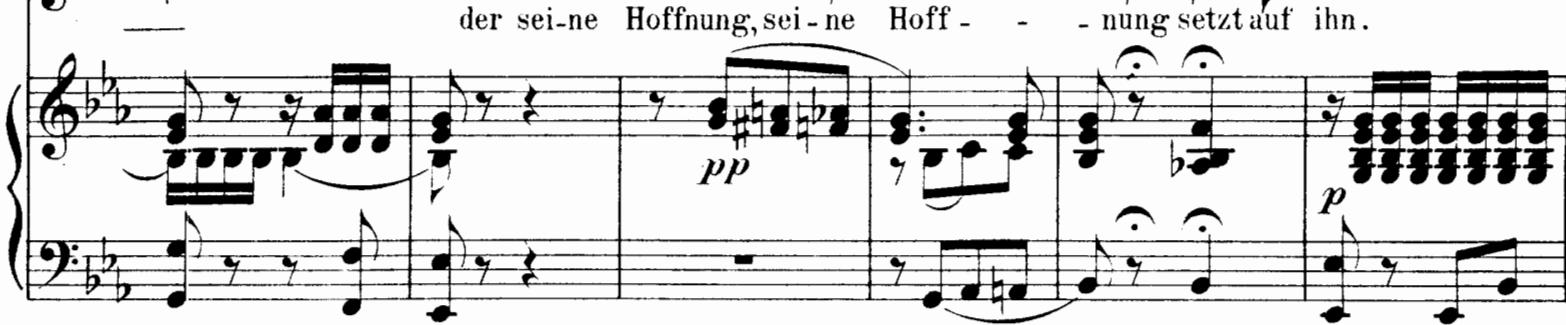

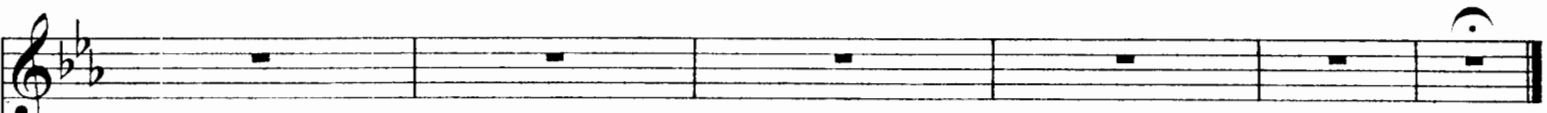
?

$\frac{2 b}{6}$

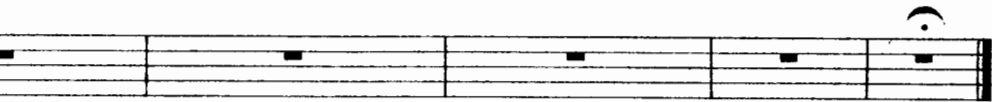

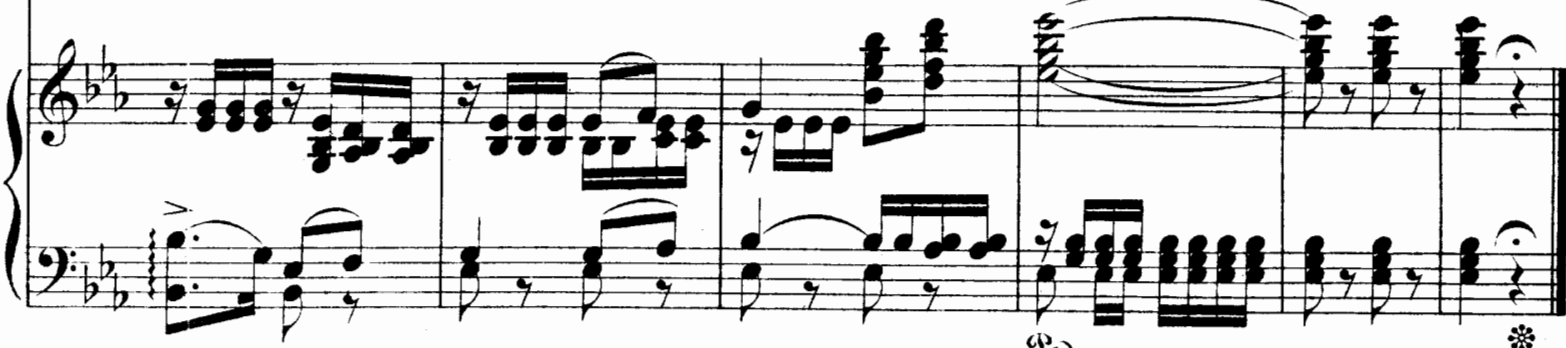

Edition Peters

i301

Ses. 


\section{Aus „Elias.“}
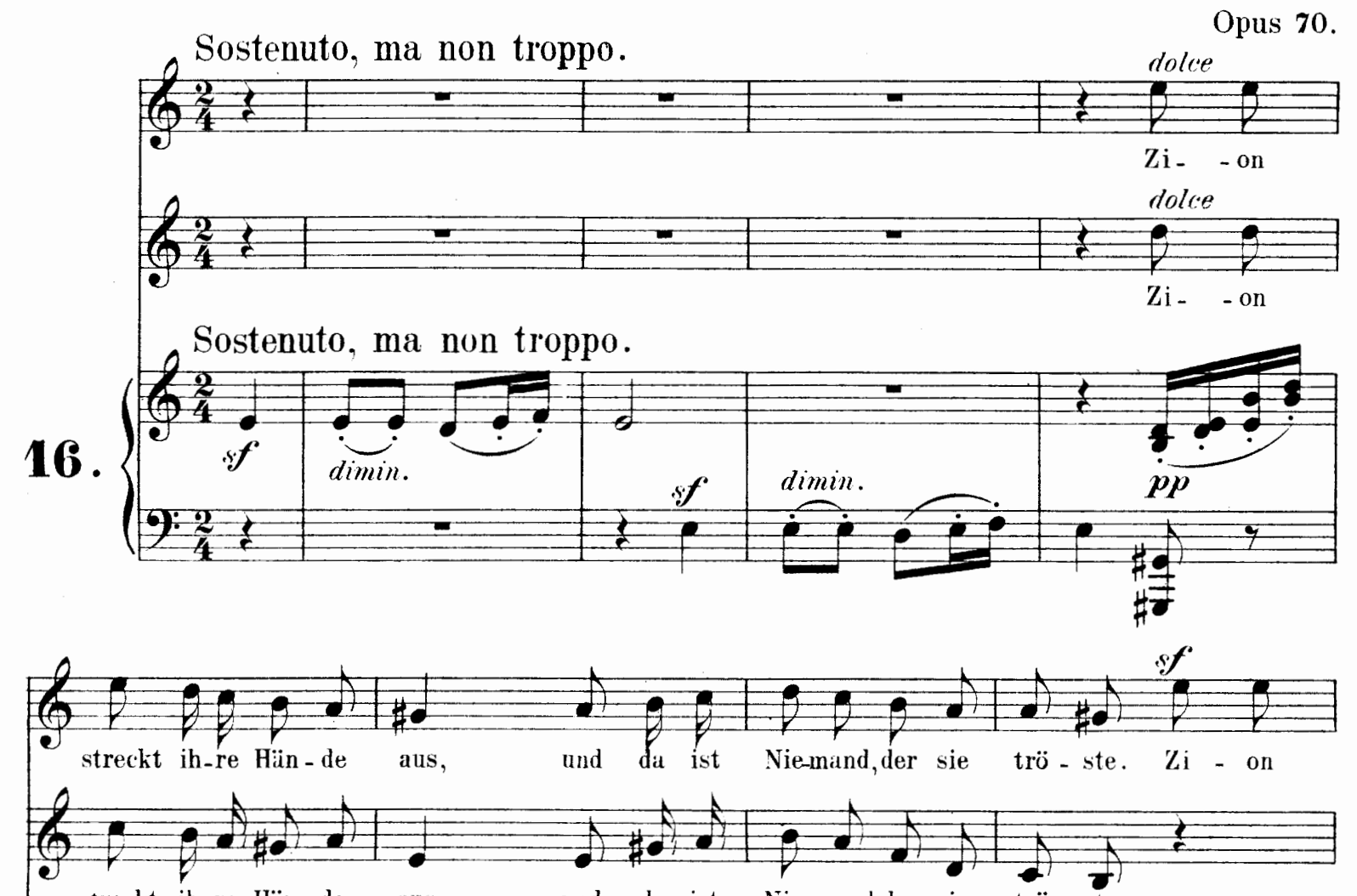

streckt ih-re Ḧ̈n-de aus, und da ist Nie-mind,der sie trö-ste.
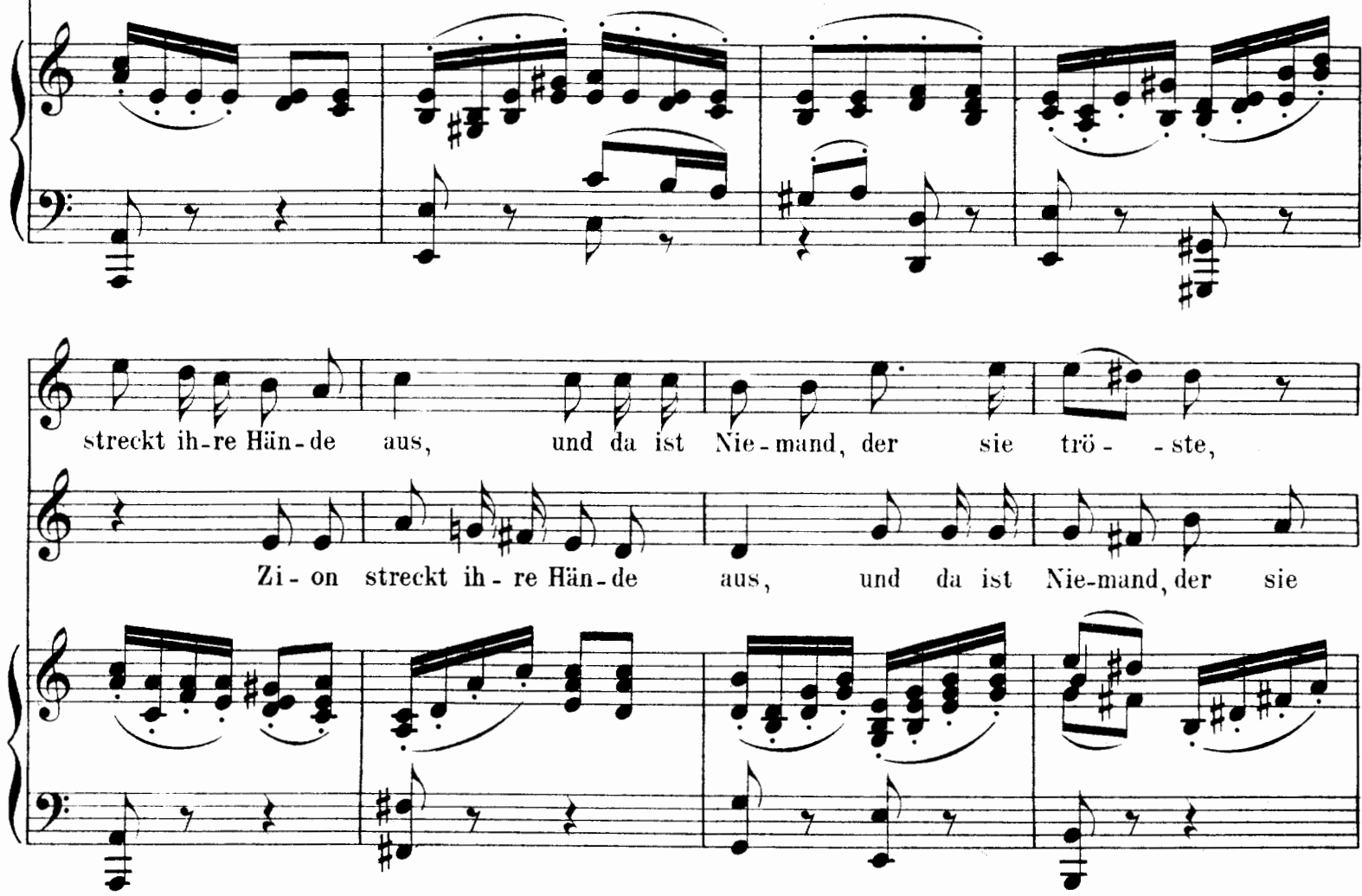

Edition Peters 

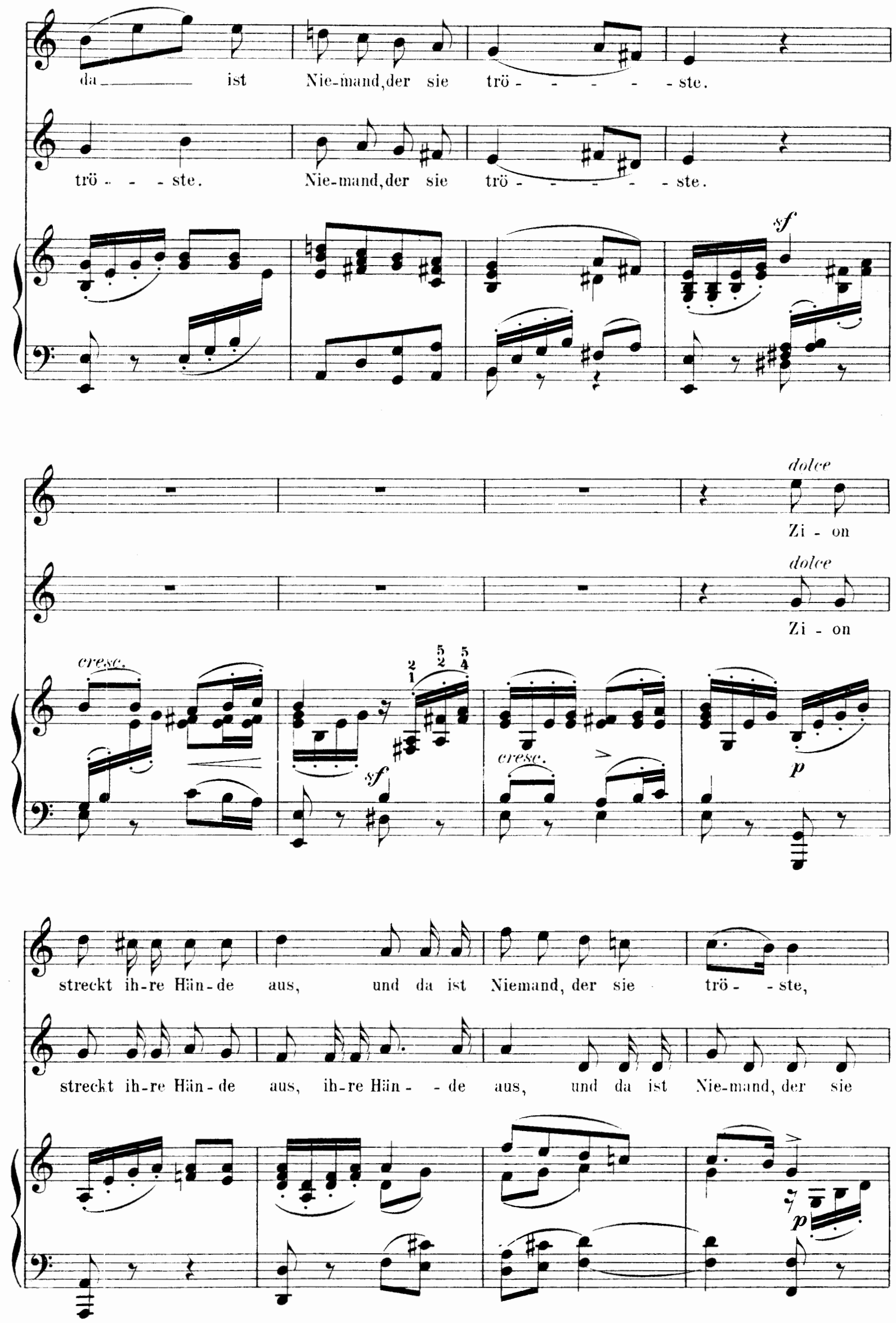

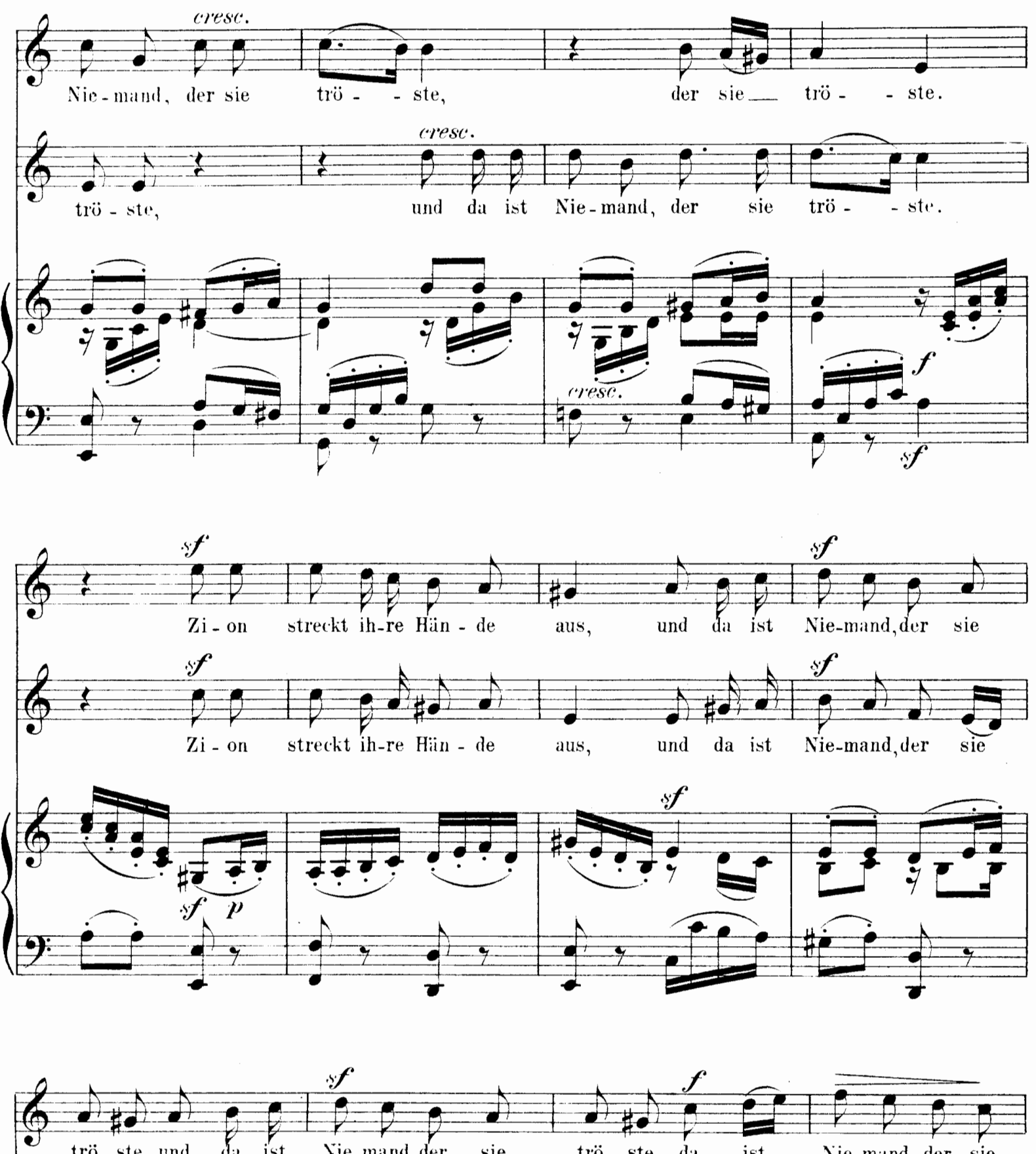
trö-ste, und da ist Nie-mand,der sie trö-ste, da ist Nie-mand, der sie

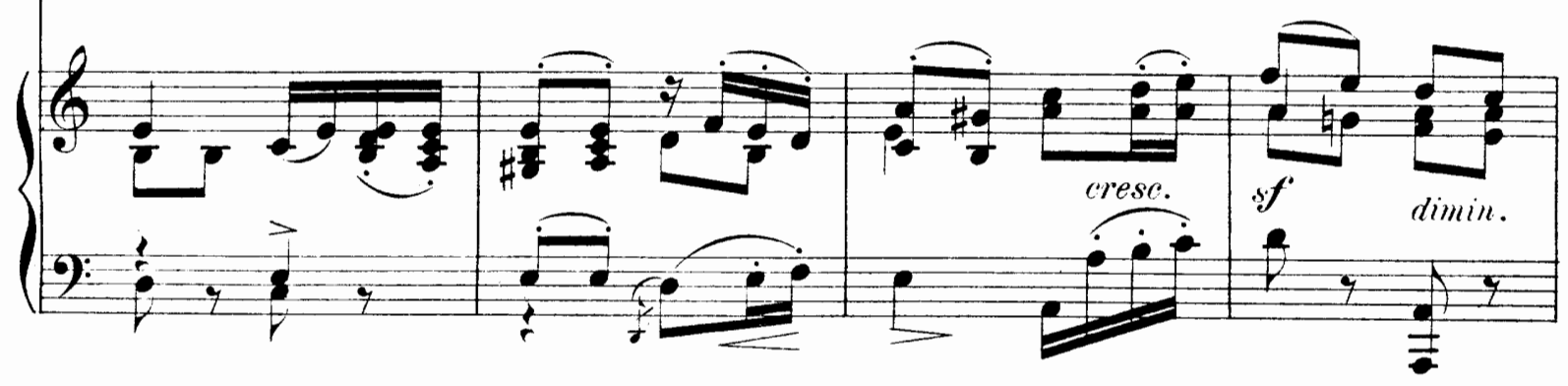




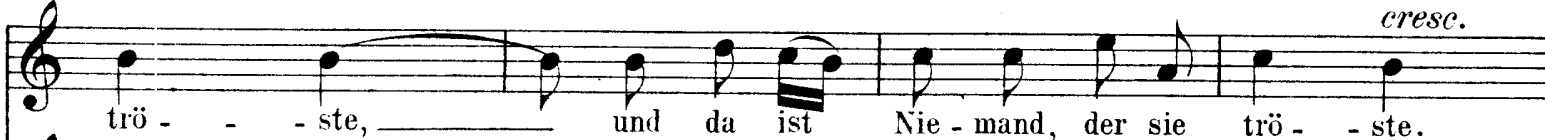

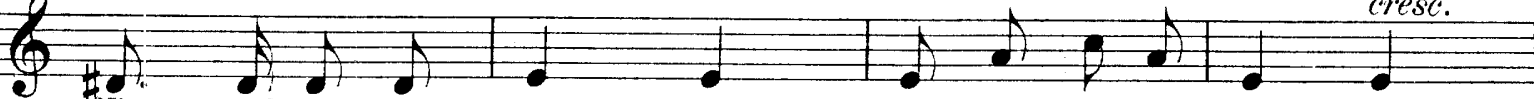
Tie - mand, der sie trö - - ste. Nie - mand, der sie trö - - ste.

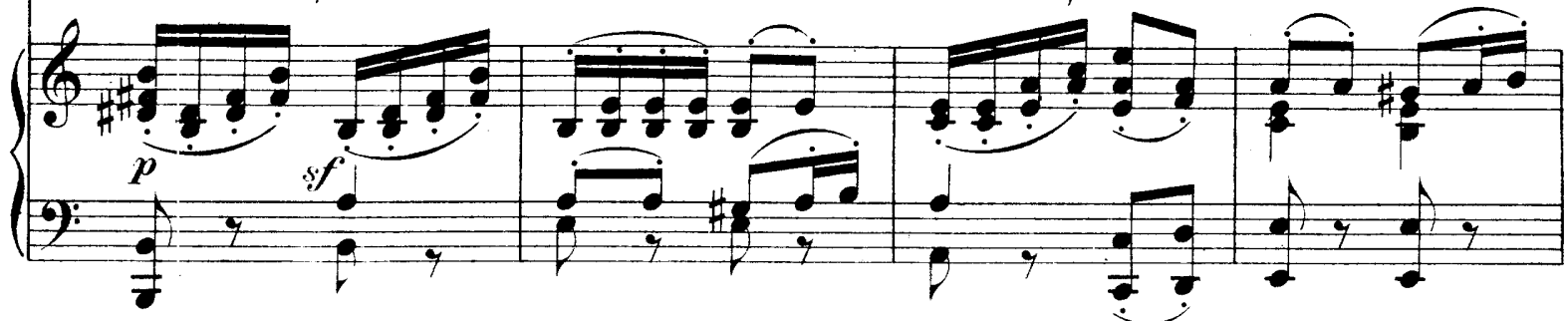

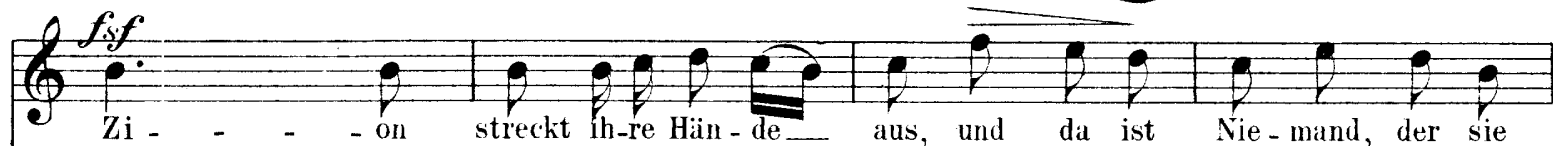
Ofsf

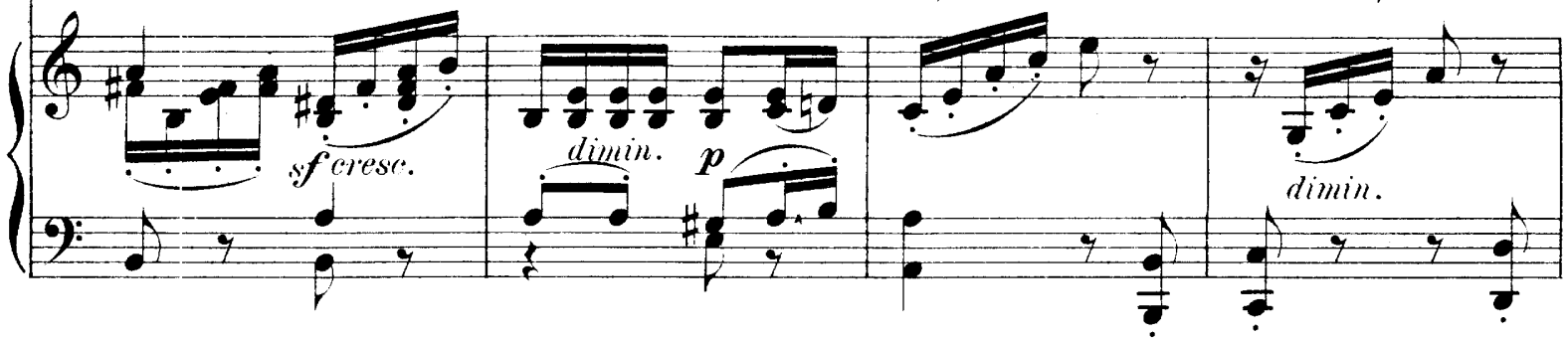
(6)

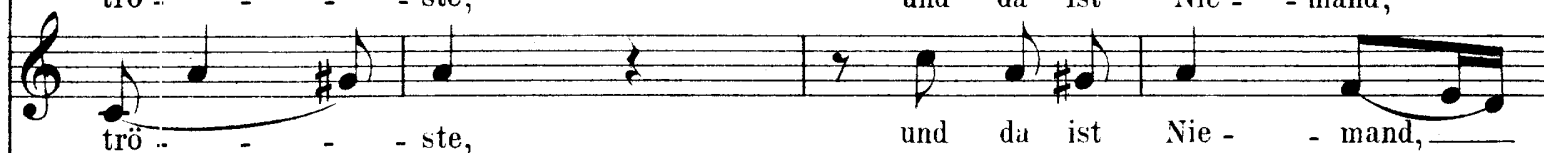

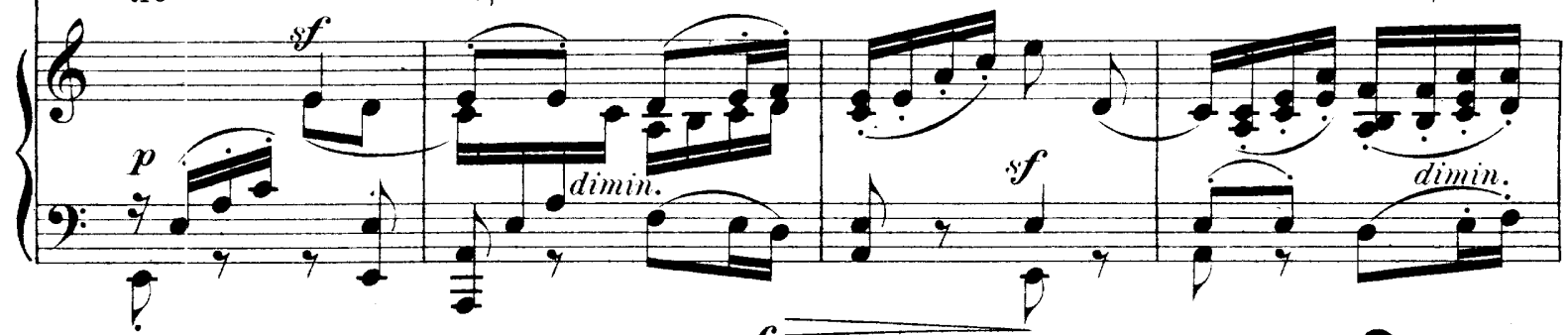

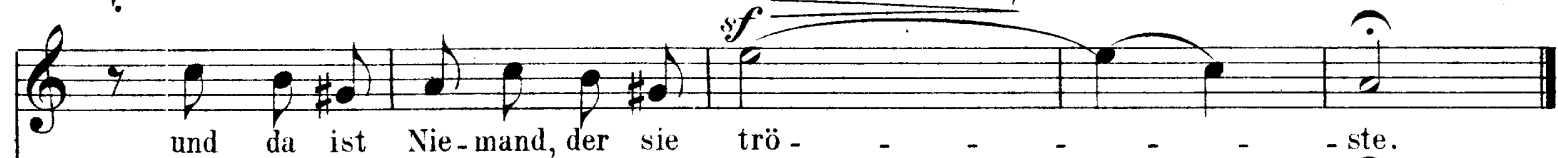
62 of und__a ist Nie-mand, der sie trö - _ _ _ _ _ - ste.

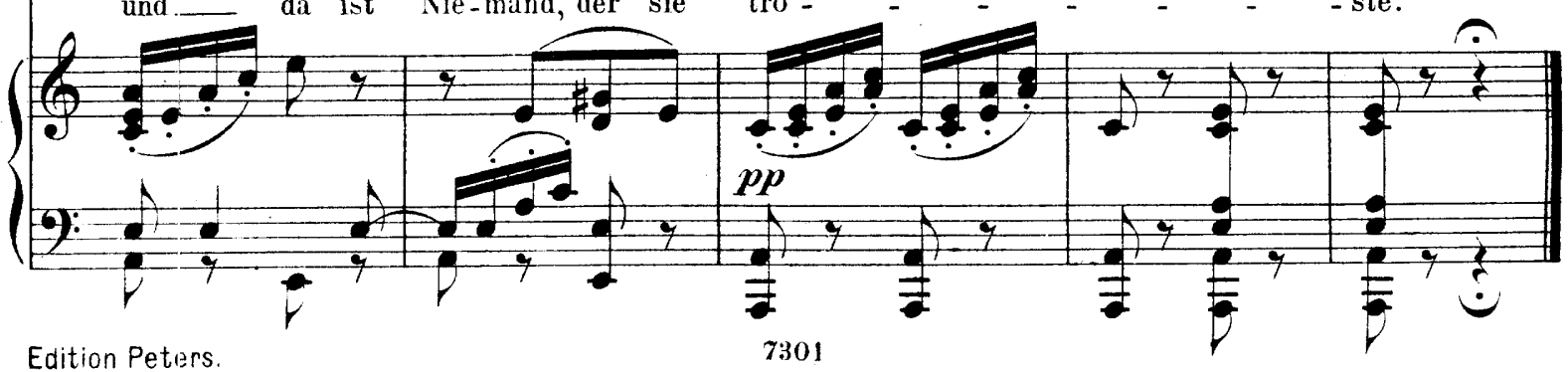




\section{Aus der Motette Opus 39 No 3.}
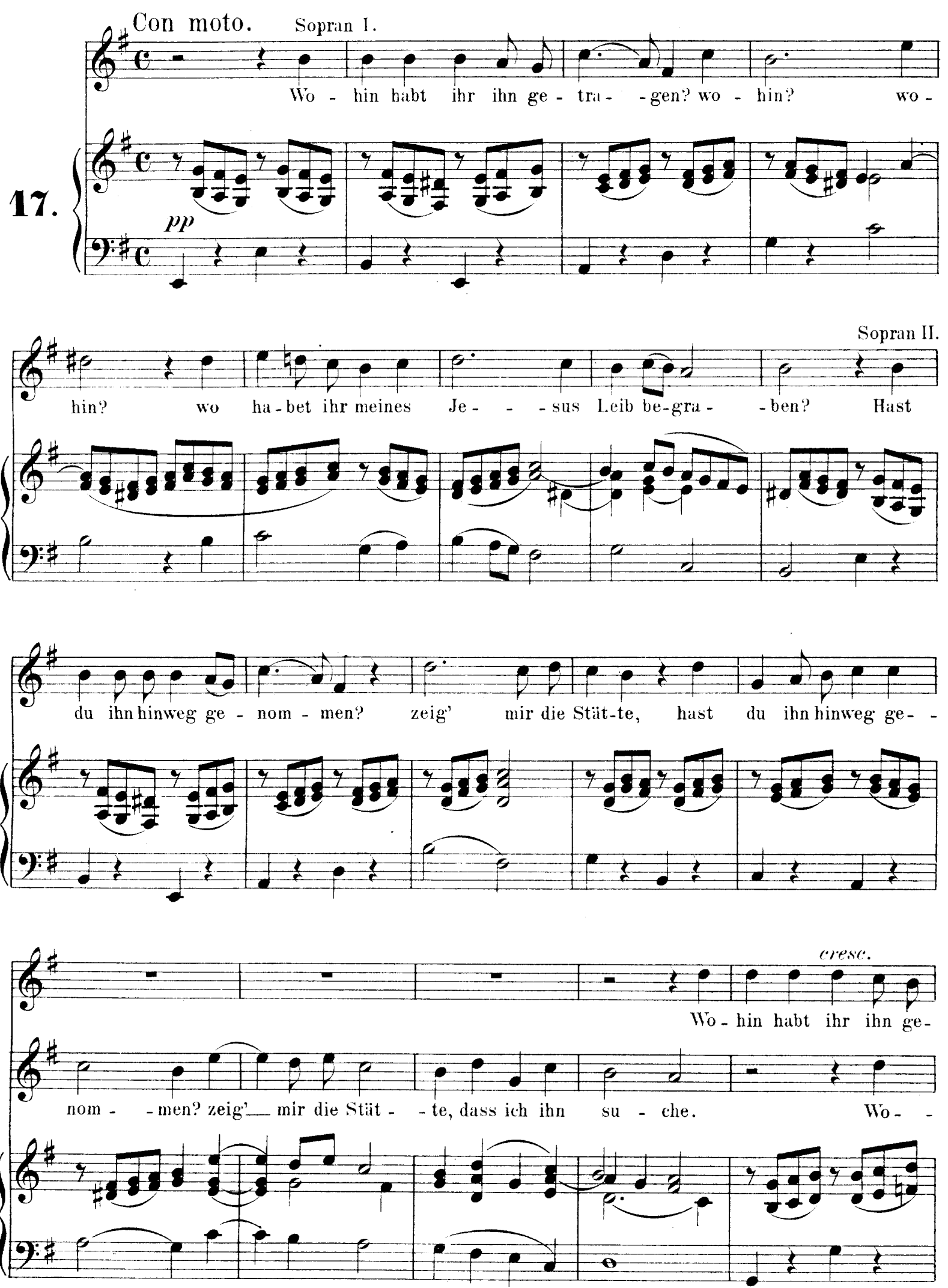
to

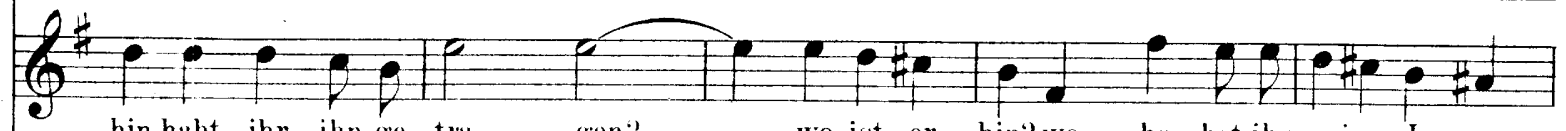

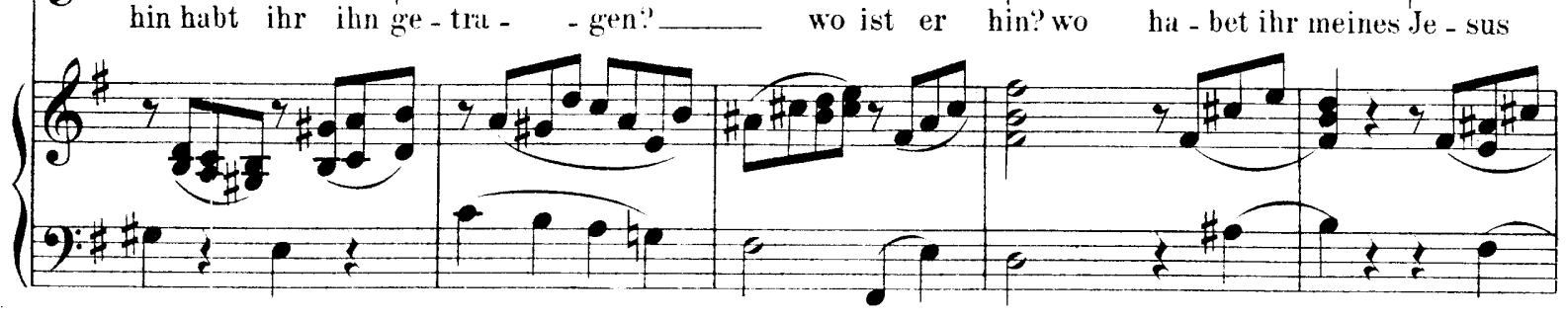

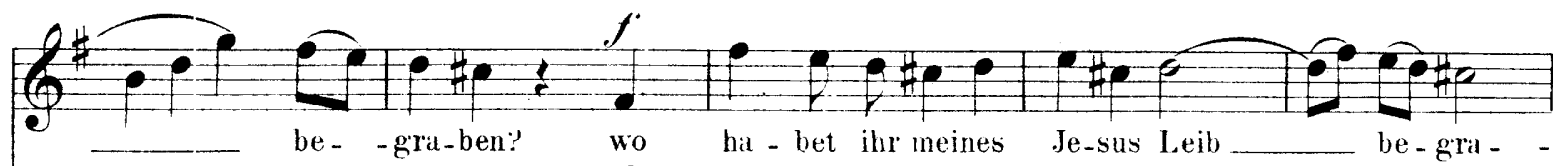

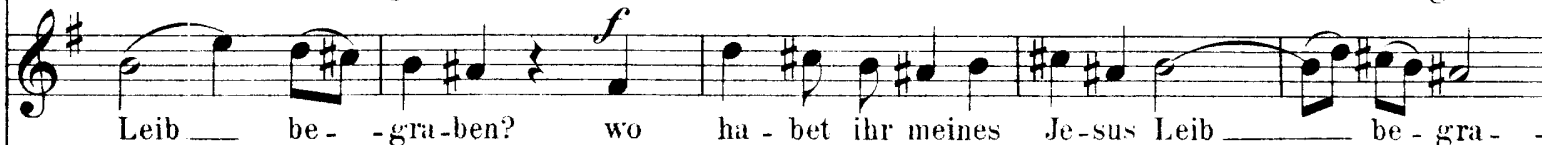

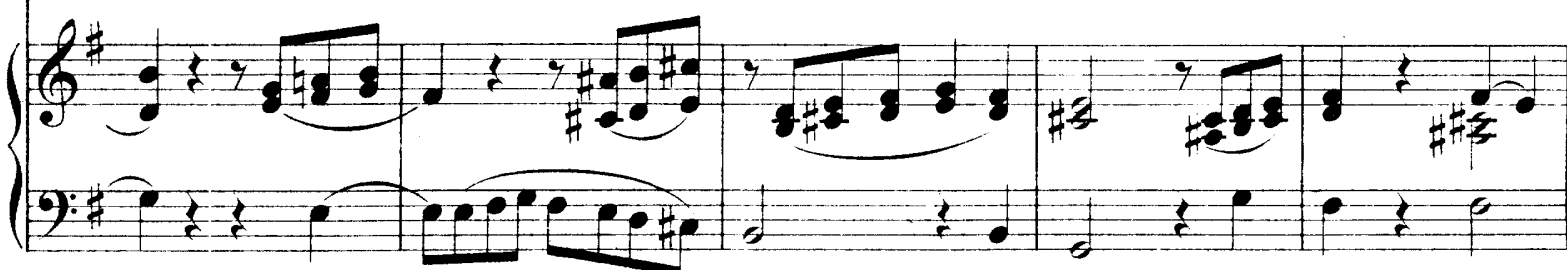

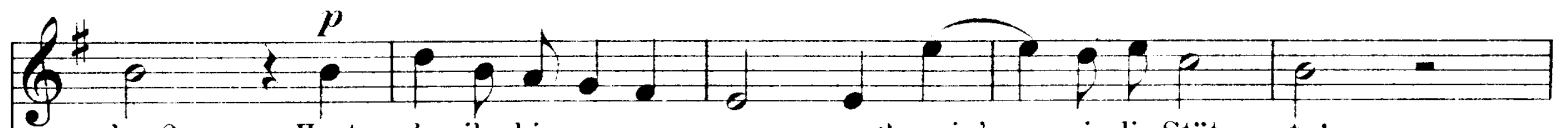
ben? Hast du ihnhinweg ge - nom - men? zeig'__ mir die Stät - - te!

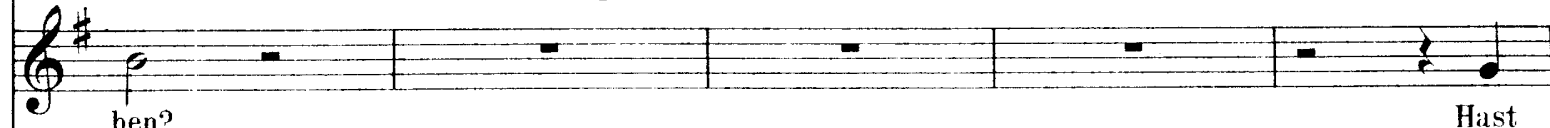

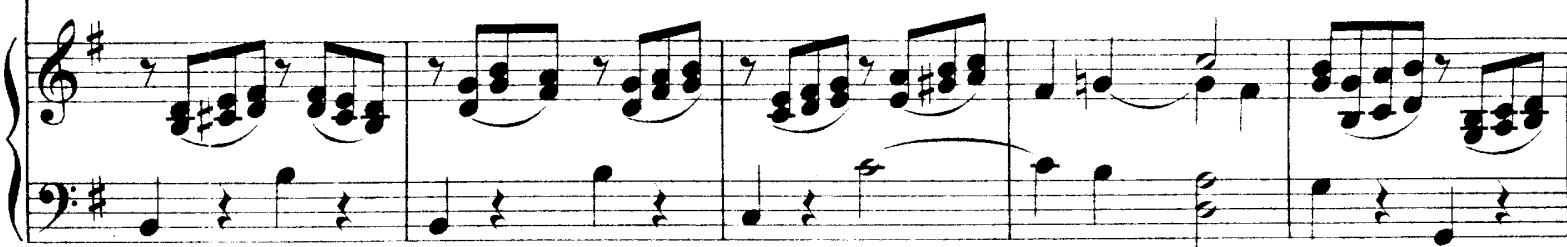

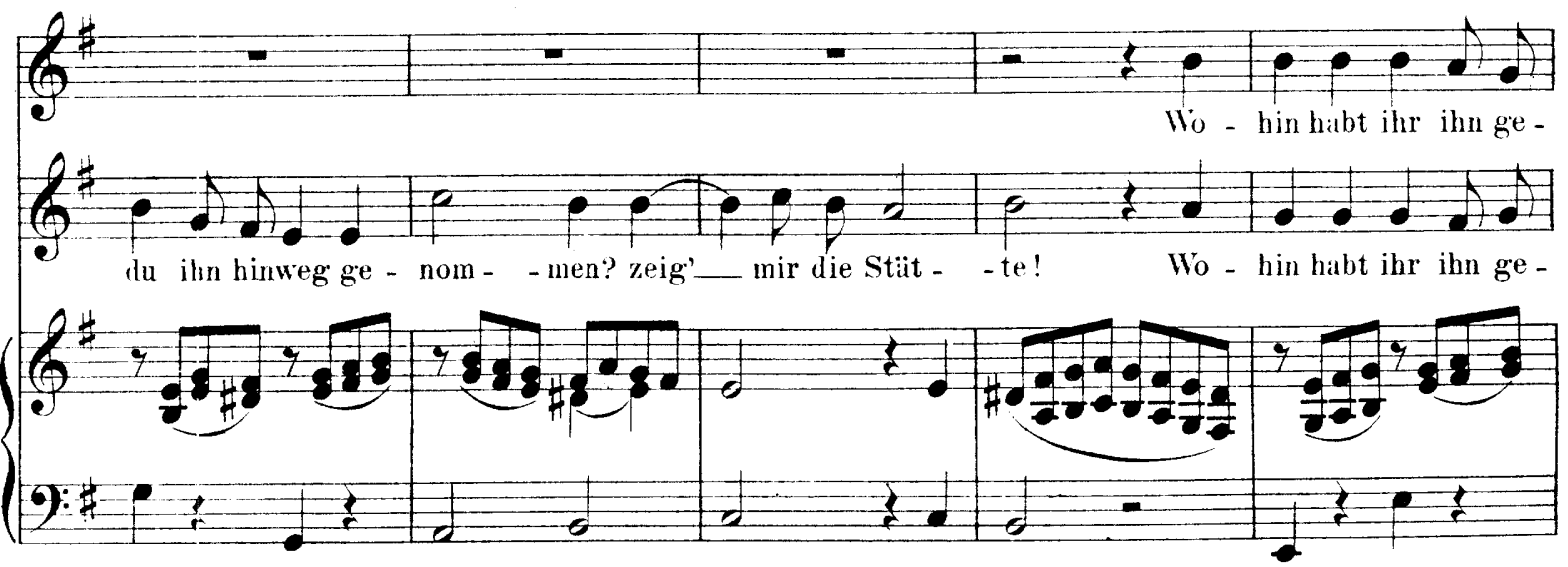
Edition Peters. 


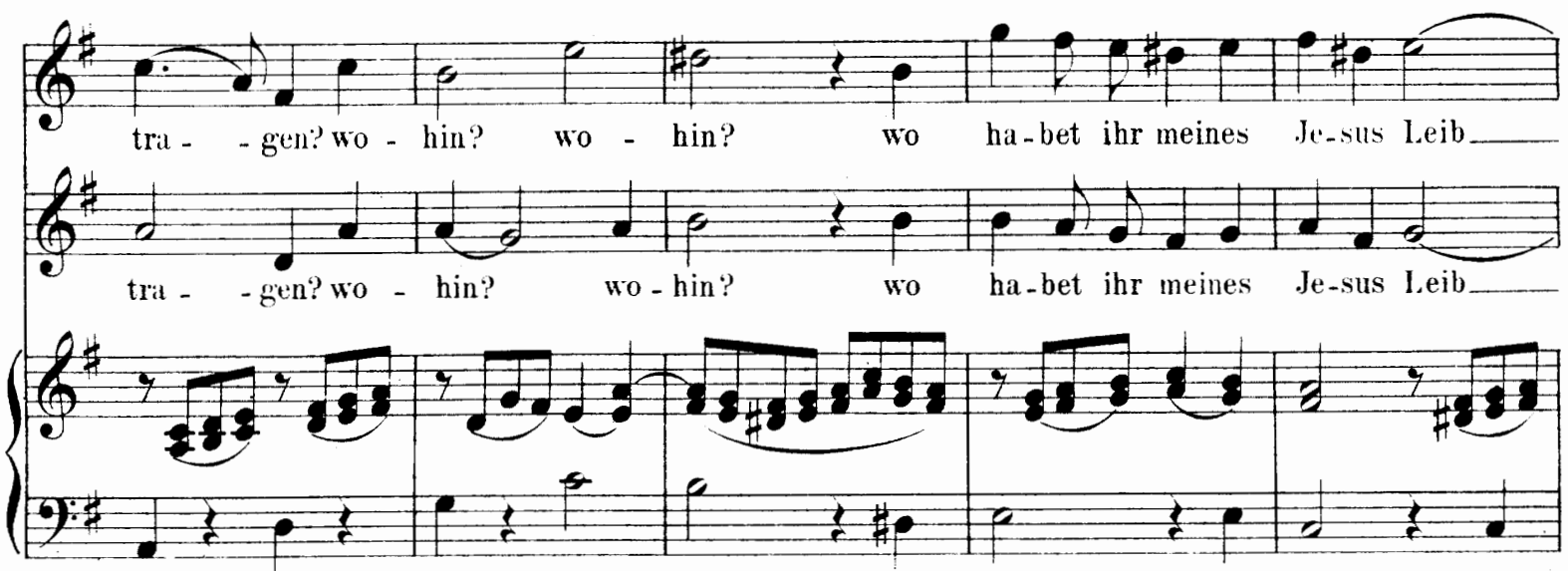

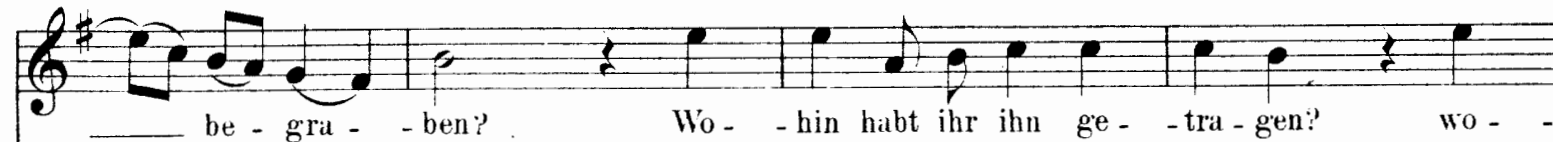

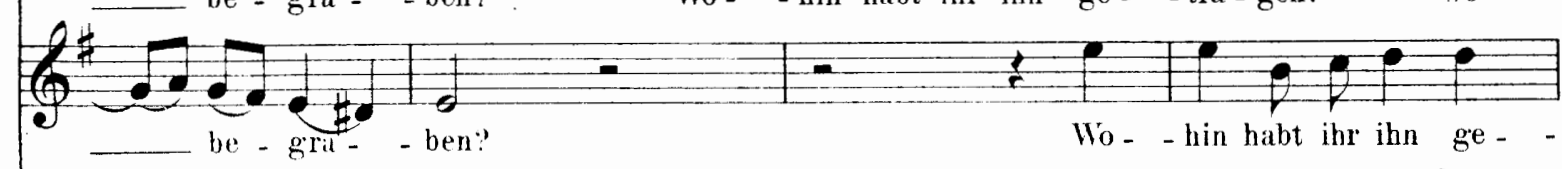

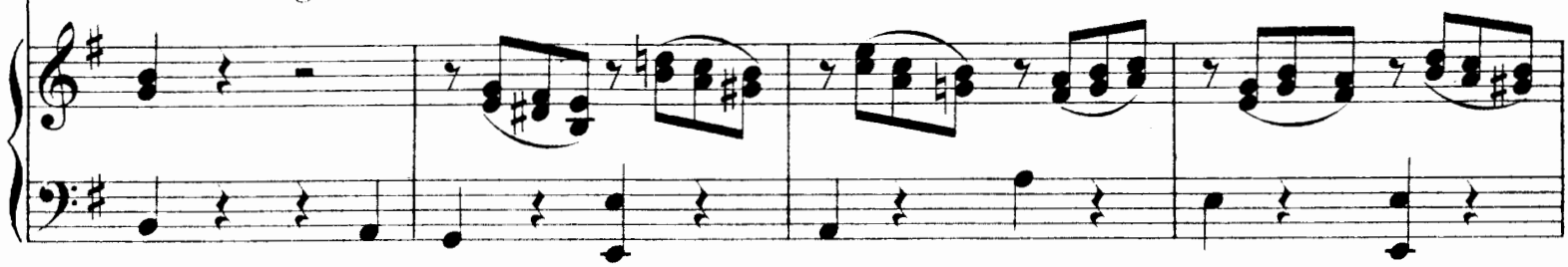

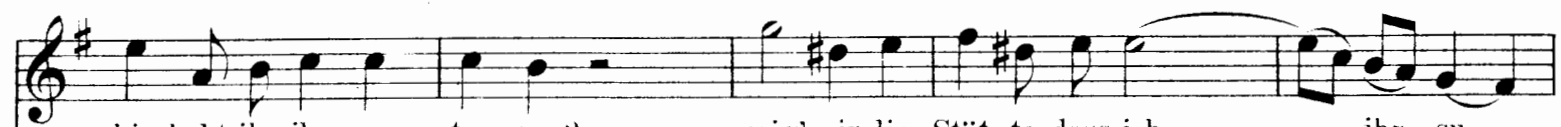
hin habt ihr ihn ge - tra-gen?

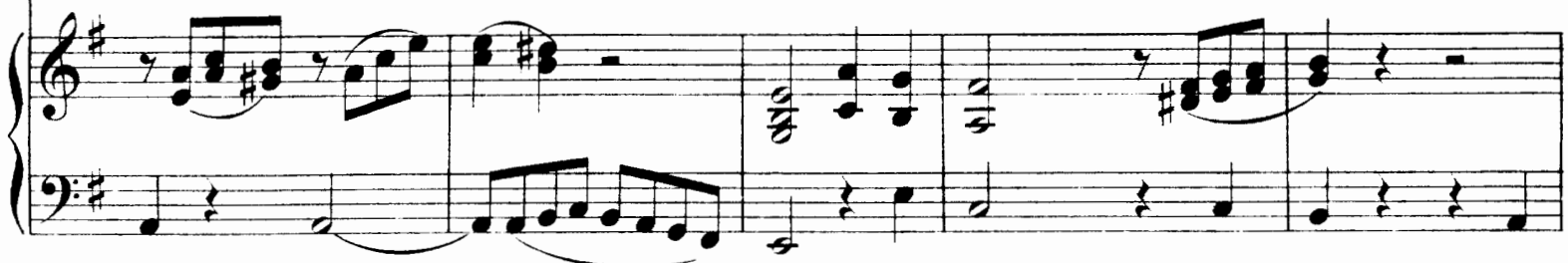

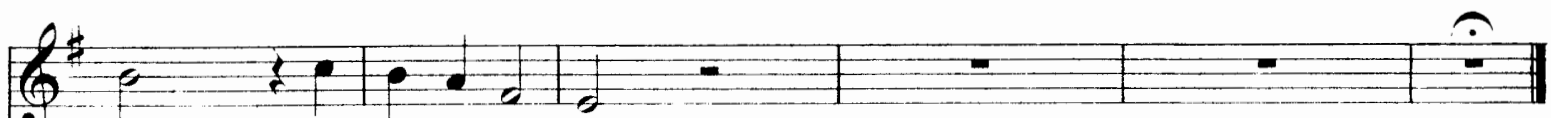
che, dass ich ihn su - che.

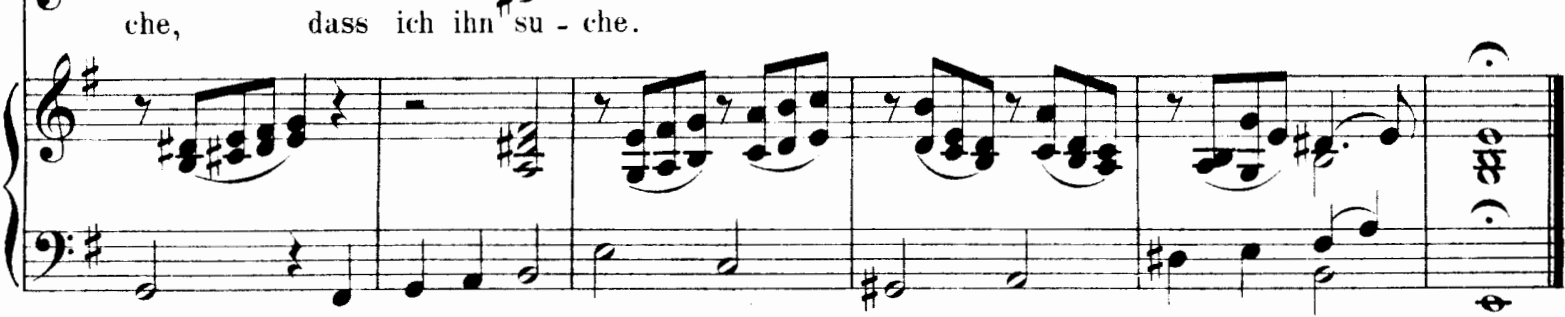


Allegretto non troppo.

Opus 74.

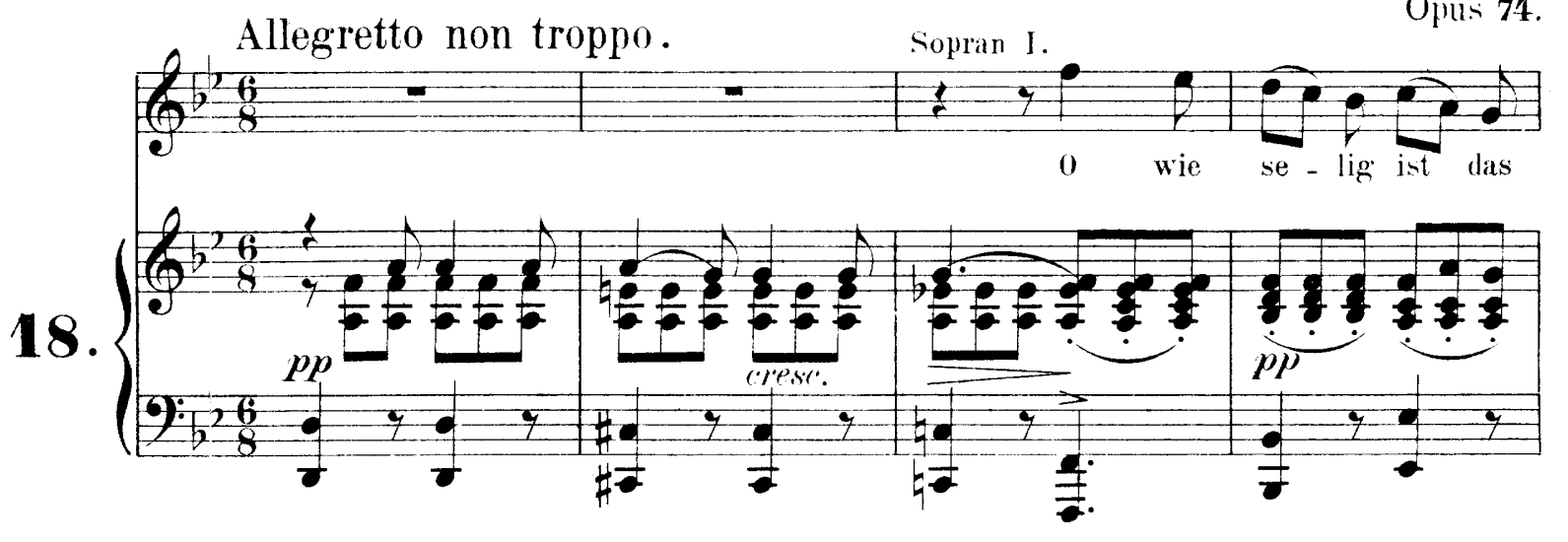

$Q^{b}=9$ वेte dye? Kind, o wie se - lig, 0 wie se - lig, dis der Herr in Schutz ge -

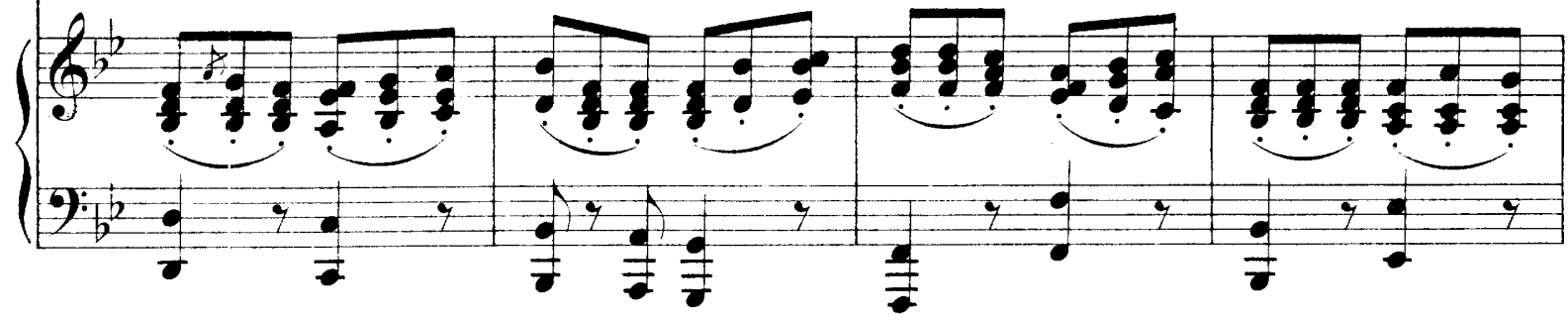
$\frac{b^{2}}{\text { nom - men, denn Kin-der, die ihm folgsam sind, lïsst er zu }}$

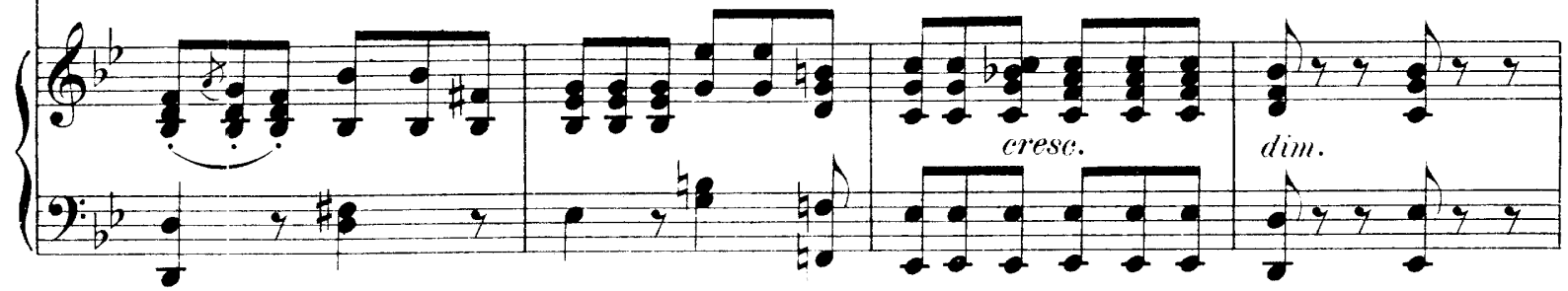

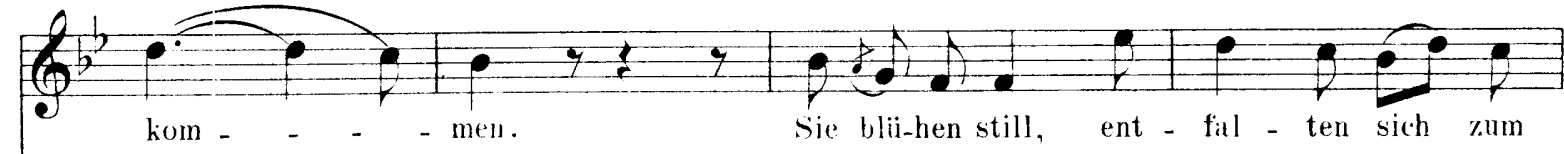

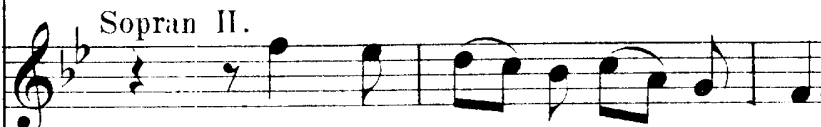
0 wite se - lig ist das Kind, o wie se - lig, o wie

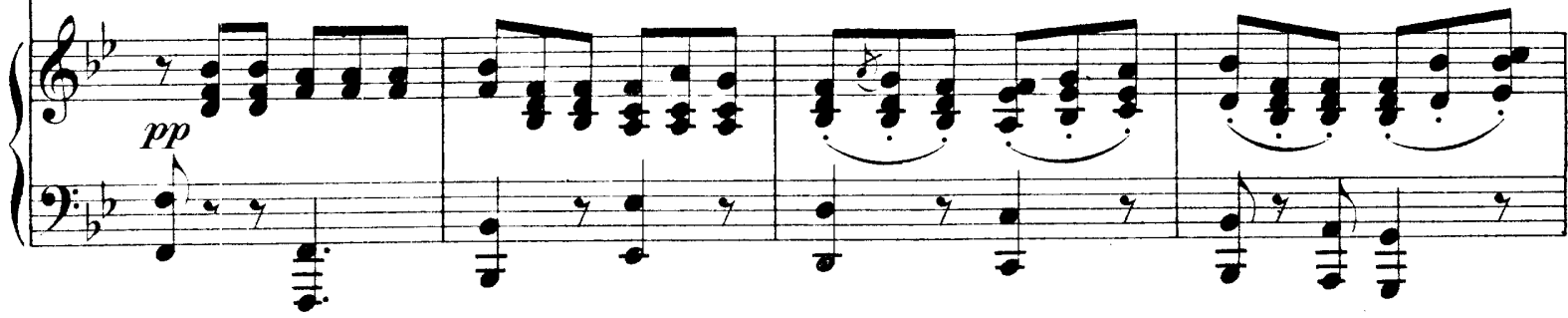
Eaition Peters 


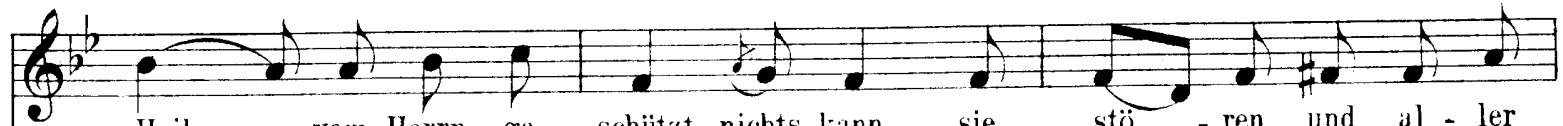
2 Heil,___ vom Herrn ge - schützt; nichts kann sie stô- - ren, und al - ler

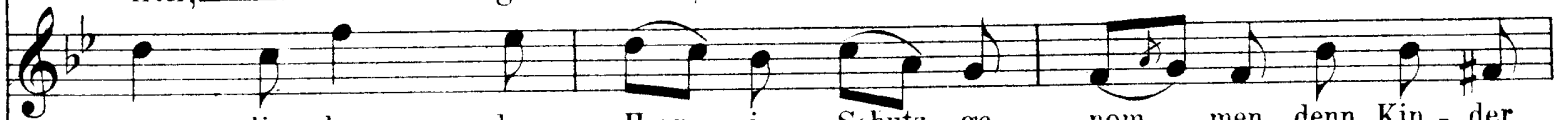
se - - lig, das der Herr in Schutz ge - - nom - men, denn Kin - der,

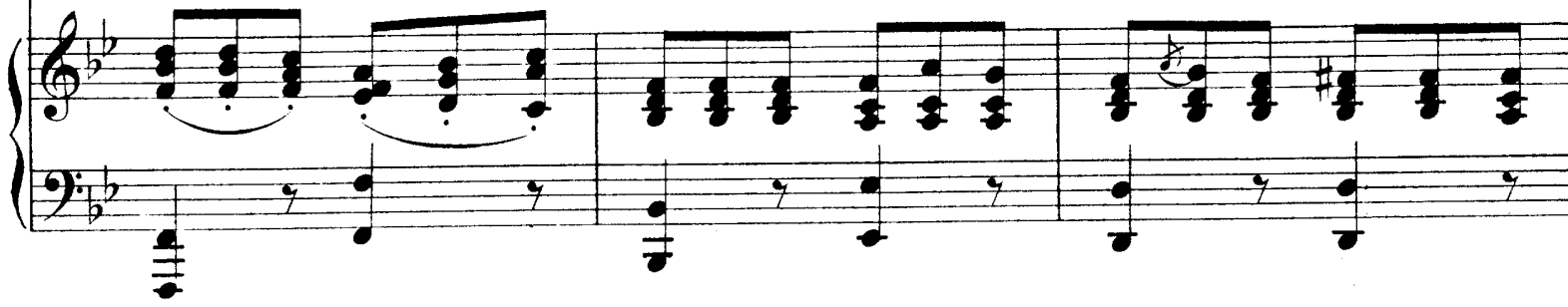

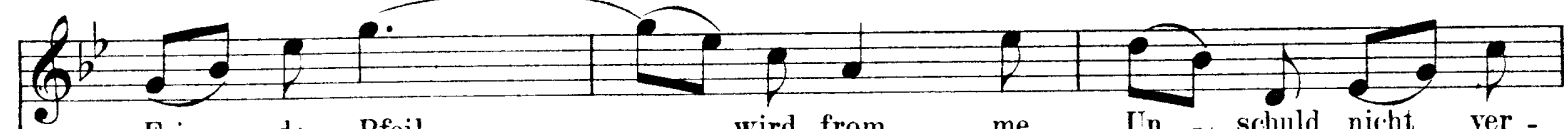
Fein - de Pfeil__ wird from - - me In _ schuld nicht ver -

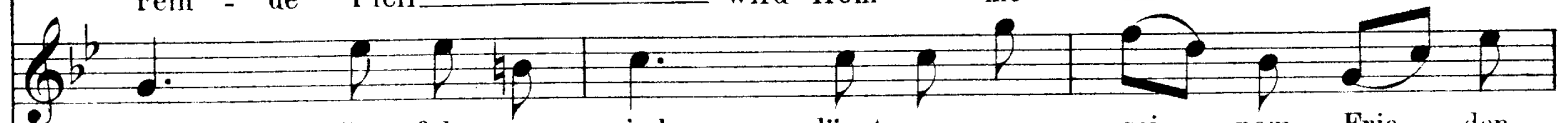
(2) die folg-sam sind, lisst er zu sei - nem Frie - den \begin{tabular}{|l|l|l|l|l|l|l|l|}
\hline \\
\hline
\end{tabular}

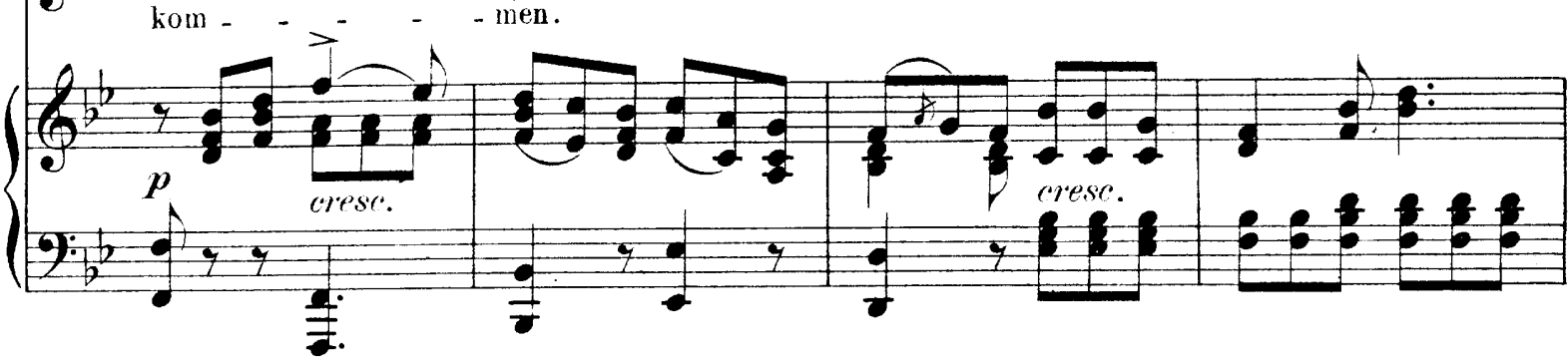

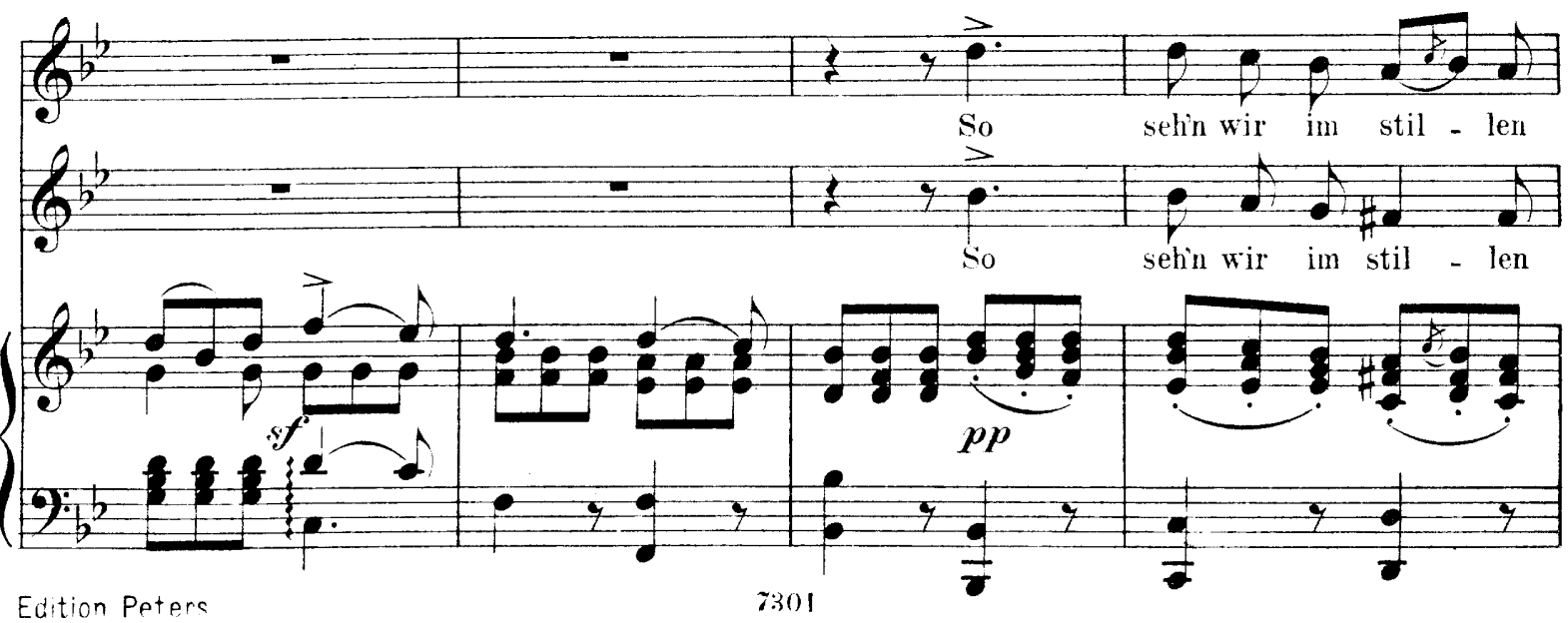



$\left(\frac{6}{2}+b_{\text {Thal }}^{b}\right.$

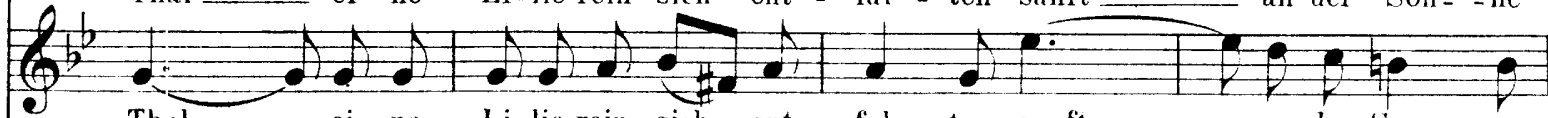

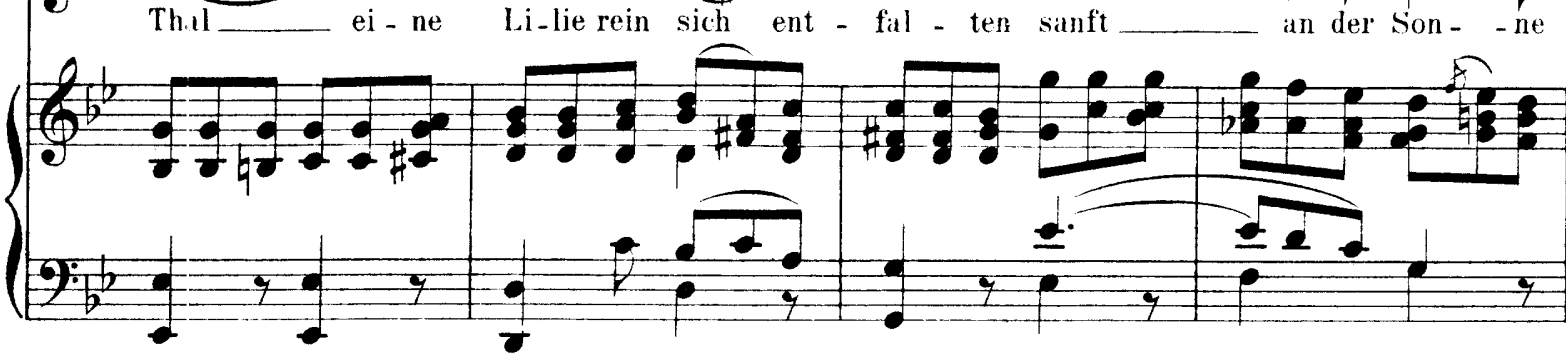

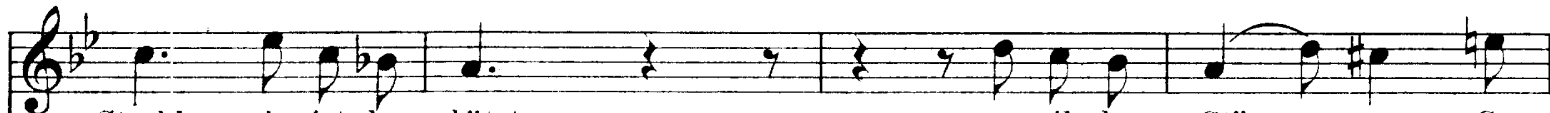
StrahI; sie ist be-schützt for wil-der Stür - - me Ge -

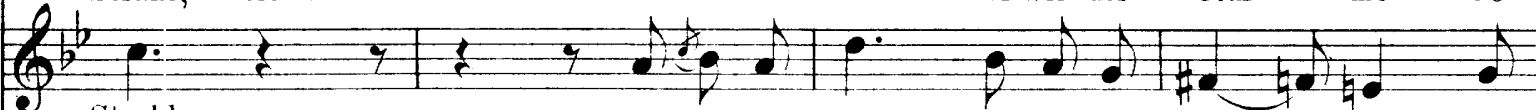
Strabl; sie ist be - scibützt vor wil-der Stür - - me Ge -

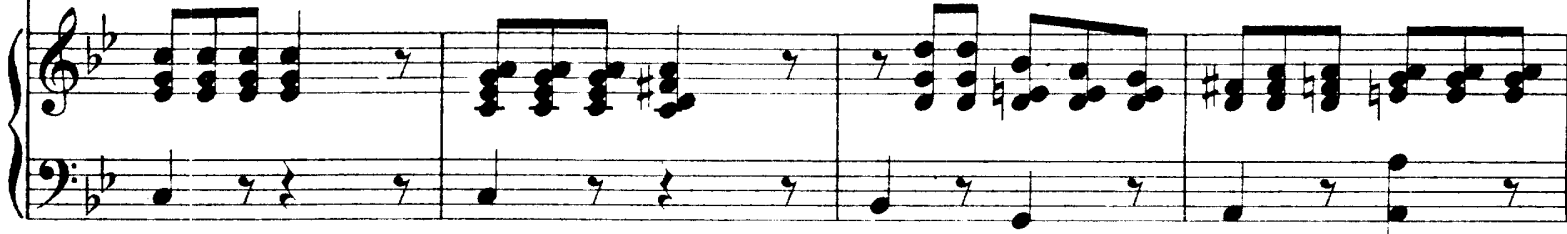

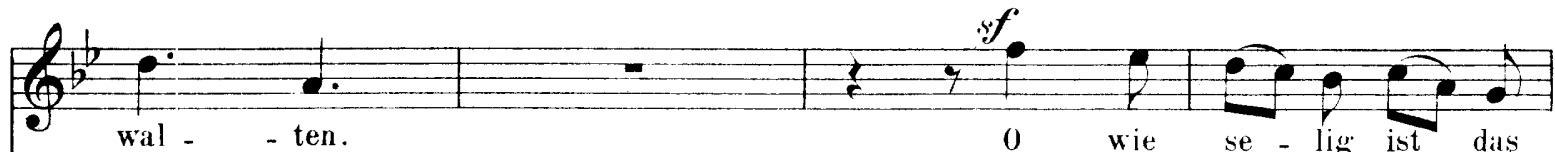

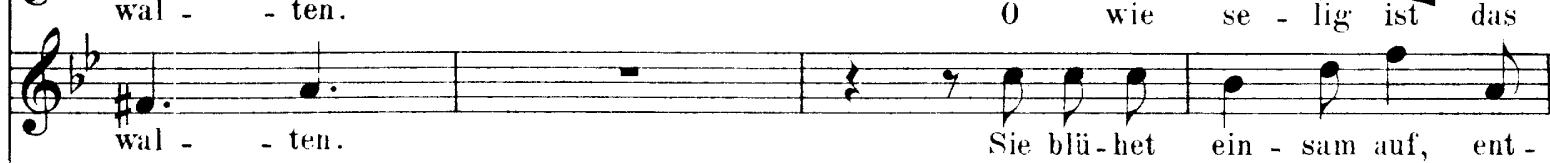

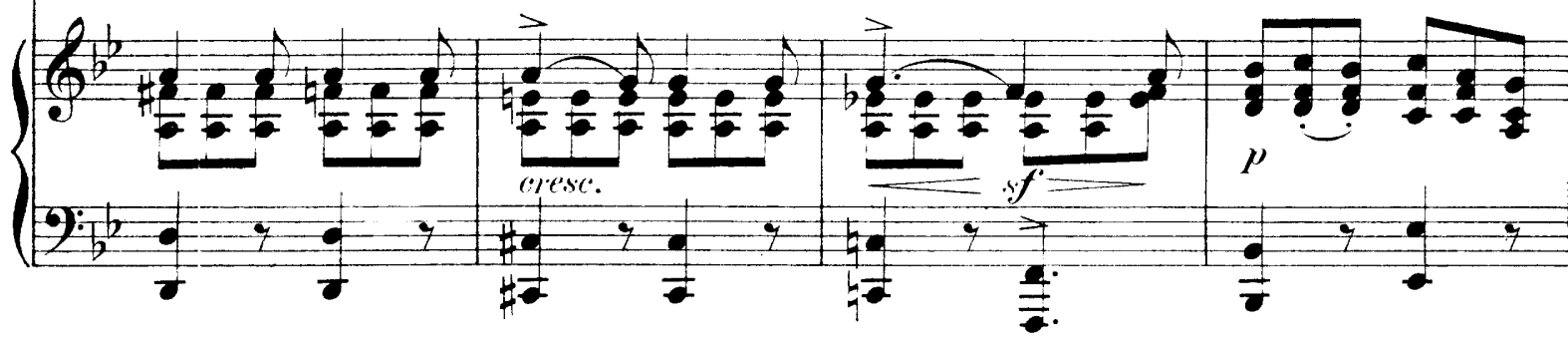

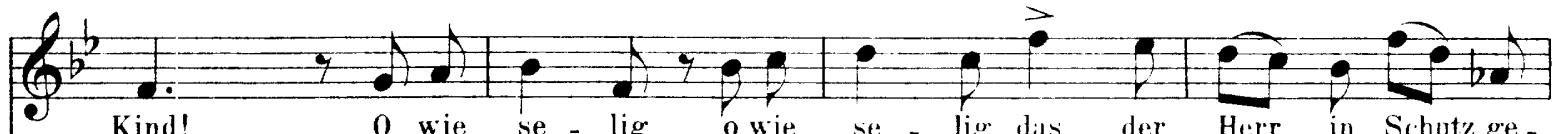
Kind! 0 wie se - lig, owie se - lig. dis der Herr in Schutz ge fal - tet sich zum Heil, vom Herrn be-schïtzt; nichts kann sie stören, und al - ler

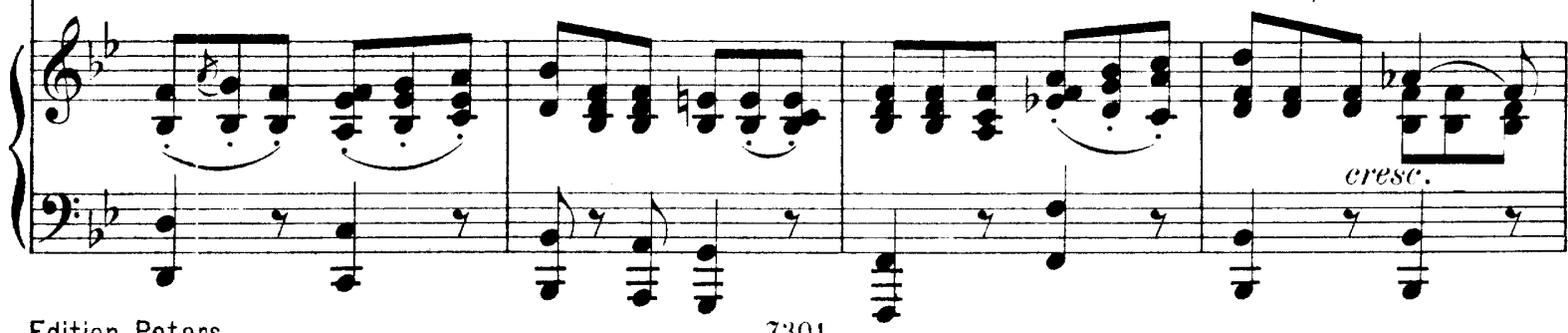
Edition Peters 
$e^{2} \frac{1}{\text { nom - men! ks wird zu }}$ sei - nem Frieden, sei - - - - nem

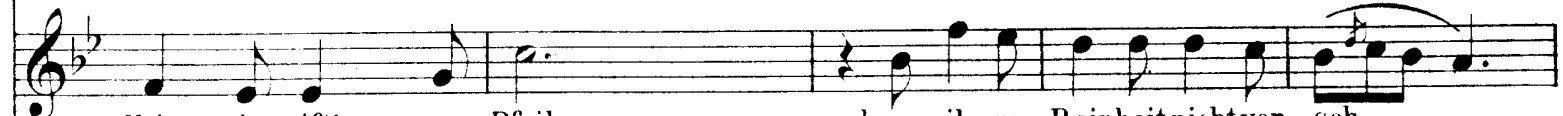

Fein - de gift'- -ger Pfeil. kann ih-re Reinheitnichtver - seh - - -

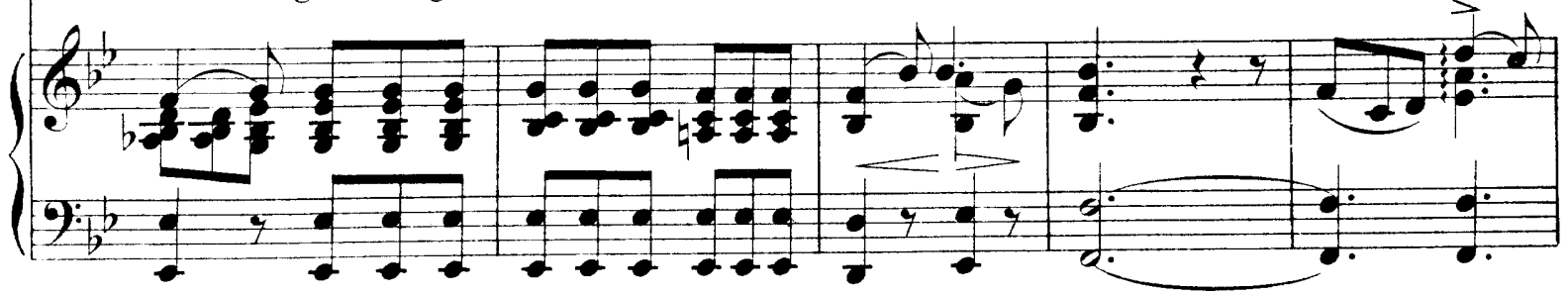

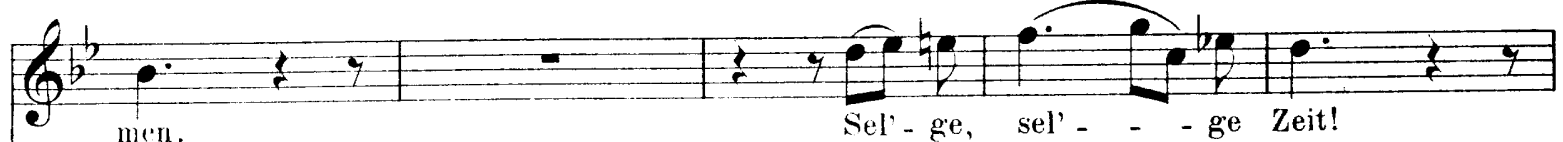

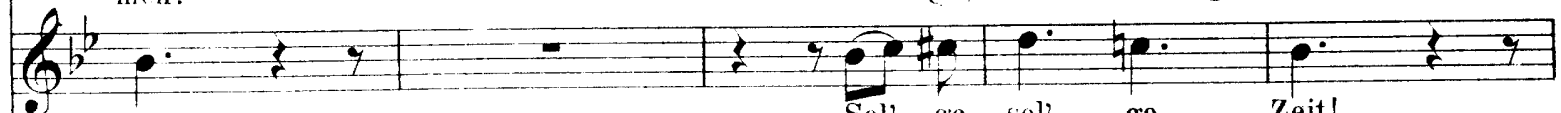

ren. Sel' - ge, sel' - ge Zeit!

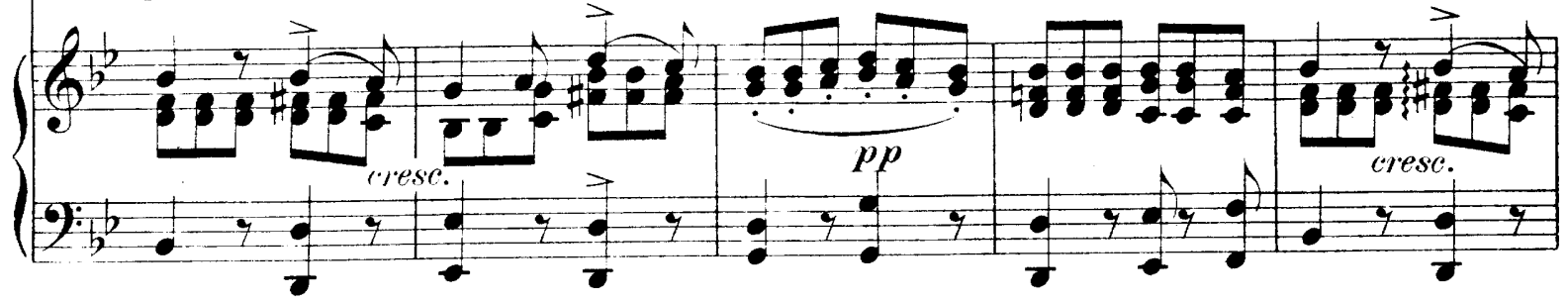

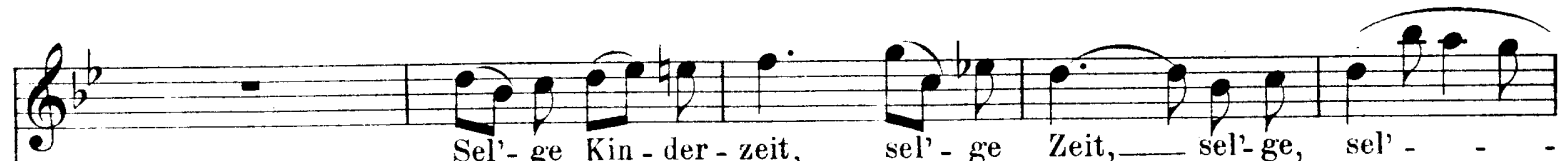
$Q^{b}$ Sel'-ge Kin - der-zeit, sel' - ge Zeit,_ sel'-ge, sel' - - -

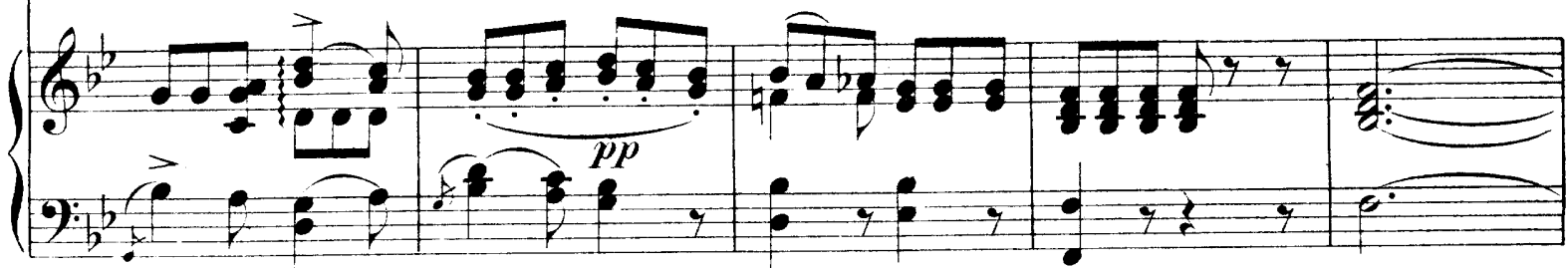

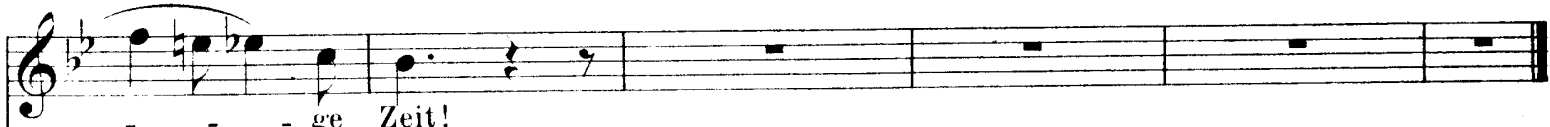

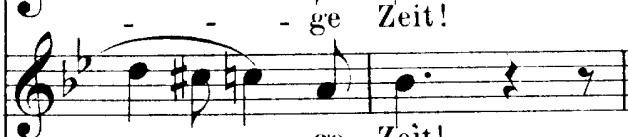

C - _ - ge Zeit!

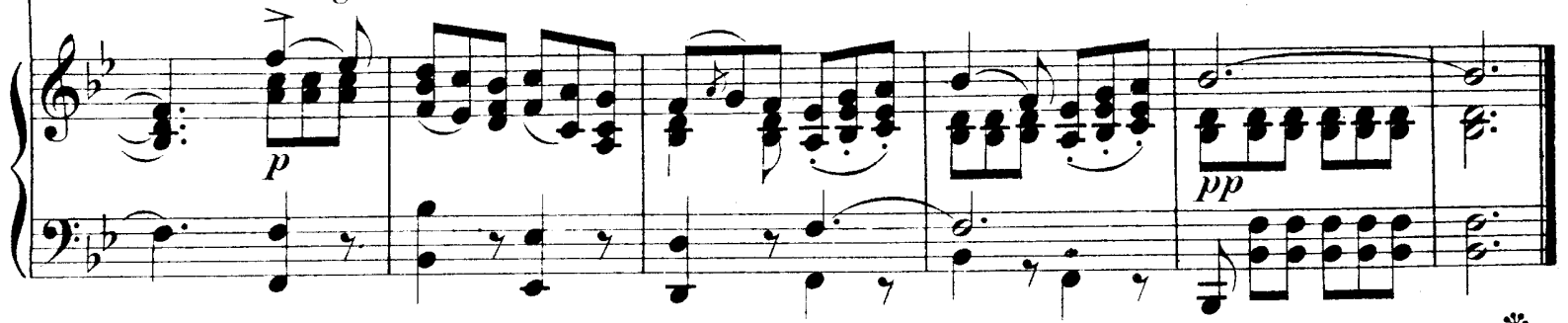

